\title{
Implications of Solar Energy Alternatives for Community Design
}

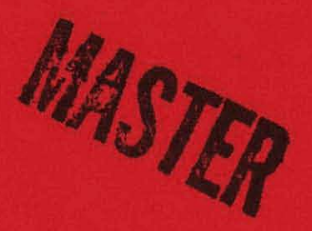

HARVARD UNIVERSITY

Department of Landscape Architecture Department of Architecture

Graduate School of Design

for

OAK RIDGE NATIONAL LABORATORY Community Systems Program

Energy Division

Research Contract W-7405-eng-26 


\section{DISCLAIMER}

This report was prepared as an account of work sponsored by an agency of the United States Government. Neither the United States Government nor any agency Thereof, nor any of their employees, makes any warranty, express or implied, or assumes any legal liability or responsibility for the accuracy, completeness, or usefulness of any information, apparatus, product, or process disclosed, or represents that its use would not infringe privately owned rights. Reference herein to any specific commercial product, process, or service by trade name, trademark, manufacturer, or otherwise does not necessarily constitute or imply its endorsement, recommendation, or favoring by the United States Government or any agency thereof. The views and opinions of authors expressed herein do not necessarily state or reflect those of the United States Government or any agency thereof. 


\section{DISCLAIMER}

Portions of this document may be illegible in electronic image products. Images are produced from the best available original document. 


\section{Implications of Solar Energy}

\section{Alternatives for Community Design}
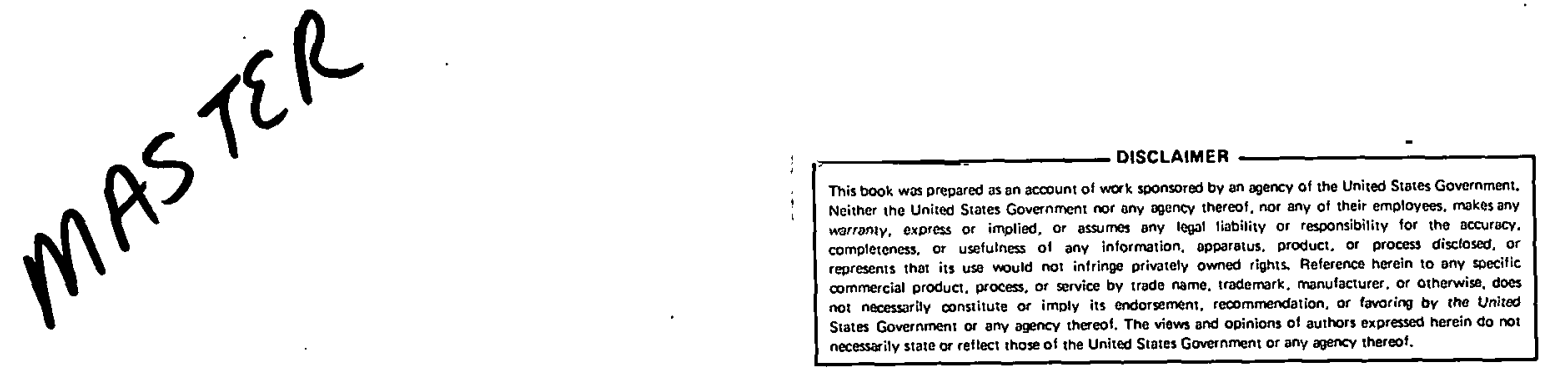

HARVARD UNIVERSITY

Department of Landscape Architecture

Department of Architecture

Graduate School of Design

for

OAK RIDGE NATIONAL LABORATORY

Community Systems Program

Energy Divisıon

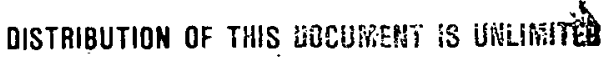

Research Contract W-7405-eng-26 
Report prepared by

HARVARD UNIVERSITY

Graduate School of Design

Cambridge, MA 02138

under subcontract number 7830

for

OAK RIDGE NATIONAL LABORATORY

Oak Ridge, TN 37830

operated by

UNION CARBIDE CORPORATION

for the

DEPARTMENT OF ENERGY

Contract Number W-7405-eng-26

For copies: of this report contact Oak Ridge National Laboratory

This report was prepared as an account of work sponsored by the United States Government. Neither the United States nor the Department of Energy nor any of their employees, nor any of their contractors, subcontractors or their employees, makes any warranty, express or implied, or assumes any legal liability or responsibility for the accuracy, completeness or usefulness of any information, apparatus, product or process disclosed, or represents that its use would not infringe privately owned rights. 
IMPLICATIONS OF SOLAR ENERGY ALTERNATIVES

FOR COMMUNITY DESIGN

Adele Santos

Professor of Architecture and Urban Design

Carl Steinitz

Professor of Landscape Architecture and Urban Design

and the following graduate students:

Robert Allen

Ernesto Bachiller

Peter Calkins

Scott Callan

Sam Coplon

Roger Courtenay

Timothy Day

Joseph DeManche

Mei-Jean Doong

Susan Franck

Richard Franz:

Shirley Fujikawa

01 ivia Fussell

Laura Garibotti

Walter Geiger

James Greenwood
Thomas James

Hugh Keegan

Gary Kesler

Wei-Ya Kwan

Clifton Lowe

Mina Marefat

John Meder

Richard Murphy

Sheila Murray

Hazem Sayed

J. Ritchie Smith

Carmen Valdes

Steve Van Ness

Anne Wattenberg

Steve Yuen

HARVARD UNIVERS ITY

Department of Landscape Architecture

Department of Architecture

Graduate School of Design

Cambridge, MA 02138

June, 1980 
2.0 PROBLEM STATEMENT

3.0 THE TUCSON SITE

3.1 TUCSON TEAM 1: R. Allen, E. Bachiller, C. Lowe, 38

M. Marefat, H. Sayed

3.2 TUCSON TEAM 2: L. Garibotti, J. Greenwood, J. Meder,

R. Murphy, J. R. Smith, S. Yuen

4.0 THE ATLANTA SITE

4.1 ATLANTA TEAM I: S. Coplon, M. Doong, S. Franck,

4.2 ATLANTA TEAM 2: J. DeManche, O. Fusse11, W. Geiger,

G. Kesler, C. Z. Valdes

5.1 PLymouth TEAM 1: P. Calkins, S, Callan, T. Day,

S. Van Ness, A. Wattenberg

5.2 PLYMOUTH TEAM 2: R. Courtenay, S. Fujikawa, T. James, W. Kwan, S. Murray 
Many people contributed to this study. We are especially grateful to George Lawson for his support and sharp questions, to Jesse Tatum for his frequent consultation on energy-related issues, and to Steve Robinson for his insightful criticism. We also wish to thank James E. Rannels, Department of Energy, for the support given to this study. The responsibility for these studies rests with the authors--faculty and students. Any opinions, findings, conclusions, or recommendations expressed are theirs and do not necessarily reflect the views of the Graduate School of Design, Harvard University. We also wish to thank:

Arlington Lithograph Kenneth Abrahams

Max Acreage

Ray Belknap

Don Cameron

Yvonne Chabrier

Chris Chadbourne

Bruce Chareton

Bruce Cox

Jane Emens

Ray Frieden

Nick Gibson

David Handl in

Allen Hodges

Tim Johnson

Warren Jones

\author{
Jim Keen \\ Michael Kim \\ Ray Moore \\ Scott Morris \\ Susan Nichols \\ Davi.d Parks \\ Karen Phillips \\ Dennis Reinhardt \\ Claire Reiniger \\ M. L. Richardson \\ Anne Spirn \\ Bob Stromberg \\ Didier Thomas \\ Gordon Tully \\ Ortude White \\ Pat Williams
}


A graduate-level studio at the Harvard School of Design explored how a policy of solar-based energy independence will influence the design of a new community of approximately 4500 housing units and other uses. Three large sites outside Tucson (a cooling problem), Atlanta (a humidity problem), and Boston (a heating problem) were selected. Each is typical of its region. A single "program" was assumed and designed for. Each site had two teams, one following a compact approach and one following a more dispersed approach. Each was free to choose the most appropriate mix of (solar) technology and scale, and was free to integrate "energy and community" in the design as it saw fit. These choice and integration issues are key areas where our experience may be of interest to those involved in community design and solar energy. 
FOREWORD

Oak Ridge National Laboratory has been charged by the Department of Energy with a responsibility for "mission analysis" of small solar thermal power systems (less than $10 \mathrm{MW}(\mathrm{e})$ ). As a part of this support function, we must consider not only technology development per se but potential markets in the residential, commercial, and industrial sectors, as well. In the mission analysis context, this study of solar community design was commissioned as a response to rising conventional fuel costs, improving supply side prospects for commercially viable solar thermal power systems, and rapidly growing community and public interest in solar energy options. The study is "visual" (architectural and landscape architectural) in nature and, since it is not intended to advance the state-of-the-art in quantitative analysis, it is based in part on previous solar community analyses performed at Sandia and Lawrence Berkeley Laboratories, at the Institute for Local Self-Reliance (Baltimore and Washington, D.C. studies), and elsewhere. The investigators have been asked, in effect, to serve as surrogates for prospective residents, engineers, market intermediaries, and others who would support an actual construction project, in an effort to incorporate extensive solar supply systems and a conservation ethic as major components in the formulation of realistic community designs.

The first response of the study group appears to have been a more-or-less traditional isolation of power facilities from the community. This may have been due in part to a desire to decouple the complications of energy supply from other design issues. Even as design itcrations proceeded, however, conservative attitudes with regard to possible public safety issues and a sense of awkwardness in placing large (e.g., 11-meter dish) collectors on or among buildings tended to keep energy production facilities in unified, dedicated land use sectors.

It is interesting to note that even with this tendency toward dedicated land use, students did not choose to restrict the use of electricity (and hence collector land requirements) as aggressively as they might have by, for example, assuming substantial redesign of residential appliances. It is also significant, we feel, that the impact of design measures intended to reduce 
intra-community transportation energy use appears to have been nearly comparable in magnitude to that of the community's solar features.

From our perspective, this study suggests that quite different solar thermal and electric technologies may be appropriate for community applications depending upon how they are deployed. (As one example, the question, "Can we use heliostats half the size of those at the Sandia central receiver test facility?" arose in early consideration of a roof-mounted total energy system.) The study also suggests that very different deployment solutions might arise for differênt population densities. In low-density areas where extensive thermal distribution systems tend to be less attractive than separate solar space conditioning and hot-water systems, centralized solar electric facilities may not be difficult to site. Where population densities are high, however, and heat recovery from not too distant solar power facilities would be attractive, dual use of land may become an important issue.

While the issues raised in this study will become clearer as actual implementation proceeds, we are hopeful that Harvard's work. will help to inform and encourage greater interaction in a disciplined manner. between engineers/ researchers and the designers, suppliers, purchasers; and eventual users of community solar energy sys.tems.

C. George Lawson

Jesse S. Tatum
Oak Ridge National Laboratory July 1Q, 1980 
Without doubt, solar energy will play an increasing role in the shaping of the future urban environments of the world. There will be profound changes in settlement patterns associated with a shift towards increased reliance on solar energy. These changes will influence the design of houses as well as their organization into local and larger community patterns. These changes carry with them an increasingly sensitive response to conditions of site, climate, vegetation, and building technology, all oriented toward energy conservation. These technical considerations will, in turn, have profound influences on the "users" of future houses and communities.

The major research questions for this study were established in a letter from George Lawson, Smali Solar Thermal Power Systems Mission Analysis, Oak Ridge National Laboratory) as follows: "What are the forms of future communities that may be built using solar energy as a source for electricity and heat? How will the community evolve? What concessions will be required or made for space (privacy) and comfort (space heating and cooling) and costs of energy systems? What flexibility of 'life styles' will exist?"

In response, a graduate-level studio at the Harvard Graduate School of Design explored the influence of a policy of solar-based energy independence on the design of a new community incorporating approximately 4,500 housing units and other uses. Three large sites outside Tucson, Atlanta, and Boston were selected. The sites, though similar in size, are each typical of their own region in terms of topography, climate, and site conditions.

A single "program" was identified and designed for. Each site had two teams, one following a compact approach and one following a more dispersed approach to community design. Each was free to choose the most appropriate mix of solar energy technology and scale, and was free to integrate energy considerations into the community design as it saw fit. These choices and integration issues are key areas in which our experience may be of interest to those involved in community design and solar energy. This comparative approach encouraged the discovery and testing of important regional 
differences in a design case-study approach.

\subsection{THE ORGANIZATION OF THE STUDY}

The research studio was conducted between February and May, 1980 by Professors Santos and Steinitz with 31 graduate students in landscape architecture, architecture, urban design and city planning. The study was organized into six major phases, explained below.

Pha se 1: Background Orientation

During Phase 1, January and February, a series of briefing seminars were conducted in Cambridge, Massachusetts, by members of the Oak Ridge National Laboratory (Small Solar Thermal Power Systems Mission Analysis) and by participating technical specialists. The purpose of these seminars was to urfenl participants to the primary technical, design and evaluative issues which were to be considered during the study. Seminars were conducted by the following persons:

- George Lawson, Oak Ridge National Laboratory, on energy policy;

- Jesse Tatum, Oak Ridge National Laboratory, on energy-production technology;

- Michael Kim, Harvard Graduate School of Design, on energy-storage technology;

- Anne Spirn, Harvard Graduate School of Design, on energy-conservation site-planning principles;

- Steve Robinson, Architect, on energy-conservation housing-design principles;

- Gordon Tully, Architect, on energy-conservation housing-design principles;

- Tim Johnson, Massachusetts Institute of Technology, on energy-conservation building-construction technology.

During this phase, student groups prepared and presented state-of-the-art research reports in response to the following questions:

- Describe the energy usage of residential, industrial, institutional, 
commercial, and transportation activities in each of the three regional contexts. What are the peak energy loads by time of day and season and the relative growth rates? What aspects of energy usage could be resolved by better design or community management? What energy budgets should we assume for each land use, in each regional context?

- What are the implications of the new "Building Energy Performance Standards" (BEPS) on building design and site design?

- For each of the three regions, outline the basic principles for building and site design. Illustrate these principles with diagrams and built examples.

- What are the basic principles governing the use of plant material and earth grading in passive solar design? Describe a range of built examples.

- Summarize the princples, advantages, and disadvantages of passive versus active solar design for heating and cooling buildings. What are the likely differences in approach for the three study regions for each of the land uses?

- What solar energy production systems are available to ensure selfsufficiency at the "neighborhood" level and at the "community" level? What are the land requirements? What are the implications for site layout and building groupings?

- What legal issues arise in the use of solar energy? Describe some of the current cases.

These reports were distributed as a baseline text for the class and to key participants. This information helped identify the technical assumptions which would guide the design case studies.

Phase 2: Field Trip

A ten-day field trip was undertaken by the research participants in February. Each student had the opportunity to visit the three sites and to observe, first-hand, regional examples of various energy systems in operation and their impact on building and site development projects. 
The itinerary for the trip was:

Atlanta: Georgia Technical Institute and Shenandoah (Atlanta site).

Tucson: University of Arizona and Rocking K Ranch (Tucson site).

Phoenix: Arizona State University.

Santa Fe: Sandia Laboratory and Los Alamos Laboratory.

Boston: $\quad$ Talcott estate (Plymouth site).

Several housing developments were visited at each stop. Figures 1.0.1 through 1.0 .18 show selected examples of technologies seen.

Phase 3: Initial Site Descriptions and Evaluation

Two major tasks were conducted during February and March. First, basic site development evaluations were made for each of the three selected sites. These considered such aspects as climate, soils, hydrology, vegetation--in general, those major influences on the development potential and limitations of the study sites. At the same time the program and its key assumptions were established for use by all design teams. Section 2.0 of this report presents the program and the assumptions which guided the study.

Phase 4: Community Design

During this period (March and April), six alternative community designs were prepared, two for each of the three sites. Teams were formed from among the disciplines represented in the class and on the basis of similar individual preliminary designs prepared at the very beginning of the phase. As a generalization, each site had a "centralized and higher technology" scheme and a "decentralized and lower technology" scheme prepared for it. However, a11 of the six designs were based upon the identical quantitative land-use program. Thus, the major differences by which the designs can be compared are related to the regional site conditions and to the scale and technology of the approaches decided upon by the design teams. The work included a site evaluation, a phased development plan, a site plan, an energy strategy, and a spatial energy plan, and various specific design studies emphasizing appropriate housing design. Two intermediate reviews and one final presentation were held between March and May on the various aspects of the design studies. 
The final presentation was held at the Graduate School of Design at Harvard University, on May 23, 1980, before an audience of approximately 200 persons, including representatives of the Oak Ridge National Laboratory, the Department of Housing and Urban Development, and the Department of Energy. Each of the six design studies was presented (as included in this report), and each presentation was followed by long and lively discussion. Figure 1.0.19 is from this event.

Phase 5: Report

This report is one product of the final phase of this study. Section 2 describes the program for the study. Sections 3, 4, and 5 describe the three sites and the six alternative community designs. Section 6 summarizes some of the key implications of solar energy alternatives on community design as they were found during the course of these design case studies. 
THIS PAGE

\section{WAS INTENTIONALLY LEFT BLANK}




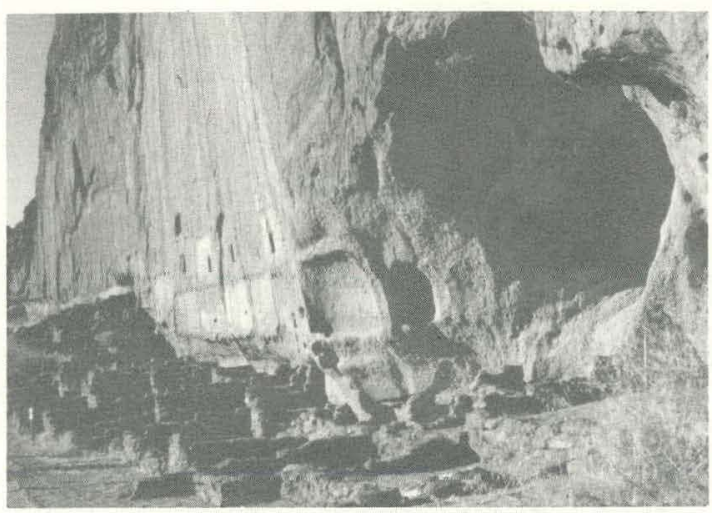

Fig. 1.0.1

Cave Dwellings

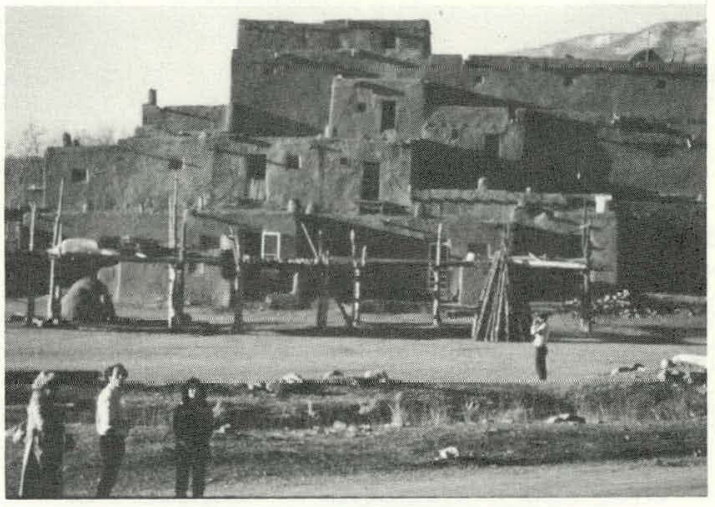

Fig. 1.0.2

Taos Pueblo

Taos, New Mexico

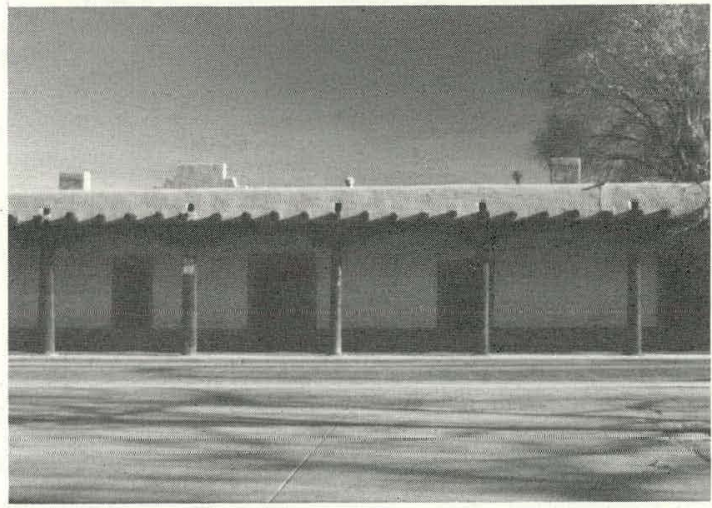

Fig. 1.0.3

The Plaza

Santa Fe, New Mexico

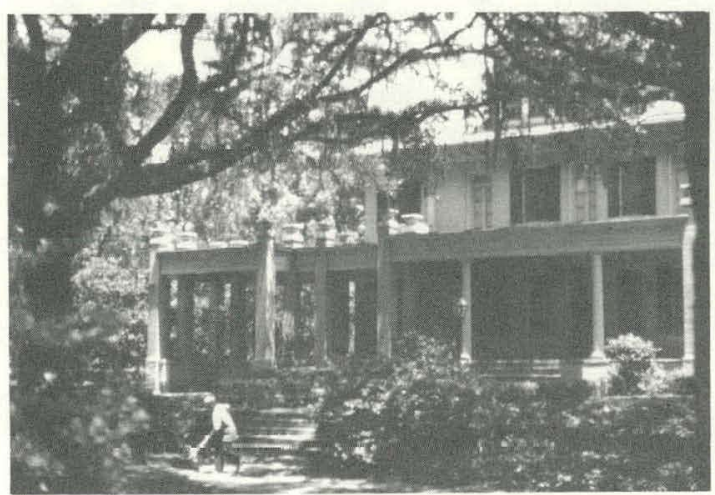

Fig. 1.0.4

Typical Georgia Residence Newnan, Georgia 

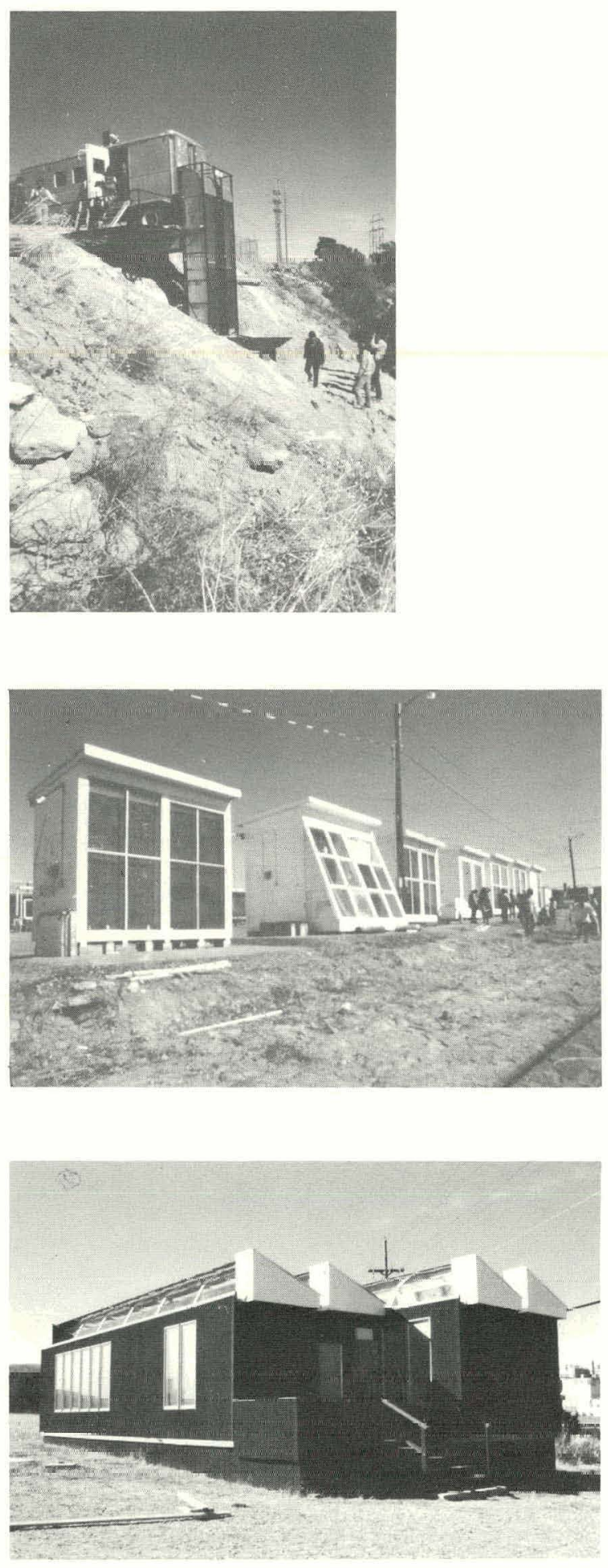

Fig. 1.0 .5

Closed Loop Natural Convection System

Los Alamos, New Mexico

Fig. 1.0 .6

Experimental Trombe Wall Systems Los Alamos, New Mexico

Fig. 1.0.7

Passive Solar Mobile Home with Roof Pond System Los Alamos, New Mexico 

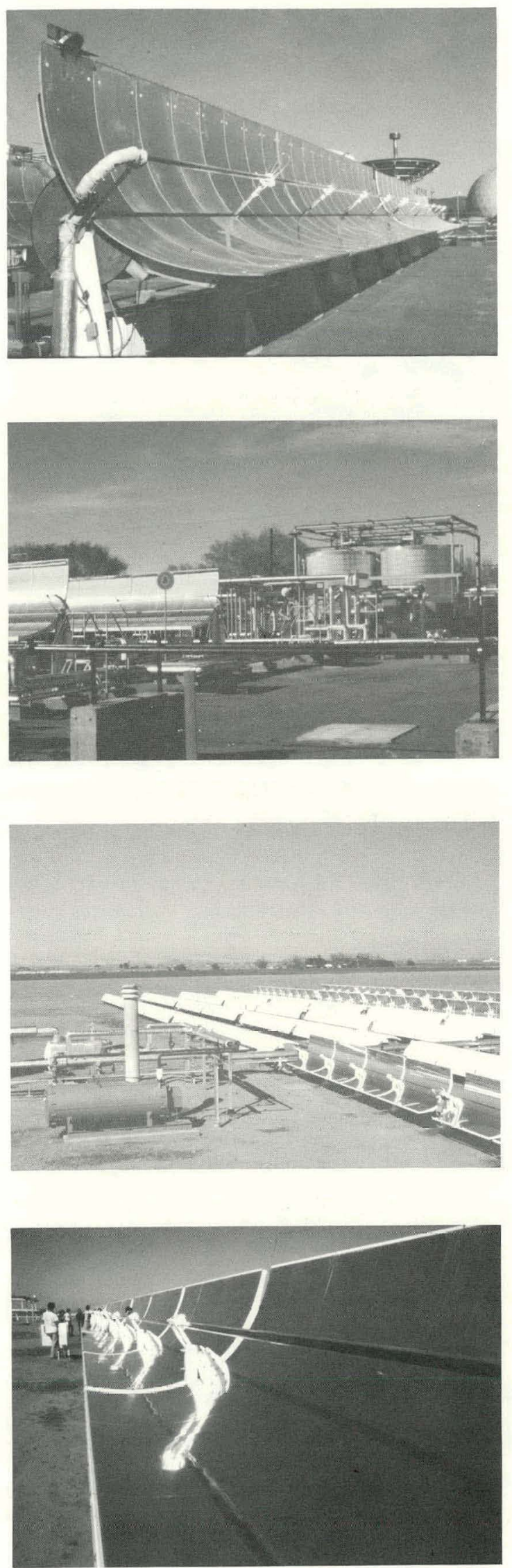

Fig. 1.0 .8

Parabolic Hexcell Trough Concentrator Sandia, New Mexico

Fig. 1.0 .9

Parabolic Trough Concentrator and Hot-0il Heat Exchange System Sandia, New Mexico

Fig. $\quad 1.0 .10$

Parabolic Trough Concentrator Coolidge Solar-Powered Irrigation Facility, Arizona

Fig. 1.0.11

Parabolic Trough Concentrator Coolidge Solar-Powered Irrigation Facility, Arizona 

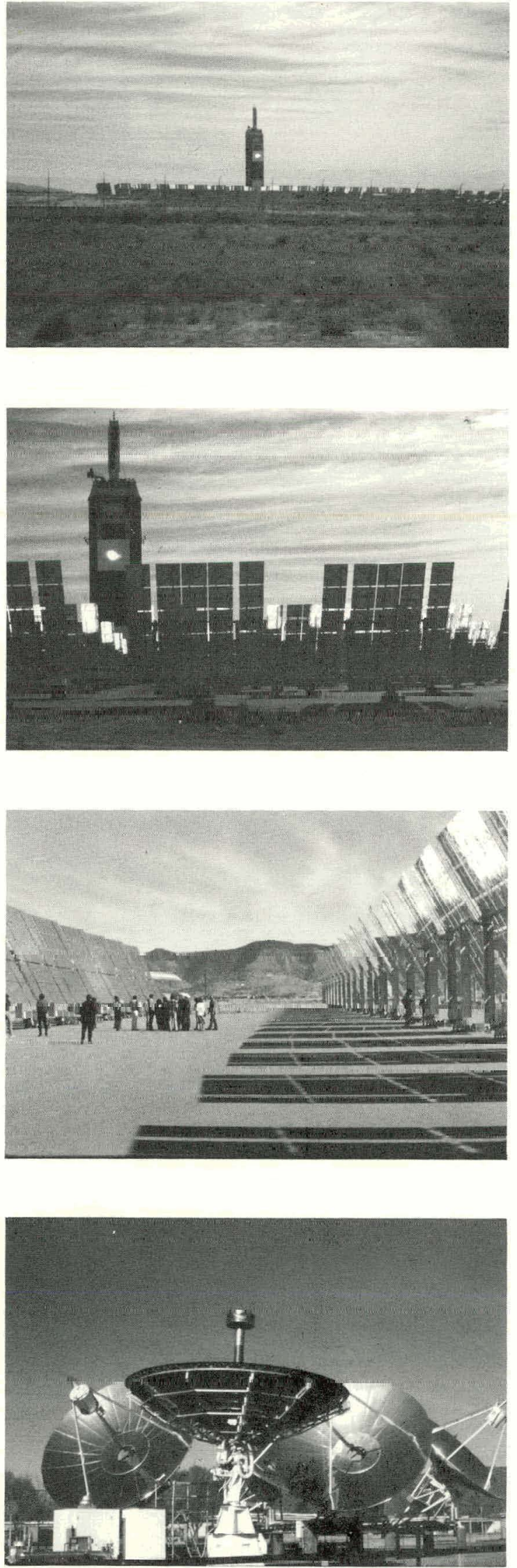

Fig. 1.0 .12

Central Thermal Receiver with Field of Heliostats

Sandia, New Mexico

Fig. 1.0 .13

Central Thermal Receiver with Field of Heliostats

Sandia, New Mexico

Fig. 1.0 .14

Heliostat Facet

Sandia, New Mexico

Fig. 1.0 .15

Dish Reflector with Mounted Turbine Sandia, New Mexico 

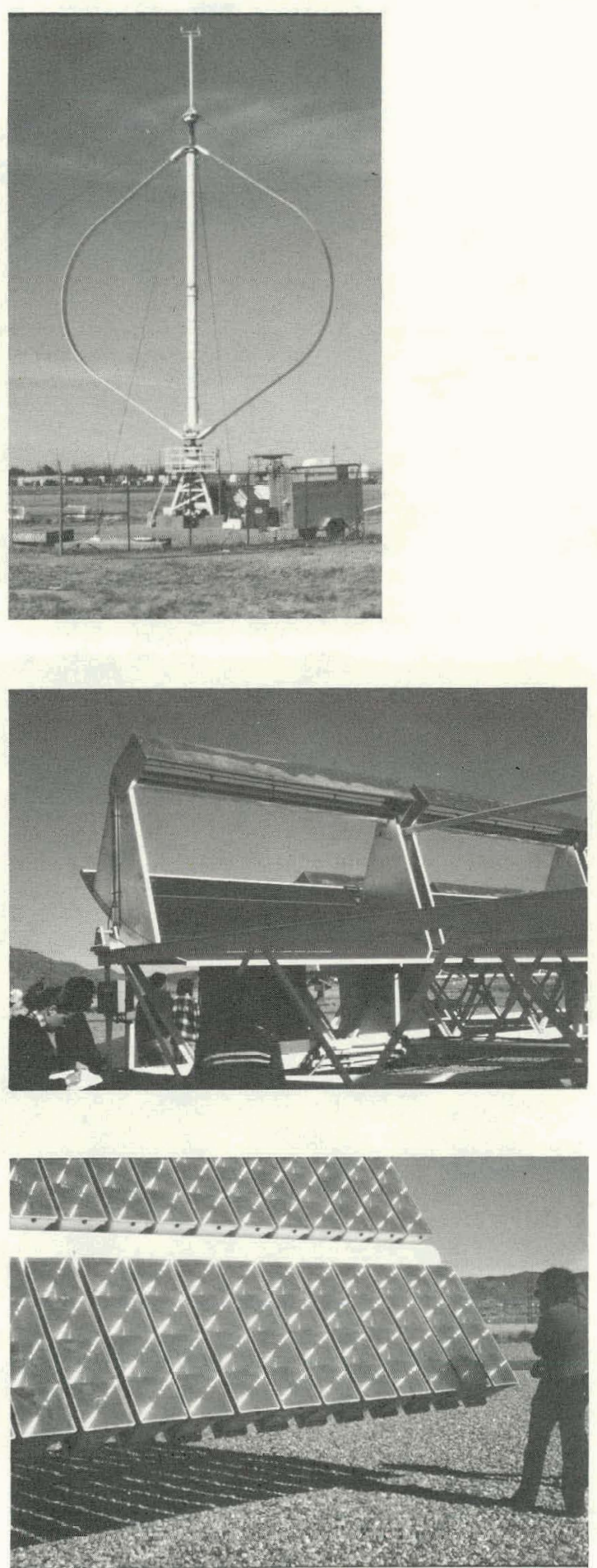

Fig. 1.0 .16

Darrieus Vertical Wind Turbine Sandia, New Mexico

Fig. 1.0 .17

Photovoltaic Parabolic Trough Actively Cooled Array Sandia, New Mexico

Fig. 1.0 .18

Photovoltaic Fernell 2-Axis Concentrator Sandia, New Mexico 

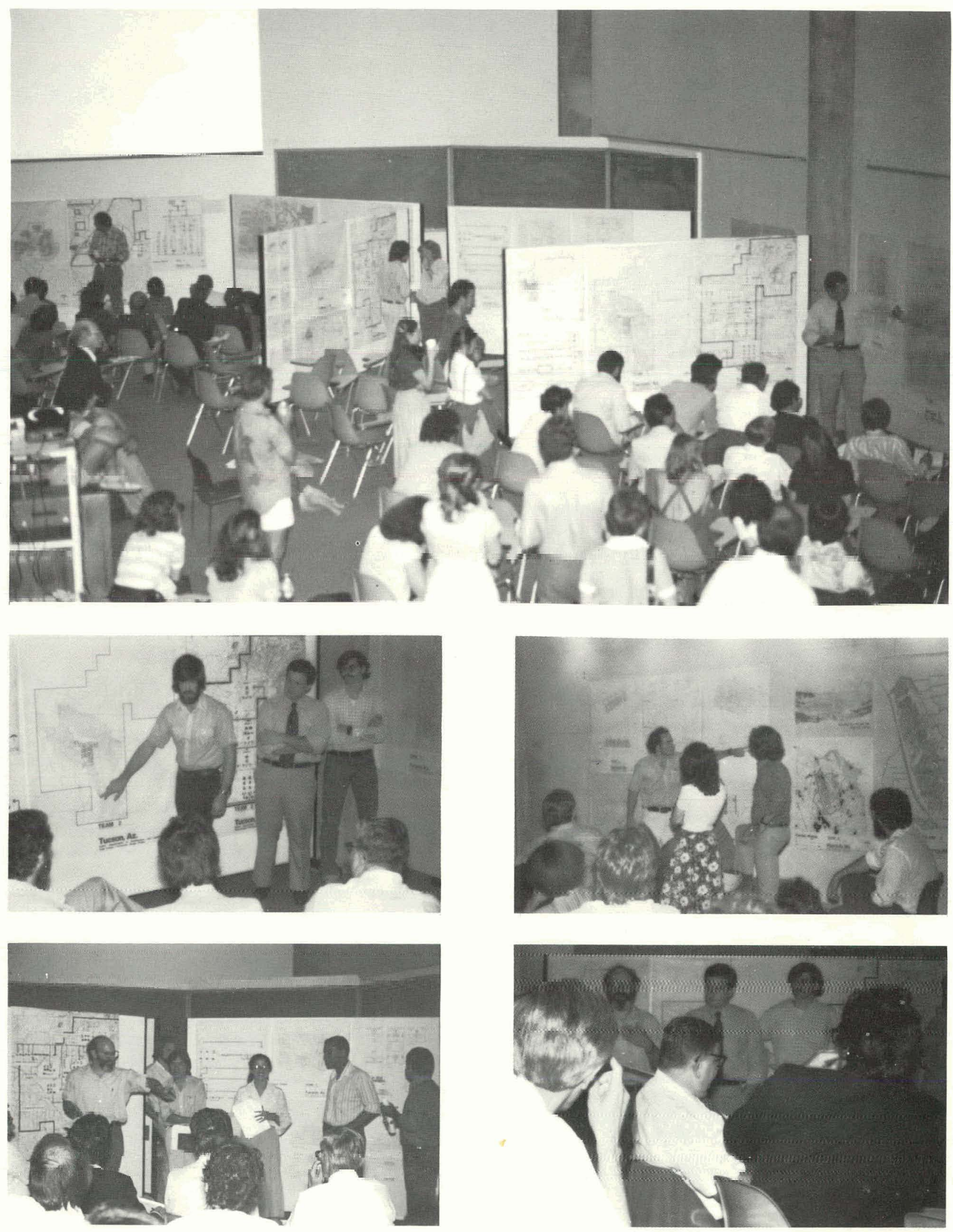

Fig. 1.0.19 Final Presentation at Harvard Graduate School of Design (photographs by Roy Carter) 
For the purposes of comparison, one development program for a community of 4,500 households was adopted for the three sites. This size community was selected because a sufficient number and diversity of activities could be supported, yet the scale of the design problem could be resolved in one academic semester.

The program was based on the Village of Woodbridge, currently being developed by the Irvine Company within the City of Irvine to the south of Los Angeles.

This model was selected because the "village" program and standardswere jointly typical of planned developments adjacent to major metropolitan areas. The development contained a significant proportion of higher density low-rise housing. The planning and marketing studies had been thoroughly documented and were available to the design teams.

It was expected that the cultural differences by region could be reflected in the choice of recreational facilities and amenities and in the development of housing types. The quantity and type of industry was chosen by each team, based on the regional context, the appropriateness of the site, and the existing patterns of accessibility. The program as given follows:

\subsection{POPULATION}

There is a wide cross-section of family sizes and age profiles. Most of the population fall into the middle to upper-middle income group. We can assume that $55 \%$ of two-or-more-person households will have two incomes. Approximately $20 \%$ of the population earn less than $\$ 20,000,32 \%$ earn $\$ 20-30,000,33 \%$ earn from $\$ 30-40,000$, and $15 \%$ earn over $\$ 40,000$. 


\begin{tabular}{|c|c|c|c|c|c|c|c|}
\hline \multirow{2}{*}{ Household Type } & \multirow[b]{2}{*}{$\%$} & \multirow{2}{*}{$\begin{array}{c}\# \\
\text { People }\end{array}$} & \multirow{2}{*}{$\begin{array}{l}\text { Size } \\
\text { of } H^{*}\end{array}$} & \multirow{2}{*}{$\begin{array}{l}\text { Age of } \\
\mathrm{HH} \text { Head }\end{array}$} & \multicolumn{2}{|c|}{ Children } & \multirow[b]{2}{*}{ Income Range } \\
\hline & & & & & Number & Age & \\
\hline Young Singles & 3.5 & 160 & 1.0 & $20-30$ & 0 & - & up $\operatorname{to} \$ 20,000$ \\
\hline Adult Singles & 2.5 & 115 & 1.0 & $30-40$ & 0 & - & up to $\$ 20,000$ \\
\hline Young Couple & 9.0 & 800 & 2.0 & $25-35$ & 0 & - & $\$ 15-20,000$ \\
\hline $\begin{array}{l}\text { Young Couple } \\
\text { w/Child }\end{array}$ & 18.0 & 2000 & 2.5 & $25-35$ & 400 & $0-5$ & $\$ 20-30,000$ \\
\hline $\begin{array}{l}\text { Fami Ty: } \\
\text { Moderate- Income }\end{array}$ & 9.0 & 1200 & 3.0 & $25-35$ & 400 & $0-10$ & up to $\$ 20,000$ \\
\hline Moving-Up & 23.5 & 3165 & 3.0 & $35-40$ & 1055 & $5-10$ & $\$ 25-40,000$ \\
\hline Established & 15.0 & 2363 & 3.5 & $35-45$ & 1013 & $10-15$ & $\$ 30-50,000+$ \\
\hline Moving-Down & 11.0 & 1485 & 3.0 & $40-45+$ & 495 & $10-18+$ & $\$ 35-50.000+$ \\
\hline Empty Nester & 9.0 & 800 & 2.0 & $45+$ & 0 & - & $\$ 25-40,000+$ \\
\hline Totals & 100.0 & 12088 & & & 3363 & & \\
\hline
\end{tabular}

\subsection{HOUSING}

This is a suburban low-rise community with a bias towards home-ownership. Approximately $25 \%$ of the dwellings are single-family detached, $50 \%$ are grouped housing (patio homes, townhouses, etc.), 15\% are condominiums (various low-rișe high-density forms, up to four floors), and 10\% are apartments. The housing standards are a guide to the sizes of dwellings (low end) being built for this user profile. Mobile homes are not discounted as an option. Housing densities are not given and depend on housing forms adopted for the regional context.

\begin{tabular}{|c|c|c|c|c|c|c|c|c|}
\hline \multirow[b]{2}{*}{ Household Type } & \multicolumn{5}{|c|}{ Housing Type } & \multirow[b]{2}{*}{$\begin{array}{l}\text { Approx. } \\
\text { Sq. Ft. }\end{array}$} & \multirow[b]{2}{*}{$\begin{array}{l}\text { Bed- } \\
\text { rooms }\end{array}$} & \multirow[b]{2}{*}{ Baths } \\
\hline & $\begin{array}{c}\# \\
\text { DU's* }\end{array}$ & $\begin{array}{l}\text { Apts. } \\
\text { \#DU's }\end{array}$ & $\begin{array}{c}\text { Condo's } \\
\text { \#DU's }\end{array}$ & $\begin{array}{c}\text { Cluster } \\
\text { \#DU's }\end{array}$ & $\begin{array}{r}S F^{\star} \\
\# D U^{\prime} S\end{array}$ & & & \\
\hline Young Singles & 160 & 160 & - & - & - & $400-750$ & $0-1$ & 1 \\
\hline Adult Singles & 115 & 70 & 45 & - & - & $750-1100$ & $1-2$ & $1-1 \frac{1}{2}$ \\
\hline Young Couple & 400 & - & 160 & 240 & - & $900-1350$ & $1-2$ & $1-1 \frac{1}{2}$ \\
\hline $\begin{array}{l}\text { Young Couple } \\
\text { w/Child }\end{array}$ & 800 & - & 240 & 560 & - & $1100-1350$ & $2-2 \frac{1}{2}$ & $1 \frac{1}{2}-2$ \\
\hline $\begin{array}{l}\text { Family: } \\
\text { Moderate-Income }\end{array}$ & 400 & 220 & 80 & 100 & - & $750-1100$ & 2 & $1-1 \frac{1}{2}$ \\
\hline Moving-Up & 1055 & - & - & 740 & 315 & $1350-1500$ & $21_{\varepsilon}-3$ & 2 \\
\hline Established & 675 & - & - & - & 675 & $1500-2000+$ & $3-4$ & $2 \frac{1}{2}-3$ \\
\hline Moving-Down & 495 & - & - & 360 & 135 & $1340-1500+$ & $2 \frac{1}{2}-3$ & $2-2 \frac{1}{2}$ \\
\hline Empty Nester & 400 & - & 150 & 250 & - & $1100-1350+$ & $2-2 \frac{1}{2}$ & 2 \\
\hline
\end{tabular}

Totals

* Dwelling Unit (DU), Single Family (SF), Household (HH) 


\subsection{RECREATION}

This is a recreationally oriented community with a well developed program of amenities. Small parks closely related to residential areas compensate for higher-density living and smaller private open spaces. One major recreational feature is included in each site design (lake, major park, etc.) as appropriate to the context.

For neighborhood recreation, twenty or more small parks of 1-3 acres are located within easy walking distance of each dwelling. Parks are programmed to appeal to different age groups. Within these parks, the following activities occur: twelve amenities (swimming pools with diving, tennis courts, etc.), eight children's wading pools, twelve "tot lots", and ten courts (volleyball, multi-purpose, basketbal1).

For community recreation, there are: one junior olympic pool, one swimming club (pools to suit all ages for year-round use), one tennis club (ten lighted tennis courts for year-round use). plus club house, and one special recreational feature (e.g., a 30-acre lake for boating/swimming) with trails for biking and hiking as appropriate.

\subsection{EDUCATION}

There are approximately 4,000-4,500 students attending the school system, not all of whom reside in the community. The schools, based on the Irvine Unified School District model are smal1, neighborhood-oriented, and located to enable most children to walk to school. The schools are to share the parks as play space. The school buildings serve other purposes in the community and act as neighborhood centers. The schools are part of a system, much like a university complex, with slightly different emphases, enabling a greater range of specialties to be offered. 


\begin{tabular}{lcccc} 
School Program & $\begin{array}{c}\# \\
\text { On-site } \\
\text { Children }\end{array}$ & Age & $\begin{array}{c}\# \\
\text { Schools }\end{array}$ & Acres \\
\hline Pre-School & 660 & $0-4$ & $4+$ & $1-2$ \\
Elementary School (K-6) & 1622 & $5-11$ & 3 & 4 \\
Middle School (7-9) & 625 & $12-14$ & 1 & 5 \\
High School (10-12) & 291 & $15-17$ & 1 & 6 \\
College Age & 165 & $18+$ & & \\
\hline
\end{tabular}

Total

3363

\subsection{RETAIL}

The retail serves a larger market than the resident community. Regional shopping is easity accessible to the new community. The center is designed to exhibit a special flavor which will attract a wider market.

The overall program involves 125,000 square feet of retail on one or two levels in a central location and 20,000 square feet of retail within residential or recreational areas. Based on current, typical standards, the parking is as follows:

- personal services: one auto/250 sq. ft. gross

- retail stores: one auto/200 sq. ft. gross

- supermarket one auto/150 sq. ft. gross

- restaurants one auto/50 sq. ft. gross

- shopping center one auto/250 sq. ft. gross

\subsection{OFFICE}

Office space is of two kinds: professional/medical space within the retail center, and company headquarters with an office/industrial park setting. Professional offices would be approximately 10,000 square feet. Current typical parking standards are as follows. 
- window service office (e.g., banks): one auto/175 sq. ft. gross

- professional offices: one auto/250 sq. ft. gross

\subsection{ENTERTAINMENT}

There are four movie theaters in one complex to be located with the central retail area. The total capacity is 800 seats.

\subsection{CHURCH}

Three sites are provided of 2-4 acres each.

\subsection{INDUSTRY}

An industrial office park contains regional headquarters, distribution centers, showrooms, and $1 i$ ght manufacturing. The proportions of these activities is site dependent. It is not likely that there is a close relationship between the resident community and these locally available jobs. The Village of Woodbridge does not have an office/industrial park associated with it. The following standards are based on the Woodlands Metro Center Land Sales, associated with the Woodlands new community outside Houston:

\begin{tabular}{llc} 
& $\begin{array}{c}\text { Approximate } \\
\text { Size (sq. ft.) }\end{array}$ & $\begin{array}{c}\text { Land Requirements } \\
\text { (sq. ft./acre) }\end{array}$ \\
\hline Manufacturing Distribution Center & 19,000 & 4,000 \\
Regional Distribution Center/Warehouse & $50,000-200,000$ & 12,000 \\
Office Headquarters & 10,000 & 10,000 \\
Speculative Office & 50,000 & 15,000
\end{tabular}

The prevailing parking standards are as follows:

- manufacturing: one auto/350 sq. ft. gross

- warehouse: one auto/1,000 sq. ft. gross

- research labs: one auto/300 sq. ft. gross

- offices: one auto/250 sq. ft. gross 


\subsection{COMMUNITY SERVICE}

The community exists within a wider suburban context, having access to services such as garbage pick-up. All members of the community balong to an association which manages services not supplied by the larger municipality. The following activities have to be housed: fire station (2-3 acres), police station ( $\frac{1}{2}$ acre) post office (part of central retai1), library (1 acre), community association or "club house" (2 acres), and park maintenance (2 acres). Local transportation provision varies by site concept and the desired degree of self-sufficiency. Appropriate land is made available to suit the selected system.

The time frame for the project is 5-10 years. The technology would have to be in line by this period. The build-out time, depending on location, would be 10-15 years. The project will have to be phased over three periods: where the community begins, what it. incorporates initially, and the direction of growth will be critical.

Other uses will surround the property in time. The likely mix will be similar to the program described here. Portions of the site not selected for development will be sold off and may require access through the community.

The project will be partiy subsidized by federal programs. This will include housing subsidies for $20 \%$ of the dwelling units and subsidies to support the solar experiments.

The development team is likely to retain portions of the site (e.g., retail center) and will have a long-term interest in the property. They are likely to sell off lots to a variety of builders who may build fifty dwellings or less and may sell a proportion of the single-family lots to individual purchasers.

Today, it is unlikely that there will be a relationship between the industry and residential users. With increasing energy costs in the future, this proposition may change. 


\subsection{GOALS}

Some basic goals:

-Maximum use of solar energy within the constraints of providing an ecologically viable environment.

- Good solar access to all buildings.

-Minimum use of the automobile within the community.

Energy efficiency in the choice of all materials and construction techniques.

-Efficient use of sewers and water mains.

Minimum length of roads and services.

-Economy in subdivision layout to minimize costs to consumers.

- Convenient and functional relationships between land uses.

- Linkage to future surrounding communities.

-Maximum protection of ecologically sensitive landscape.

\subsection{ISSUES}

-Each context for the project has a special vernacular. How can this be incorporated, or will a new aesthetic evolve out of the local energy constraints?

- Communities evolve over time both socially and technologically, in particular, solar technology is changing rapidly. How can these changes be anticipated and planned for?

-While the community will be "incomplete" by necessity at each successive stage, there will need to be a particular image associated with. it. 0ther than the use of solar energy (which may be prevalent by that stage), what special qualities and features will compel 4,500 households to live there?

-Although the projected population is moderate in scale, how can a range of environmental choices be provided?

-Despite the highly segregated patterns promoted by typical zoning, relationships within a community are much more complex. How can the complexity of associations within the community be respected, while rationally ordering land uses? 
- The requirements of solar access can lead to residential patterns which are contrary to existing cultural patterns. How can we respect the nature and function of the residential street, be economical in the use of 1 and and provide good solar conditions as well?

-The character of the existing landscape is a major attraction of each context. On two of the sites the vegetation may be directly in conflict with solar requirements. How can environmental amenity be retained while solving solar access? 
THIS PAGE

\section{WAS INTENTIONALLY \\ LEFT BLANK}


The Rocking K Ranch is situated on 5000 acres ten miles southeast of Tucson, Arizona. The site is bounded to the north by the Saguaro National Monument. Summers are very warm $\left(74^{\circ}-98^{\circ} \mathrm{F}\right)$ and winters are $\operatorname{cool}\left(40^{\circ}-69^{\circ} \mathrm{F}\right)$. The annual rainfall for Tucson is 11 inches and the prevailing winds are from the southsoutheast. Climate tables are shown in Figure 3.0.2.

The site can be divided into two sections. The foothills of the Rincon Mountains in the northern section slope down to the Rincon Creek floodplain in the southern section. The foothills contain areas of exposed bedrock and are dissected by deep arroyos. The predominant plant species are saguaro and palo verde. The floodplain contains deep alluvial soils and is characterized by a more lush vegetation. The most dominant natural features of the site are the floodplain of the Rincon Creek and the exceptional views to the Tanque Verde Mountains to the north and the Rincon Mountains to the east. 


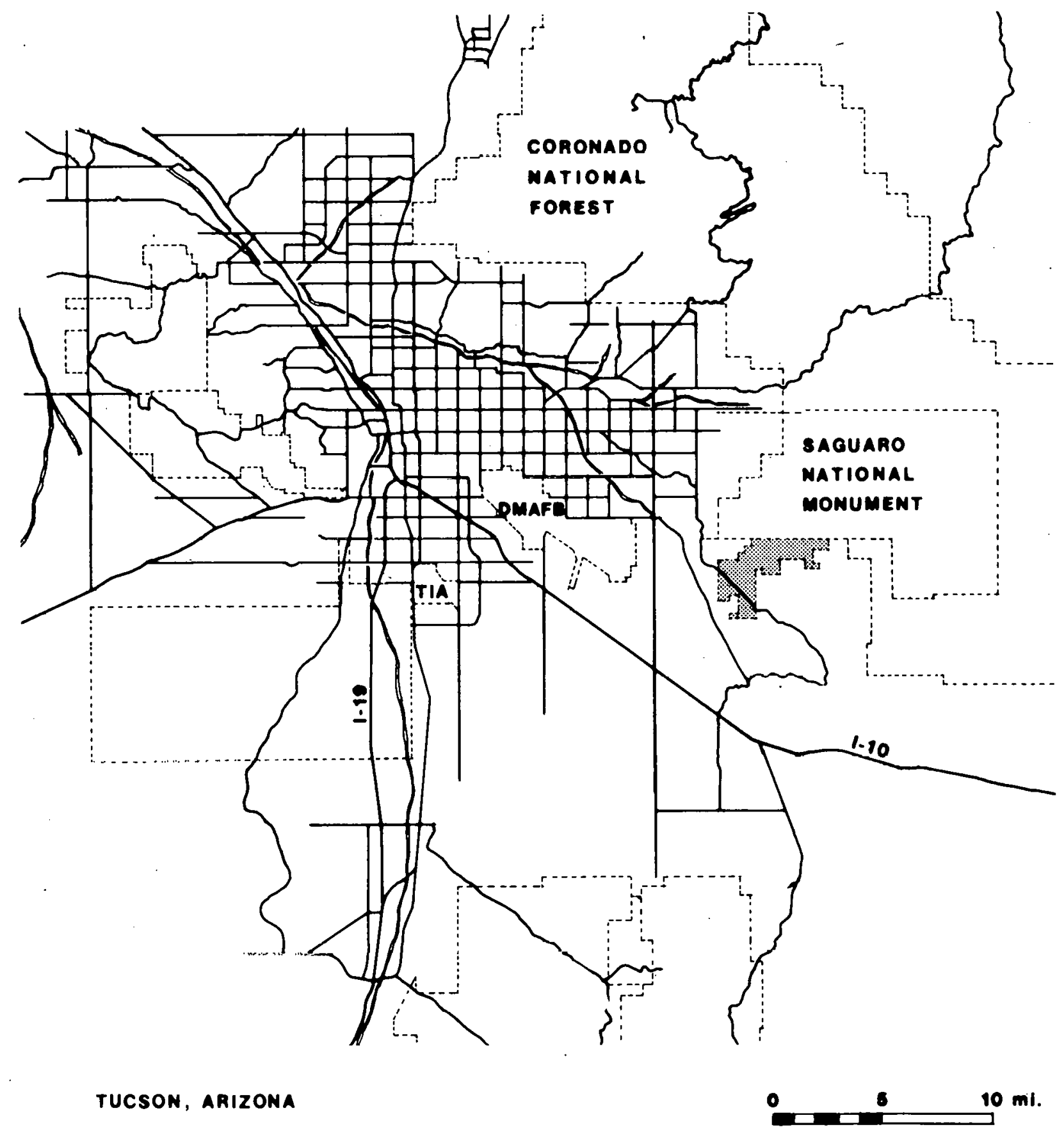

Fig. 3.0.1 


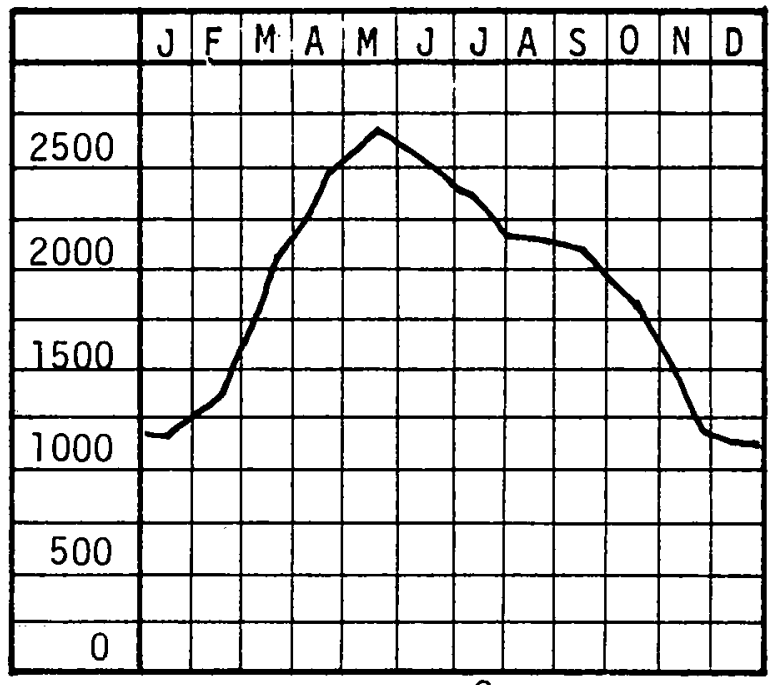

Solar Radiation BTU/FT2 Day
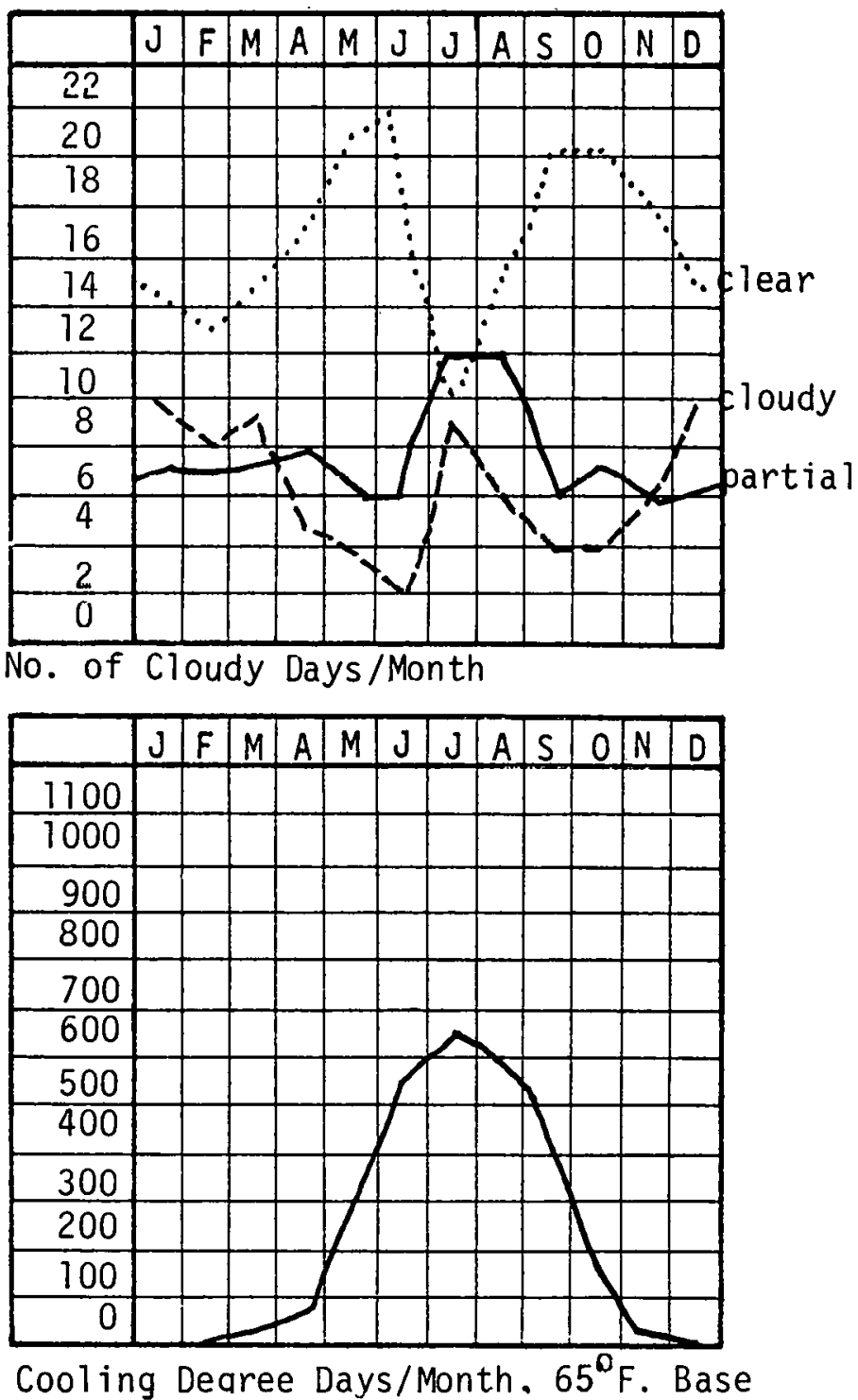

Table 3.0.2

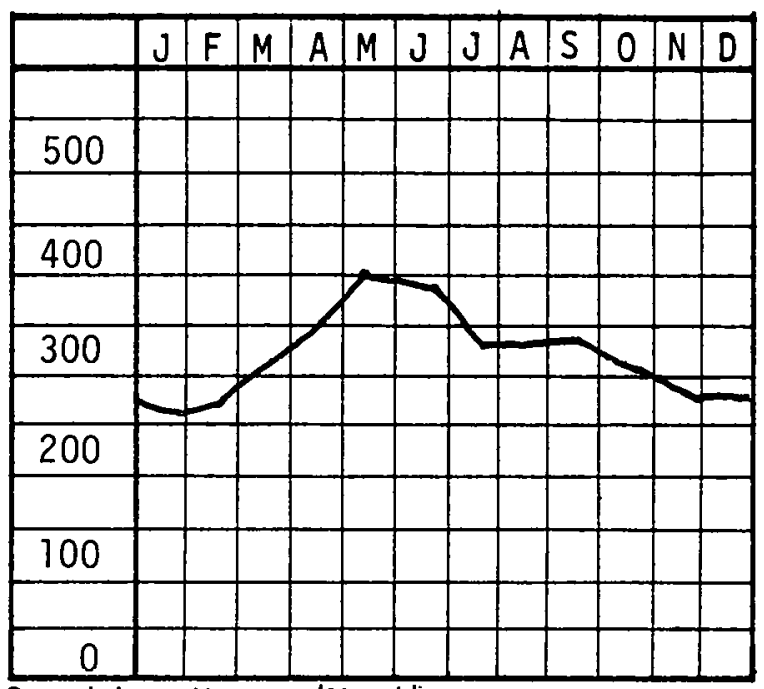

Sunshine Hours/Month

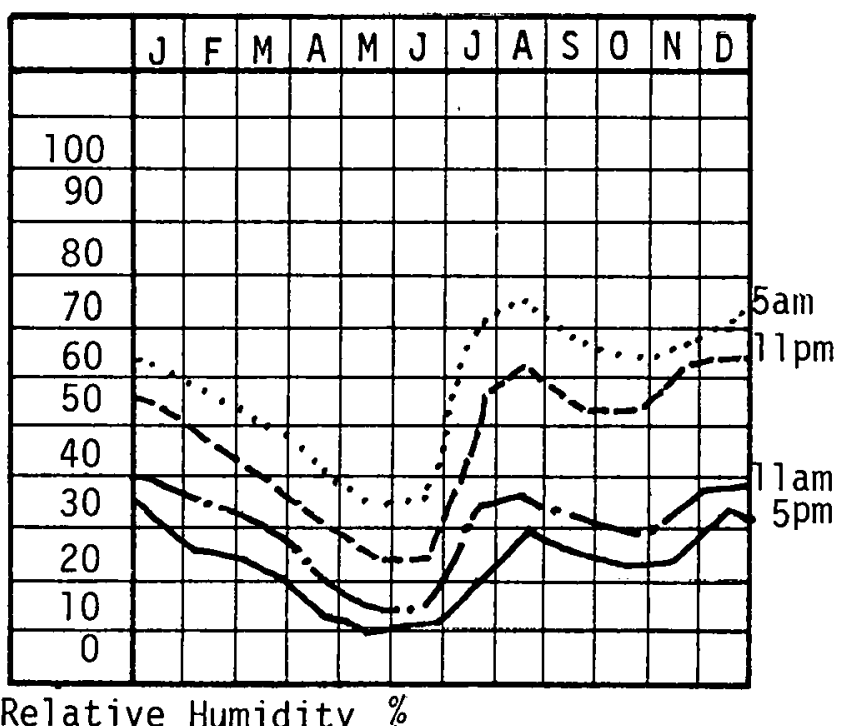



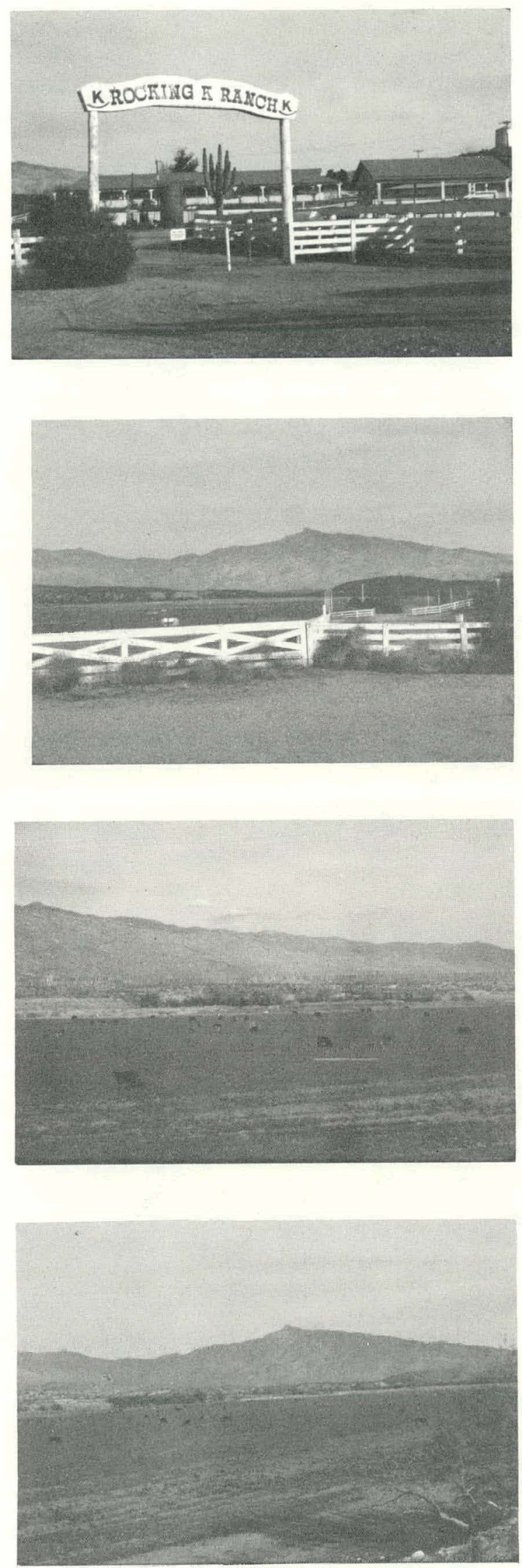

Fig. 3.0 .3

Entrance to Rocking $K$ Ranch

Fig. $3 \cdot 0.4$

Pasture at Rocking $K$ Ranch

Fig. 3.0 .5

Pasture land, looking north to Tanque Verde Range

Fig. 3.0 .6

Pasture 1and, looking east to Rincon Mountains 

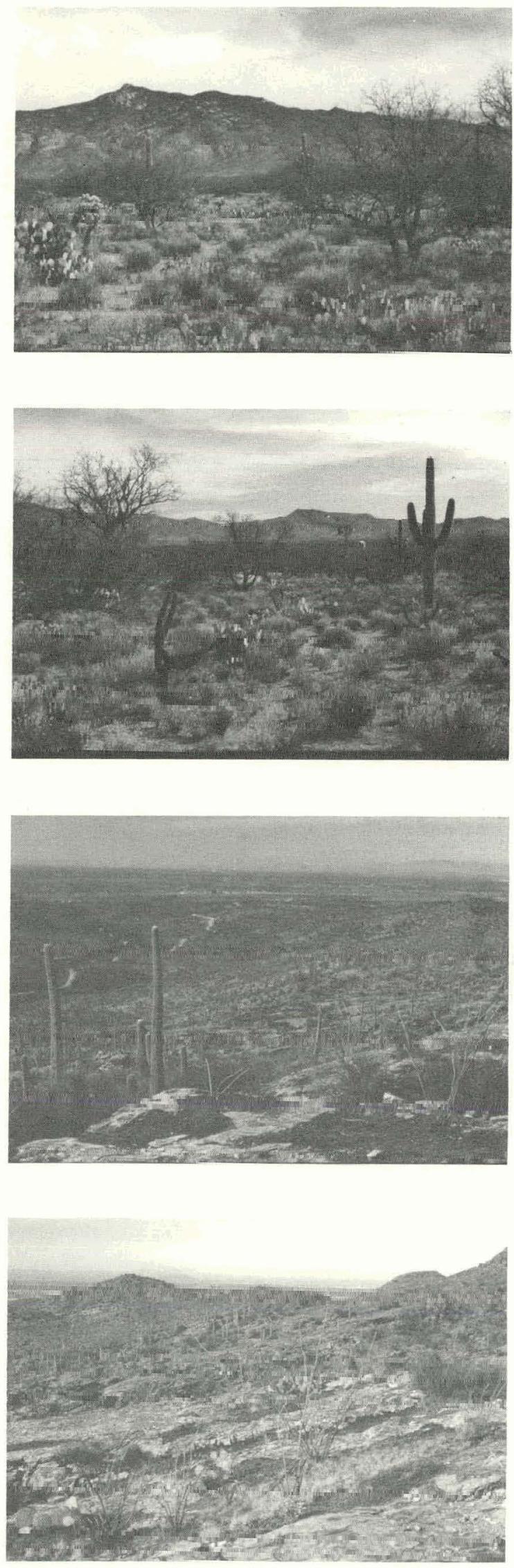

Fig. 3.0.7

Saguaro/Palo Verde association in the bottom 1and

Fig. 3.0 .8

Saguaro/Palo Verde association in the bottom 1 and

Fig. 3.0.9

Steep, rocky, dry slopes of Saguaro/Palo Verde

Fig. $3 \cdot 0 \cdot 10$

Steep, rocky, dry slopes of Saguaro/Palo Verde 


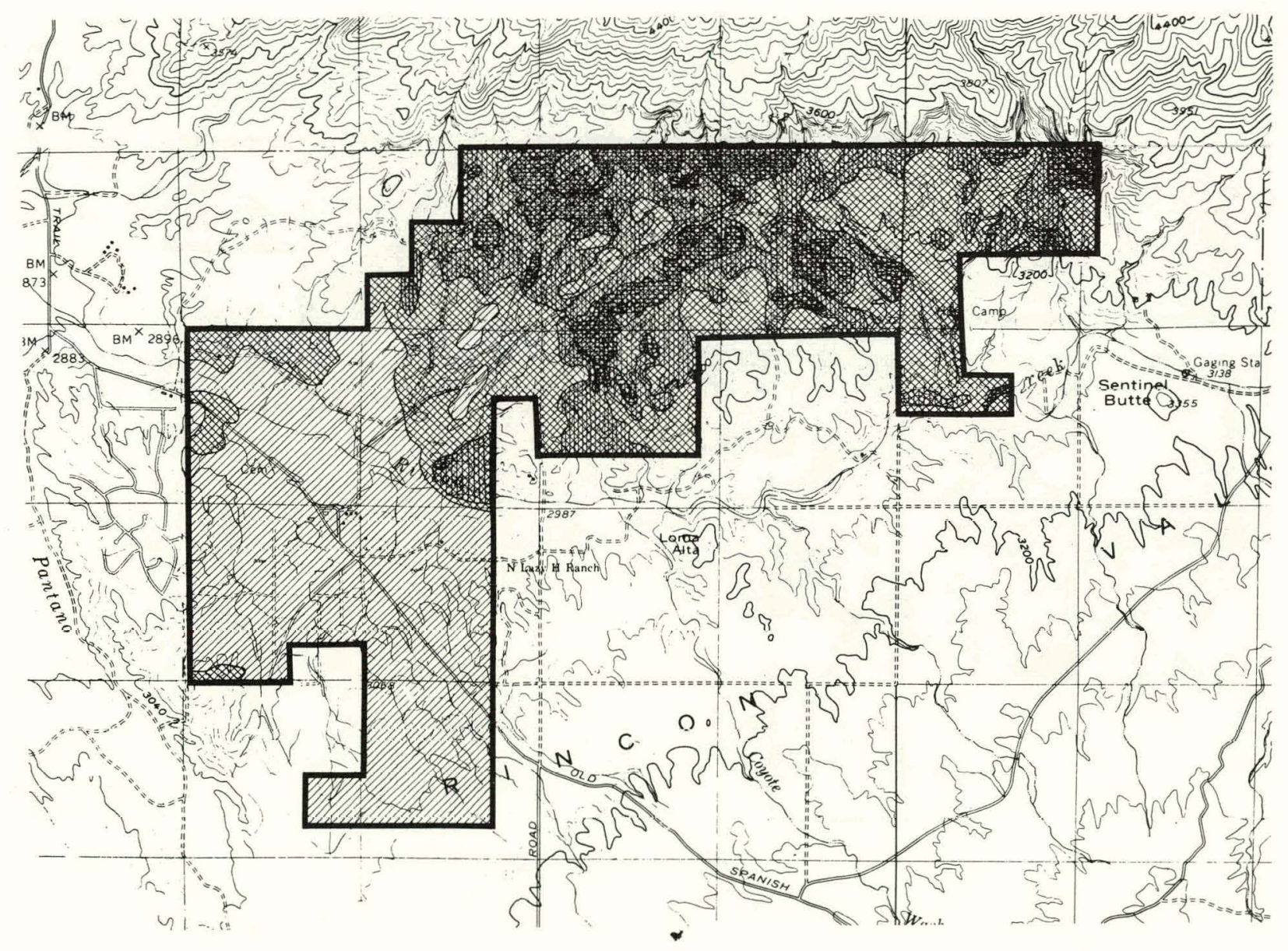

\section{Slope}

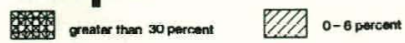

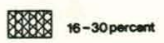

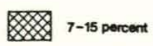

Tucson, Az.

HGSD Departments of Architecture and Landscape Architecture Solar Energy - Community Design Studio Spring 1980

Fig. 3.0.11 


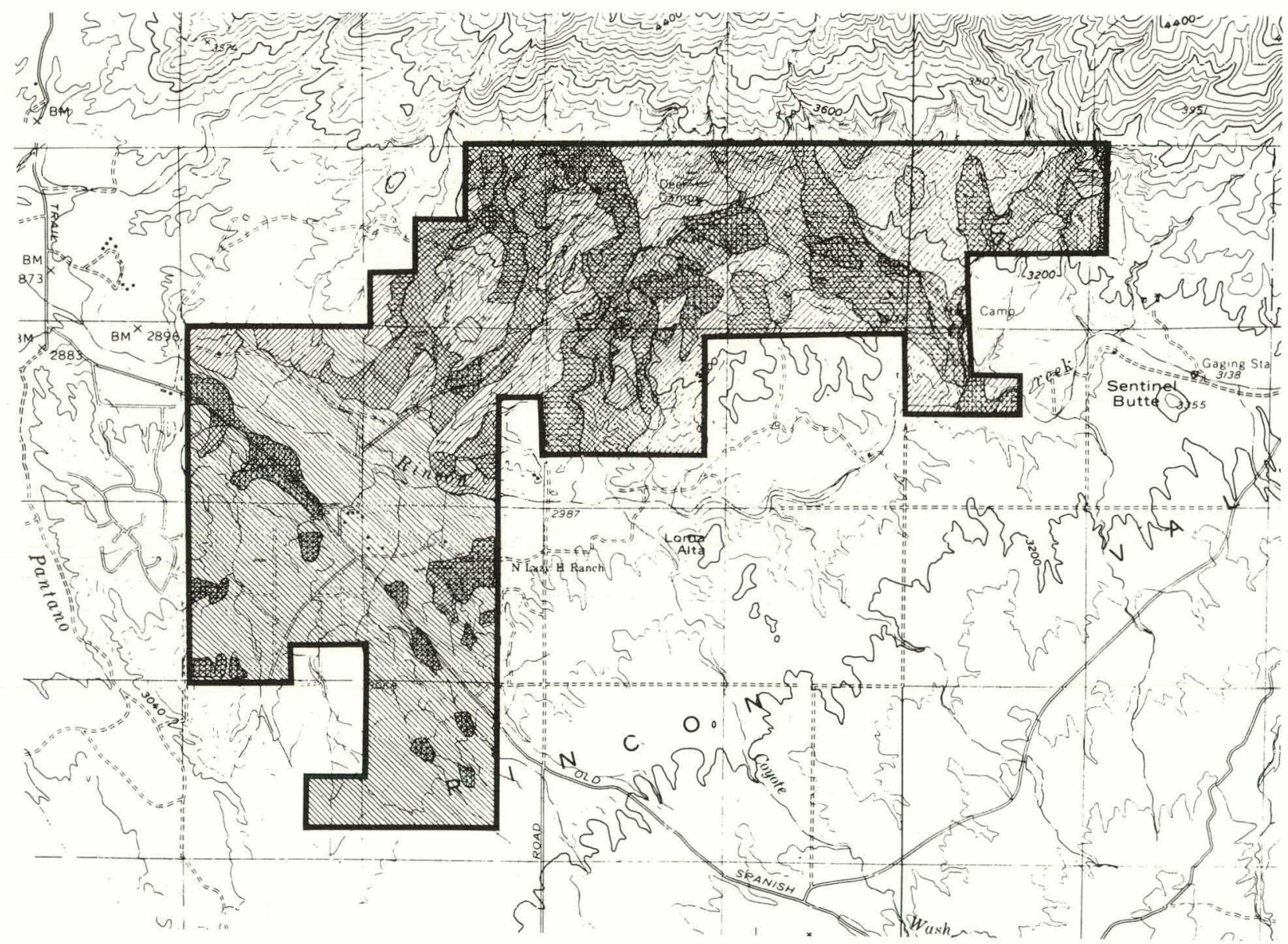

\section{Orientation}

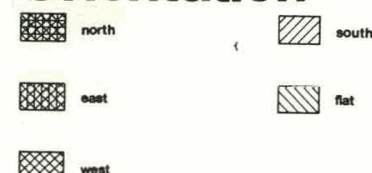

most

Fig. 3.0 .12
Tucson, Az. HGSD Departments of Architecture Solar Energy · Community Design Studio
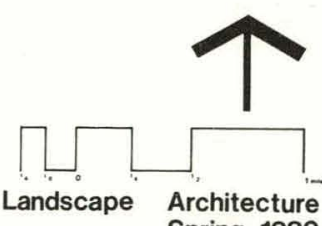

Spring 1980 


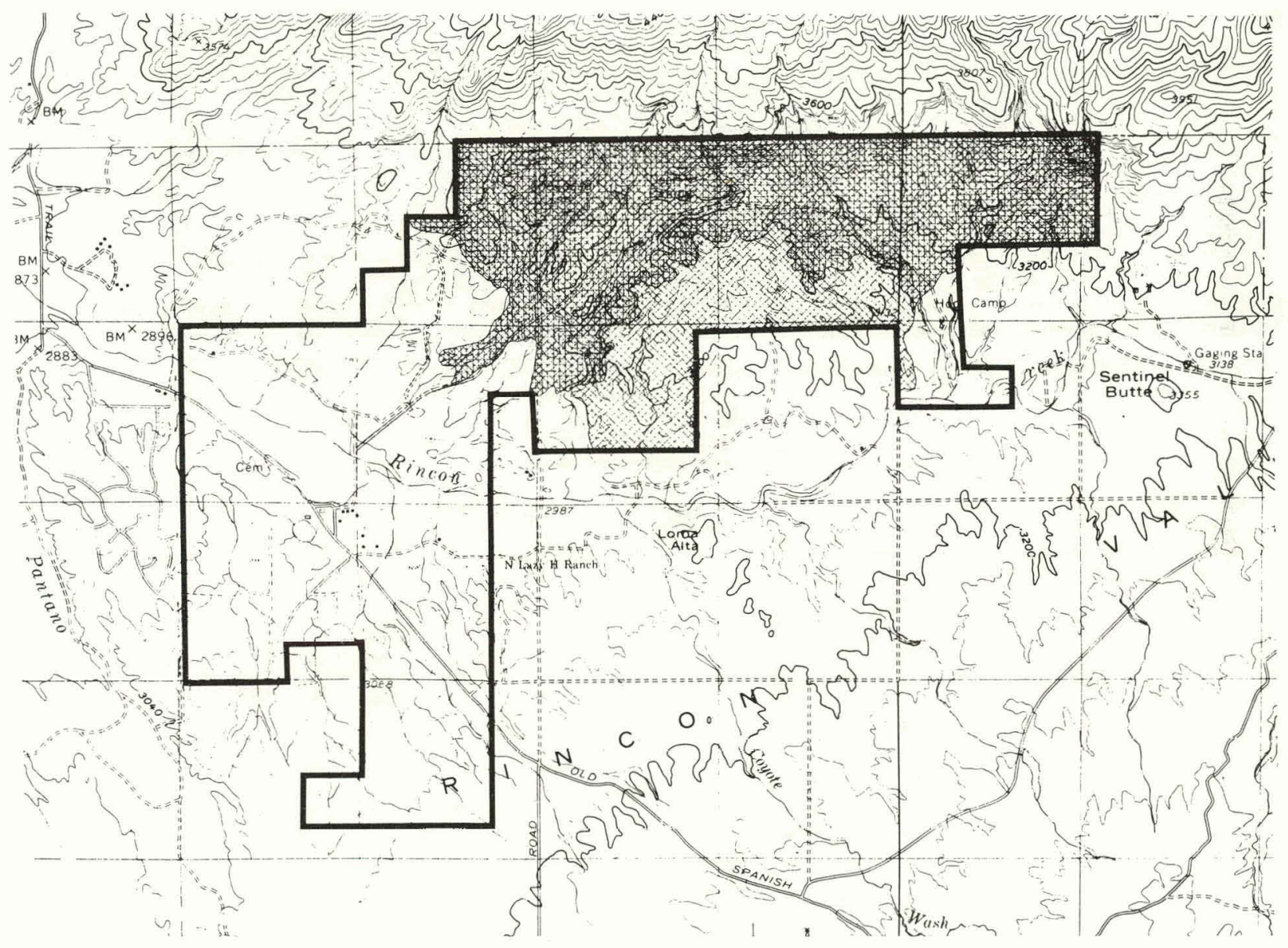

\section{Soils}

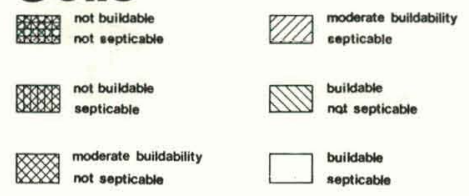

Fig. 3.0 .13 


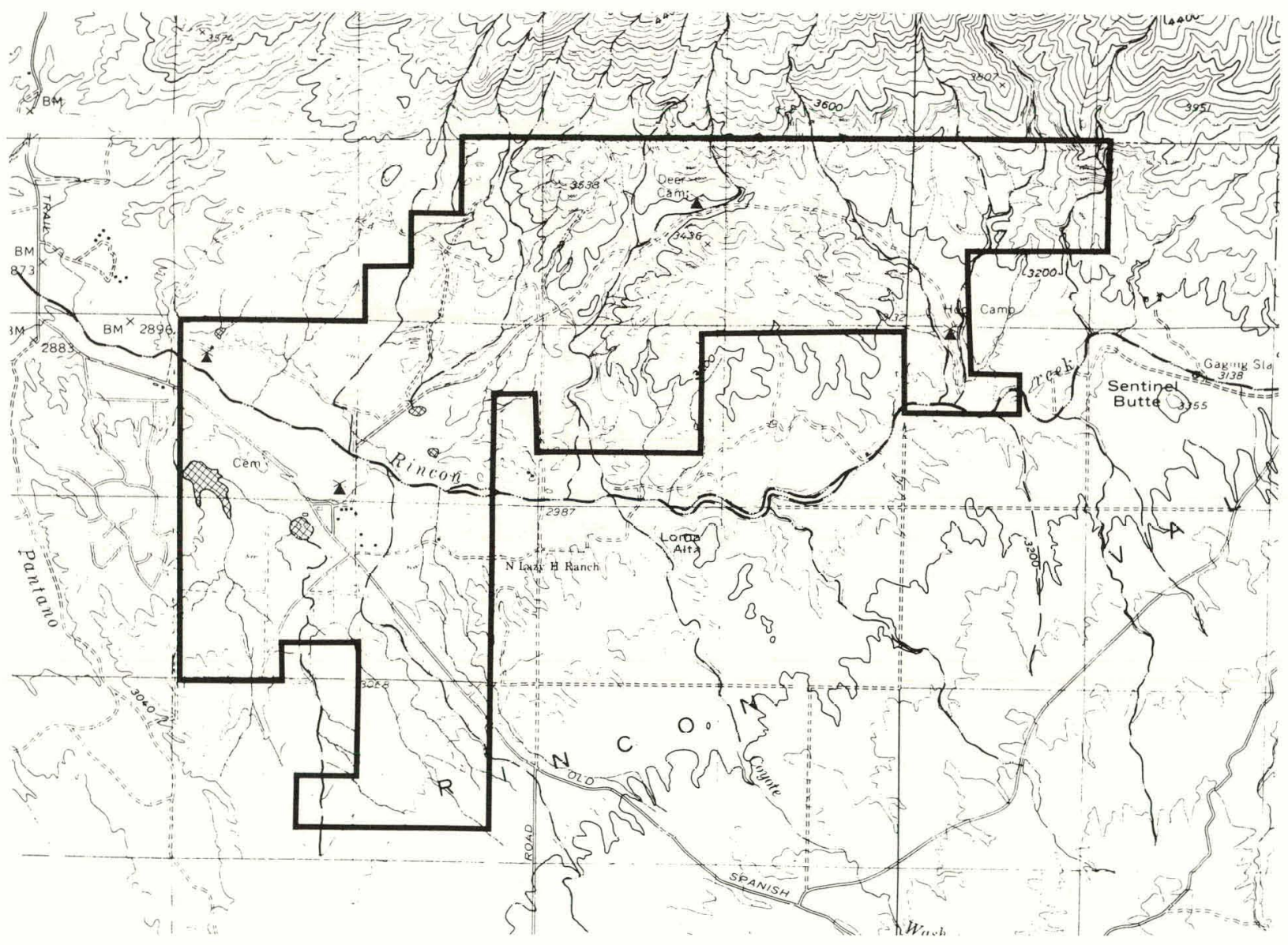

Hydrology

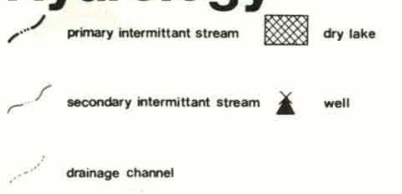

Fig. 3.0.14 


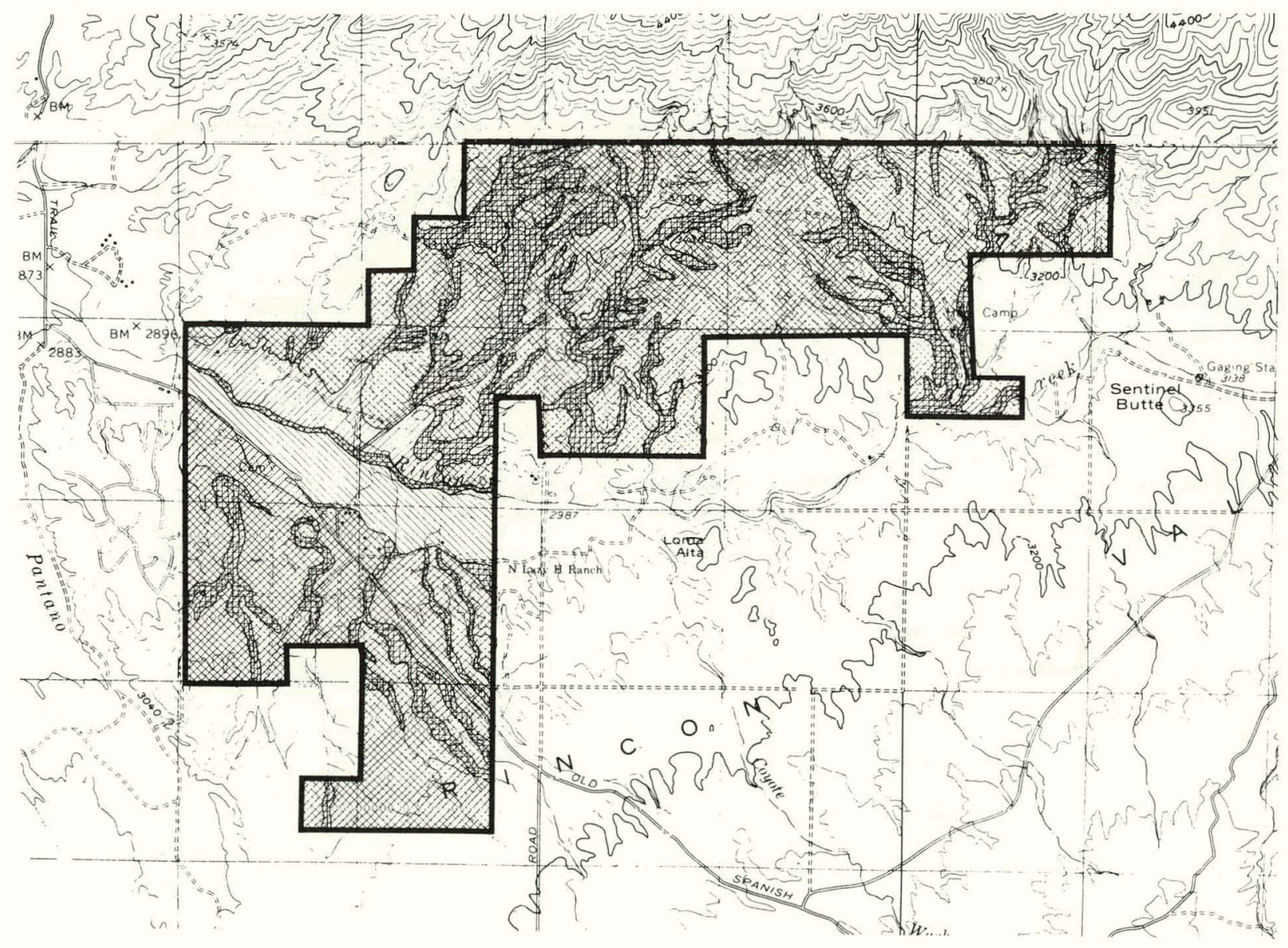

\section{Vegetation}

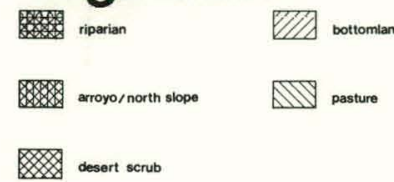

Fig. $3 \cdot 0.15$ 

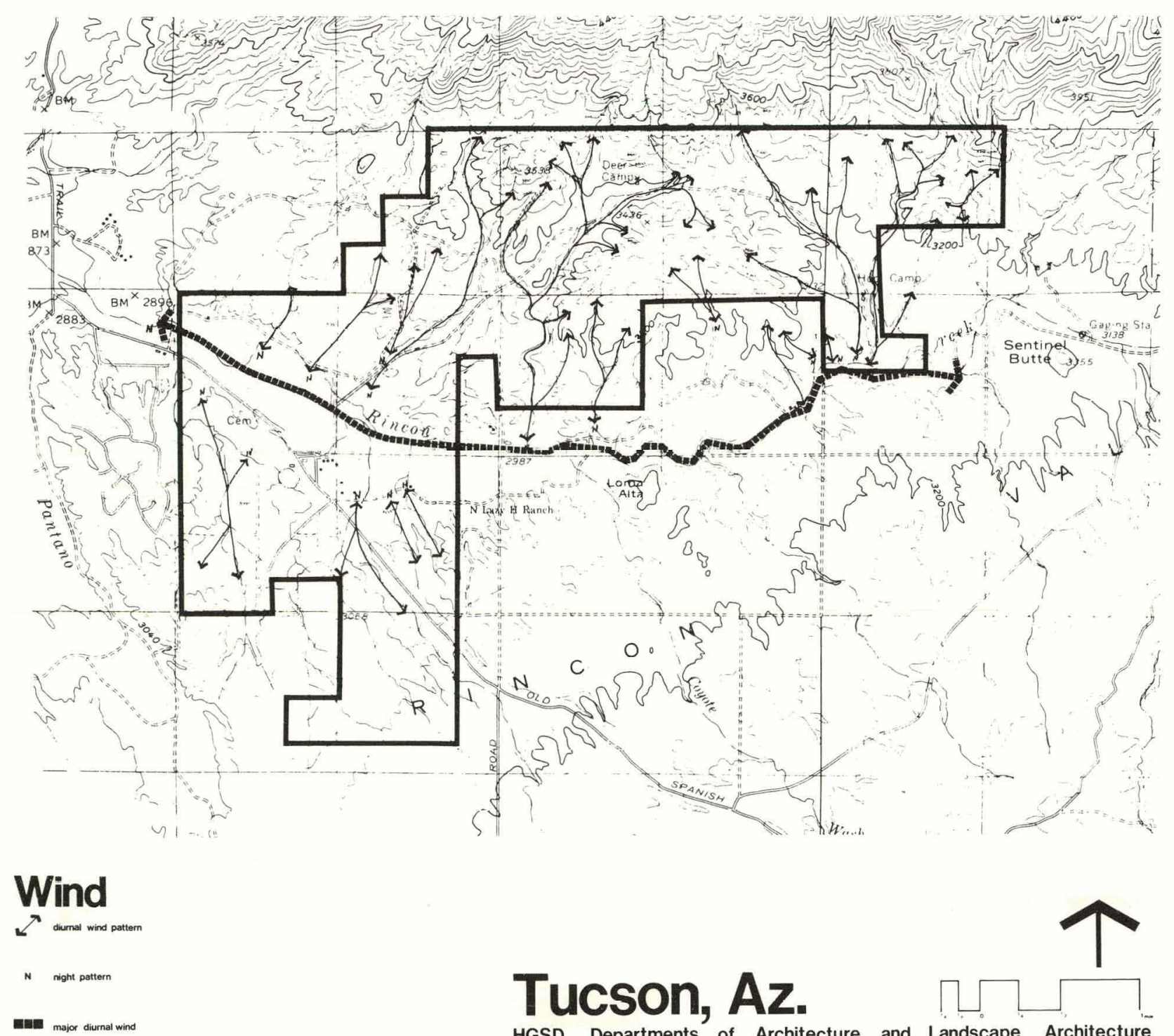

Fig. 3.0 .16 


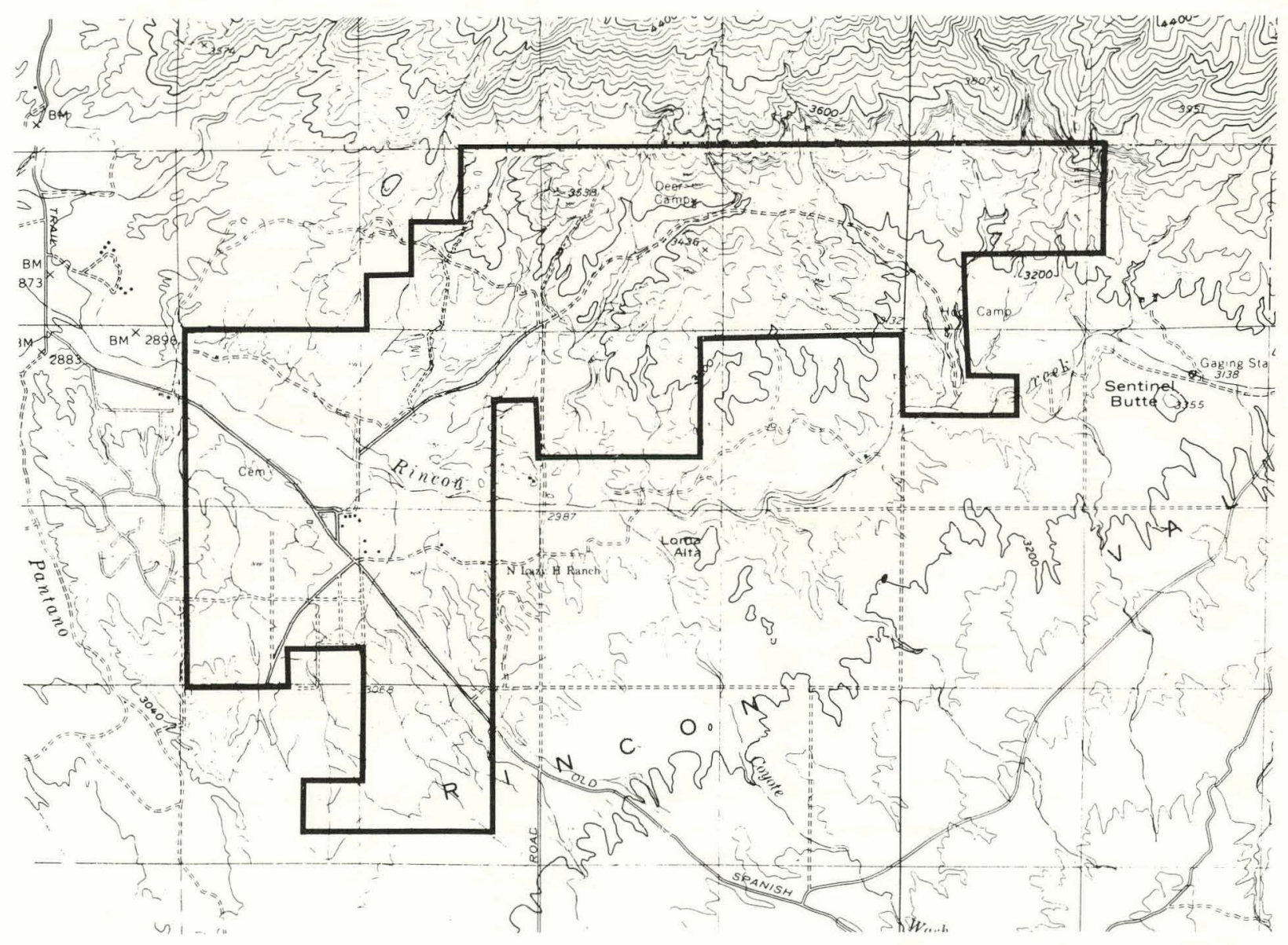

\section{Utilities}

I/ improved roadis row.
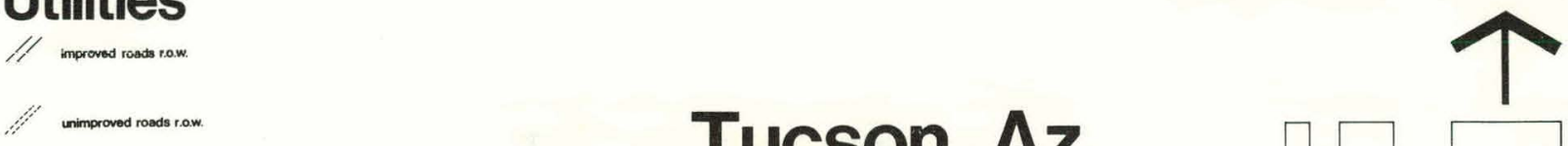

Fig. 3.0.17 


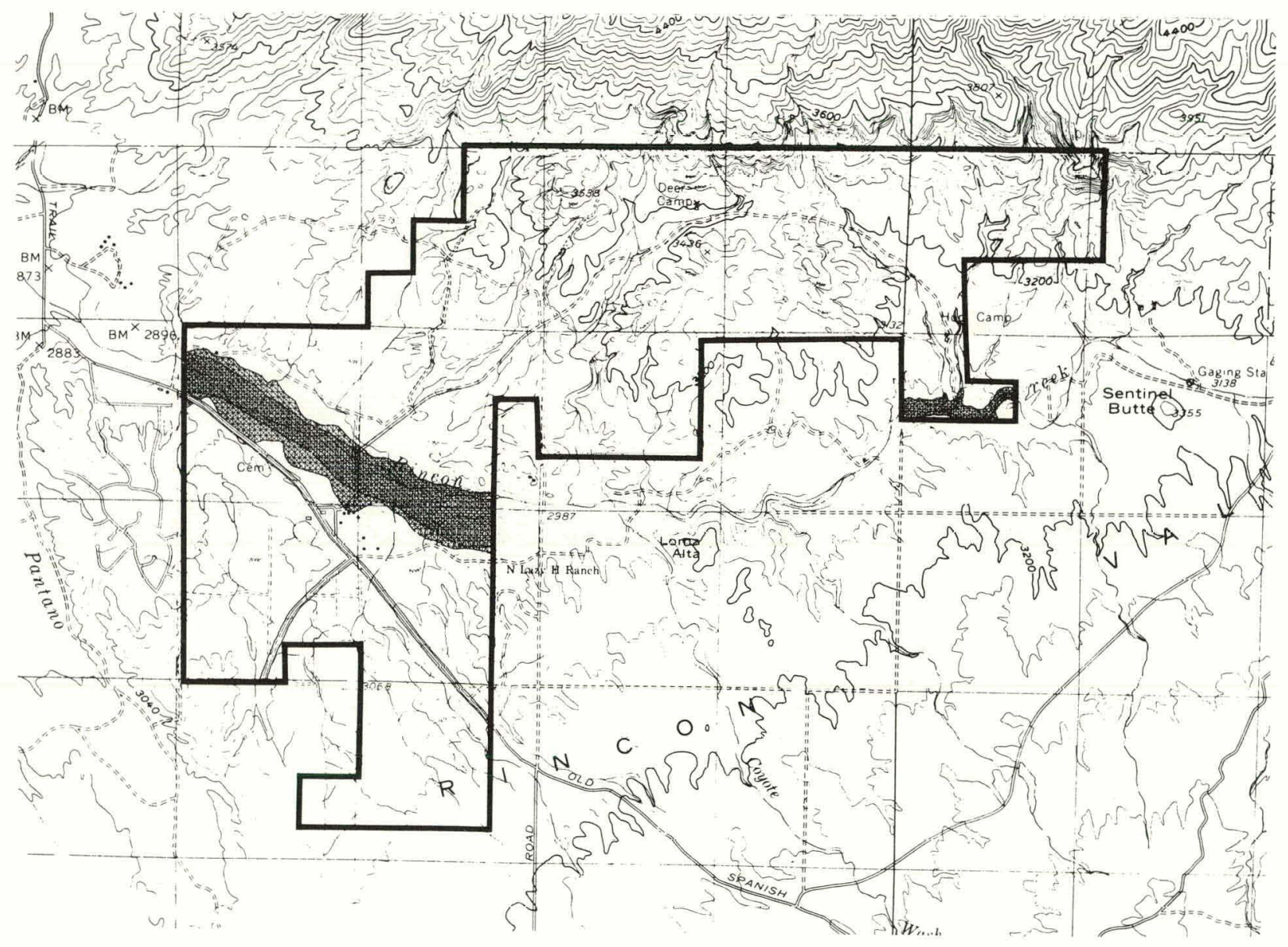

\section{Legal Constraints}

慗

Iroodtringe

Fig. 3.0 .18 


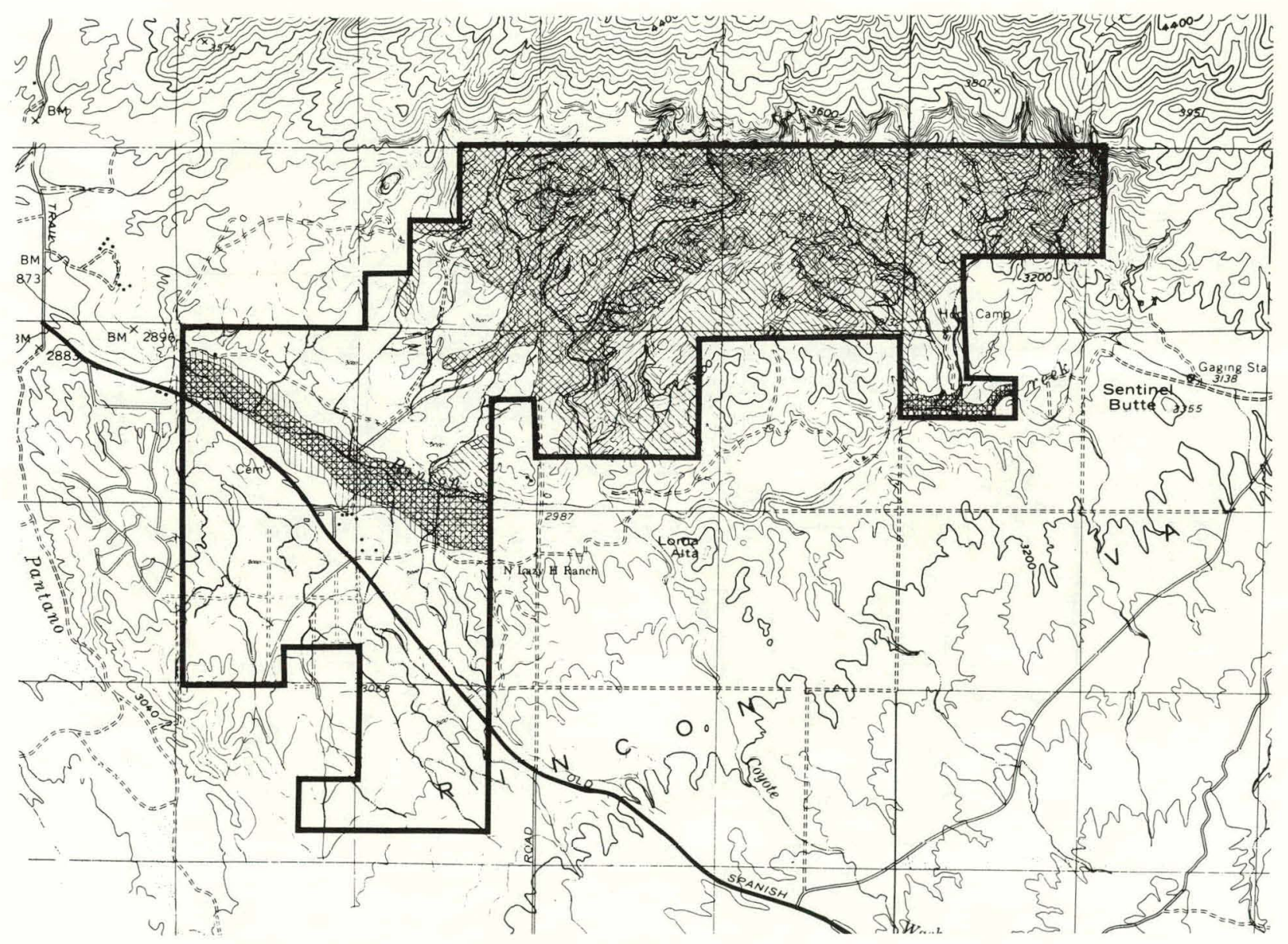

\section{Development Constraints /Sewered}

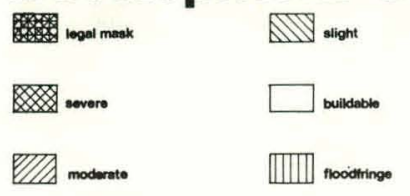

Fig. 3.0.19

Tucson, Az. HGSD Departments of Architecture
Solar Energy - Community Design Studio
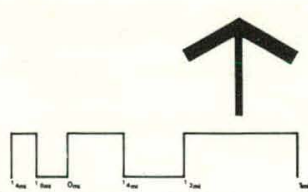

and Landscape Architecture Spring 1980 


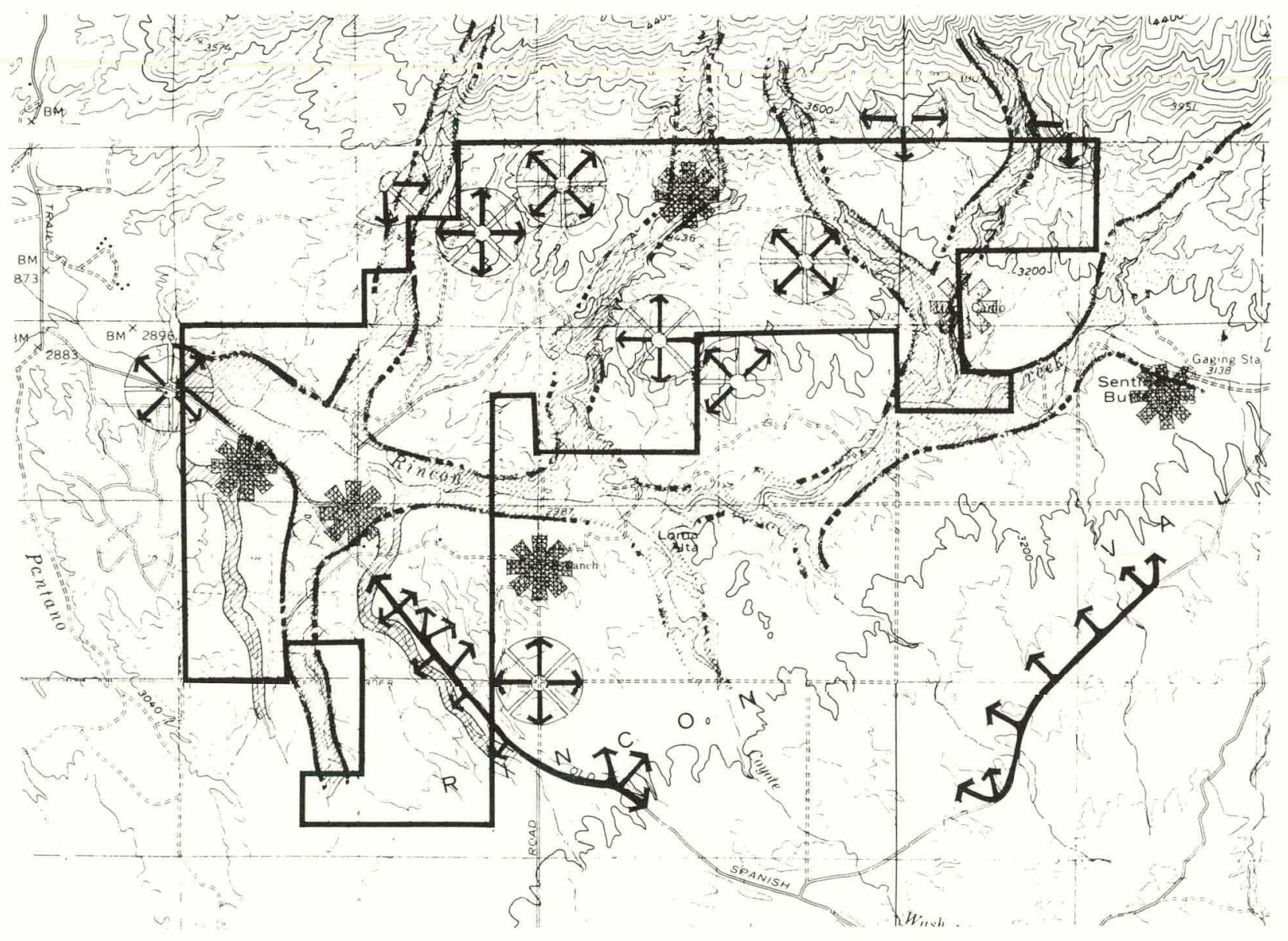

Site Amenities

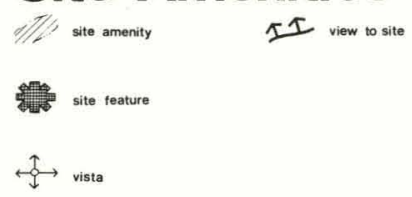

Fig. $3 \cdot 0.20$ 
THIS PAGE

\section{WAS INTENTIONALLY \\ LEFT BLANK}




\subsubsection{DESIGN STRATEGY}

Tucson 1's primary goal is to take full advantage of the sun for passive summer cooling and winter heating. The team proposes a dense compact plan sited north of the Rincon Creek flood plain. The community will resemble a "hill town" rising up the foothills of the Rincon mountain range and be visible from 0ld Spanish Trail. The town is oriented towards Tucson and the valley. Local streets are oriented east-west with north-south boulevards.

Community Plan Description (Figs. 3.1.1.1, 3.1.1.2, 3.1.1.3)

The main gateway to the town is through a tree-lined boulevard that leads to a town center which surrounds a main plaza. Shops and offices are located off the main plaza within smaller courtyard complexes. The high-density housing consisting of three- and four-story walk-up apartments, with private and public courtyards, are located along this major north-south boulevard and close to the town center. A high school is within walking distance of the town center and the high-density housing. The boulevard extends north to a natural amphitheater that is carved into the rocks. It forms a focus for community activities and regional attractions. A cultural center and an elementary school complete this complex. Higher-density housing is located further north in the foothills. The housing follows the natural contours and steps down the hillside, creating a "hilltown" view from the town and surrounding region.

Throughout the entire town the arroyos are left in their natural state to channel water, wind, and fresh air from the foothills into the town. The arroyos also offer contrast to the orthogonal pattern of the town, enhancing its design. Areas which are "unbuildable" are left as open space, and the entire area south of the flood plain is reserved.

Future development is presumed to occur south of the 0ld Spanish Trail. A sewage treatment plant is located on the farthest site border to the west of town. The heliostat field, wind turbines, and pumped hydro water storage are dispersed within the hills to the northeast of the site. An office park is 
located along the northern edge of the flood plain.

Phasing (Fig. 3.1.1.2)

The community has been planned to take up all available, buildable land north of the flood plain. Phase 1 includes part of the town center, the high school, an elementary school, the high- and medium-density housing, and the community recreation facilities.

In Phase 2, an additional elementary school will be built, together with more high- and medium-density housing, the cultural center, and ampitheater.

During Phase 3, the growth of the neighborhood centers, and high- and mediumdensity housing will continue.

\subsubsection{ENERGY STRATEGY (Figs. $3.1 .2 .4,3.1 .2 .5$ )}

The primary goal in the design of a solar community in Tucson is to approach $100 \%$ self-sufficiency. To achieve this, the team's strategy is to lower the overall energy consumption of the community on a day-to-day basis and to design the community and individual structures to respond to the climatic conditions of the site.

\section{Assumptions}

It is assumed that in ten years the life style of Americans will change in response to the energy crisis. Individuals will be more conservative in their energy use and will tend to live closer to work, reducing commuting distances. The automobile will be used less frequently. It is assumed that appliances will become more efficient. People will adapt to livina with a solar enerav system and their daily routines will alter. The design reflects approaching a $100 \%$ self-sufficient solar energy community with the support of wind turbines and a pumped hydro storage facility in addition to the primary solar thermal electric supply. A power exchange link to the regional power grid is provided. Structures can be designed in the Tucson climate to rely on $100 \%$ passive heating and cooling systems, allowing the elimination of mechanical air-conditioning and 
reduce the total energy load by approximately $40 \%$. If the $100 \%$ figure cannot be met, a central chiller and seasonal storage system might be considered as a back-up system.

\section{Electrical Generation Strategy}

A central power system will provide electricity, thermal energy and domestic hot water to housing; community services, and commercial and institutional buildings. The central plant consists of "power-tower" collector systems, one for each of the three development phases. Each receiver can provide up to about 60 mega-watt hours of electricity or as much as 100 meyd-wall hours thermal per day with electric output reduced to about $50 \mathrm{MWh}(\mathrm{e}$ )/day (in a cogeneration mode) to each of the three phasing districts. Each power-tower recelver has a heliostat field of approximately 47 acres. The industrial office park has a central receiver system of its own, connected into the community grid, drawing additional energy during its peak hours and feeding any surplus back into the community during non-operational periods. This exchange helps to balance weekly and seasonal peak loads, reducing the overall size of the central power system. Certain functions such as offices, industries, stores, and schools only operate five days a week so that a significant amount of energy is often available for charging long-term storage (e.g., pumped hydro) or for sale by the community on weekends.

If $100 \%$ on-site self-sufficiency is to be achieved, a longer-term pumped hydro st.nrage system and a back-up wind power system might be considered for the site as indicated in the supply table and energy diagram. (An alternative is greater reliance on the regional power grid.) While the site would allow a 100-foot head, more than 100-million cubic feet of water would be required to store one full day's electricity supply. Open ponds at the top and bottom of such a system might result in prohibitively large evaporatfve water losses, and conventional closed tanks would probably be prohibitively expensive. For less than a full day's supply, however (perhaps in combination with community load reductions or storage dispatching coordinated with utility or on-site fuel fired back-up), such. a system could be considered. With an average wind speed of about 9 miles per hour in Tucson, the Darrieus wind turbines included in the design are currently economically marginal, though by no means prohibitive if projected cost goals are achieved. Slightly higher wind speeds may also be available at specific 
sites due to local variations in topography. The Tucson area experiences so few cloudy days, however, that elimination of both the pumped hydro and wind power systems in favor of the regional power grid would not greatly alter the community's basic energy self-sufficiency. Even without these systems, the design would result in production of significantly more energy than would be consumed within the community.

Thermal Generation Strategy

Despite a goal of $100 \%$ self-sufficiency, certain concessions in the design of the community and the uncertainty of architectural energy performance may make it unfeasible to realistically consider total reliance on passive heating and cooling systems. It is quite possible, however, that an $80-85 \%$ (better than BEPS) reduction in heating demands can be reached. Therefore, a supplemental heating and cooling system may be needed to meet these added demands. One option is a seasonal hot-water and ice-storage system. Heat exchangers would provide cooling during the summer months and heating in the winter. Heatpump Annual Cycle Energy Systems (ACES) such as this might be selected for their remarkable energy efficiency potential, although their economics in a back-up operating mode (especially in a centralized configuration with expensive thermal distribution systems) are marginal. This or some other back-up system would only be required, however, if passive design features are, in fact, inadequate to cover full loads. 


\section{TUCSON 1}

\section{ASSUMPTIONS AND EXPLANATIONS}

1. $85 \%$ of thermal heating and cooling demands met by passive solar technologies.

2. $100 \%$ of domestic hot water demand met by solar flat-plate collectors on a building by building basis.

3. Office and industrial development assumed to be independentiy selfsufficient, not included.

\begin{tabular}{|l|l|l|l|}
\hline $\begin{array}{l}\text { TYPE OF BUILDING OR } \\
\text { DEMAND }\end{array}$ & UNITS/AREA & ELECTRICAL \\
\cline { 2 - 4 } & QUANTI'TY & $\begin{array}{r}\text { AREA/UNIT } \\
\text { OOR } \\
\text { TOTAL AREA }\end{array}$ & MWh/ Day \\
\hline
\end{tabular}

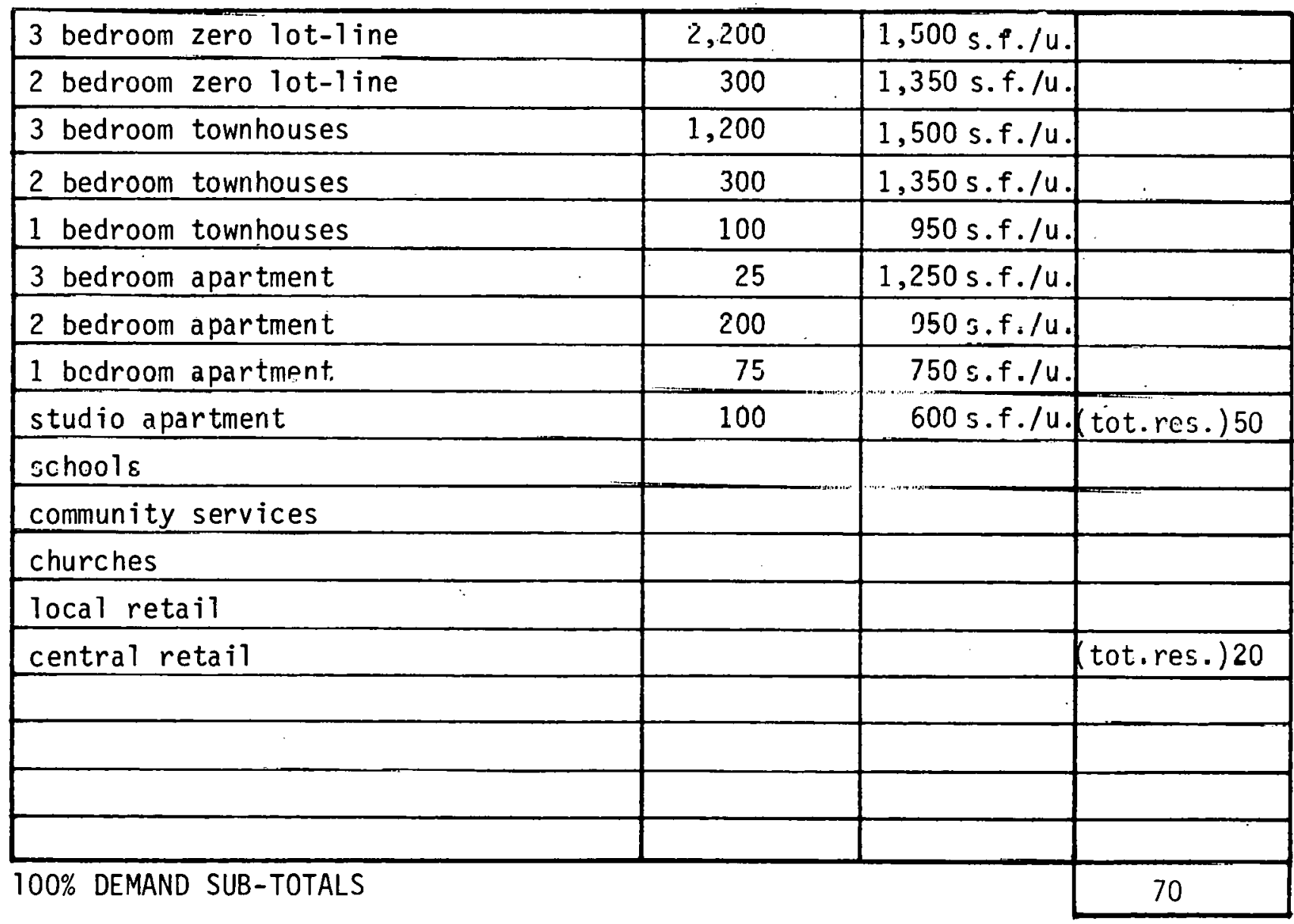

\section{total community energy demand}


4. Approximate average demands are shown for heating and cooling. Only $15 \%$ of these loads are to be met by "active" systems.

\begin{tabular}{|l|l|l|l|l|l|}
\hline \multicolumn{2}{|l|}{ HEATING LOAD } & \multicolumn{2}{l|}{ COOLING LOAD } & \multicolumn{2}{l|}{ DOMESTIC HOT WATER } \\
\hline $10^{6}$ Btu/Day & Mwh(Th)/Day & $10^{6}$ Btu/Day & Mwh(Th)/Day & $10^{5}$ Btu /Day & Mwh(Th)/Day \\
\hline
\end{tabular}

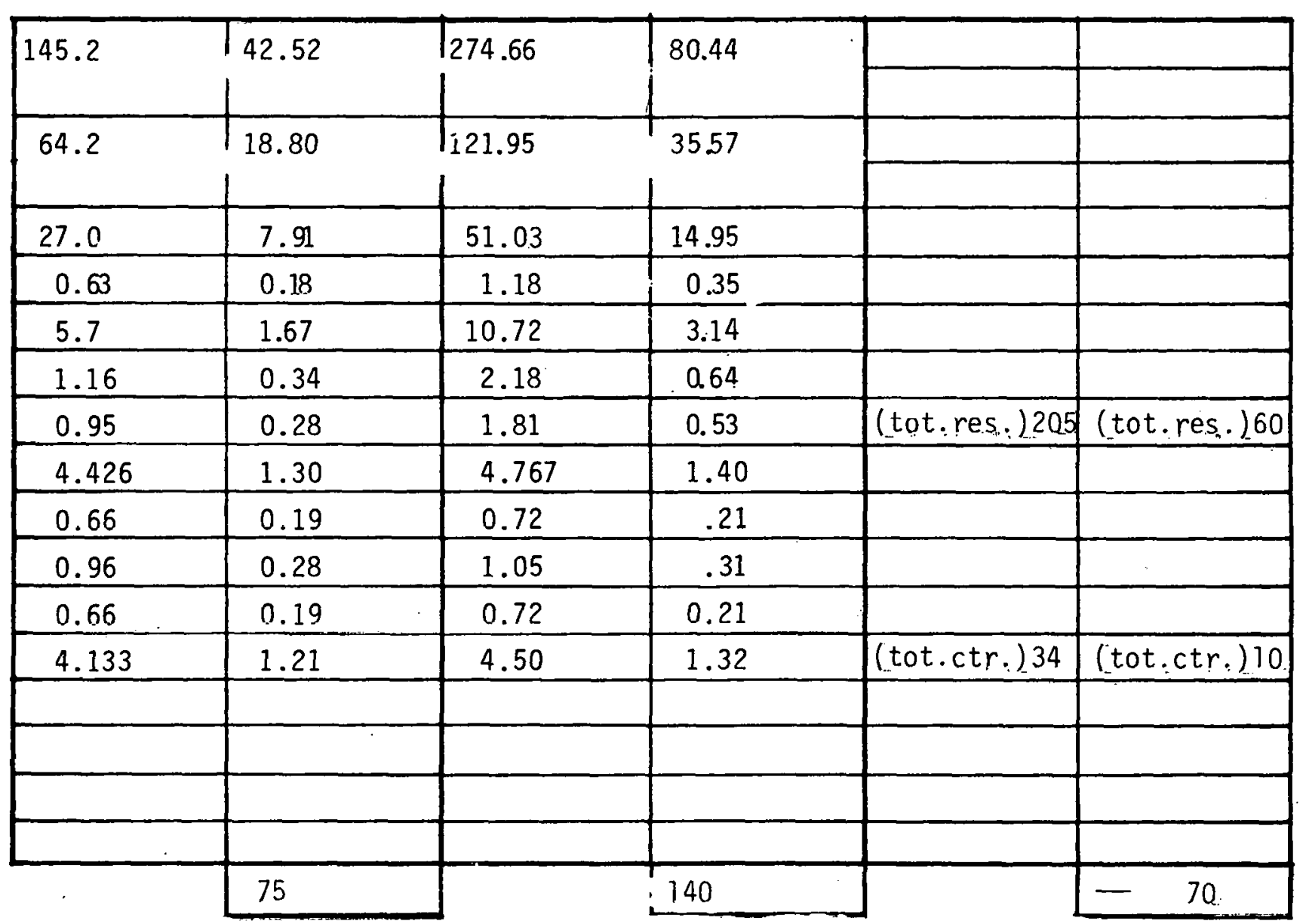


TUCSON 1

supply

ASSUMPTIONS AND EXPLANATIONS

1. Excess electricity supply from central receiver and Darrieus wind turbines is sold to local utility grid.

ENERGY SOURCE

APPLICATION

CONFIGURATION

SUPPLY

Mwh/Day

STORAGE SYSTEMS \begin{tabular}{|l|l|l|l}
\hline 1. ice and hot water & augment supply for & seasonal & optional \\
\hline storage & peak heating/cooling & & \\
\hline
\end{tabular}

2. pumped hydro reservoir supply/demand $117,500,000 \mathrm{cu} . \mathrm{ft}$;

optional buffer

cu, ftig.

SUPPLY SYSTEMS

\begin{tabular}{|l|l|l|l|}
\hline 1. central receiver & electrical, peak & 140 acres & 180 MWh(e) \\
\hline heliostat fields & heating and cooling & electric only & \\
\hline & demands & with thermal & \\
\hline & & recovery & \\
\hline 2. Wind turbines & augment direct & 25 & \\
\hline & sunshine & Darrieus wind & \\
\hline & & turbines & \\
\hline & & & \\
\hline
\end{tabular}

\section{total community energy supply}




\section{THIS PAGE \\ WAS INTENTIONALLY \\ LEFT BLANK}




\subsubsection{SITING ISSUES AND HOUSING}

High and medium-density housing is comprised of three main housing types, each designed to accommodate the varied slopes of the site.

High-Density Apartments (Figs. 3.1.3.7, 3.1.3.8, 3.1.3.9)

These are two and three-story walk-up units with common courtyards located on $0-5 \%$ slope, and having an average density of $26 \mathrm{~d} . u$. per acre. These units are designed for the high-density regions located near "the boulevard." Considerations in the design of these units are: milimal east-west exposure, shaded parking for cars, flexible configurations in massing, natural ventilation, views, flexible interior living spaces that orlent ellher worth or south depending on the season, and southern and shaded outdoor spaces for each unit. Entrances to the courts are raised to signify entrance and passage, and serve to shade the paved courts and provide ventilation to the interior architectural space.

The units in the north are 2-3 bedroom units (1800 sq. ft.), each with north and south private open space. The units in the south are 1-2 bedroom units (1200 sq. ft.). Hot water is provided by the central system (for units on the distribution system) and by flat-plate collectors. Heat is provided by viriect gain through a thermal chimney used in conjunction with "spancrete" extruded concrete planks, which provide radiant floor heat to the unit. Direct gain is controlled by mullion design as well as by overhaings. The thermal chimney automatically adjusts its vent in warm weather and draws cool air from the covered parking alley, cooling the slab and venting the fumes from the parking area. The use of dense wall materials and good cross-ventilation assist in providing additional cooling.

High-Density Apartments (Figs. 3.1.3.14, 3.1.3.15).

The apartments have two or more storys with small courts and terrace enclaves, accessible by diagonal staircases. When located on $0-5 \%$ slopes an average density of $8 \mathrm{~d} . u$. per acre is achieved. The diagonal element acts as a transition accommodating a variety of slope conditions. The building type 
responds to street access from the south, with staircases, entries, and courts on the south elevation. In designing the plans, consideration is given to the summer's climatic conditions. The courtyards are in shade and cooling is via artificially amplified breezes and by cool air from a rock bed in the basement. A stairway continues up to the roof, which is used as a garden. The roof-top gardens reduce the need for recreational space at ground level and allow more space for a greater housing density.

High-Density Terraced Apartments and Townhouses (Figs. 3.1.3.16, 3.1.3.17)

The hilltop terraced housing is located on $7-20 \%$ slopes and has an average density of $24 \mathrm{~d} . u$. per acre. The units have optimum solar orientation, and westerly slopes. North-south arroyos create natural openings in the built pattern which, in addition to individual courtyards and terraces, balance community needs for open space.

Housing is sited on both sides of a pedestrian street. A living room is partly buried and shaded by an overhanging umbrella-like sleeping quarters. Corridors and terraces are built with southern exposure between the upper floors, and act like a brise-soleil. Apartments and townhouses have wind-scoop towers for ventilation and cooling.

Medium-Density Housing (Figs. 3.1.3.10, 3.1.3.11, 3.1.3.12, 3.1.3.13)

The neighborhood pattern for medium-density housing consists of tightly massed units: in rows or courtyard arrangements giving mutual shading and shared eastwest party walls. The housing is accessible by automobile, garages or covered parking being underneath the units. Pedestrian paths open up into public courtyards for use by residents. A wide range of house types allows for variations. and flexibility in visual and spatial form.

Density ranges from 4- $6 \mathrm{~d}$.u. per acre and though densely packed the houses are spacious with courtyards on both north and south sides. The average lot size is $2,400 \mathrm{sq}$. $\mathrm{ft}$. 


\section{THIS PAGE WAS INTENTIONALLY LEFT BLANK}




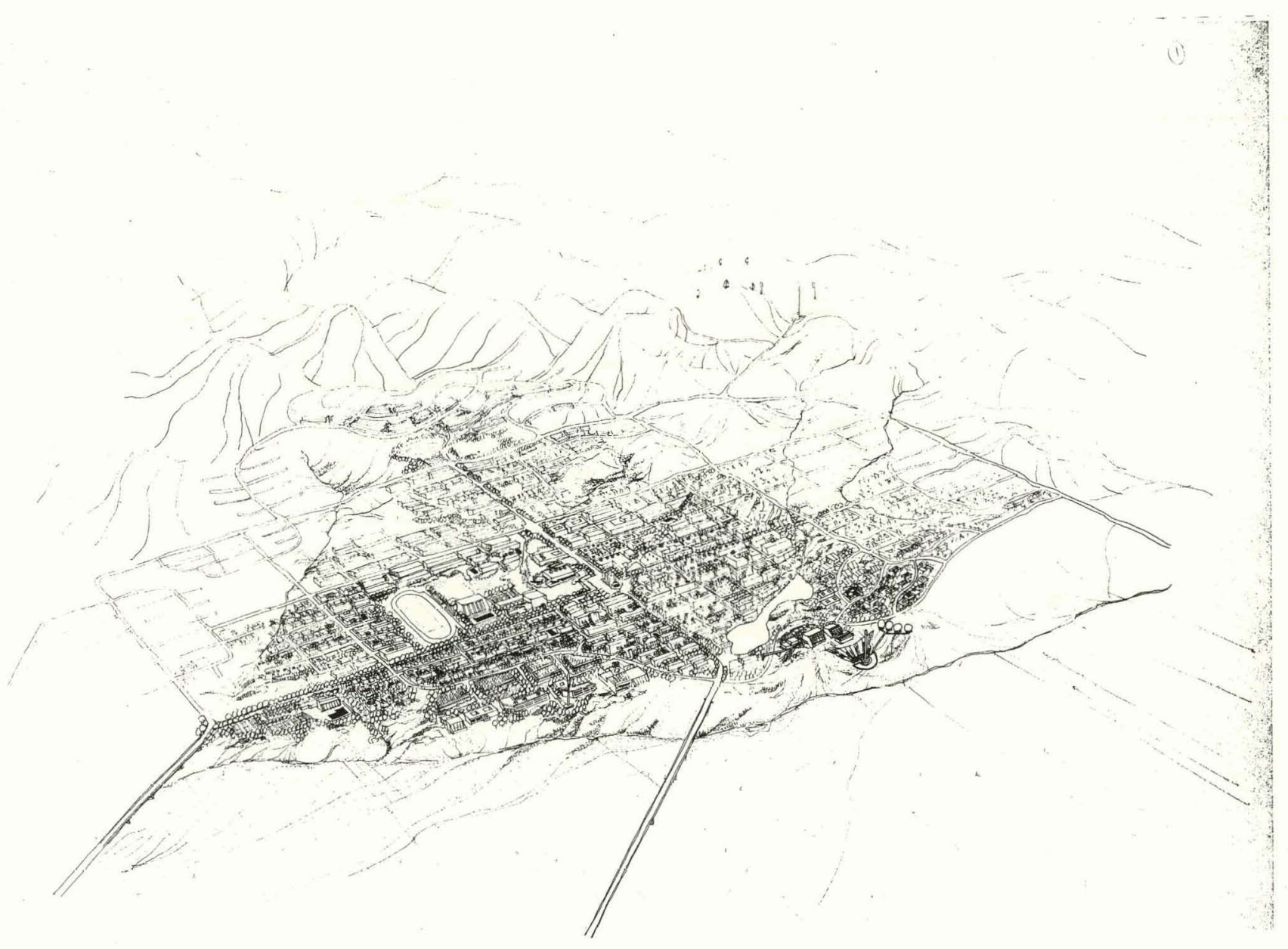

\section{TEAM 1}

Fig. 3.1.1.1

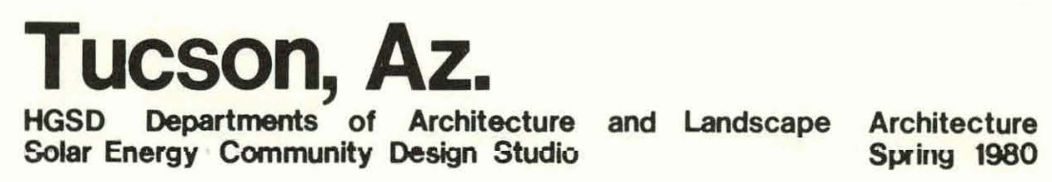




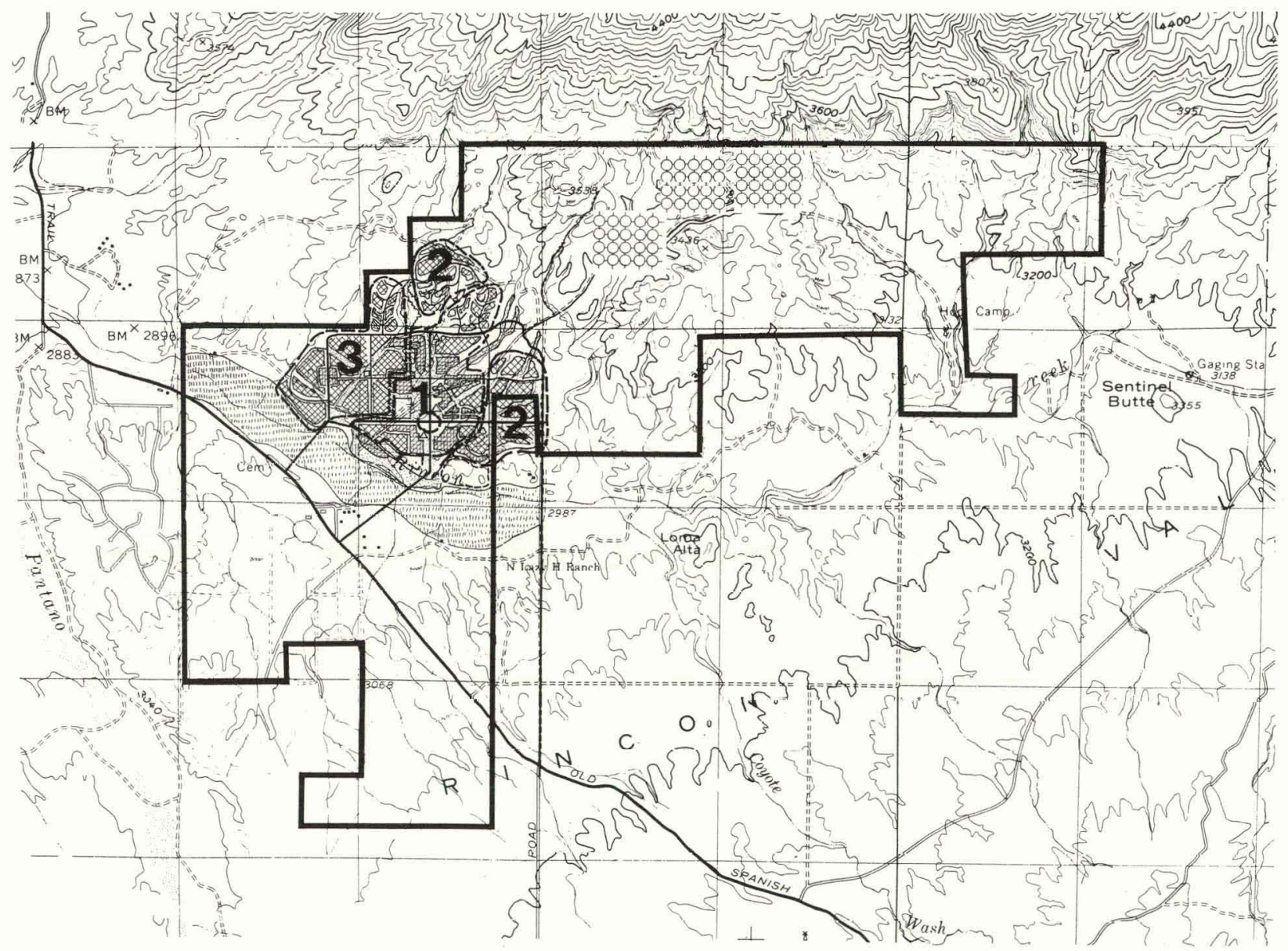

Concept / Phasing

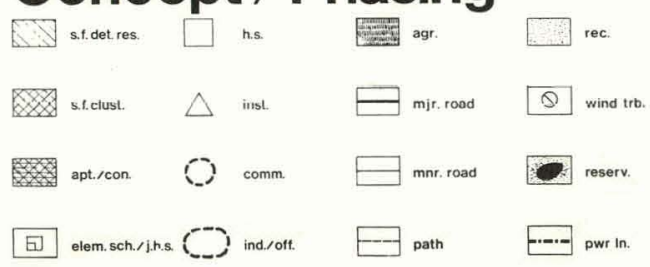

TEAM 1

TEAM 1

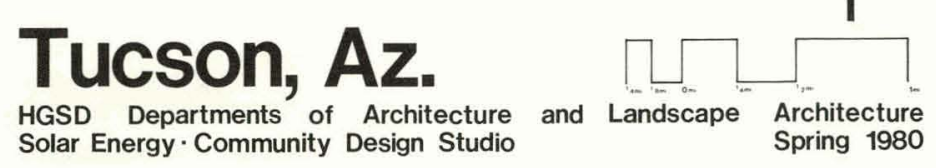

Fig. 3.1.1.2 


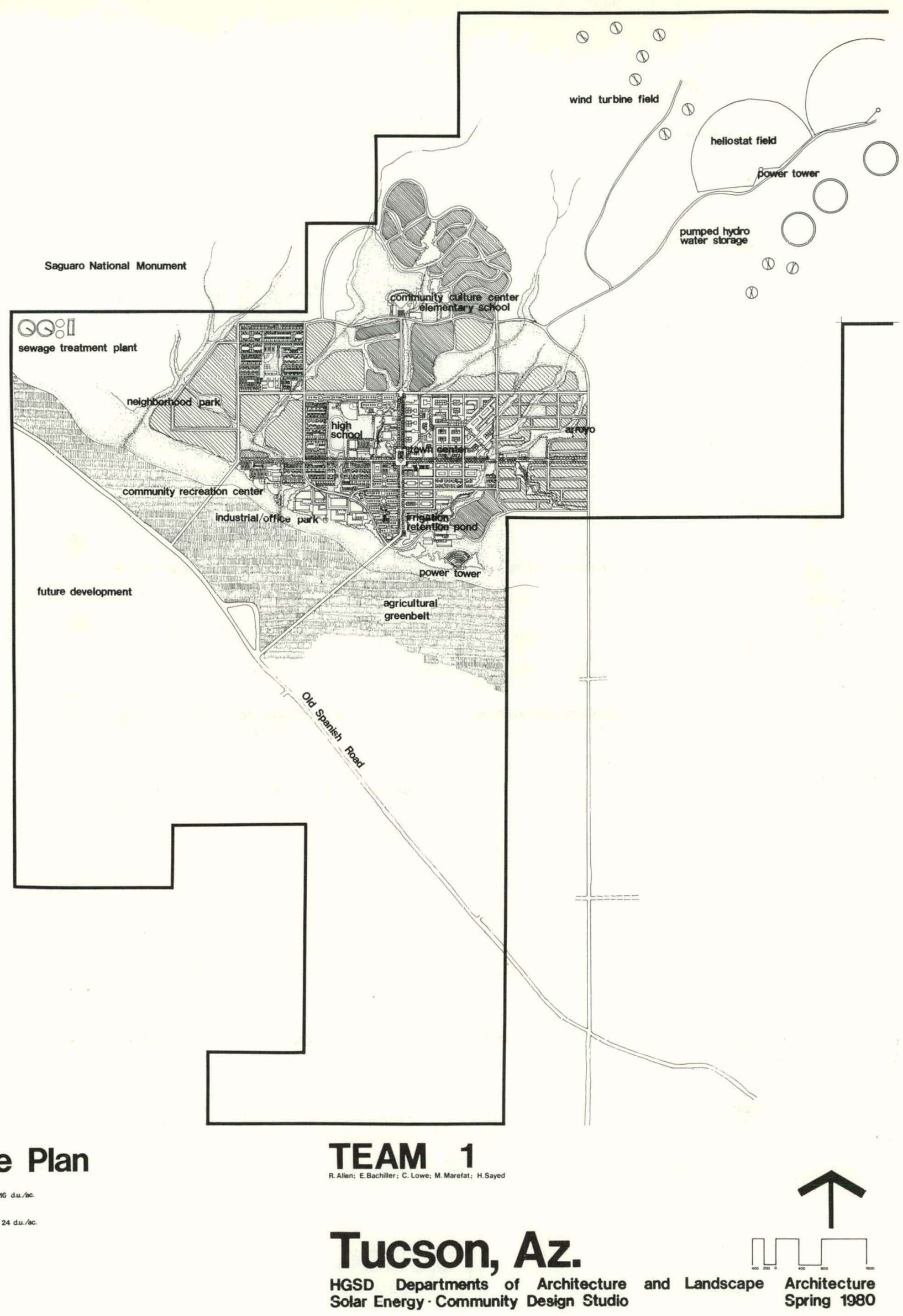

Fig. 3.1.1.3 


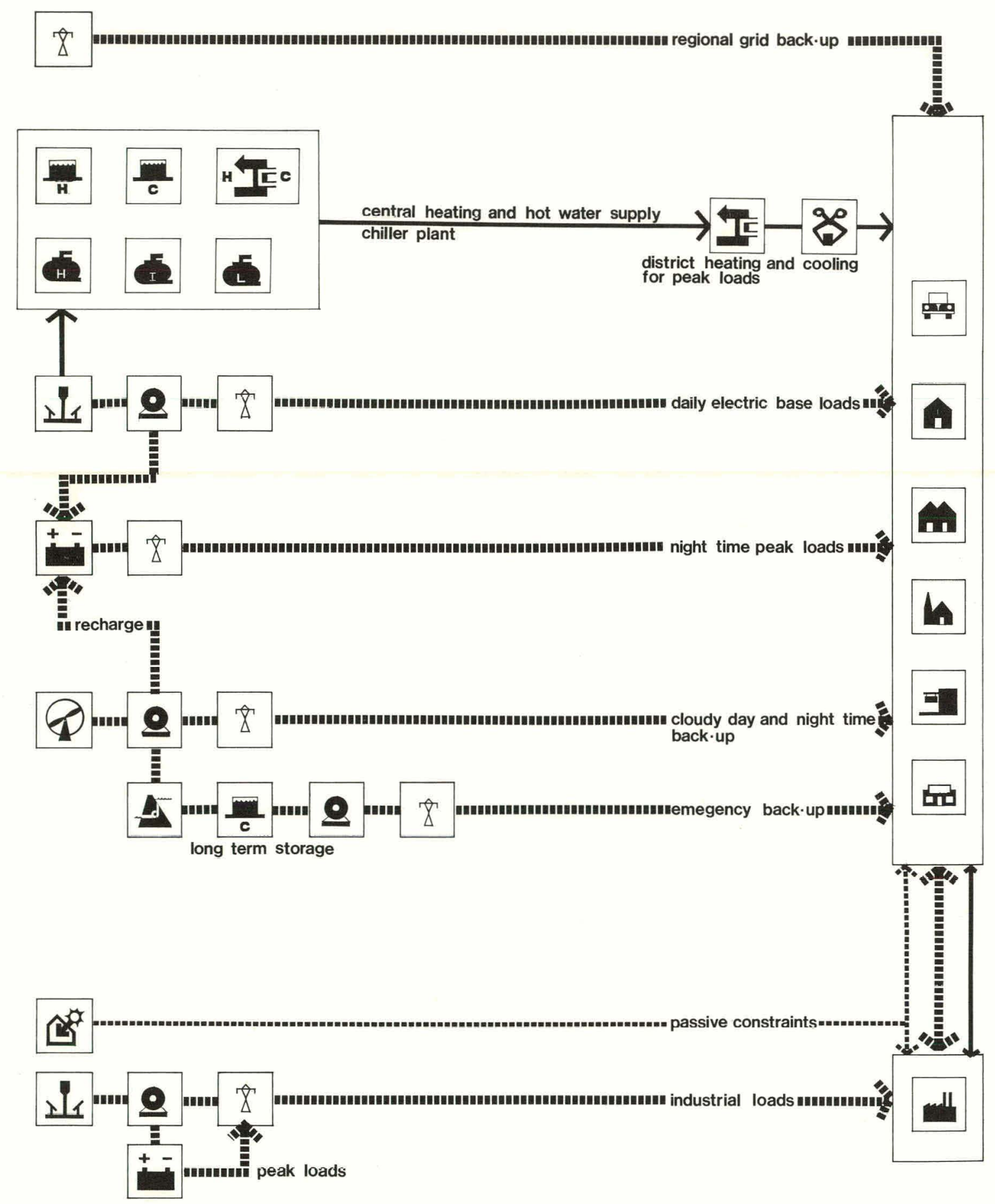

\section{Energy Diagram}

Fig. 3.1.2.4
TEAM 1

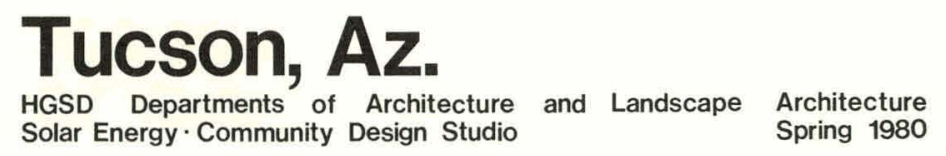




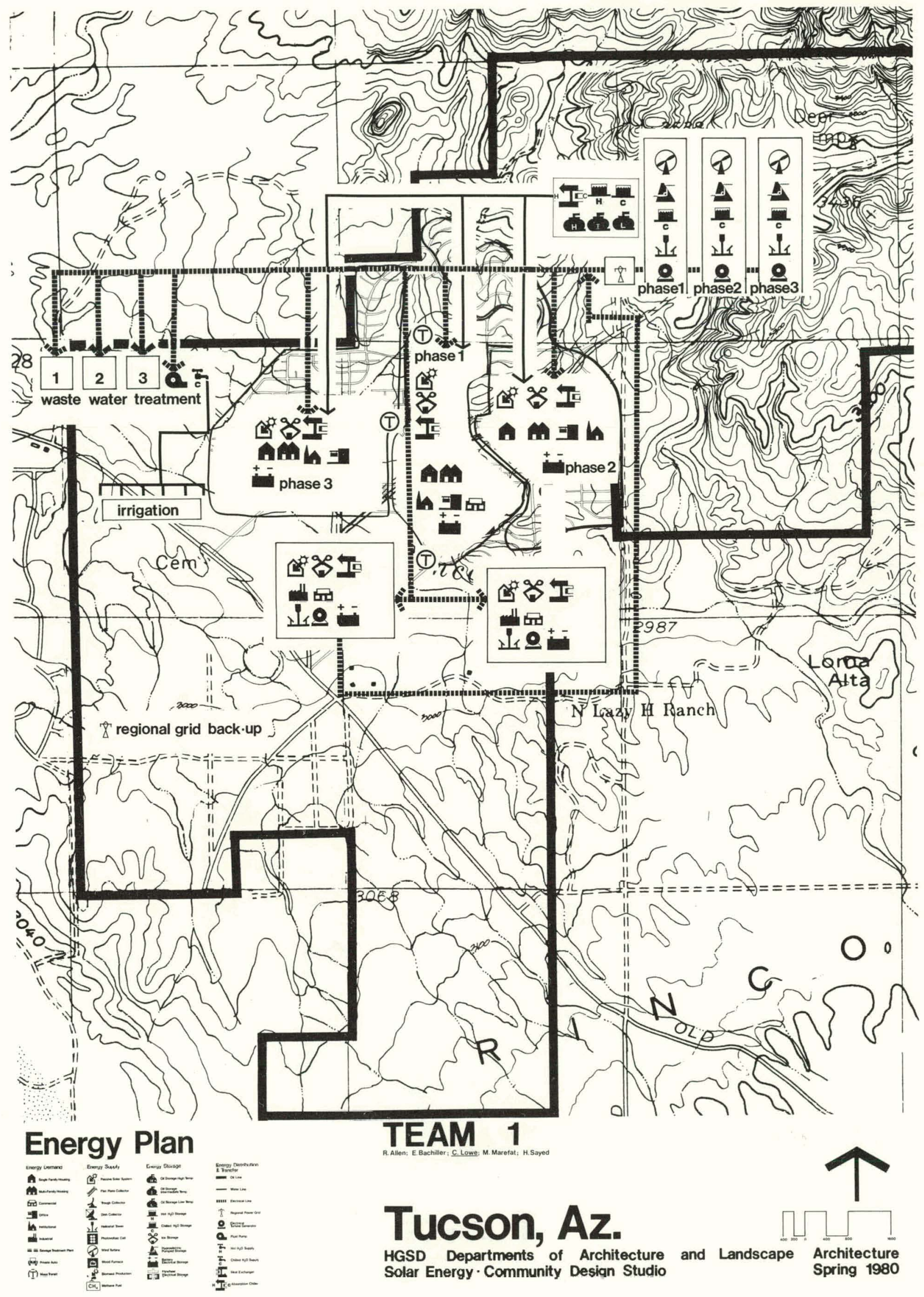

Fig. 3.1.2.5 


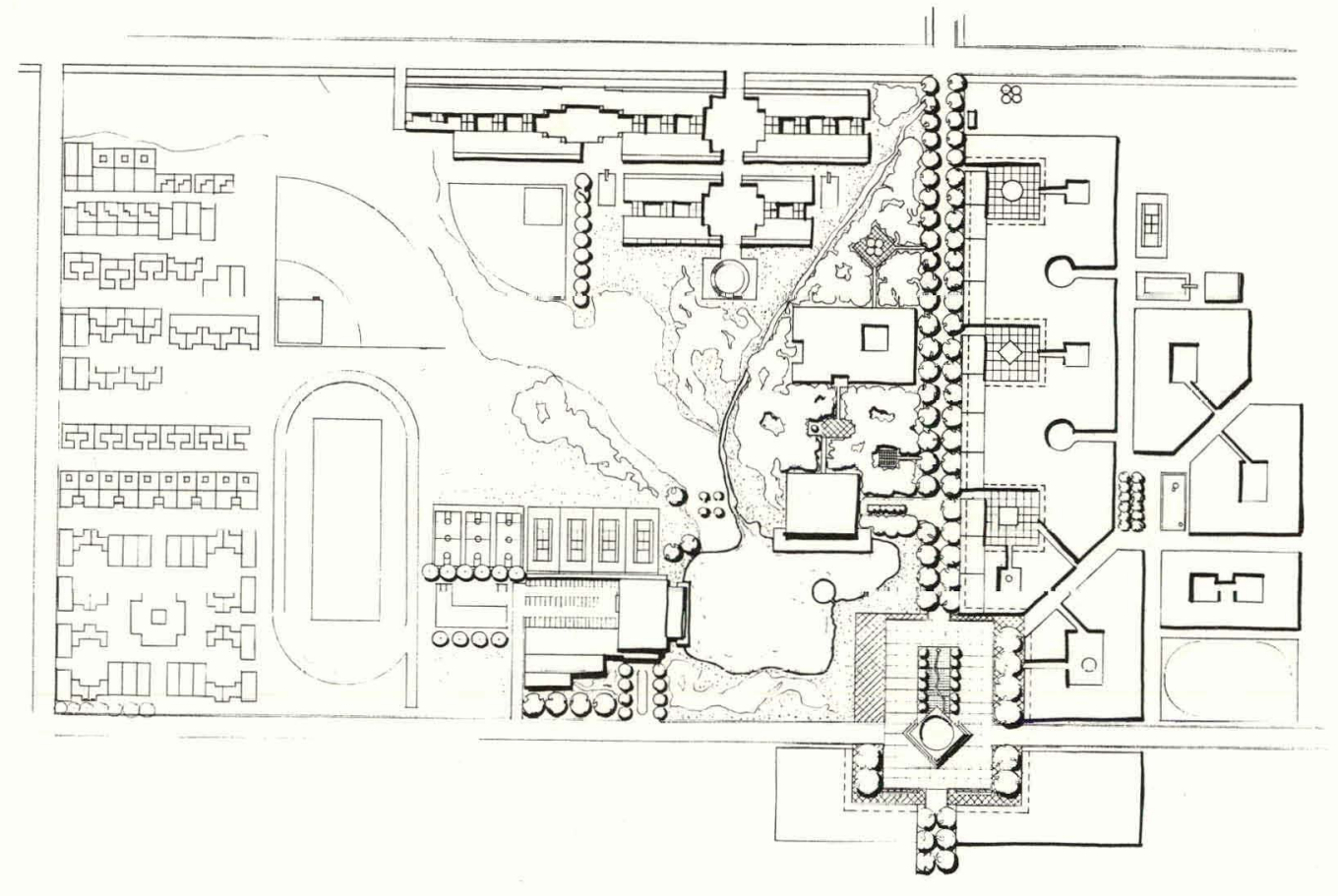

\section{Town Center}

Fig. 3.1.3.6

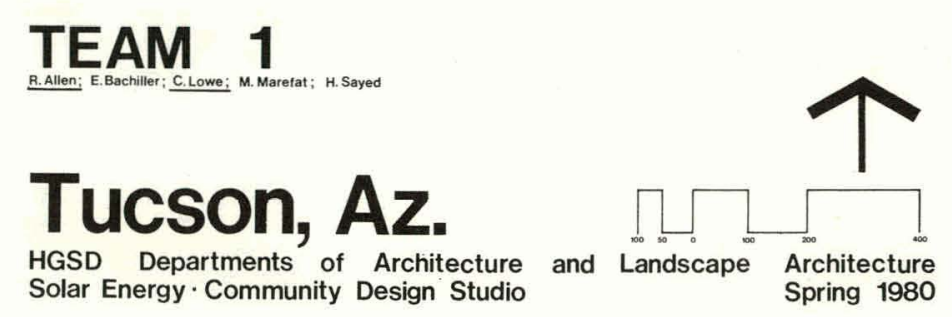



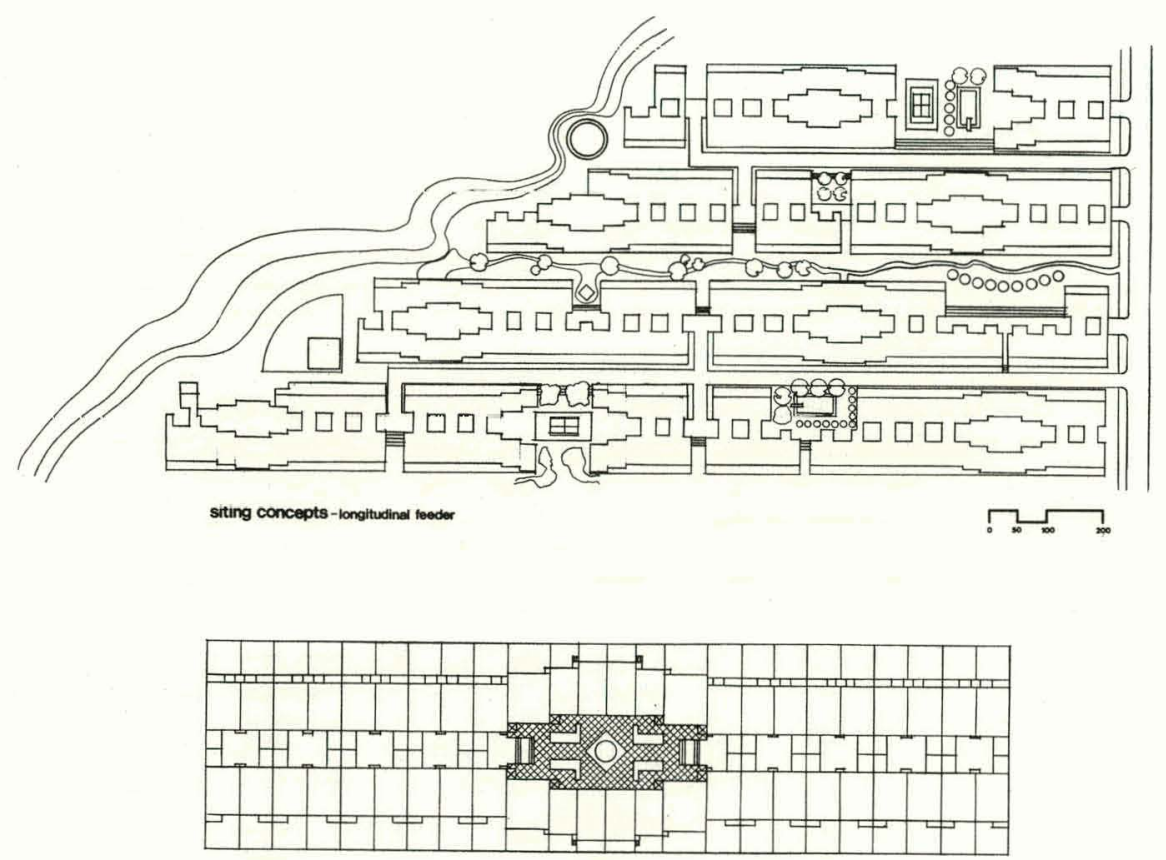

plan configuration

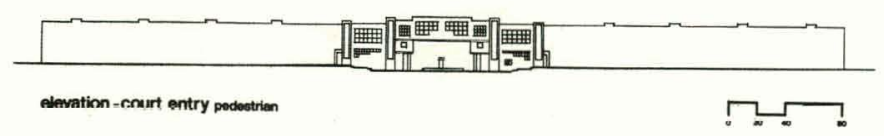

Housing

TEAM 1

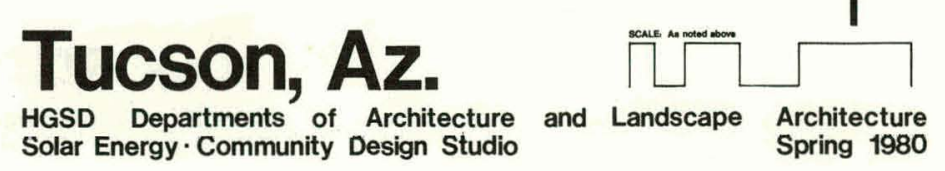

Fig. 3.1.3.7 

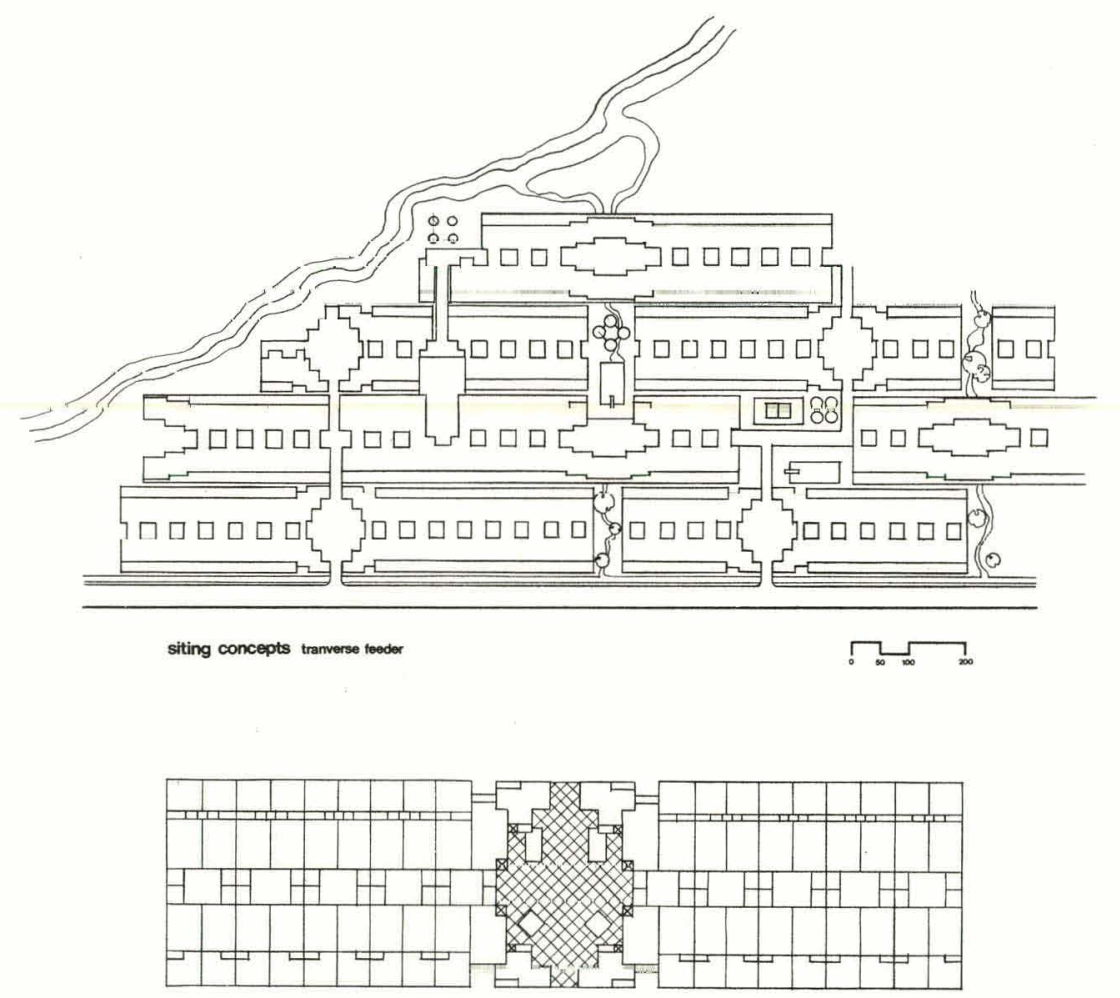

plan configuration

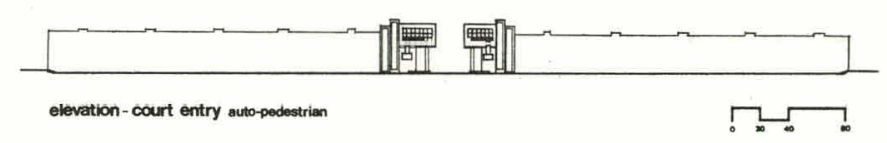

Housing

TEAM 1

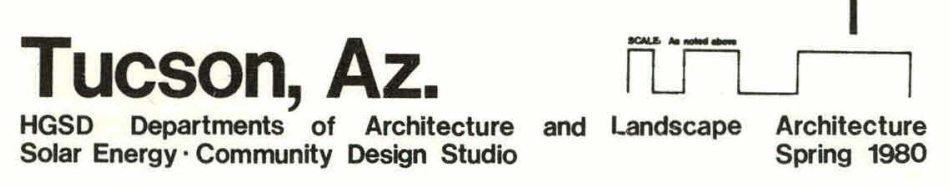

Fig. 3.1.3.8 

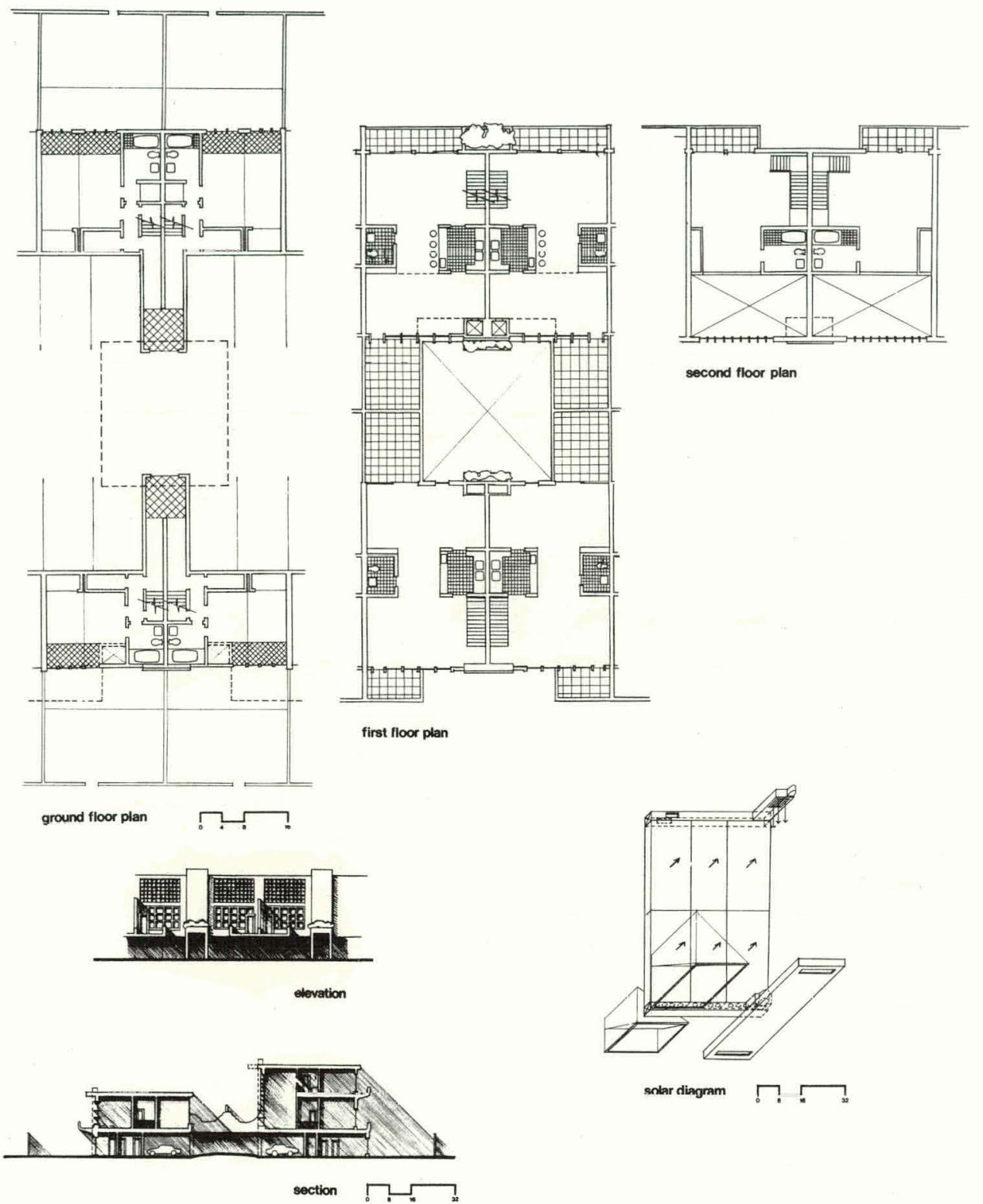

Housing

16 d.u. / acre
TEAM 1

Tucson, Az.

HGSD Departments of Architecture Solar Energy - Community Design Studio

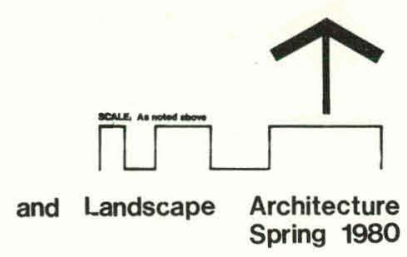

Fig. 3.1.3.9 


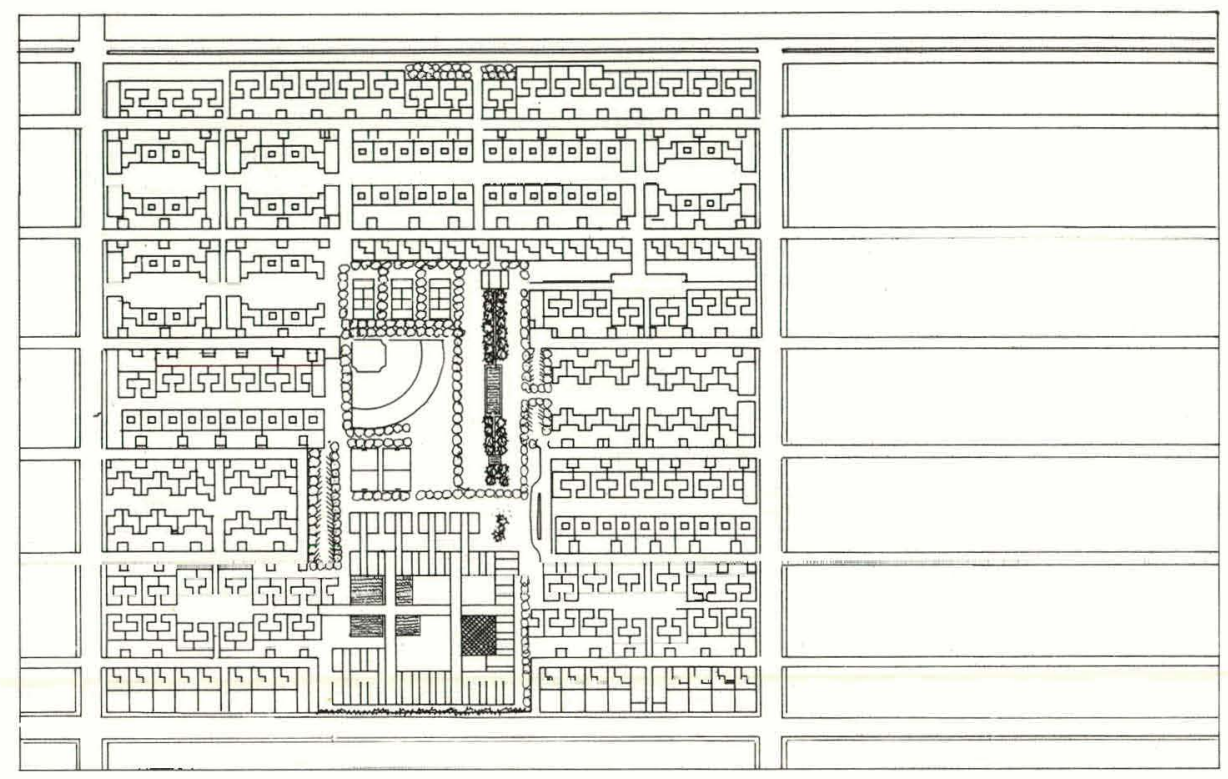

Neighborhood Site PIan
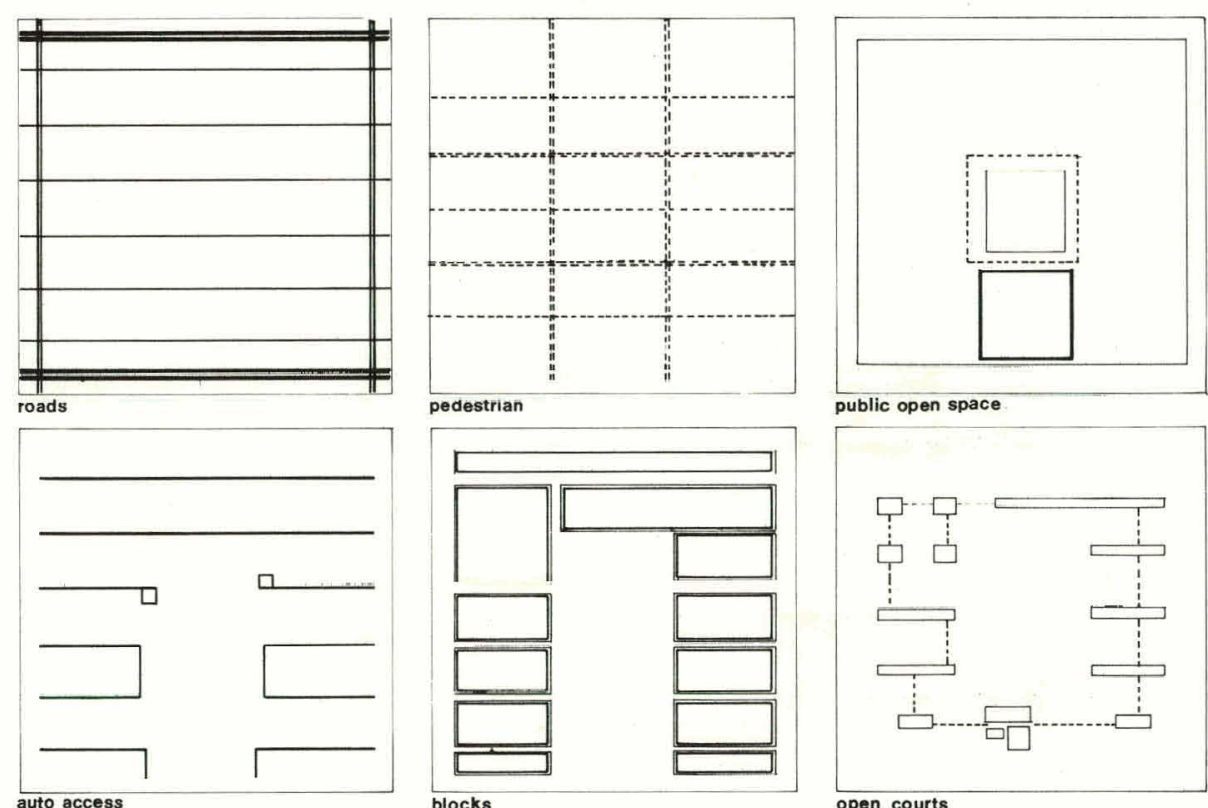

pedestrian
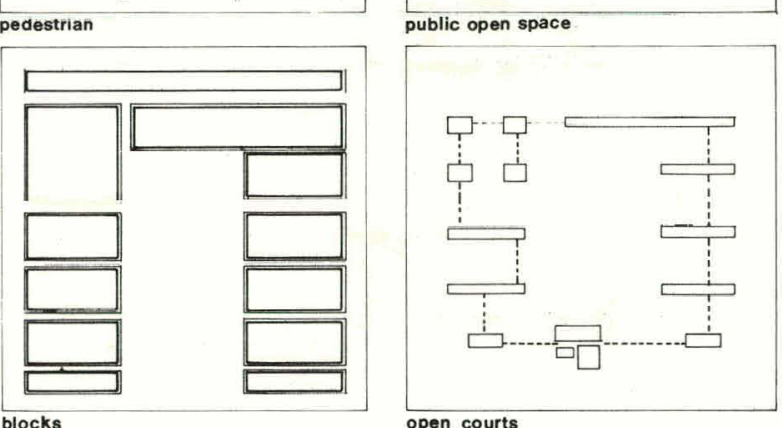

open courts

Neighborhood Analysis

Neighborhood Plan

TEAM 1

Tucson, Az.

HGSD Departments of Architecture Solar Energy $\cdot$ Community Design Studio
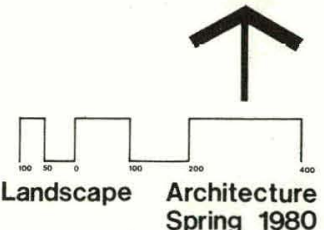

Fig. 3.1 .3 .10 

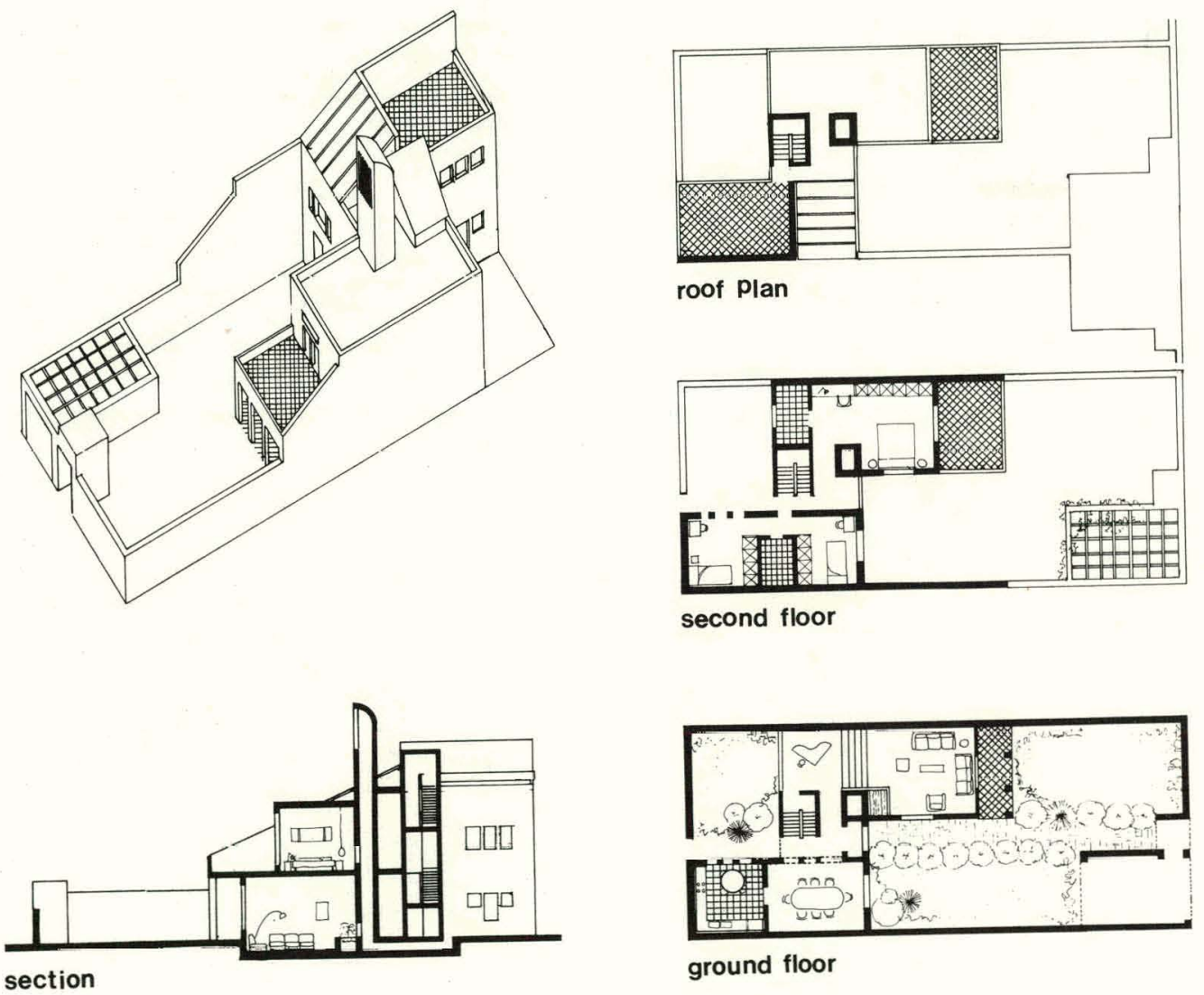

\section{Housing \\ 14-16 d.u./acre}

TEAM 1

R.Allen; E.Bochiller; C.Lowe; M.Maretat; H. Sayed

\section{Tucson, Az.}

HGSD Departments of Architecture Solar Energy · Community Design Studio

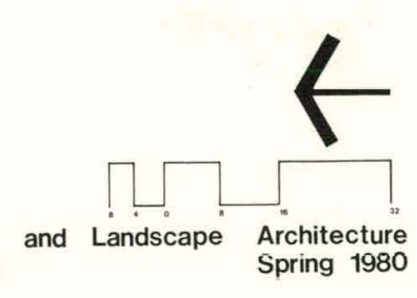

Fig. 3.1.3.11 


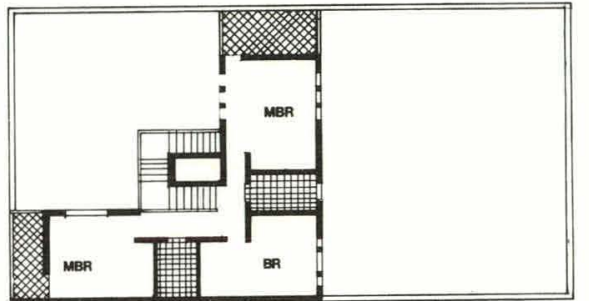

second floor

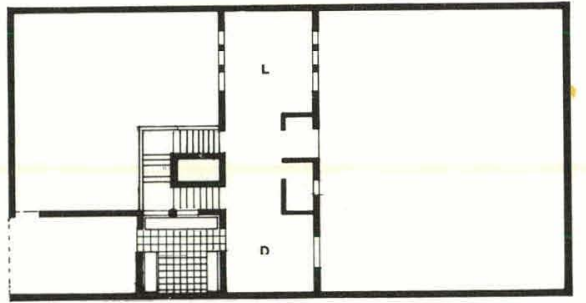

ground floor

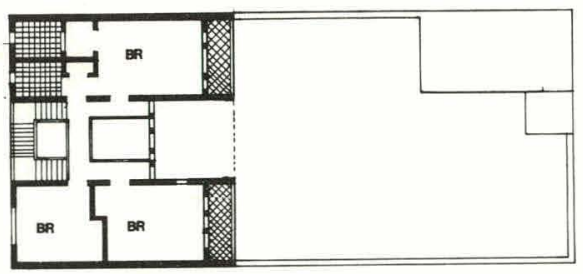

second floor

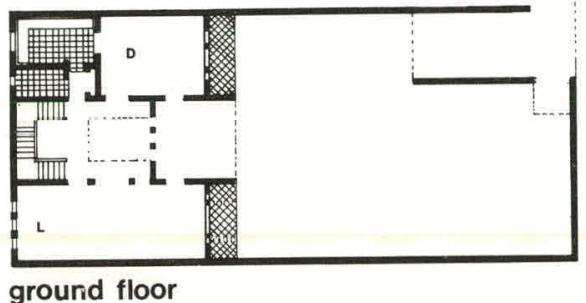

ground floor

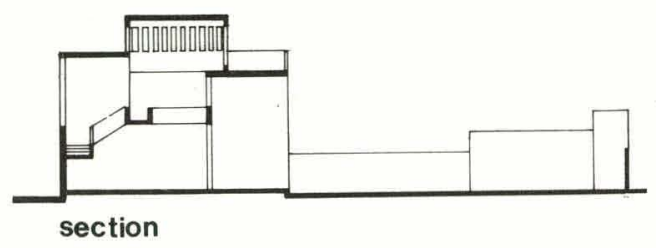

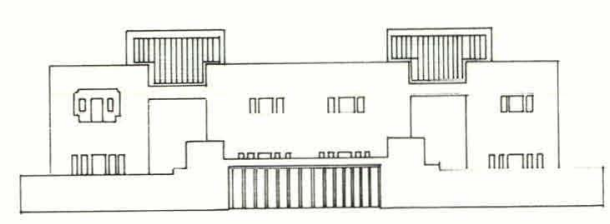

elevation

section

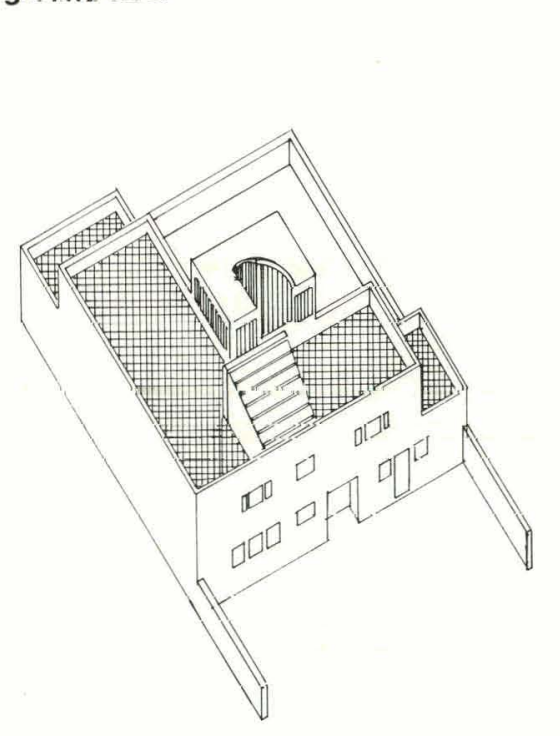

Housing

14-16 d.u./acre

\section{4-16 d.u./acre}




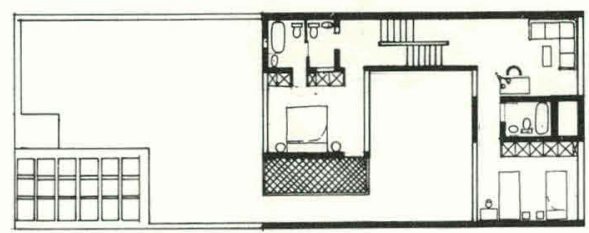

second floor

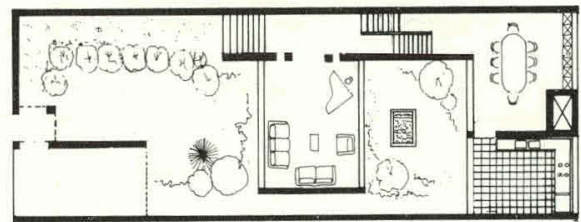

ground floor
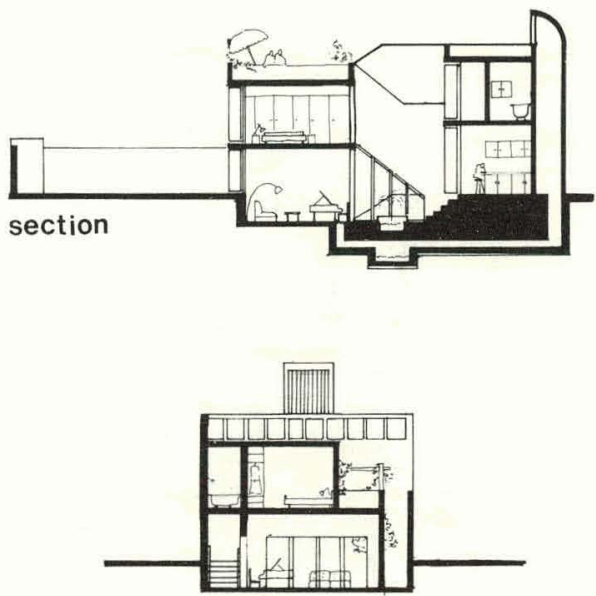

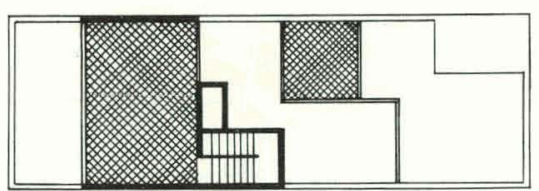

roof Plan

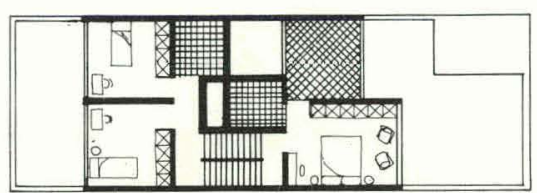

second floor

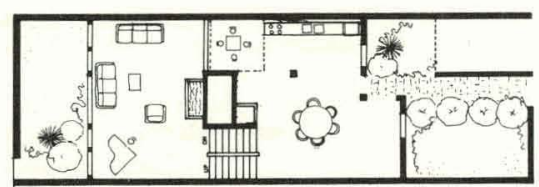

ground floor

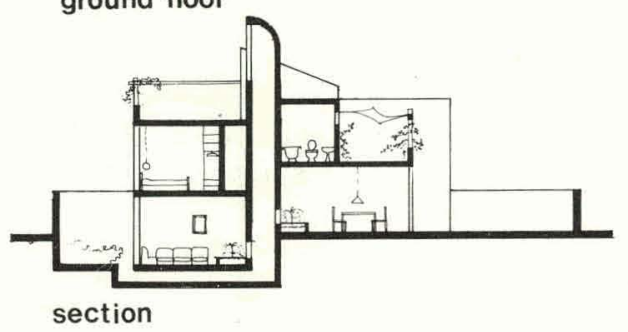

section

Housing

14-16 d.u./acre

Fig. 3.1.3.13
TEAM 1

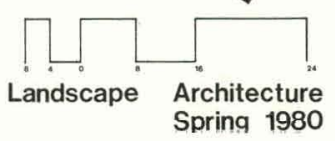




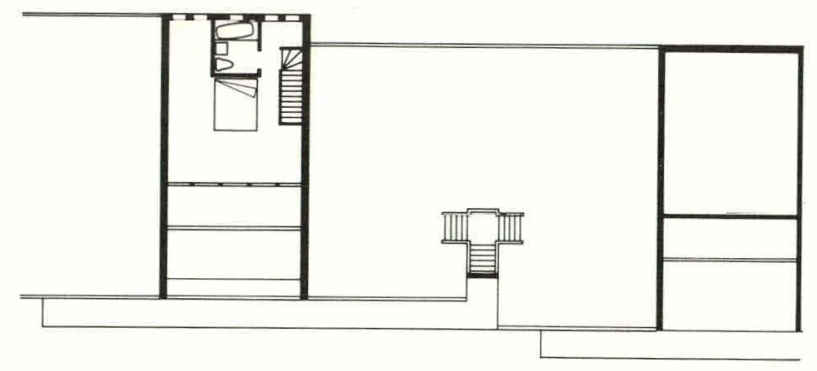

4th level

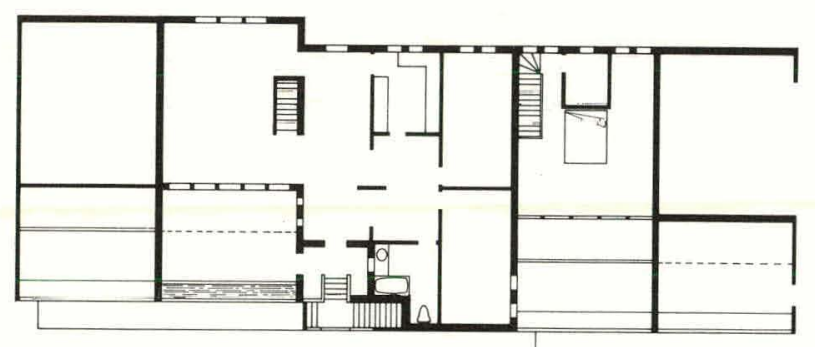

3rd level

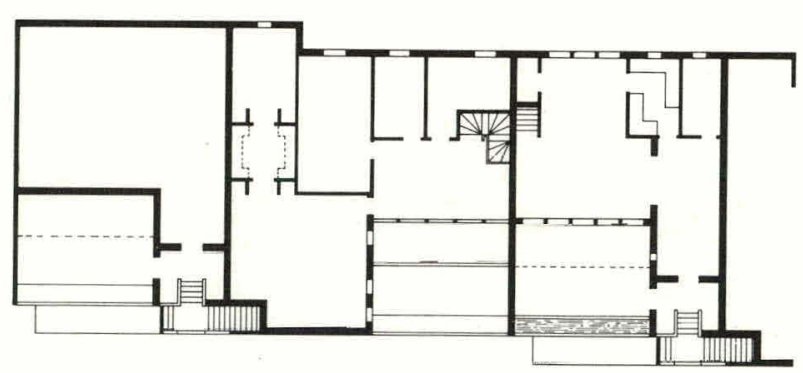

2nd level

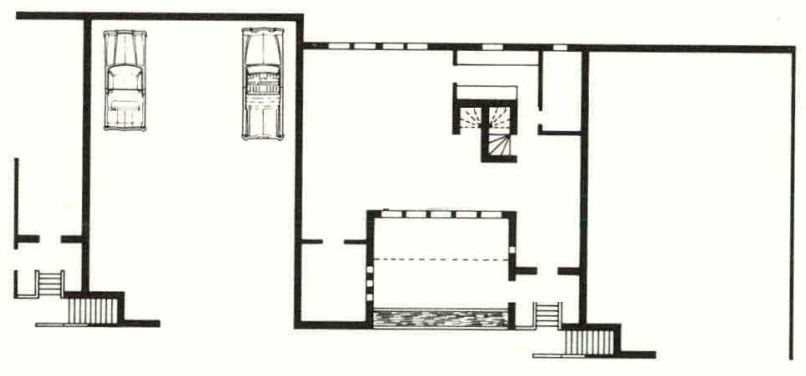

southern street entry

\section{Housing}

18 d.u. / acre

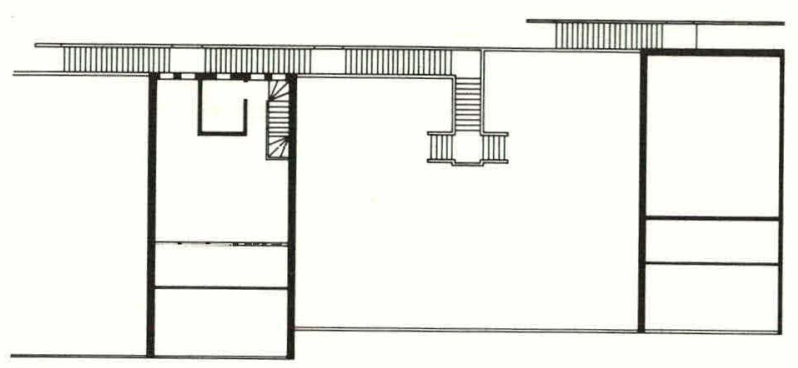

4 th level

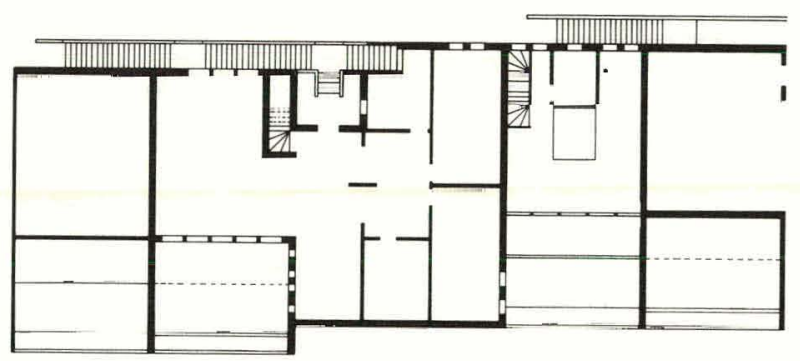

3rd level

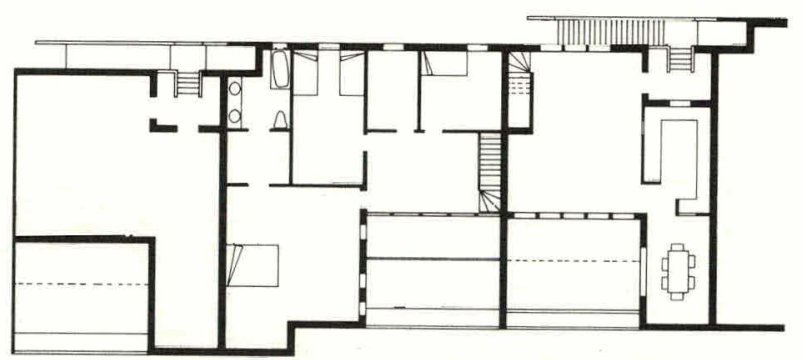

2nd level

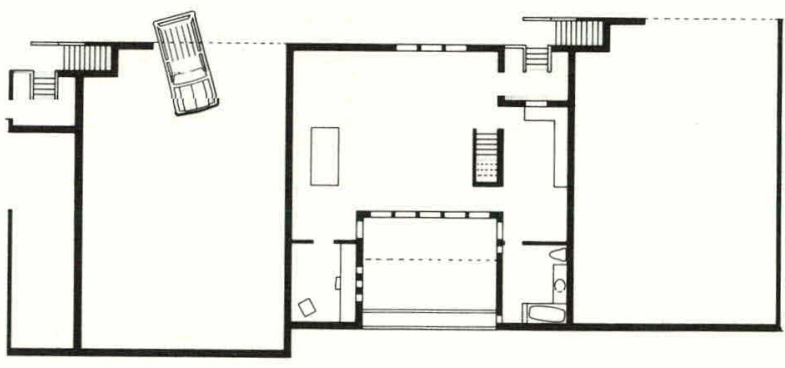

northern street entry

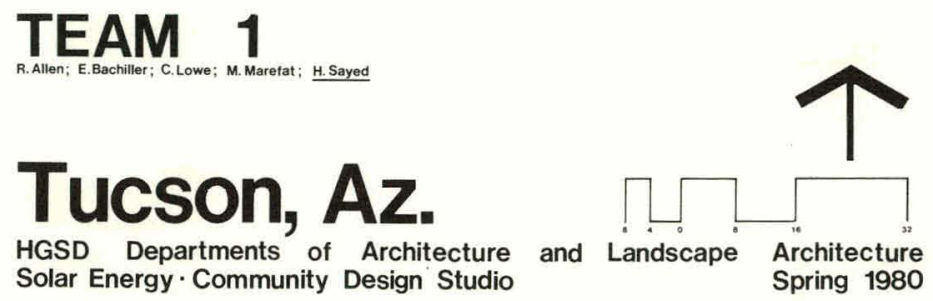

Fig. 3.1.3.14 


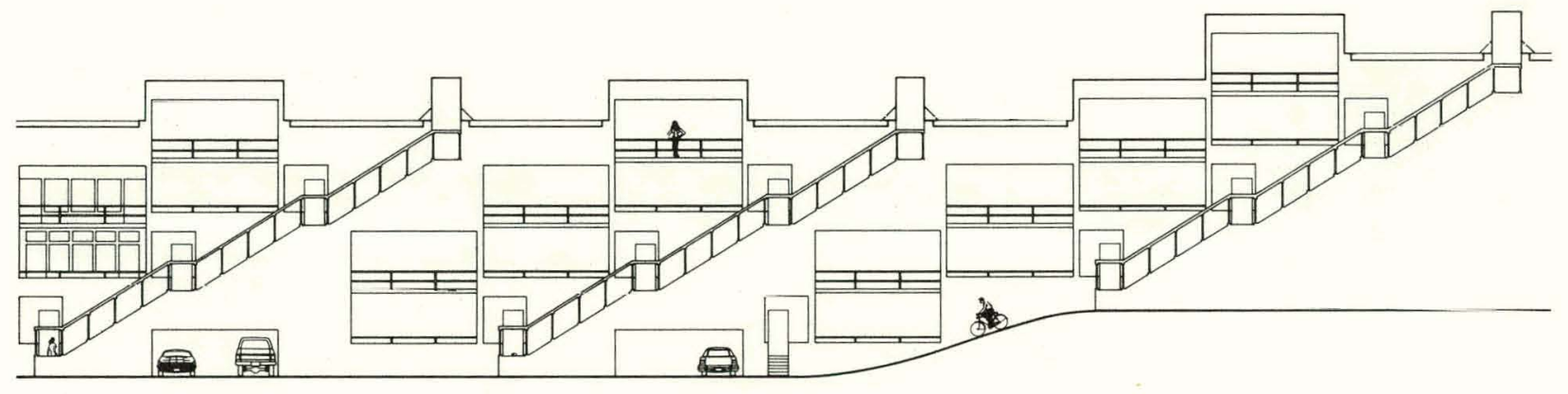

south elevation of southern entry building

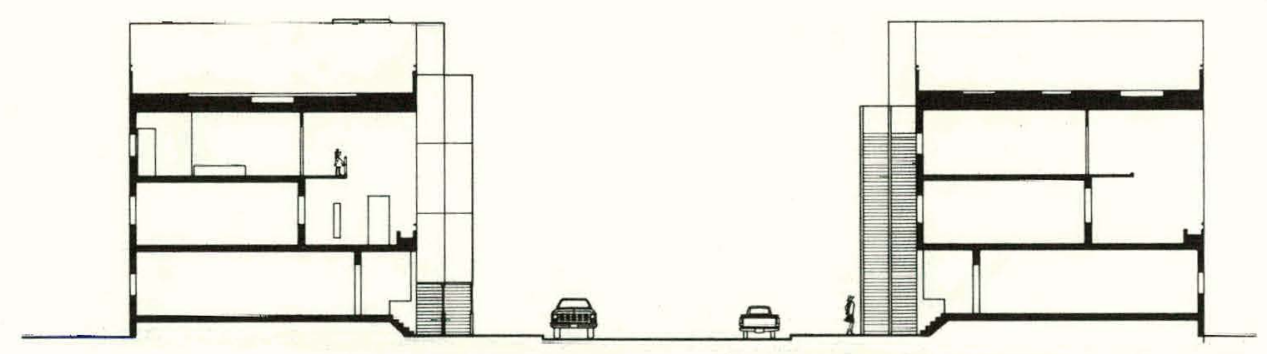

north - south section

Housing

Fig. 3.1.3.15

TEAM 1

Tucson, Az.

HGSD Departments of Architecture and Solar Energy $\cdot$ C.nmmunity Desian Studio

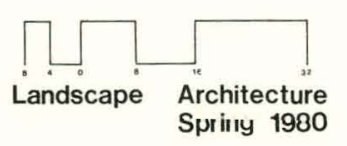
Spriny 1980 


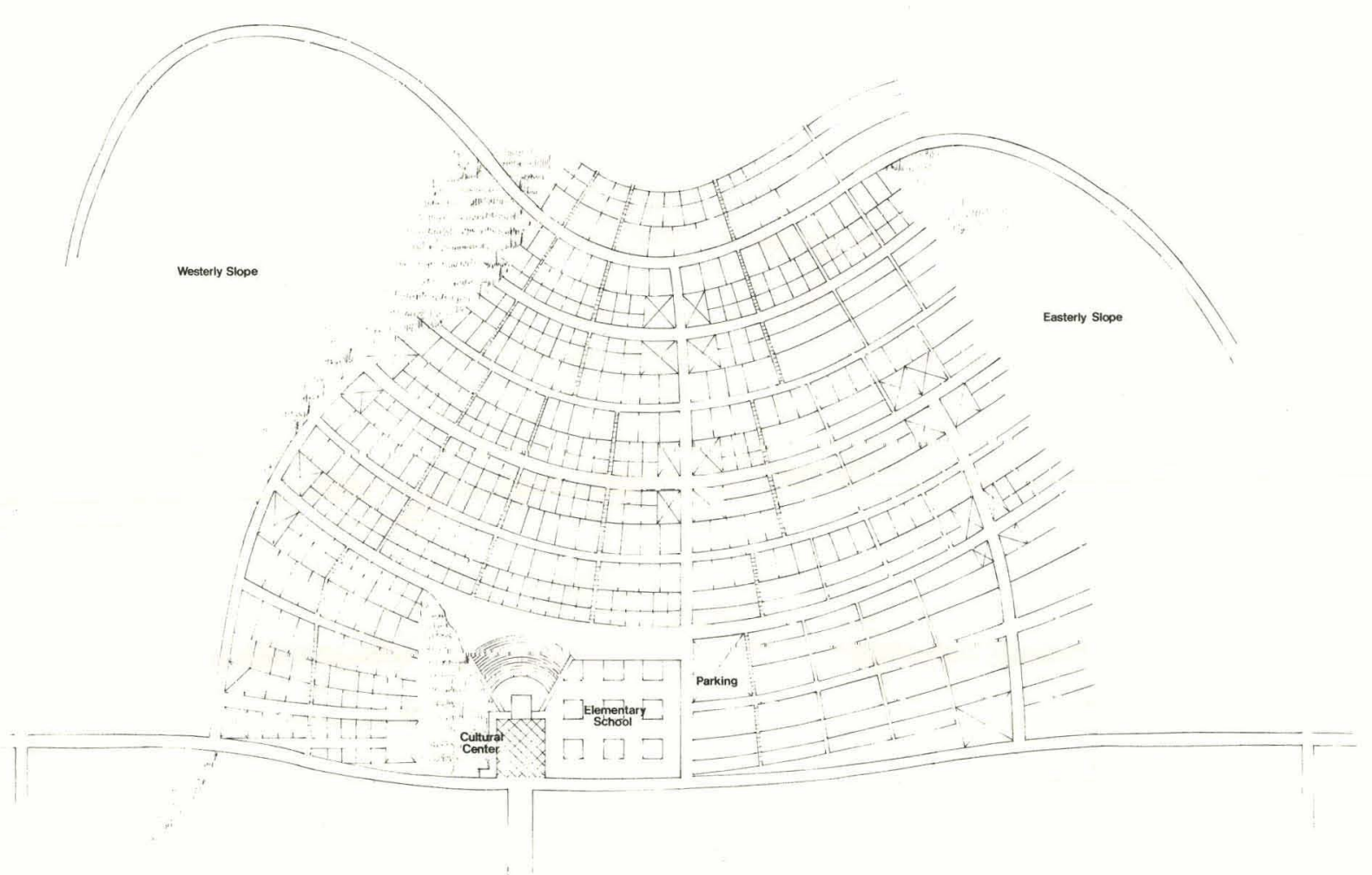

Hillside Housing

site plan

TEAM 1

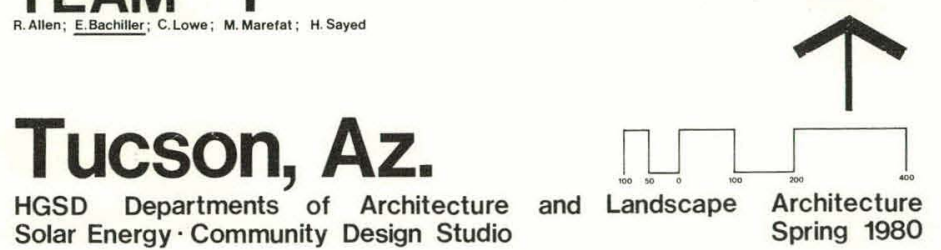

Fig. 3.1 .3 .16 


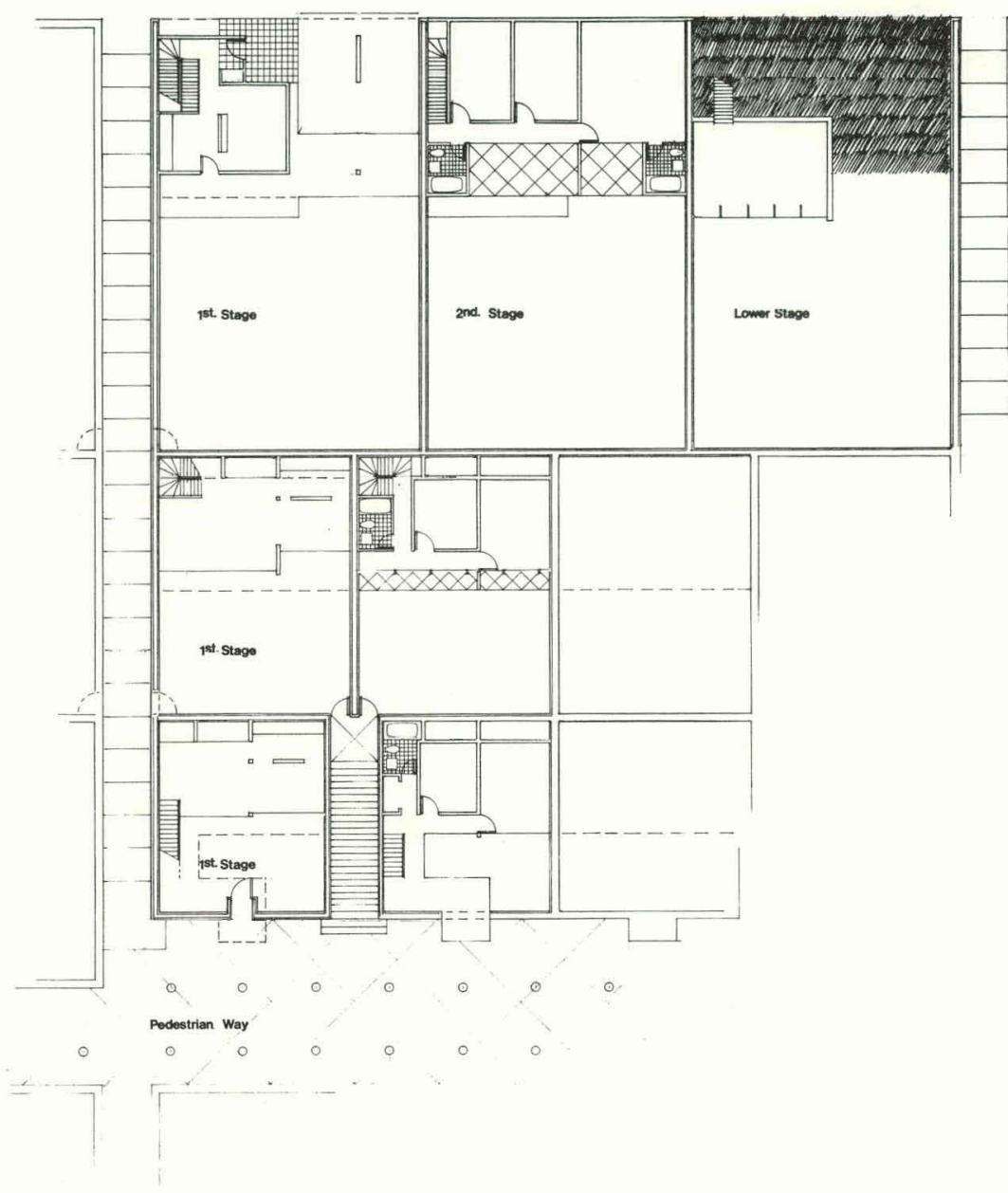

\section{Hillside Housing}

24 d.u. / acre
TEAM 1

Tucson, Az. HGSD Departments of Architecture
Solar Energy - Community Design Studio

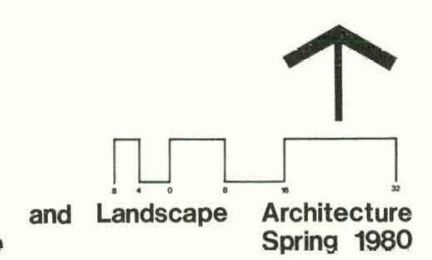

Fig. 3.1.3.17 
THIS PAGE

\section{WAS INTENTIONALLY LEFT BLANK}




\subsubsection{DESIGN STRATEGY}

The primary goals of Tucson 2 are to develop a community which preserves the primary natural amenities of the site: the flood plain of Rincon Creek, Saguaro National Monument, and the arroyos, while best utilizing solar energy and energy conservation. Development is sited south of the Rincon Creek flood plain. Passive systems provide $100 \%$ of normal heating and cooling demands for individual buildings. A centralized facility of concentrating parabolic dishes, and storage facilities of pumped hydro and flywheels complete the energy plan.

Community Plan Description

The major form determinant in the Tucson 2 scheme is the contrasting nature of the site, ranging from the green flood plain of Rincon Creek to the dry, exposed slopes of Saguaro National Monument and the Tanque Verde Mountains. The major portion of the community is located south of the flood plain, on the flat slopes with their deep alluvial soils. This provides the community with views to Saguaro National Monument, and the Tanque Verde Mountains. Also, the most scenic and rugged land is preserved for the community's recreation and conservation benefit.

The town center and higher density ( 18 du/acre) are located along the flood plain edge. The community's major north-south boulevard leads directly to the town center. The town center is within a ten minute walk from most residences and has the major community functions such as community government facilities, retail shops, professional offices, secondary educational facilities, entertainment areas, and residential dwellings. The town center, and community $\mathrm{plan}$ with its low, horizontal profile respects the character of the landscape, enabling every residence to have visual and functional access to the community's amenities.

The community's road system accentuates the views to the saguaro-covered slopes of the Tanque Verde Mountains. 0ld Spanish Trail is realigned to the 
south, leaving more space for community development between it and the flood plain. A gridded road system, historically used in Tucson and the West, is used to organize the community: The green agriculture belt and the mountain tops of the Tanque Verde Range serve as a visual terminus for these northsouth roads. The north-south roads are the major traffic collectors for the community and also channel cooling breezes through the development. The east-west roads are rotated $15^{\circ}$ from due south for optimum solar comfort, and serve the neighborhoods. By using the mountains as a terminus, a hierarchy of street widths, and street tree planting, the gridded road system orders the community in a characteristically flat and featureless landscape, while maximizing solar access and views to the mountains. The gridded system easily accommodates future urban growth.

Housing densities diminish as they proceed south from the town center and flood plain edge. Within the residential development are three neighborhood centers, established at the elementary school-neighborhood recreation complex. From each of the three centrally located neighborhood centers is an extensive pedestrain-bicycle system, with no more than a ten-minute walk. from the residences. Residents are encouraged to use the shaded, internal path system. East-west paths lead to the elementary school-neighborhood recreation centers, while north-south paths, that frequently parallel the course of the natural arroyos, lead to the town center and the community recreational hiking and horseback riding trail system in the northern, more rugged part of the site.

The residences which vary in density from 18 du/arere by the town centor, to 4 du/acre by 01d Spanish. Trail, to one ranchstead/20 acres north of the flood plain, have passive systems designed to provide $100 \%$ of their heating and cooling demands. Houses are sited $15^{\circ}$ east of south to receive maximum solar benefit and to provide every home with views to the mountains. Every home has one car for long journeys and there is a shared-vehicle system with an electric car per three dwelling units. Each block (500'x660') has its own recreational facilities including pool and tennis. Some blocks are dissected by arroyos which are left undisturbed in their natural state to channel cooling breezes and storm water runoff. 
Along the new regional road which leads directly to the town center, and old Spanish Trail, is the opportunity for development. Tucson 2 recognized the potential of this corner and is proposing it as the site for the community's office park. This is directly associated with the community's industrial park, located along 01d Spanish Trail to the east of the new road.

Phasing

Phasing is divided into four parts. Phase 1 includes the sale of the 20 acre ranchsteads and industrial park sites to increase the project's cash flow. The main north-south boulevard into the town center, the town center and its associated schools and housing and path system, are to be developed in this phase. Also, a third of the energy program (the concentrating parabolic dishes and flywheel storage) is to be constructed.

Phase 2 begins to sell office park sites to sustain cash flow. It includes the expansion to the western edge of the site. This encompasses another elementary school and its associated housing. The flood plain frontage road, to the east and west of the town center, and its associated high density housing are included in Phase 2. Additional growth will occur in the area of the 20 acre ranchsteads, the industrial park and energy production facilities. Also, the pedestrian-bicycle trail system will be completed for the central and western sections of the development.

Phase 3 completes expansion to the eastern edge of the property. This includes residential units, an elementary school, and the community recreation facilities and trail system to the north of the flood plain. The energy production facility and the industrial park are completed in this phase.

Phase 4 completes the development of the regional office park.

\subsubsection{ENERGY STRATEGY (Figs. 3.2.2.4, 3.2.2.5)}

In devising its energy supply strategy, Tucson 2 was concerned with five things: the heating and cooling demands of individual structures, the 
community-wide supply of electricity, transportation energy demands, water pumping requirements, and energy storage.

Assumptions

As shown in the energy demand table, cooling loads are larger than heating loads in the Tucson area. Domestic water for the site is pumped from underground aquifers, and the pumps used require electrical energy: Therefore this demand is included in the energy demand table. Transportation is a large portion of total community energy demand. The team's estimate of automobile usage is 3n-miles=or-less-daily commuting trips for unte-third of the cars and 10,000 annual mileage for the other two-thirds.

\section{Electrical Generation}

The team has used an all electric community solar energy system. An important benefit of an all electric approach is that, unlike the separate thermal and electrical systems, energy not needed for heating or cooling can be directed towards peaking electrical demands such as lighting and appliances. Furthermore, the surplus electric energy of the community solar energy system can be fed into the regional grid, with the local electricity utility providing an emergency energy supply for the community.

The electric energy system consists of a field of concentrating parabolic dlshes provlding solar energy for a Brayton cycle engine that generates electricity. Approximately 1.5 megawatt-hours electric can be produced daily from each acre of dishes in the Brayton cycle system. The system, pumped hydro and flywheel storage facilities are located in the southeastern portion of the site. The team has centralized the system rather than attempting to integrate it into the community, primarily because the parabolic dishes, which stand about 25 feet high, are considered to be so large that they would block views and appear to be out of scale compared to the buildings and open spaces in the community. 
Thermal Generation

In residence structures, $100 \%$ of all heating and cooling needs are supplied through passive solar energy and energy conservation measures. The team believes that technologies presently developed (and that will be developed in the near future) are in fact realistic; even today a solar roof-pond house in Atascadero, California in a climate similar to that of Tucson has achieved $100 \%$ passive heating and cooling. In this scheme, a combination of trombe walls, heavy building materials, proper solar orientation, roof ponds, sod roofs, shading devices, and natural ventilation techniques are employed to achieve the same efficiencies.

Non-residential structures are assumed to be less energy self-sufficient than housing. This is because passive solar technologies are less developed for commercial, office, institutional, and industrial buildings. The team assumes that $85 \%$ of heating and $75 \%$ of cooling demands of non-residential structures can be met by passive means. Supplementary heating and cooling energy supply for these buildings is provided by the community electricity solar energy system. Hot water demands for all buildings are met by flat plate collector systems on a building-by-building basis.

Transportation Energy Supply

Tucson 2 has assumed that the commuting needs of its residents both within the community and to shopping and employment in Tucson can be met by electric cars. One third of the vehicles in the community are electric; these 2804 vehicles are assumed to consume 0.5 kilowatt hour of electrical energy per mile (1979) and travel 30 miles per day. The electric community solarenergy system provides adequate electricity to recharge these vehicles. It is assumed that most are recharged during the day at either the homes of their owners, at the parking area near the community center, or at parking facilities in the industrial area which are equipped with electrical outlets.

The non-electric vehicles in the Tucson 2 community pose a larger problem. These 5693 vehicles, assuming an average of 40 miles per gallon and 10,000 miles of travel per year per vehicle, will consume 1.4 million gallons of 
gasoline annually. To help meet this demand, the community creates methane indirectly from solar energy. Approximately $6 \%$ of the 1 iquid fuel needs of the community's vehicles can be met by using solar energy and the community's sewage to grow algae to yield methane (Bahadori, 1979). Another three percent are met by growing a crop on the flood plain using recycled sewage water and converting this solar-grown biomass into methane (Bahadori, 1979). This does leave over $90 \%$ of the community's Tiquid transportation fuel needs unmet.

Domestic Water Pumping Energy

Assuming that community demand for domestic water is 200 gallons per day per residence and assuming that water must be pumped from a depth of 200 feet, approxiliately 614 kilowatt-hours of electrical energy are needed daily to pump the water needed by the community. Water storage tanks are located at an elevation higher than most of the town so that water can be pumped into the tanks during sunny day-time hours and then be fed by gravity into the community when it is needed.

\section{Energy Storage}

The Tucson 2 system supplies storage for overnight energy needs as well as for an overcast period of up to 24 hours. The electric communily solar energy system has been sized to supply energy for storage in flywheels and in pumped hydro facilities. Flywheels are chosen because of their relatively small size, their efficiency, and their promise as an econnmiral means of storage (Millner, 1979). Pumped hydro, or hydroelectric capacity is chosen because it is less susceptible to mechanical failure and because the energy can be stored for long periods of time without a recharging requirement.

Energy for night-time use is generated each day and stored in flywheels located at the electric community solar energy system site. As well, flywheels and pumped hydro facilities adequate for supplying all day and night energy supplies are located at this site. 
THIS PAGE

\section{WAS INTENTIONALLY LEFT BLANK}


TUCSON 2

ASSUMPTIONS AND EXPLANATIONS

1. $100 \%$ domestic hot water demand met by solar flat plate collectors on a building by building basis.

2. $100 \%$ of heating and cooling demands met by active and passive solar technologies; $85 \%$ heating and $75 \%$ cooling of non-residential demands met by electricity production

\begin{tabular}{|l|l|l|l|}
\hline $\begin{array}{l}\text { TYPE OF BUILDING OR } \\
\text { DEMAND }\end{array}$ & UNITS/AREA & ELECTRICAL \\
\cline { 2 - 4 } & QUANTITY & $\begin{array}{r}\text { AREA/UNIT } \\
\text { OR } \\
\text { TOTAL AREA }\end{array}$ & MWh/Day \\
\hline
\end{tabular}

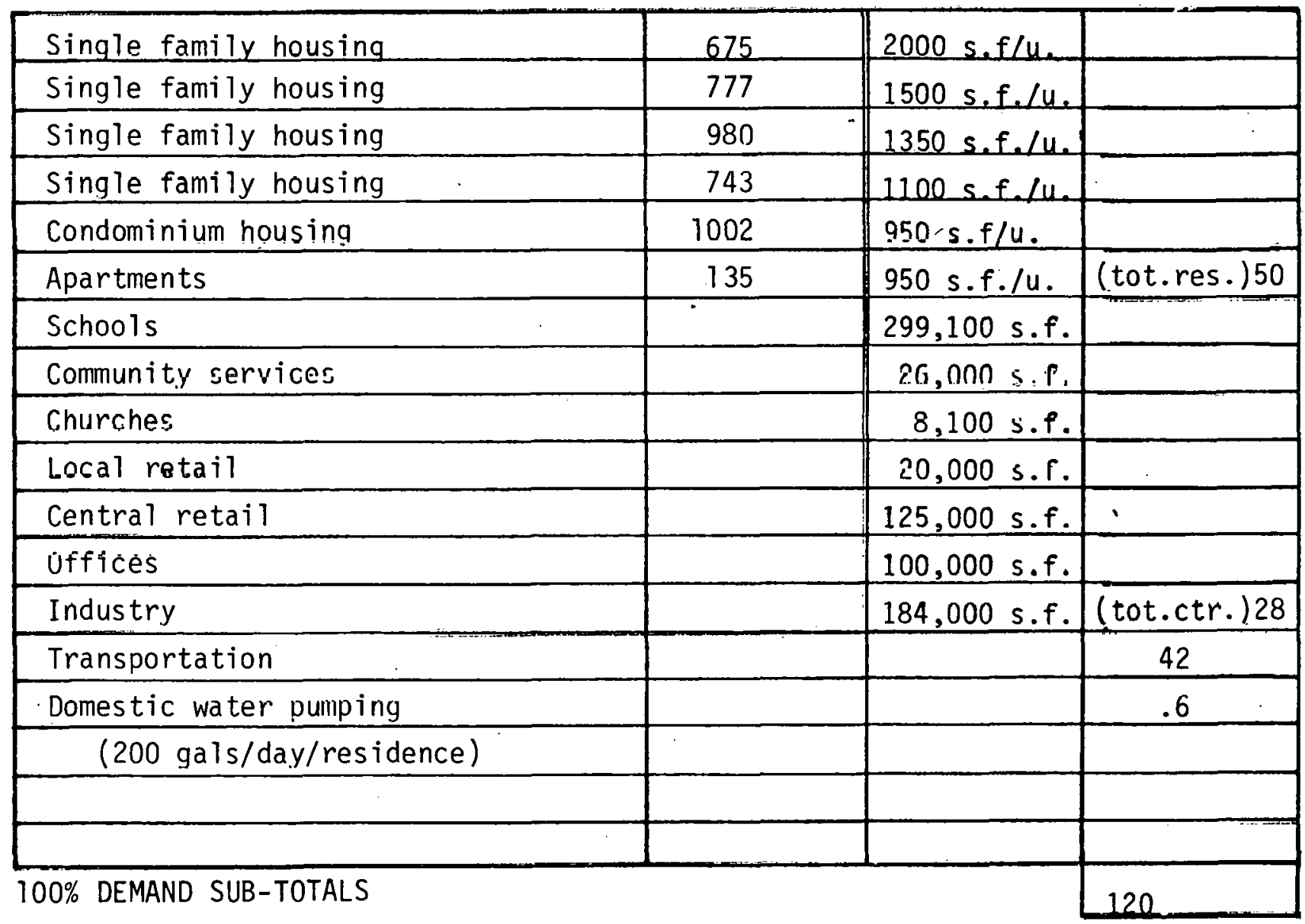

\section{total community energy demand}


TUCSON 2

demand

3. Transportation: 1/3 of community vehicles (2804) powered by electricity (@ $30 \mathrm{mile} /$ day, $0.5 \mathrm{kwh} / \mathrm{mile}$ )

$2 / 3$ of community vehicles ( 5693 of 8497 ) powered by liquid fuels; $9 \%$ of this fuel demand is met by on-site methane production.

\begin{tabular}{|l|l|l|l|l|l|}
\hline \multicolumn{2}{|l|}{ HEATING LOAD } & \multicolumn{2}{l|}{ COOLING LOAD } & \multicolumn{2}{l|}{ DOMESTIC HOT HATER } \\
\hline $10^{6}$ Btu/Day & Mwh(Th)/Day & $10^{6}$ Btw/Day & Mwh(Th)/Day & $10^{6}$ Btu /Day & Mwh(Th)/Day \\
\hline
\end{tabular}

\begin{tabular}{|c|c|c|c|c|c|}
\hline 67.43 & 19.75 & 116.18 & 34.03 & & \\
\hline 53.62 & 15.70 & 101.25 & 29.65 & & \\
\hline 64.68 & 18.94 & 122.35 & 35.83 & & \\
\hline 39.75 & 11.64 & 75.20 & 22.02 & & \\
\hline 47.10 & 13.79 & 10.32 & 3.02 & & \\
\hline 3.38 & 0.99 & 6.38 & 1.87 & (tot.res.)205 & (tot.res.)60 \\
\hline 0.50 & 0.15 & 0.94 & 0.28 & & \\
\hline 0.72 & 0.21 & 1.36 & 0.40 & & \\
\hline 0.50 & 0.16 & 0.91 & 0.28 & & \\
\hline 3.10 & 0.91 & 5.86 & 1.72 & & \\
\hline 0.38 & 0.11 & 0.71 & 0.21 & & \\
\hline 0.69 & 0.20 & 1.30 & 0.38 & (tot.ctr.) 34 & (tot.ctr.) 10 \\
\hline & & & & & \\
\hline & & & & & \\
\hline & & & & & \\
\hline & & & & & \\
\hline & & & & & \\
\hline & & & & & \\
\hline & 84 & & 130 & & 70 \\
\hline
\end{tabular}


TUCSON 2

\section{supply}

\section{ASSUMPTIONS AND EXPLANATIONS}

1. Storage capacity is generated by a maximum of $56.13 \mathrm{mwh} / \mathrm{d}$ excess daily electrical supply. Any excess over and above this is sold to the local electricity utility grid.

ENERGY SOURCE

APPLICATION

CONFIGURATION

SUPPLY

Mwh/Day

\begin{tabular}{|l|l|l|l|}
\hline STORAGE SYSTEMS & \multicolumn{3}{|l|}{} \\
\hline 1. Hydroelectric & supply/demand buffer & pondage tanks & optional \\
\hline reservoir & & $70-100 \mathrm{ft}$. head & \\
\hline & & & \\
\hline & & & \\
\hline 2. Fl ywheel storage & supply/demand buffer & centralized & optional \\
\hline & & facility & \\
\hline & & & \\
\hline (Total storage capacity is $569.8 \mathrm{mwh})$. & & \\
\hline
\end{tabular}

\begin{tabular}{|c|c|c|c|}
\hline \multicolumn{4}{|l|}{ SUPPLY SYSTEMS } \\
\hline 1. parabolic dish & electrical demand, & 85 acre field & 130 \\
\hline concentrating & ( $85 \%$ non-residential & & \\
\hline collectors & heating and cooling) & & \\
\hline 2. biomass & methane for & 116 acres of fields; & \\
\hline distillation & vehicle fuel & 47,000 gals. of gas & \\
\hline & & equivalent; $3 \%$ of & \\
\hline & & community needs & \\
\hline 3. sewage & transportation & 84,000 gals.of gas & \\
\hline distillation & fuel or back-up & equivalent; $6 \%$ of & \\
\hline & gueneralgon lectric & community needs & \\
\hline
\end{tabular}

\section{total community energy supply 30 mathe}




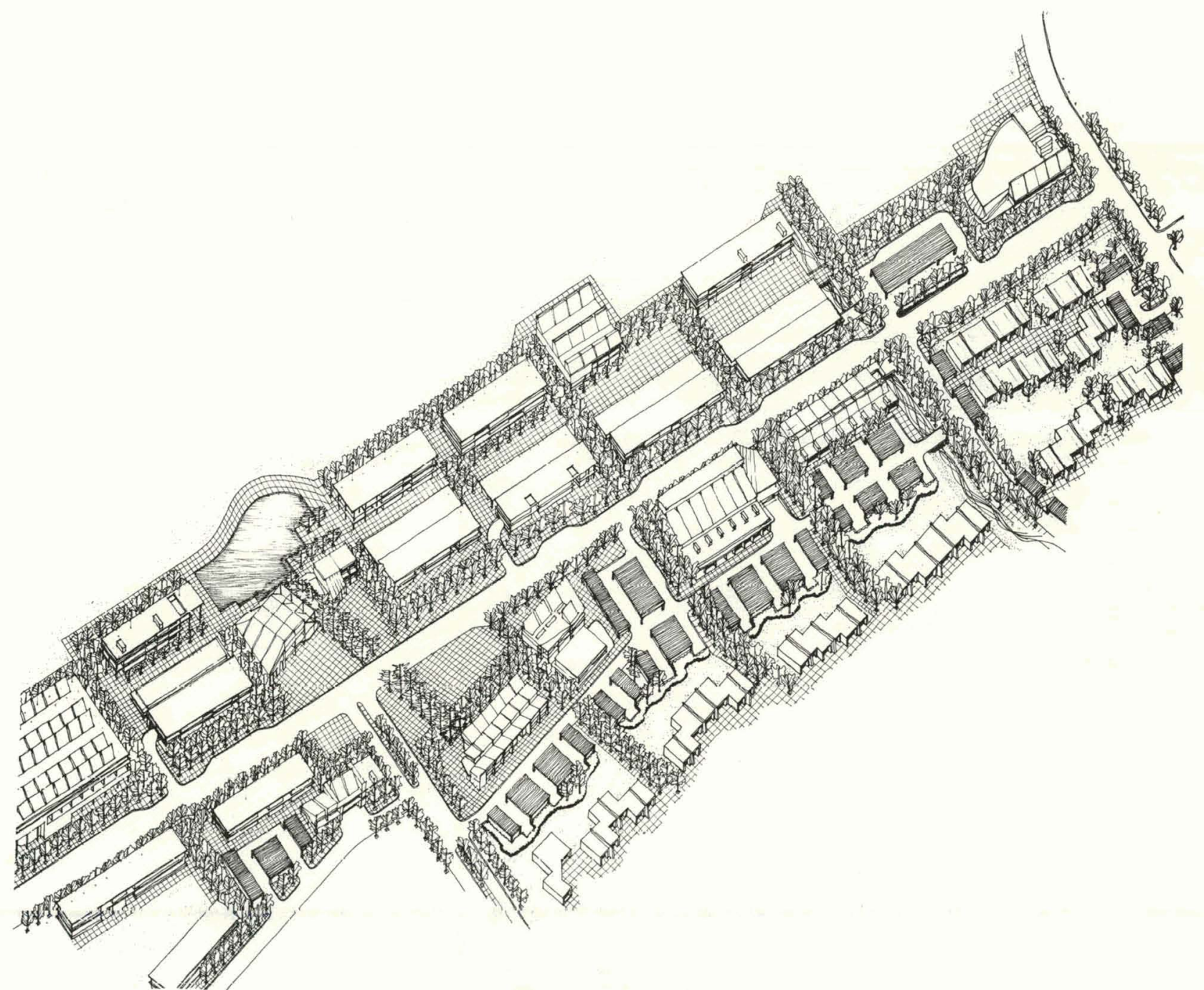

TEAM 2

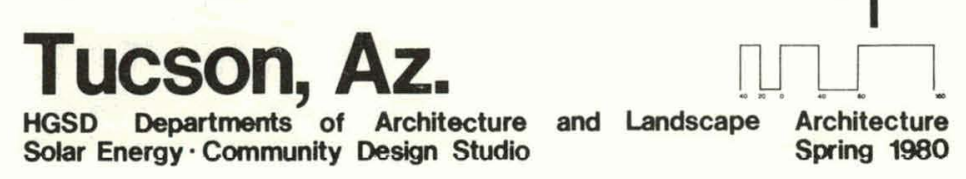

Fig. 3.2.1.1 


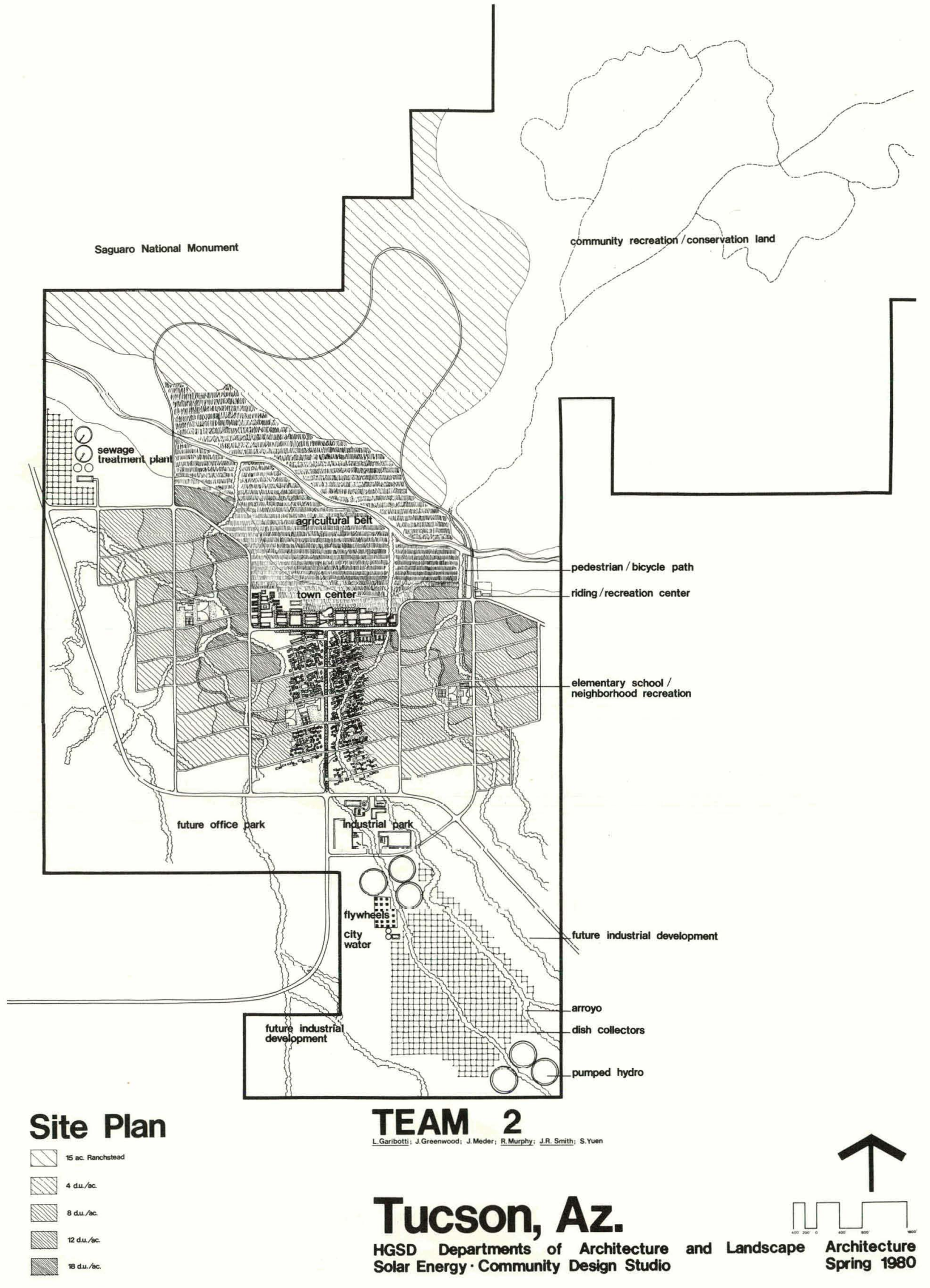

Fig. 3.2.1.3 


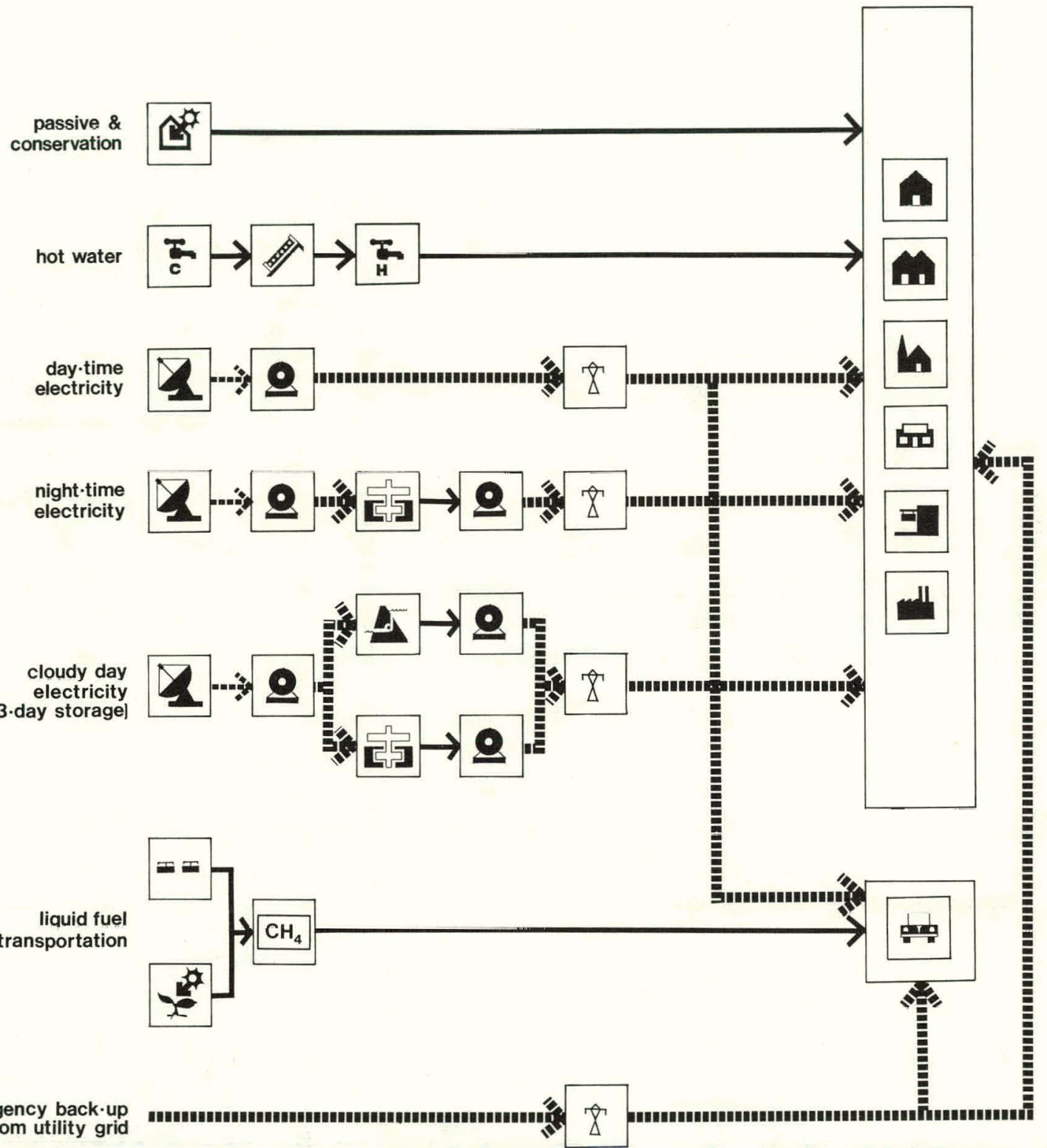

\section{Energy Diagram}

\section{TEAM 2}

L.Garibotti; J.Greenwood; J.Meder; R. Murphy; J.R. Smith; S. Yuen

\section{Tucson, Az.}

HGSD Departments of Architecture and Landscape Architecture Solar Energy Community Design Studio

Fig. 3.2.2.4 


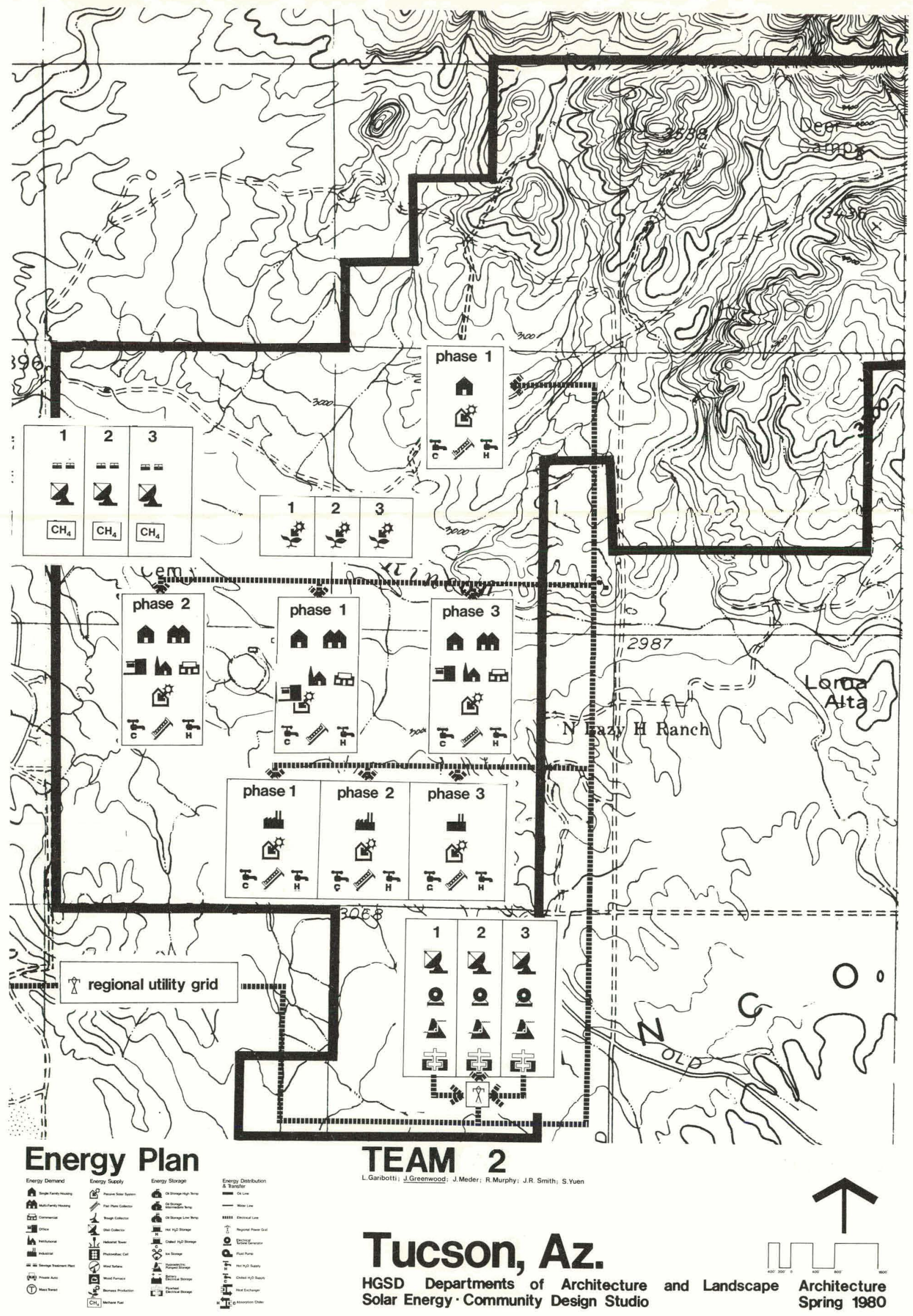

Fig. 3.2.2.5 


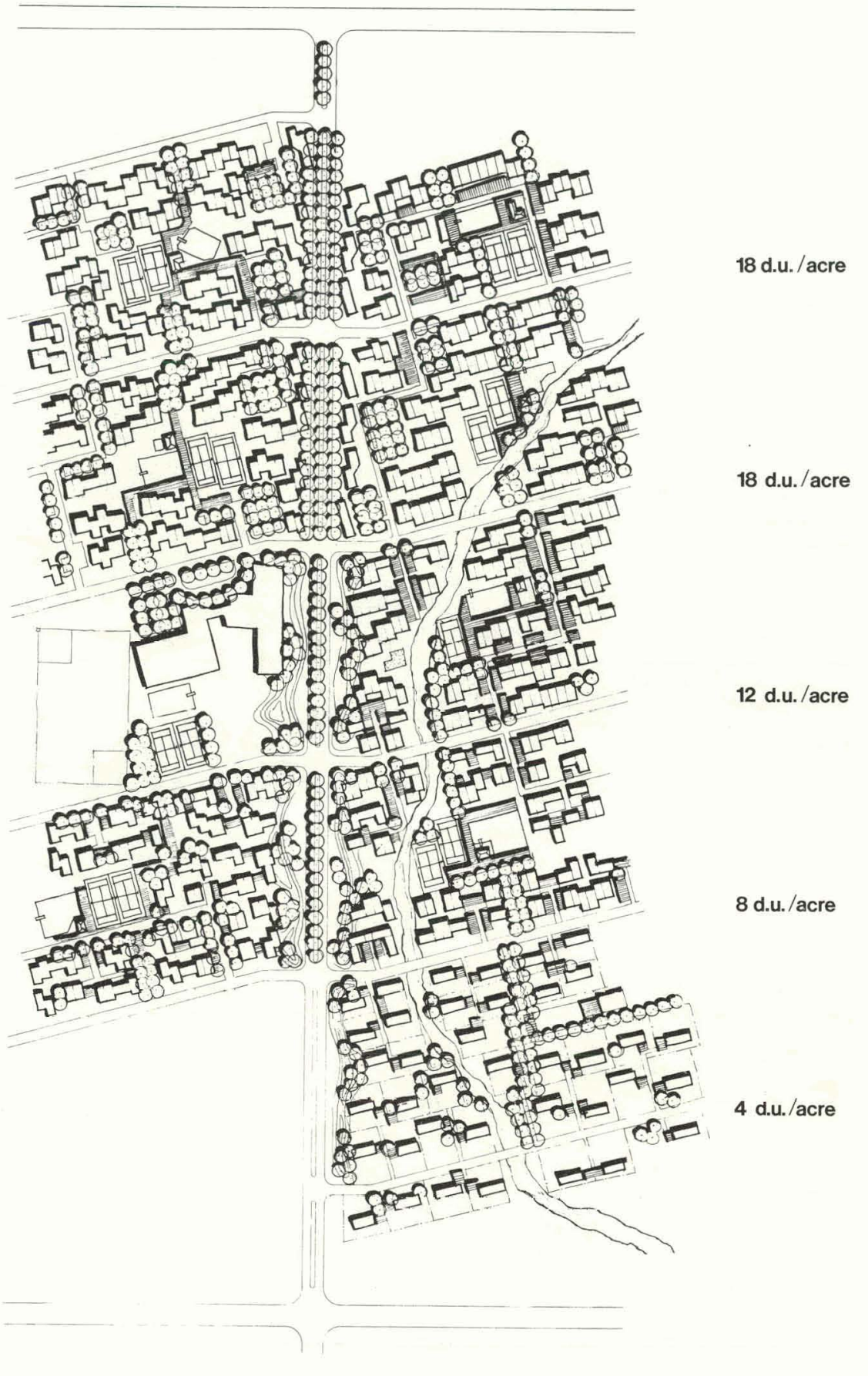

Site Plan

central residential area
TEAM 2

Tucson, Az. Solar Energy - Conmmunity nesign Sturdin
HGSD Departments of Architecture

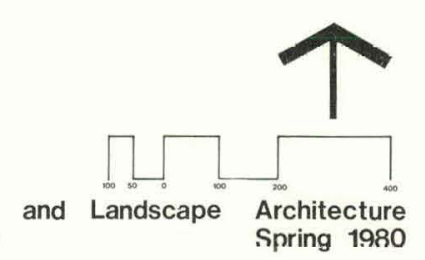

Fig. 3.2.3.6 


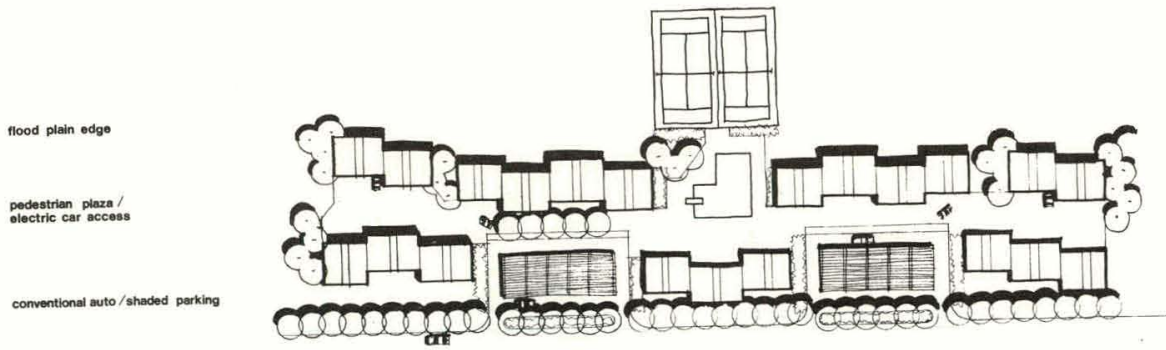

flood plain edge housing - 18 d.u. / acre

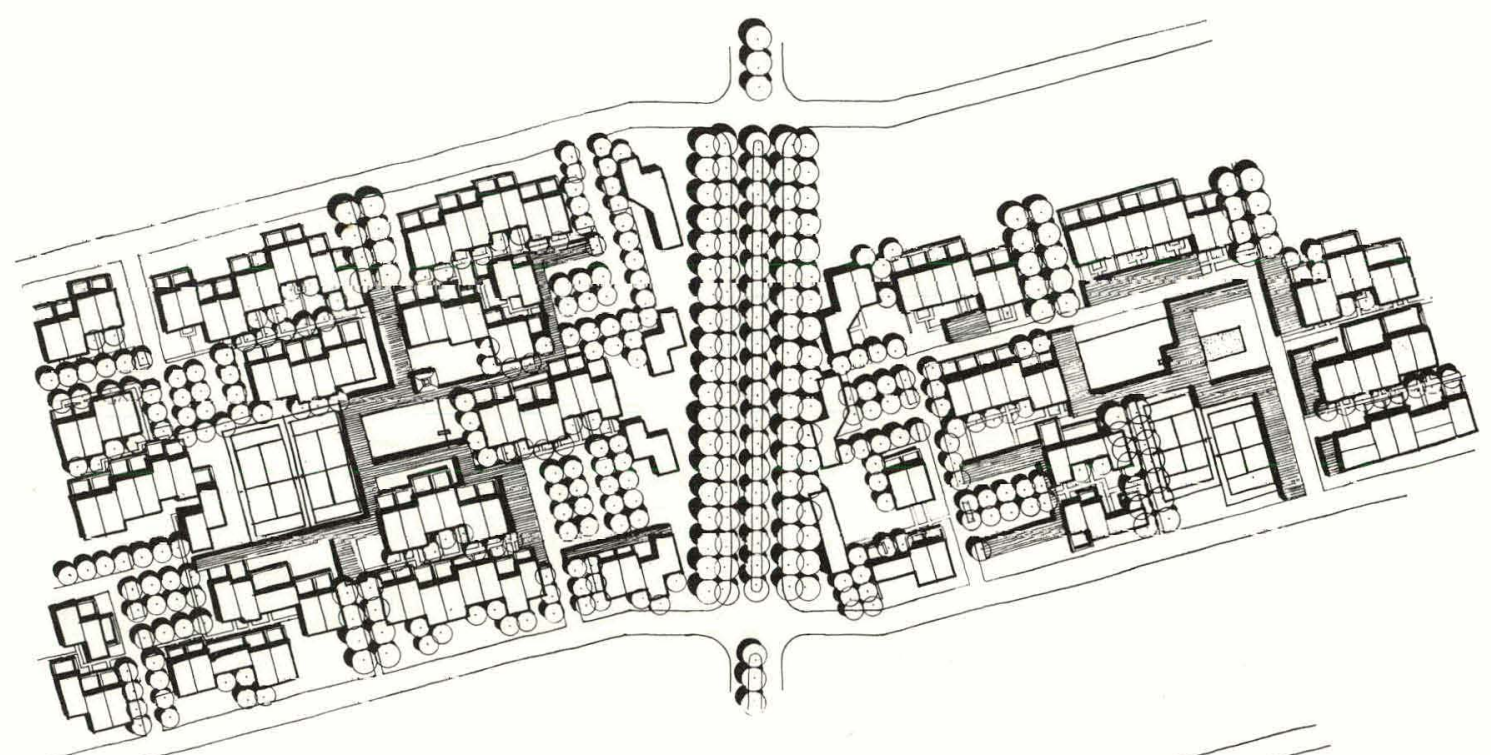

high density housing - 18 d.u. / acre
noit town nombr

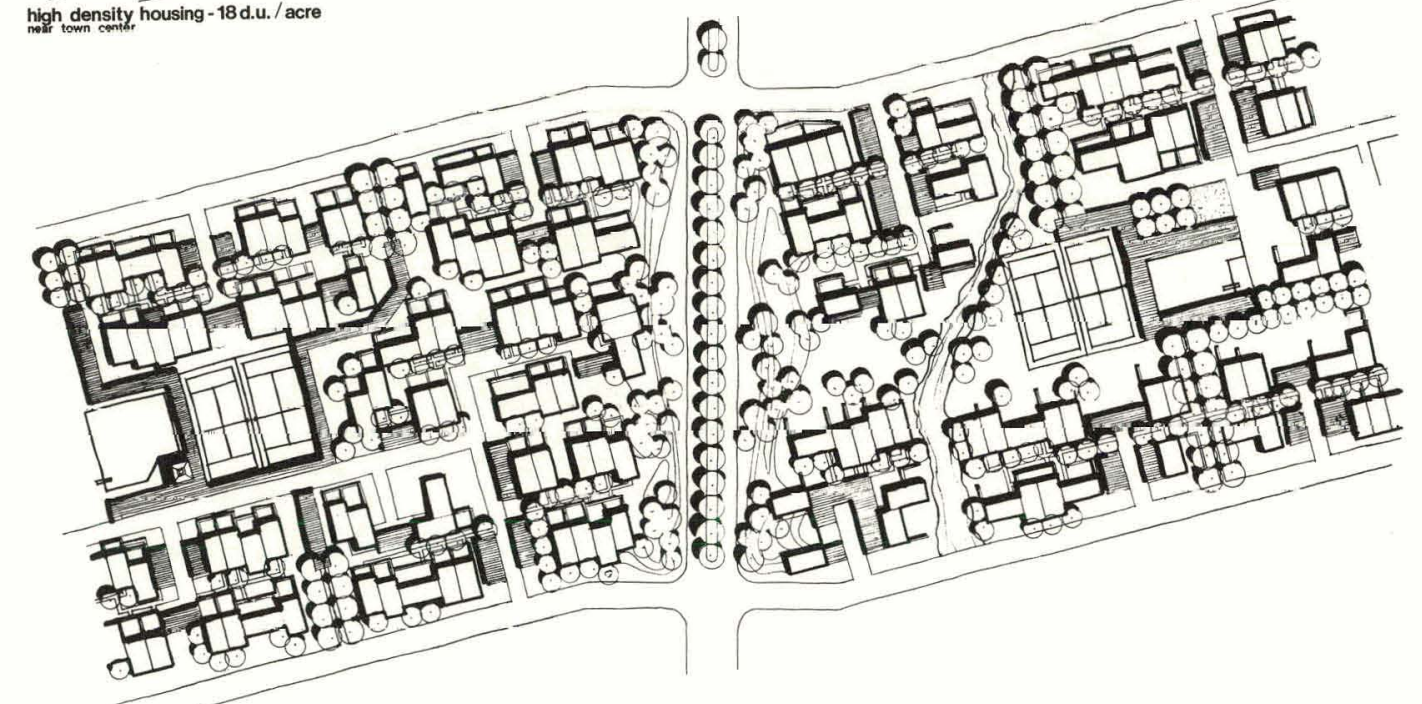

medium density housing -8 d.u./acre

\section{Block Prototypes}

TEAM 2

Tucson, Az.

HGSD Departments of Architecture Solar Energy - Community Design Studio

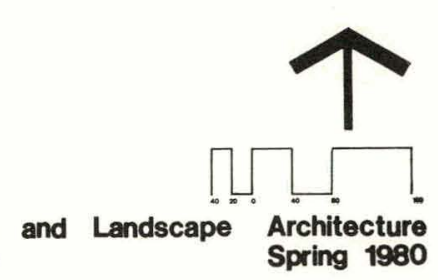

Fig. 3.2.3.7 


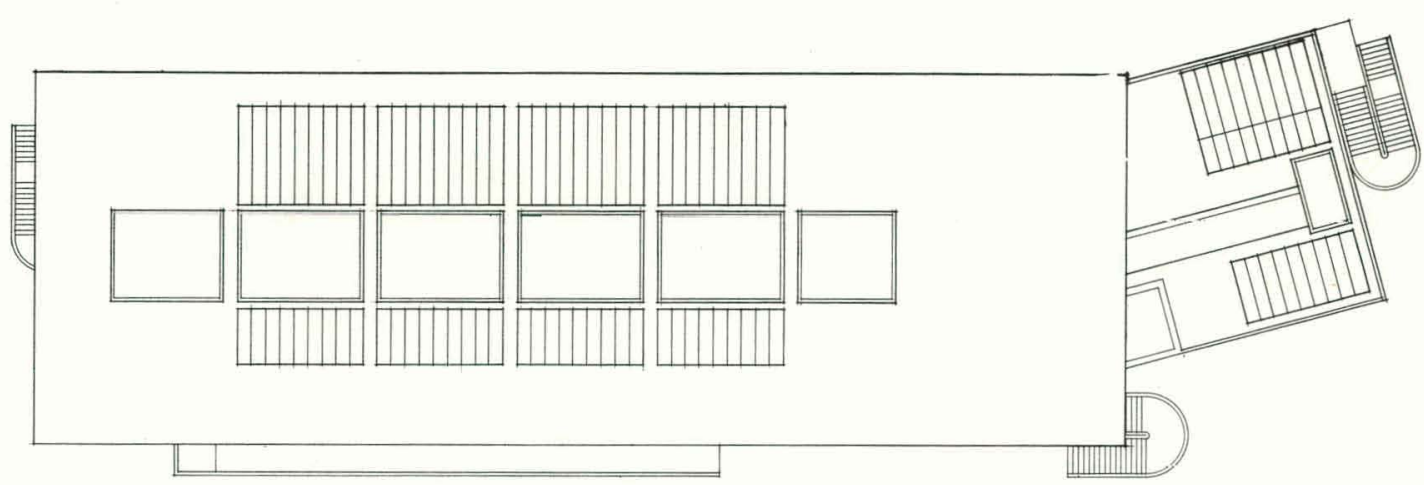

roof plan

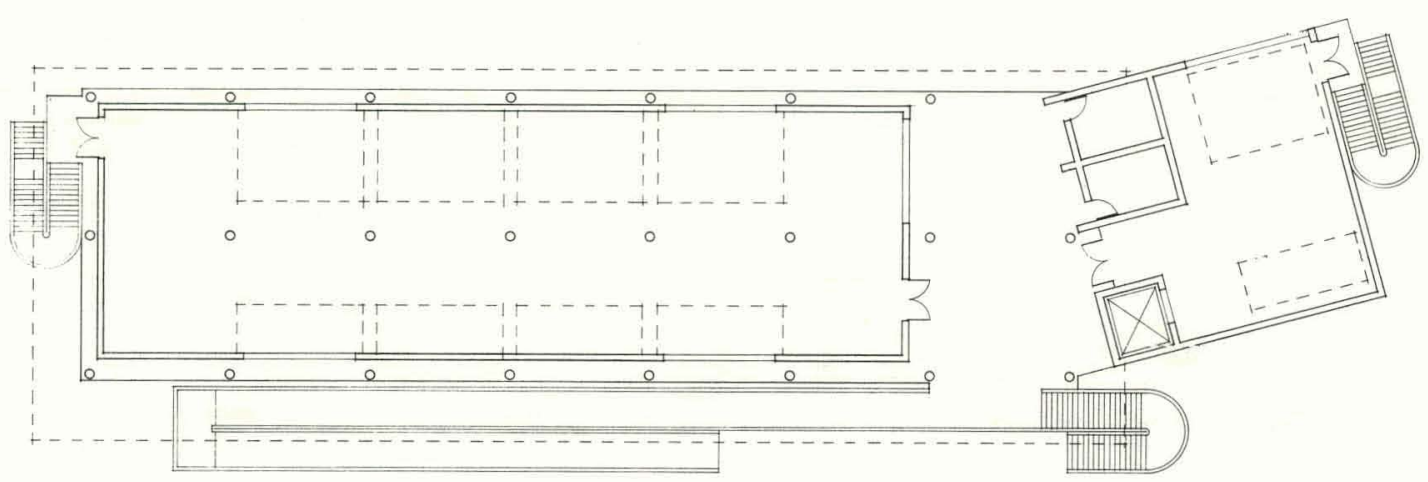

exhibition level plan

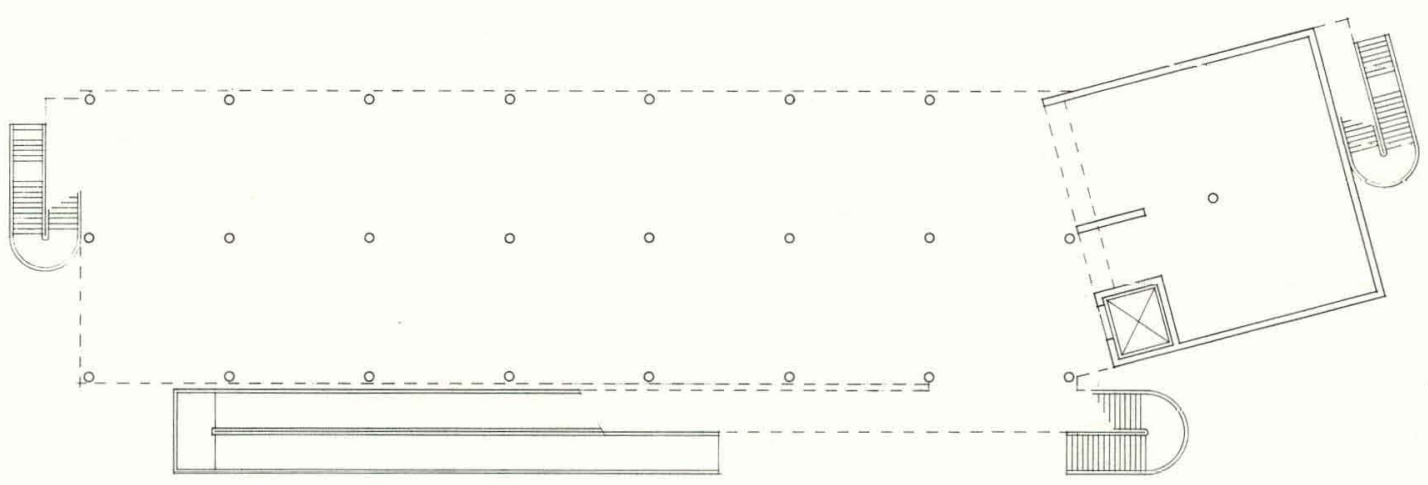

ground level plan

\section{$\underset{\text { oxhibition space }}{\text { Townter }}$}

Fig. 3.2.3.8
TEAM 2

L.Garibotti; J.Greenwood; J. Meder; R. Murphy; J.R. Smith; S. Yuen

Tucson, Az.

HGSD Departments of Architecture Solar Energy - Community Design Studio

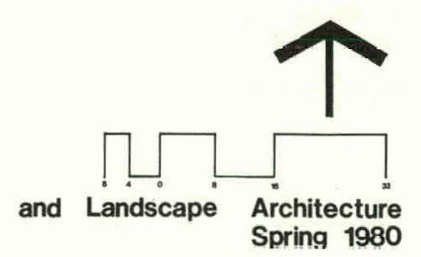

Spring 1980 


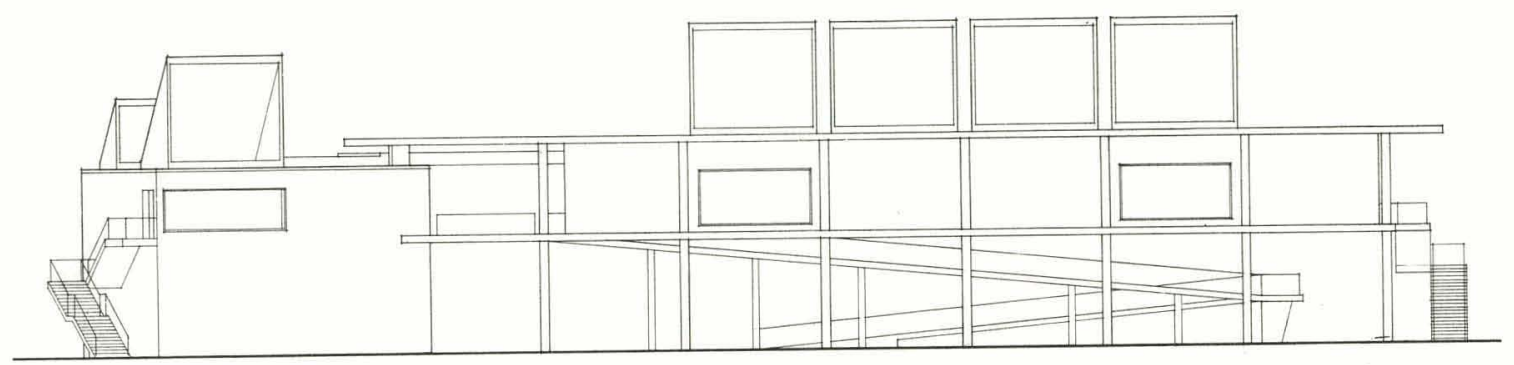

north elevation

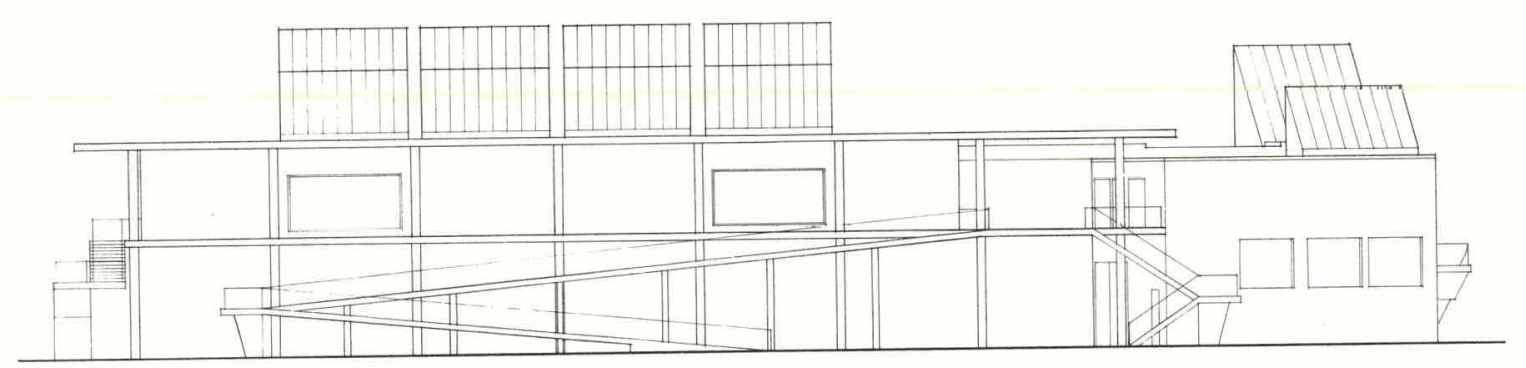

south elevation

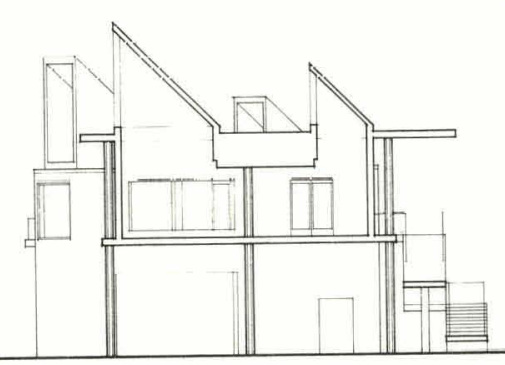

$t^{-\operatorname{mon}}$

\section{Town Center \\ retail/residential building}

Fig. 3.2.3.9
TEAM 2

TEAM

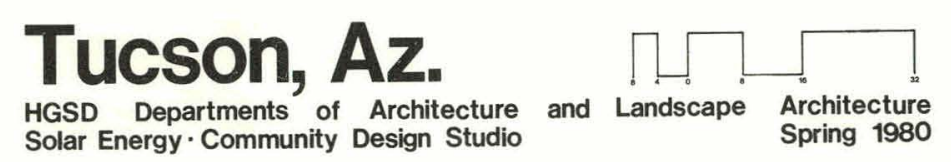




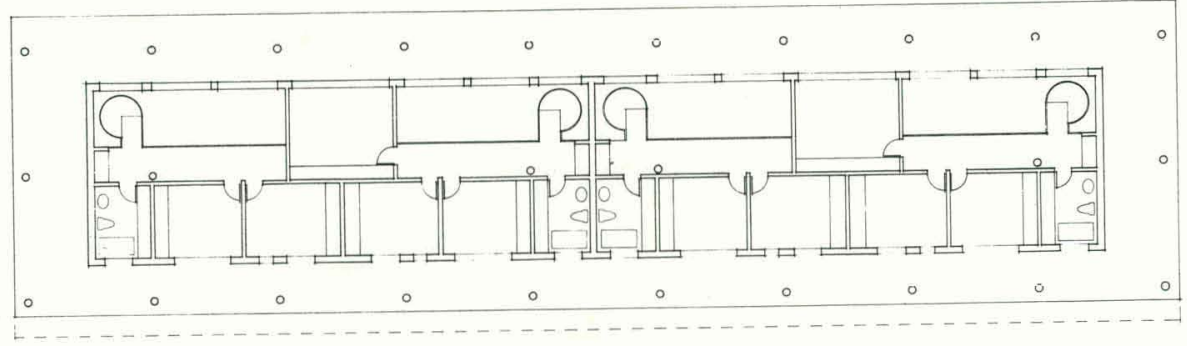

third floor plan / residential

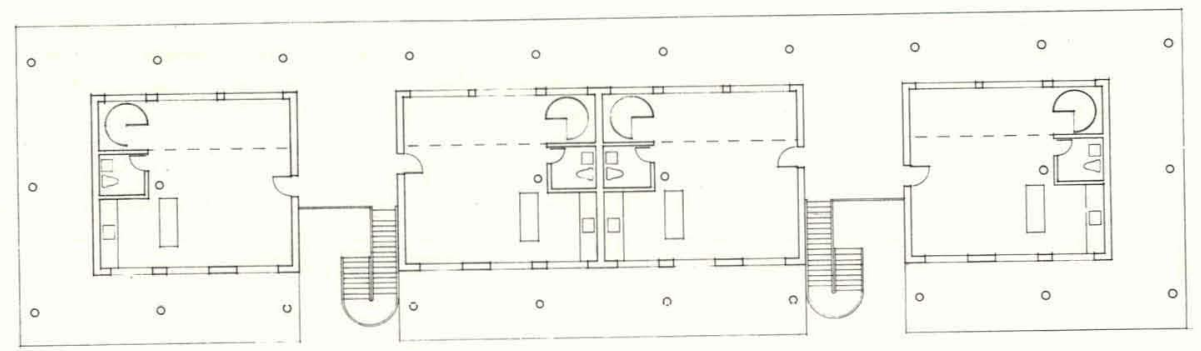

second floor plan / residential

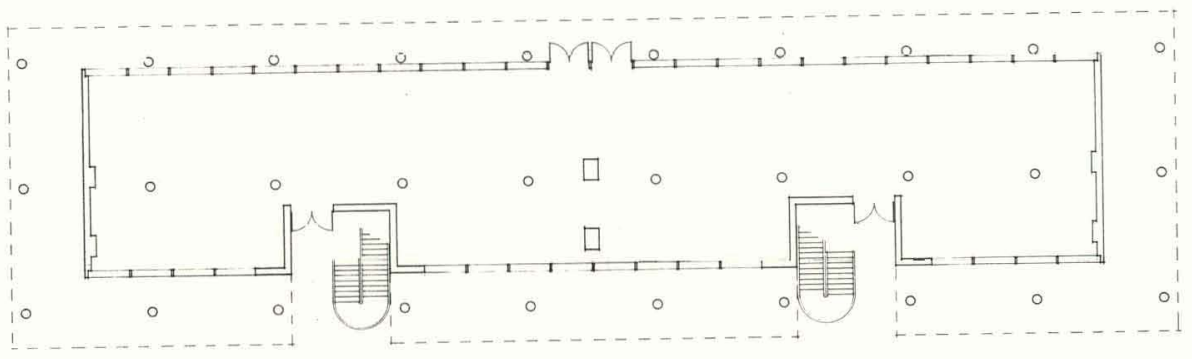

ground floor plan / retail

\section{Town Center}

TEAM 2

L.Garibotti; J.Greenwood; J. Meder; R. Murphy; J.R. Smith; S. Yuen

Tucson, Az.

HGSD Departments of Architecture and Landscape Solar Energy · Community Design Studio

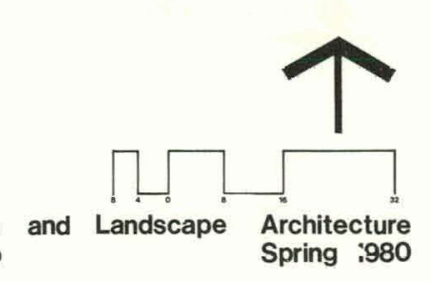

Fig. 3.2.3.10 


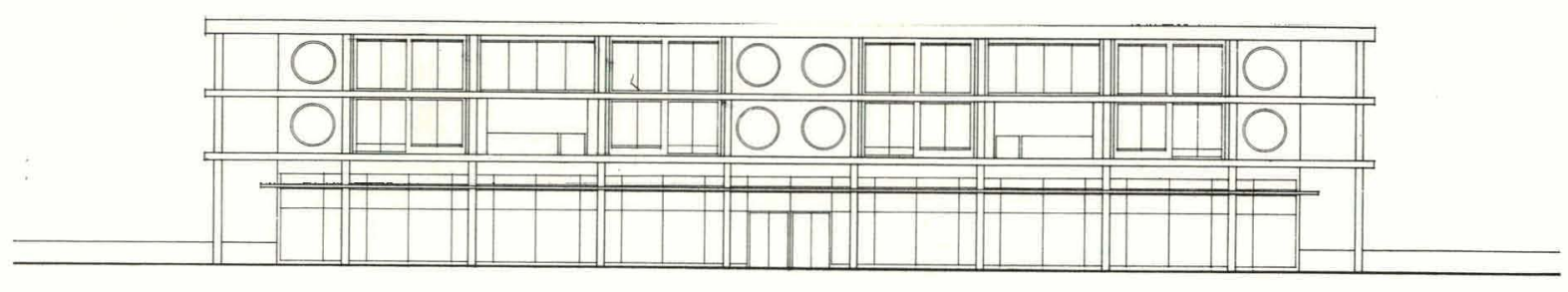

north elevation

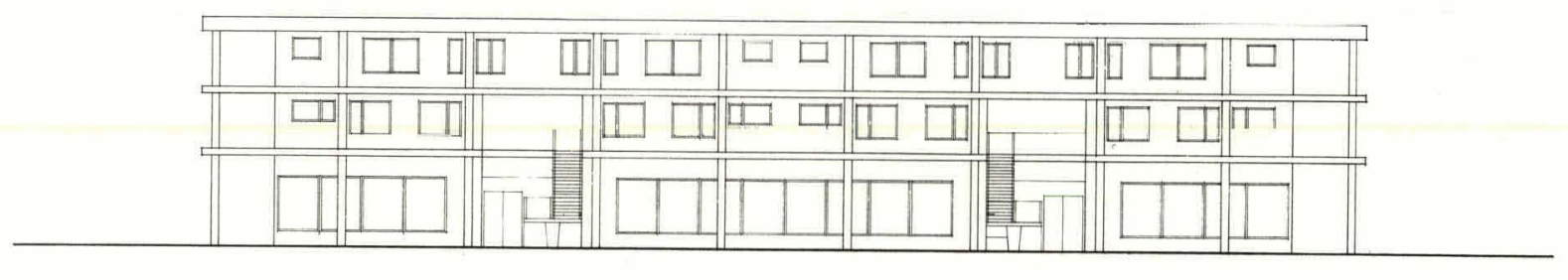

south elevation

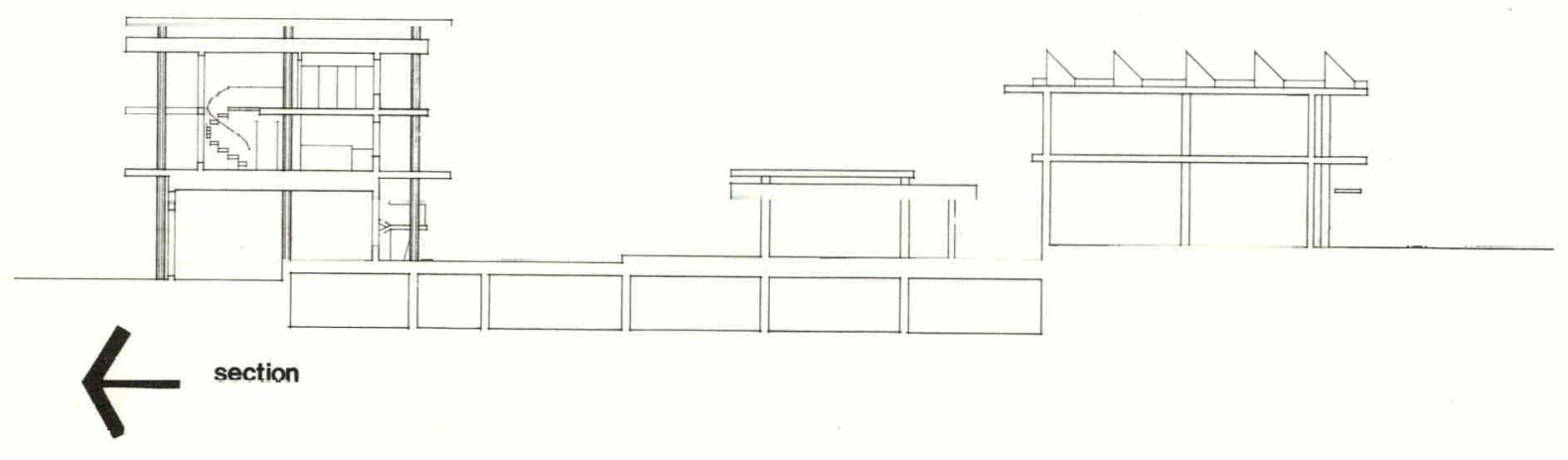

\section{Town Center}

Fig. 3.2.3.11
TEAM 2

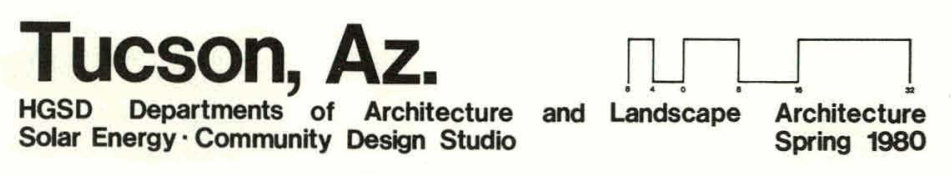




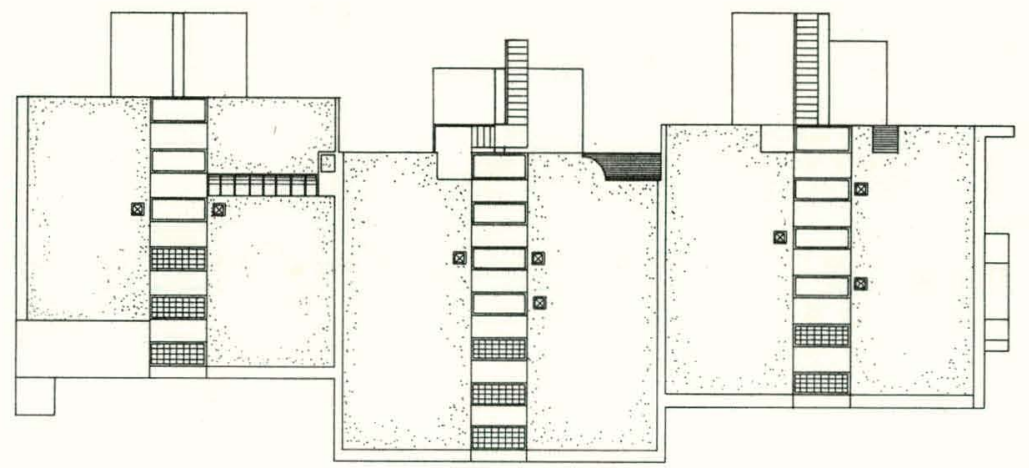

roof plan

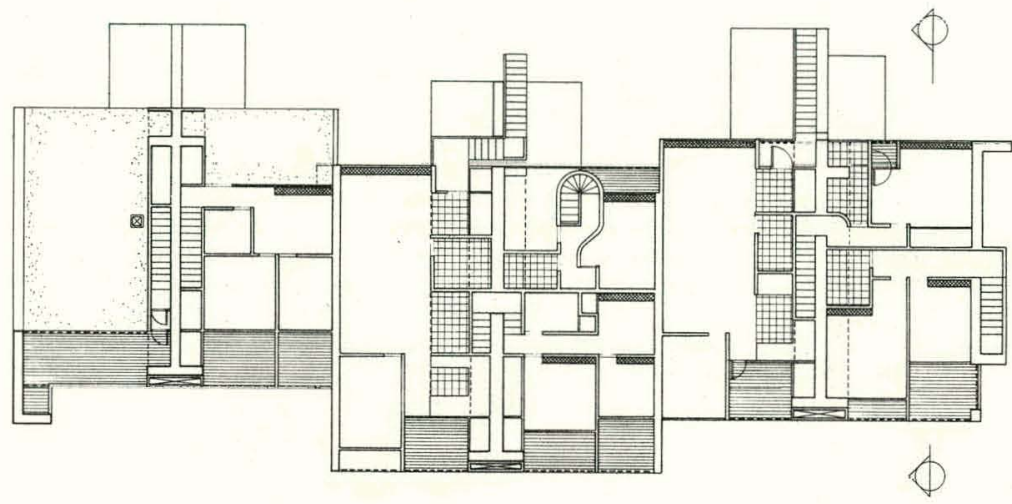

second floor plan

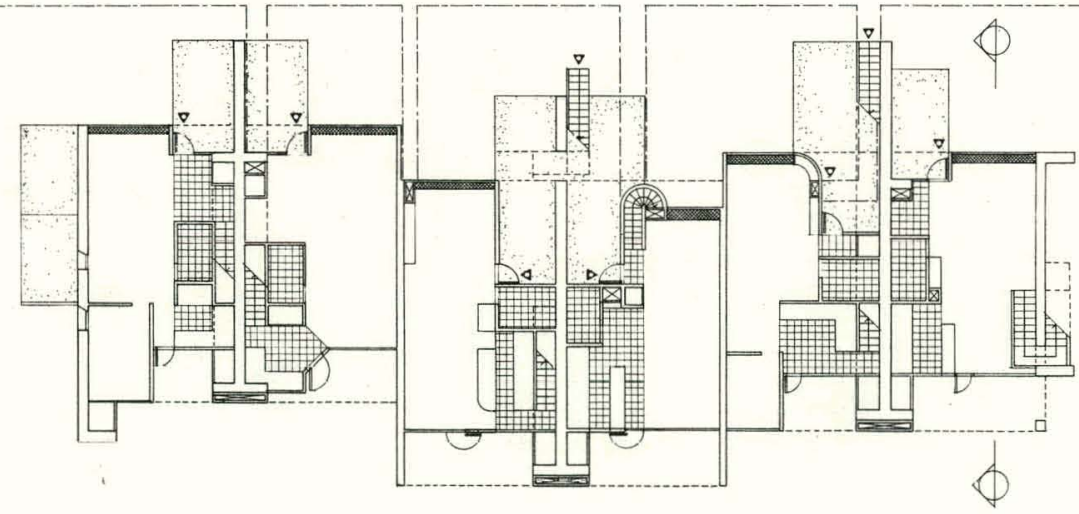

first floor plan

\section{Housing}

high density $/ 100 \%$ passive heating \& cooling 18 d. u. /acre

Fig. 3.2.3.12
TEAM 2

L.Garibotti; J.Greenwood; J.Meder; R. Murphy; J.R. Smith; S.Yuen

\section{Tucson, Az.} HGSD Departments of Architecture Solar Energy · Community Design Studio
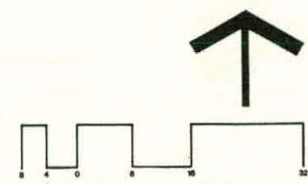

and Landscape Architecture Spring 1980 

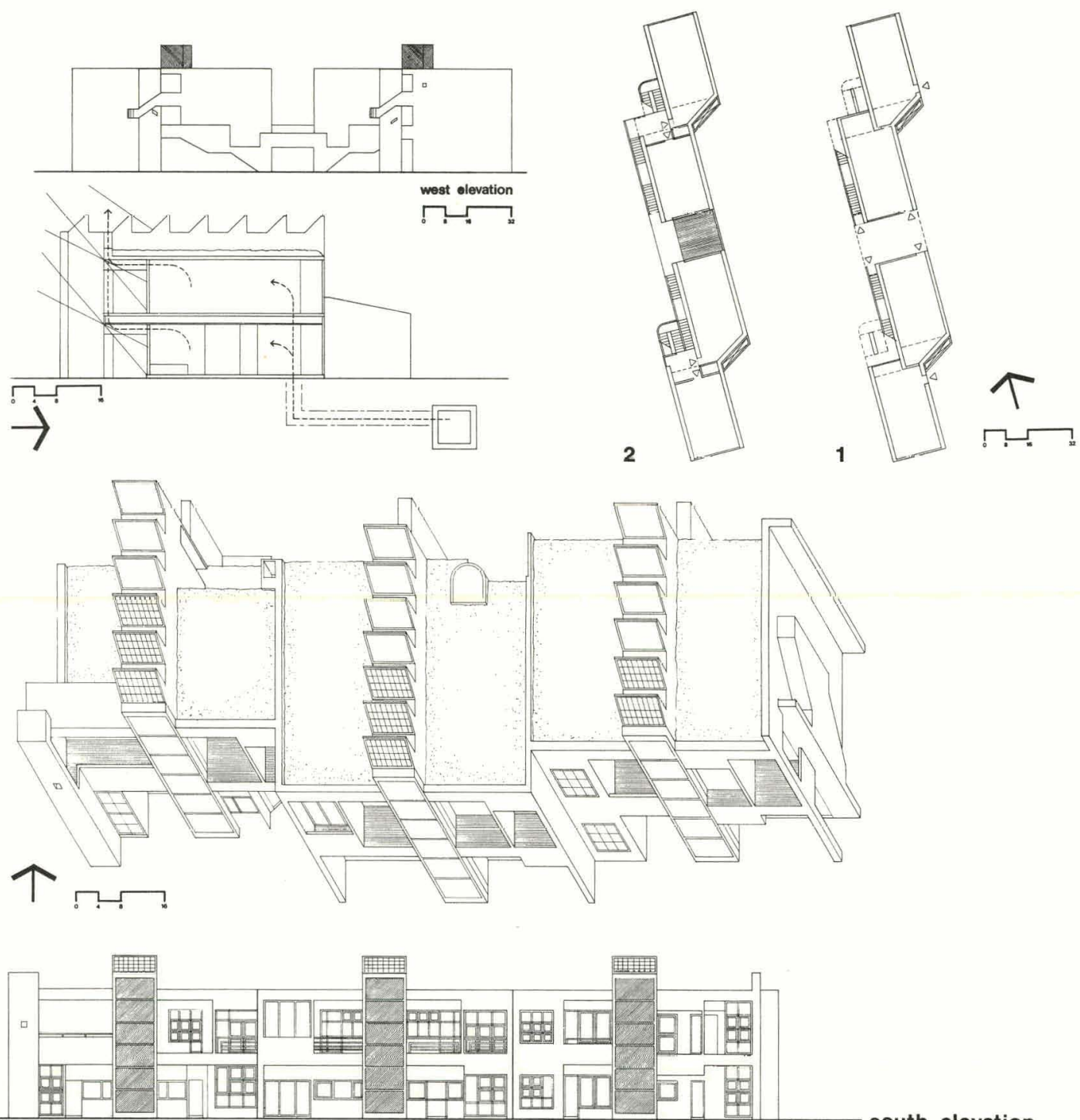

snuth qlevation

?ִ?

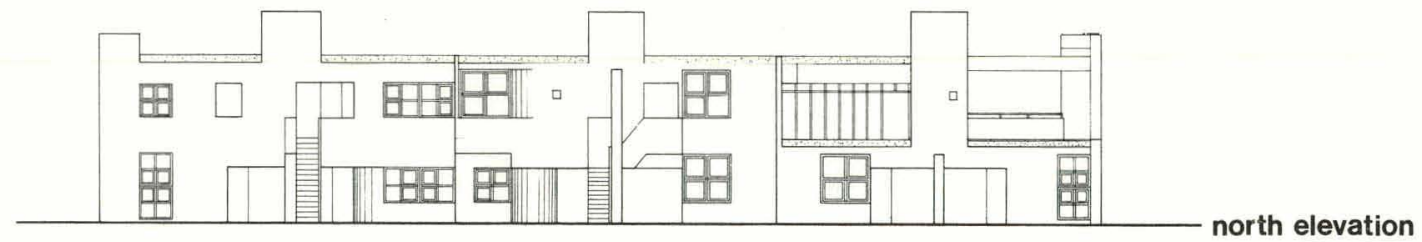

ㄴ? ?

\section{Housing}

high density $/ 100 \%$ passive heating \& cooling

Fig. 3.2.3.13
TEAM 2

L.Garibotti; J.Greenwood; L.Meder; R. Murphy; J.R. Smith; S. Yuen

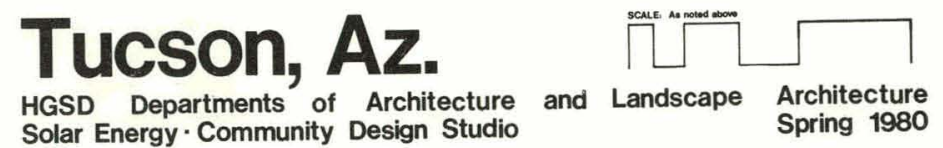


The Shenandoah site is situated on 7,400 acres surrounding the Newnan exit off Interstate 85, thirty-three miles southwest of Atlanta, Georgia. Summers are warm, and temperatures range from $75^{\circ}$ to $90^{\circ} \mathrm{F}$. The temperatures in winter range from $25^{\circ}$ to $50^{\circ} \mathrm{F}$. The annual rainfall for Newnan averages 53.5 inches, and the prevailing winds are from the northwest. Climate Tables are shown in Fig. 4.0.2.

The site is characterized by a gently rolling topography. The soils are predominantly clay and sand, and provide relatively stable soil conditions for development. A small percentage of the site is cleared land with abandoned pastures and farmland. The remaining land is covered with mixed pine-hardwood stands. Species include loblolly pine, sweet gum, river birch and scarlet oak. The most dominant natural feature on the site is the flood plain of White Creek and its associated tributaries. Uribuildable to the 100-year flood line, the flood plain divides the site into large areas of buildable land that offer opportunities for community development. 


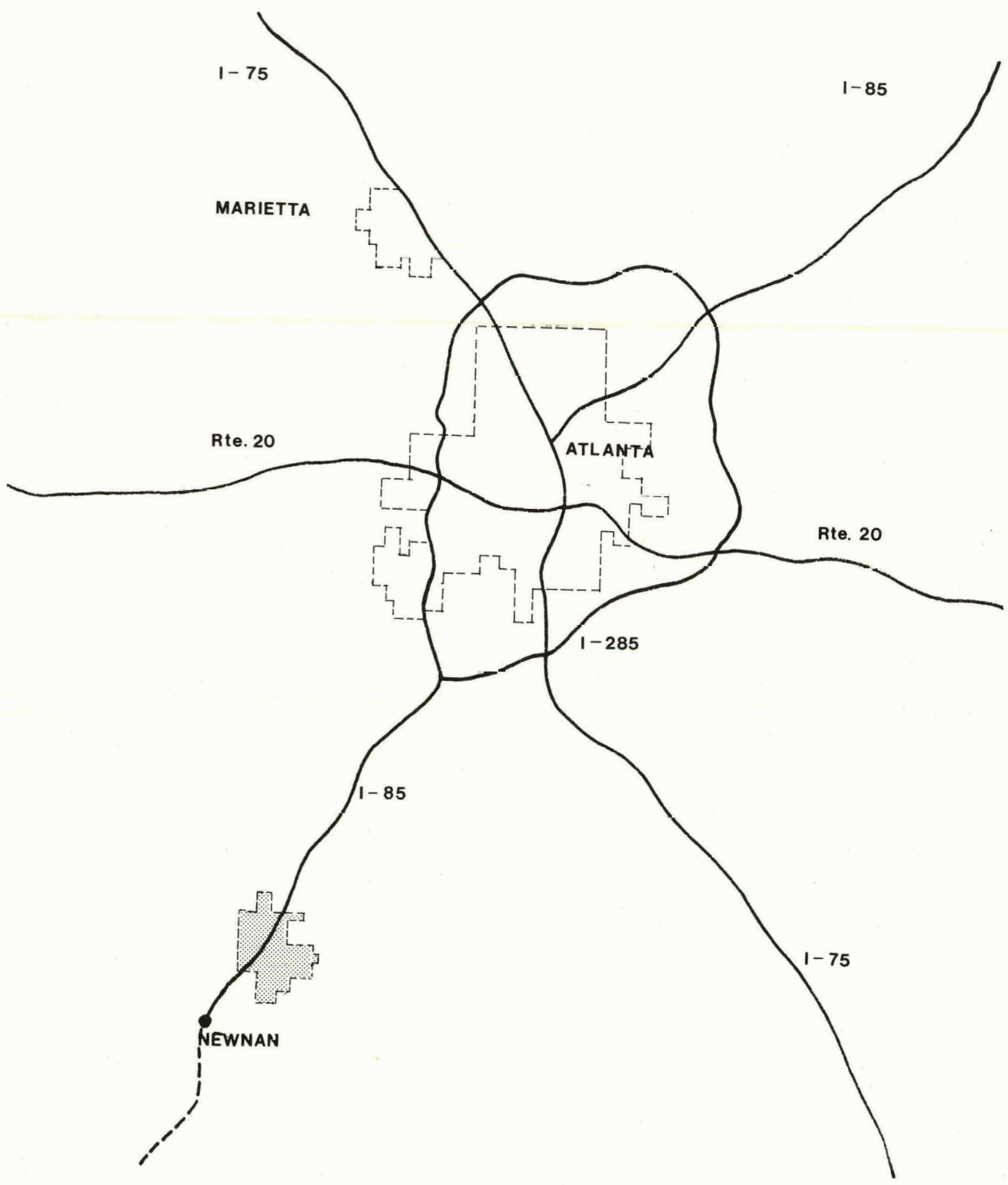

Fig. 4.0 .1

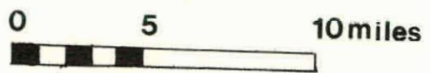




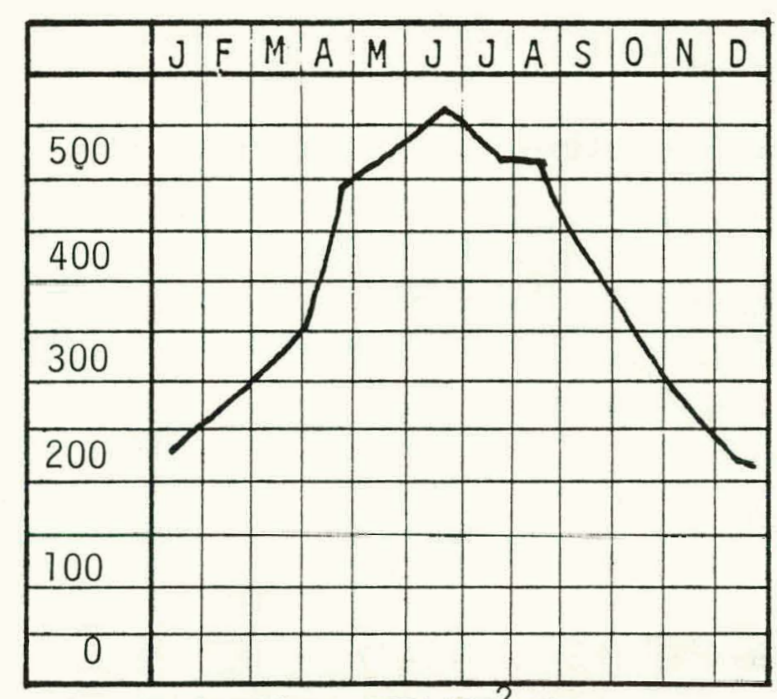

Solar Radiation BTU/FT ${ }^{2}$ Day

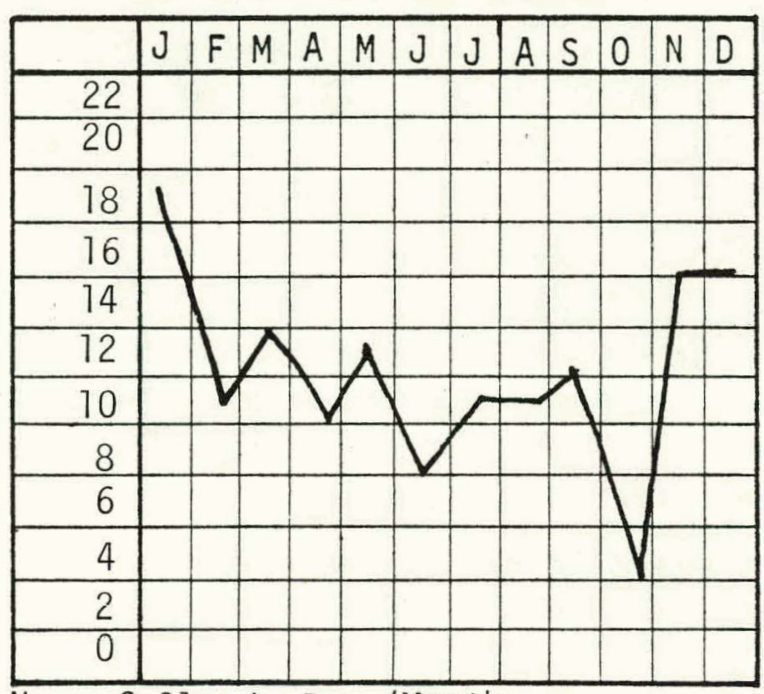

No. of Cloudy Days/Month

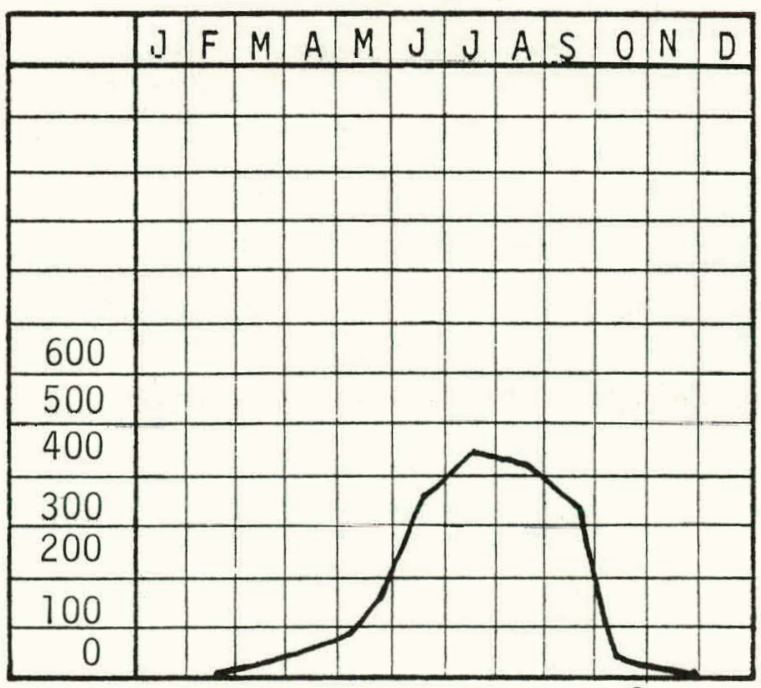

Cuoliny Degree Days/Month, $65^{\circ} \mathrm{F}$. Base

Table 4.0.2

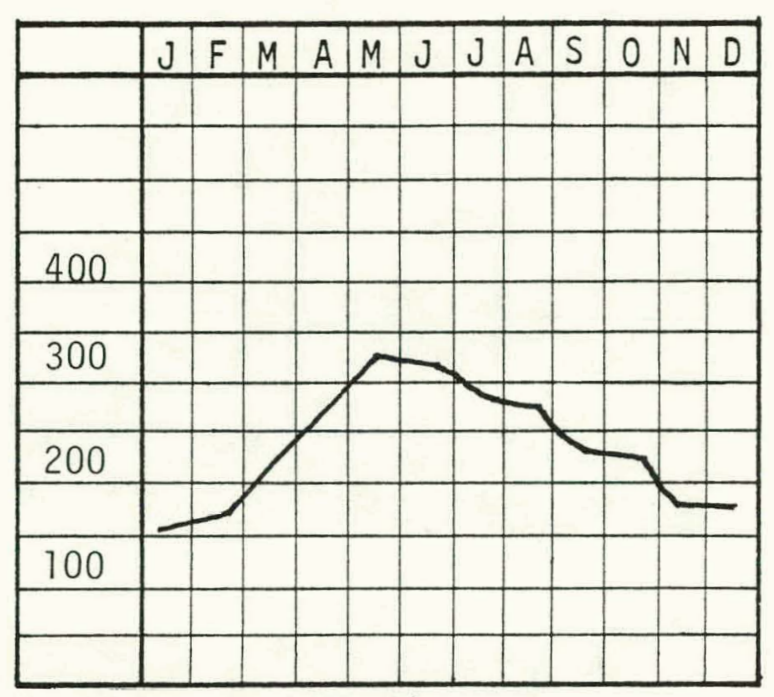

Sunshine Hours/Month
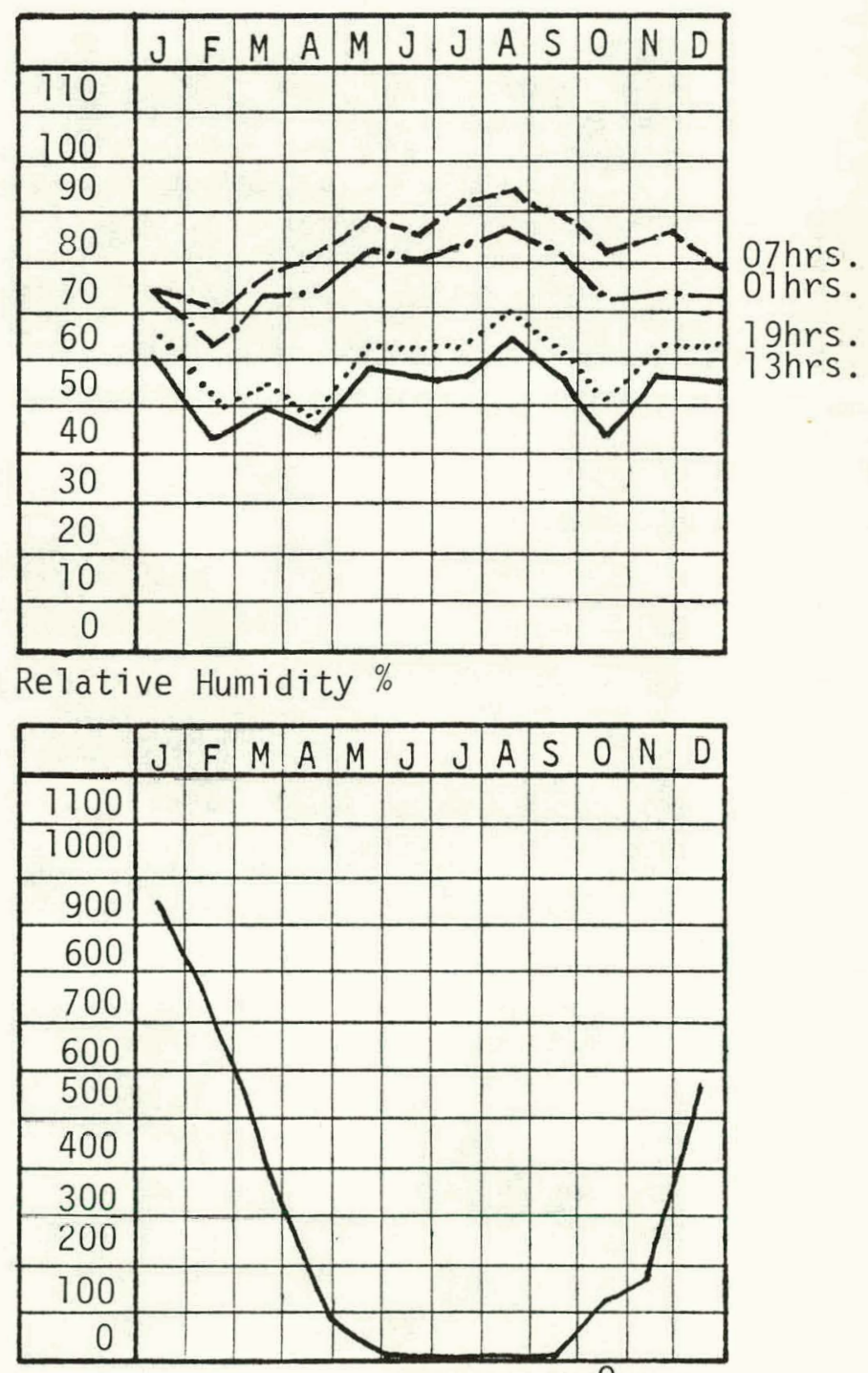

Heating Degree Days/Month, $65^{\circ} \mathrm{F}$. Base 

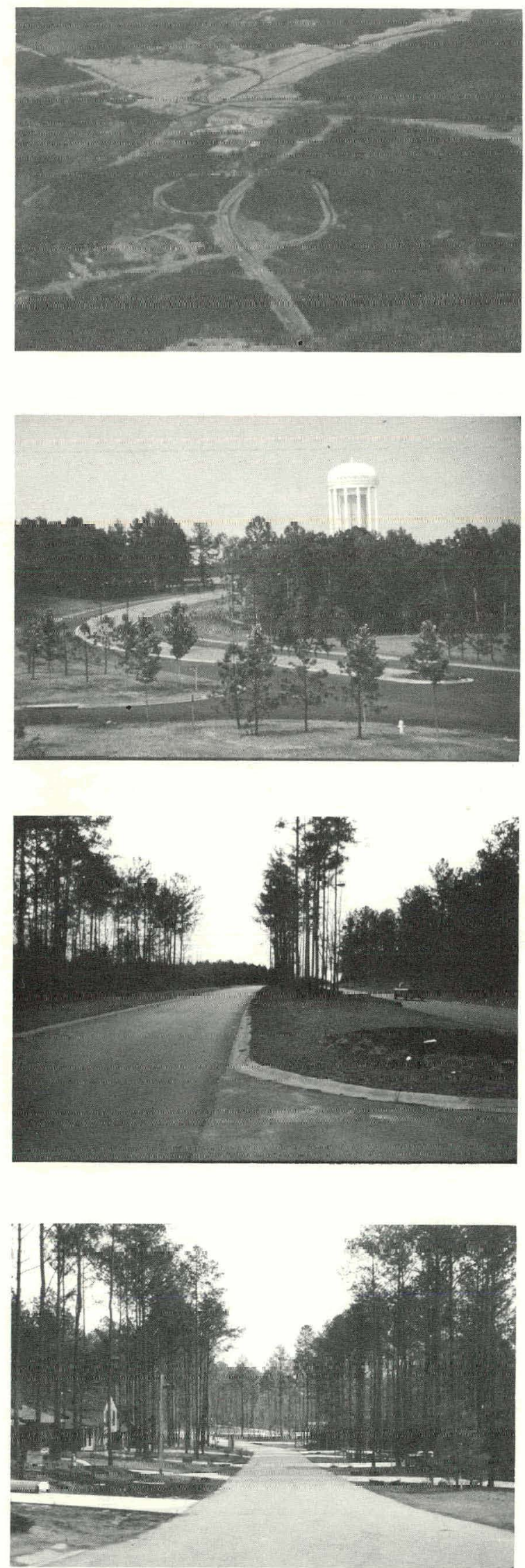

Fig. 4.0 .3

Western edge of Shenandoah property

Fig. $4 \cdot 0.4$

Entrance to the Shenandoah property

Fig. 4.0 .5

Boulevard in residential area

Fig. 4.0.6

Residential street in Shenandoah 

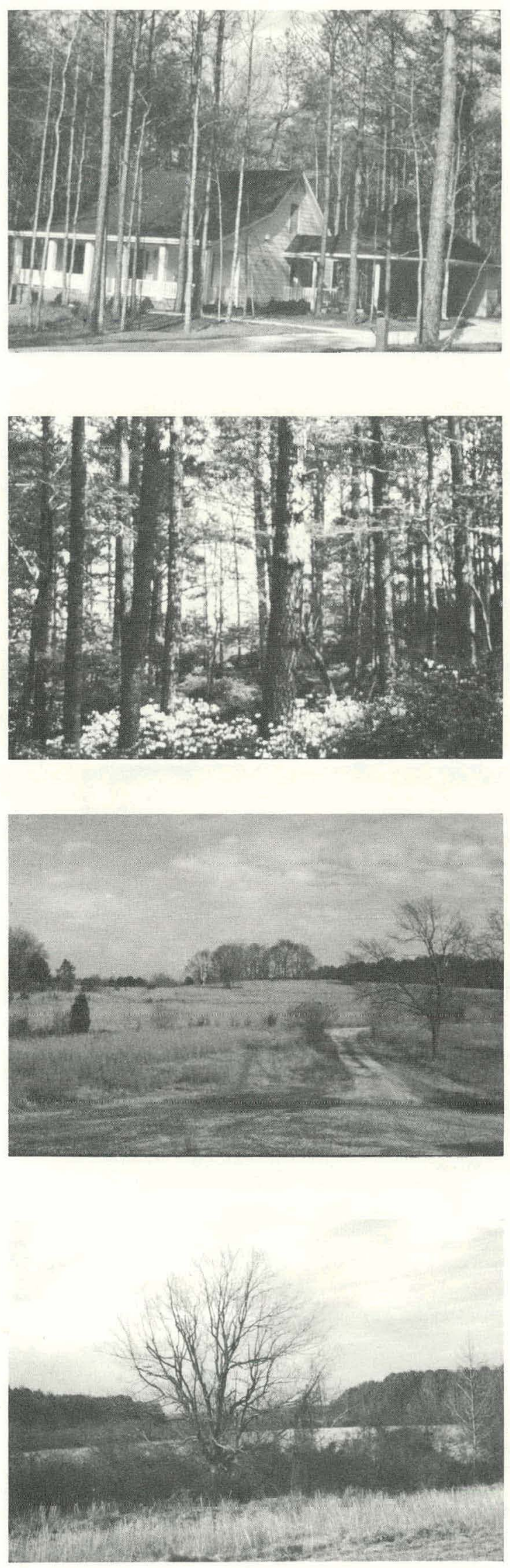

Fig. $4 \cdot 0.7$

Typical residence in Shenandoah

Fig. 4.0 .8

Pine forest

Fig. 4.0 .9

White Creek floodplain

Fig. $4 \cdot 0.10$

White Creek floodplain 


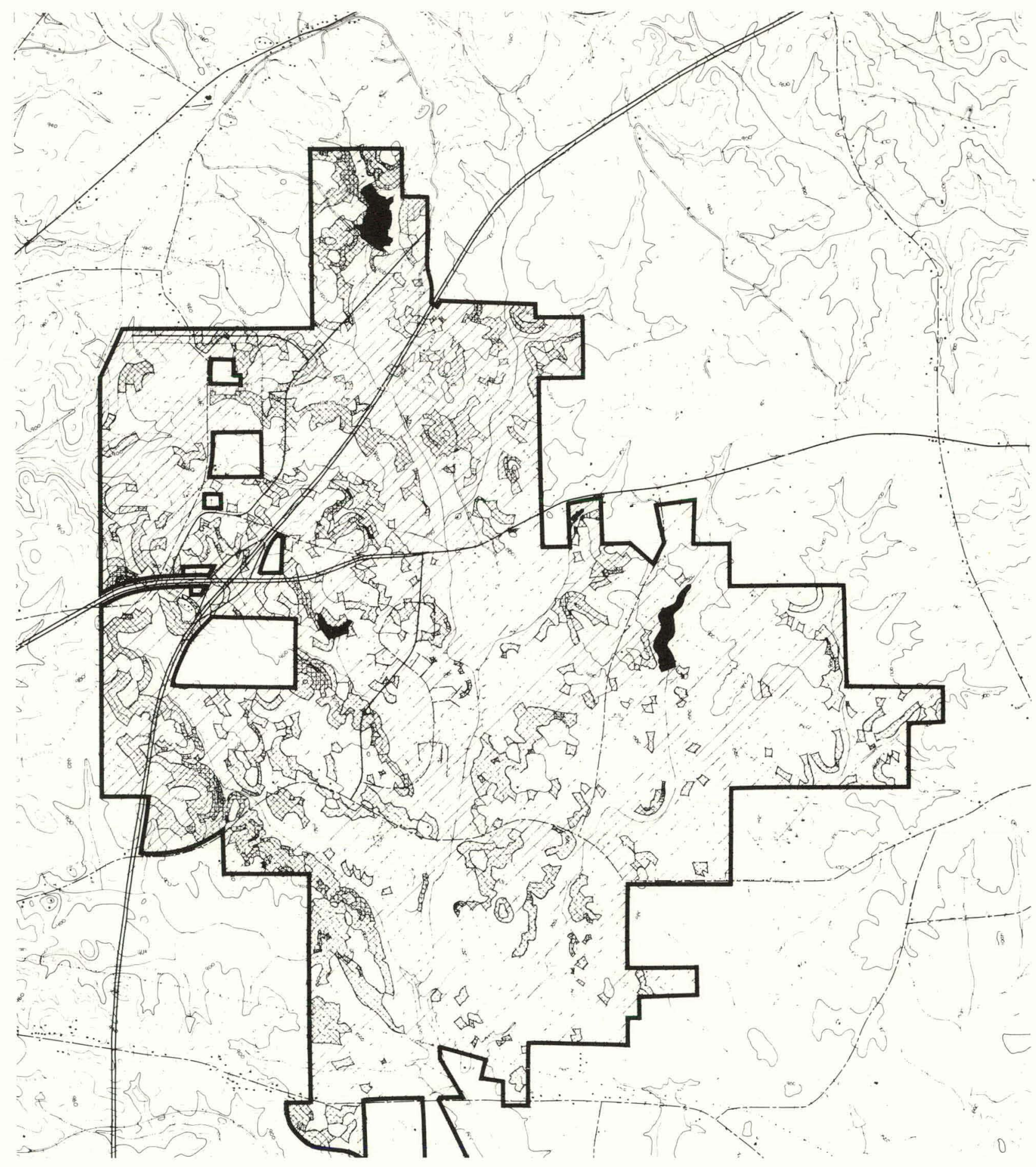

\section{Slope}

grater than 30 percent

water

7-15 percent

Fig. 4.0.11
Atlanta, Ga.

HGSD Departments of Architecture and Landscape Solar Energy · Community Design Studio

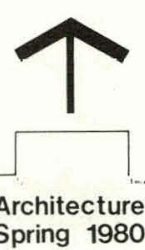

Architecture
Spring 1980 


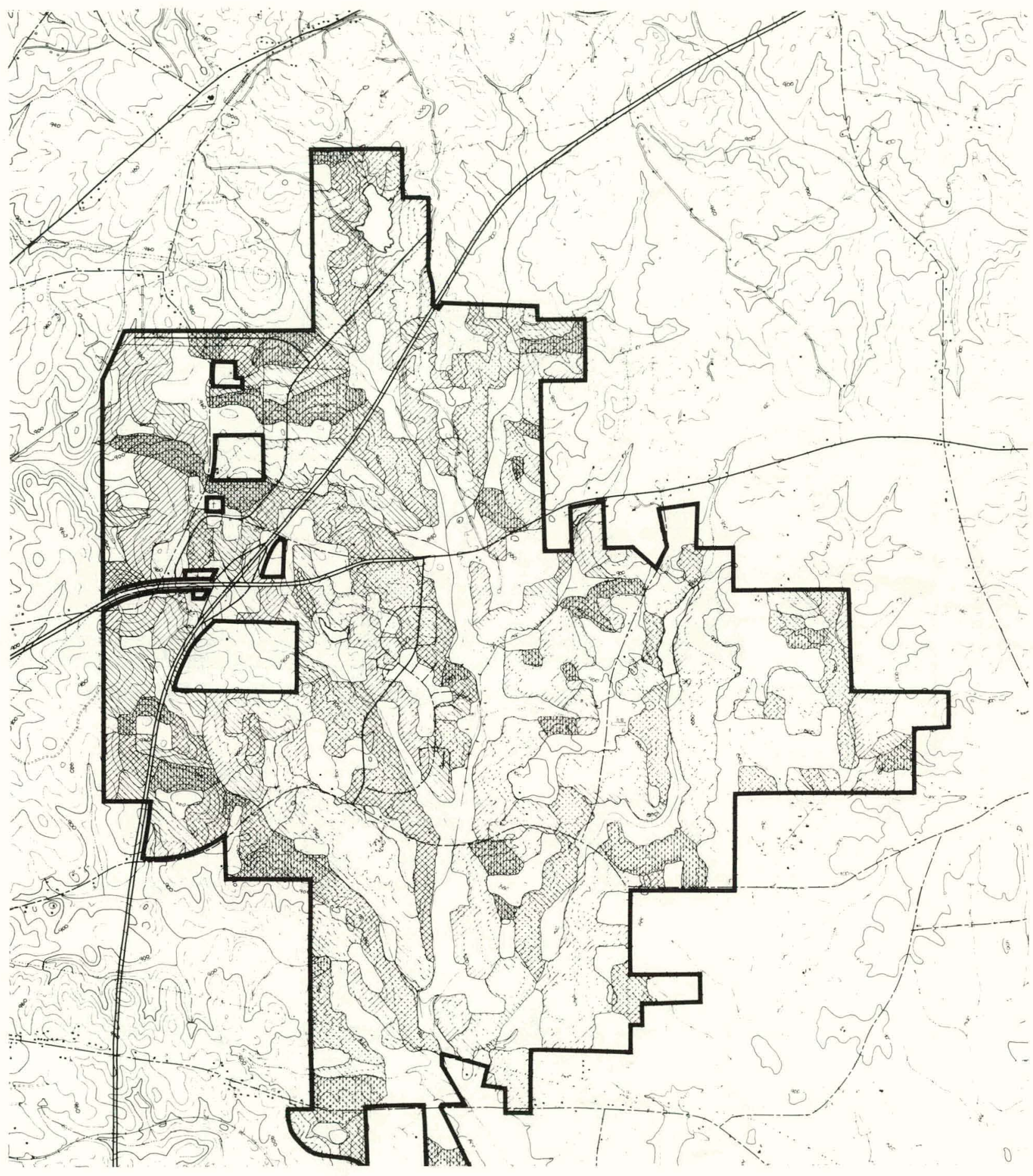

\section{Orientation}

\section{8 wata 40 woss}

Wouth

呦

Fig. 4.0.12
Atlanta, Ga.

HGSD Departments of Architecture
Solar Enerav - Communitv Desıan Studıo
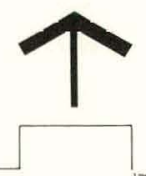

Architecture Spring 1980 


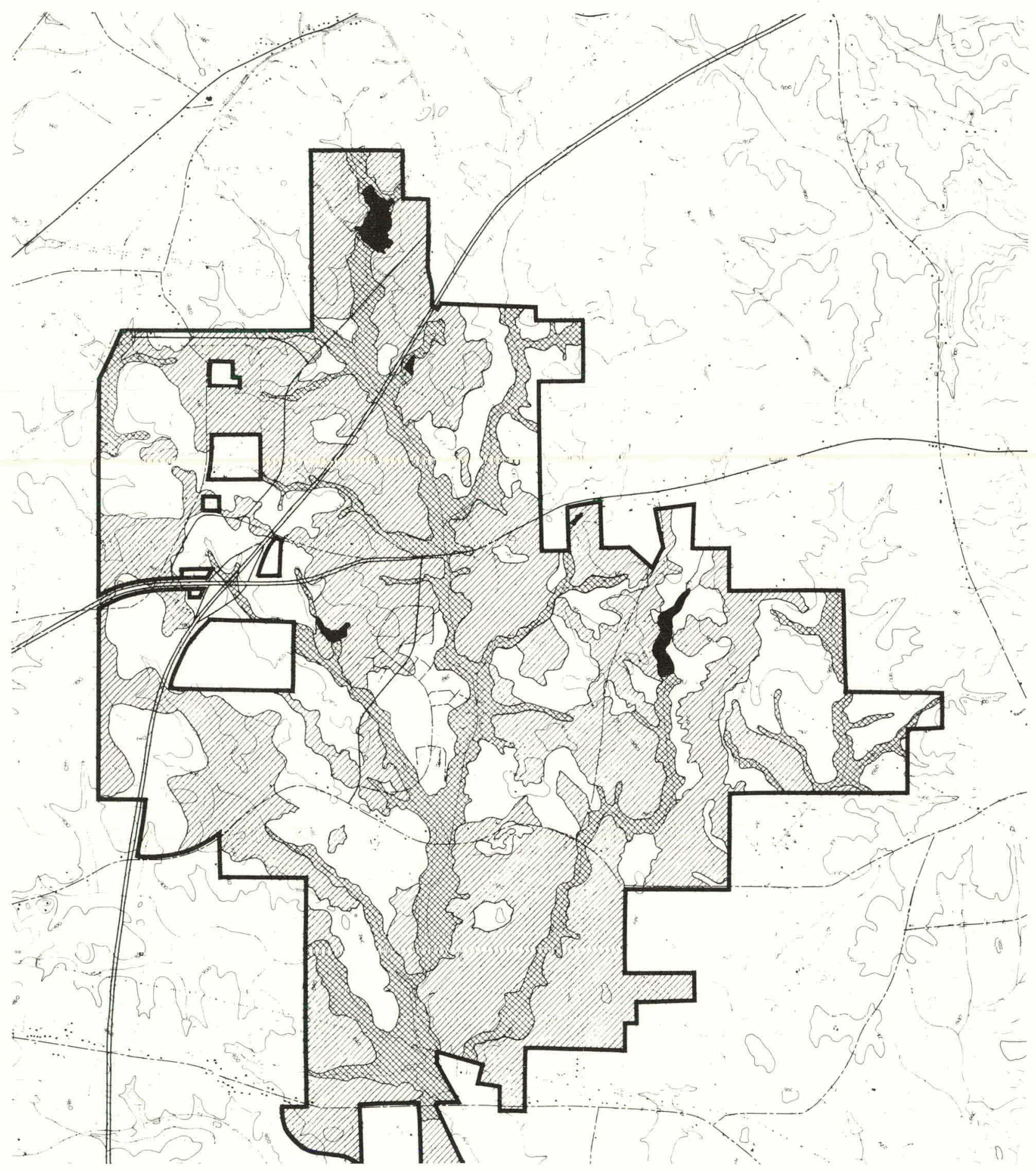

\section{Soils}

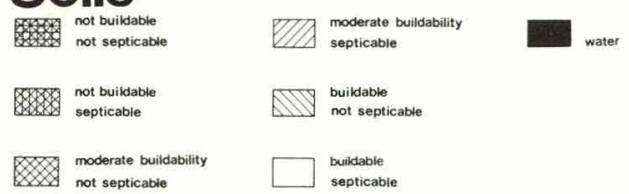

Atlanta, Ga.

HGSD Departments of Architecture and Landscape Architecture Solar Energy - Community Design Studio

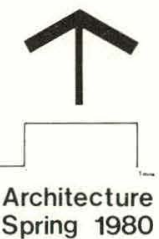

Fig. $4 \cdot 0.13$ 


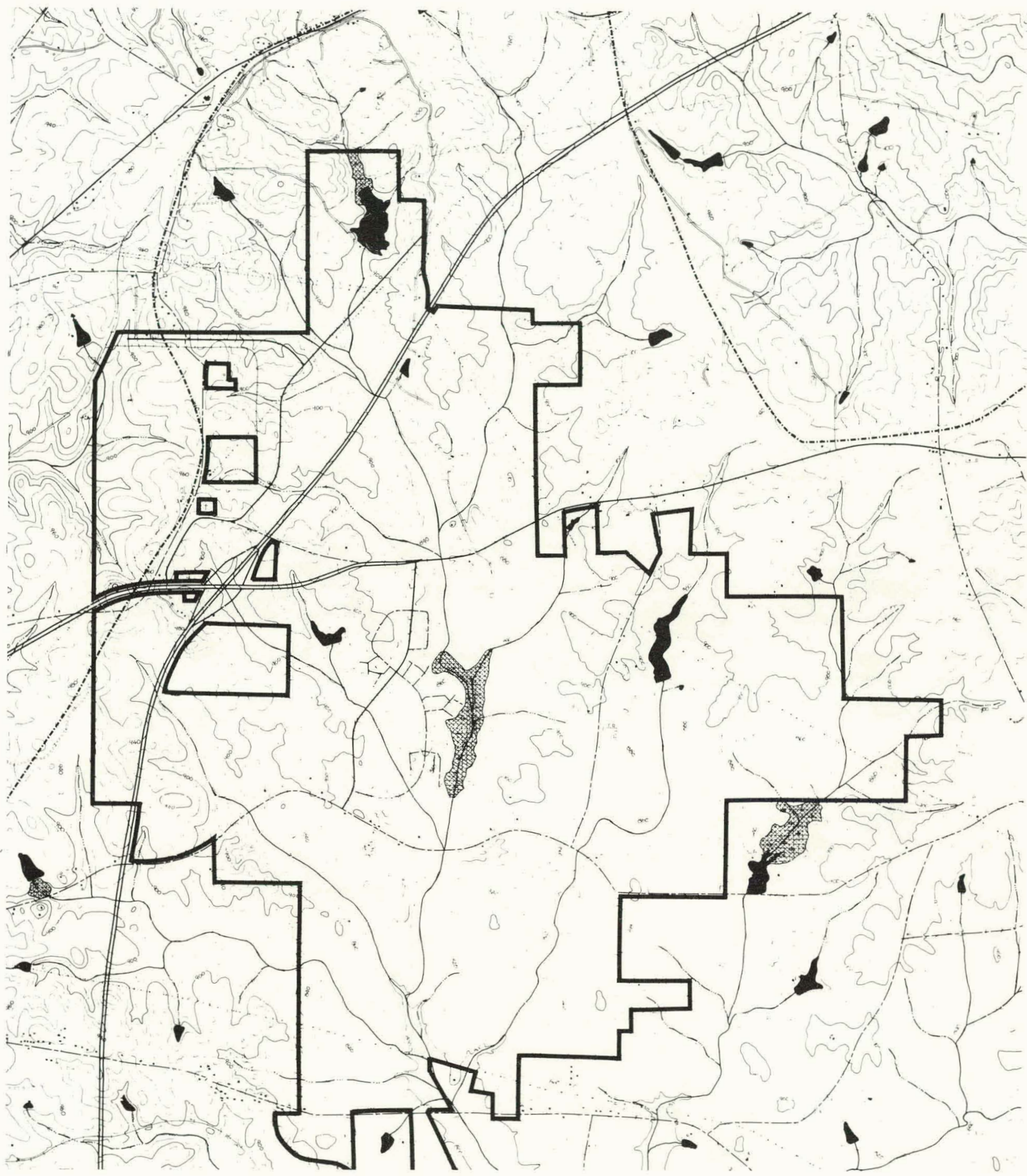

\section{Hydrology}

swamps

pirmary stream

Fig. 4.0.14
Atlanta, Ga.

HGSD Departments of Architecture and Landscape Architecture Solar Energy Community Design Studio

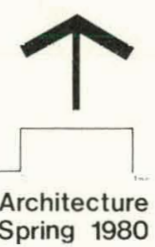




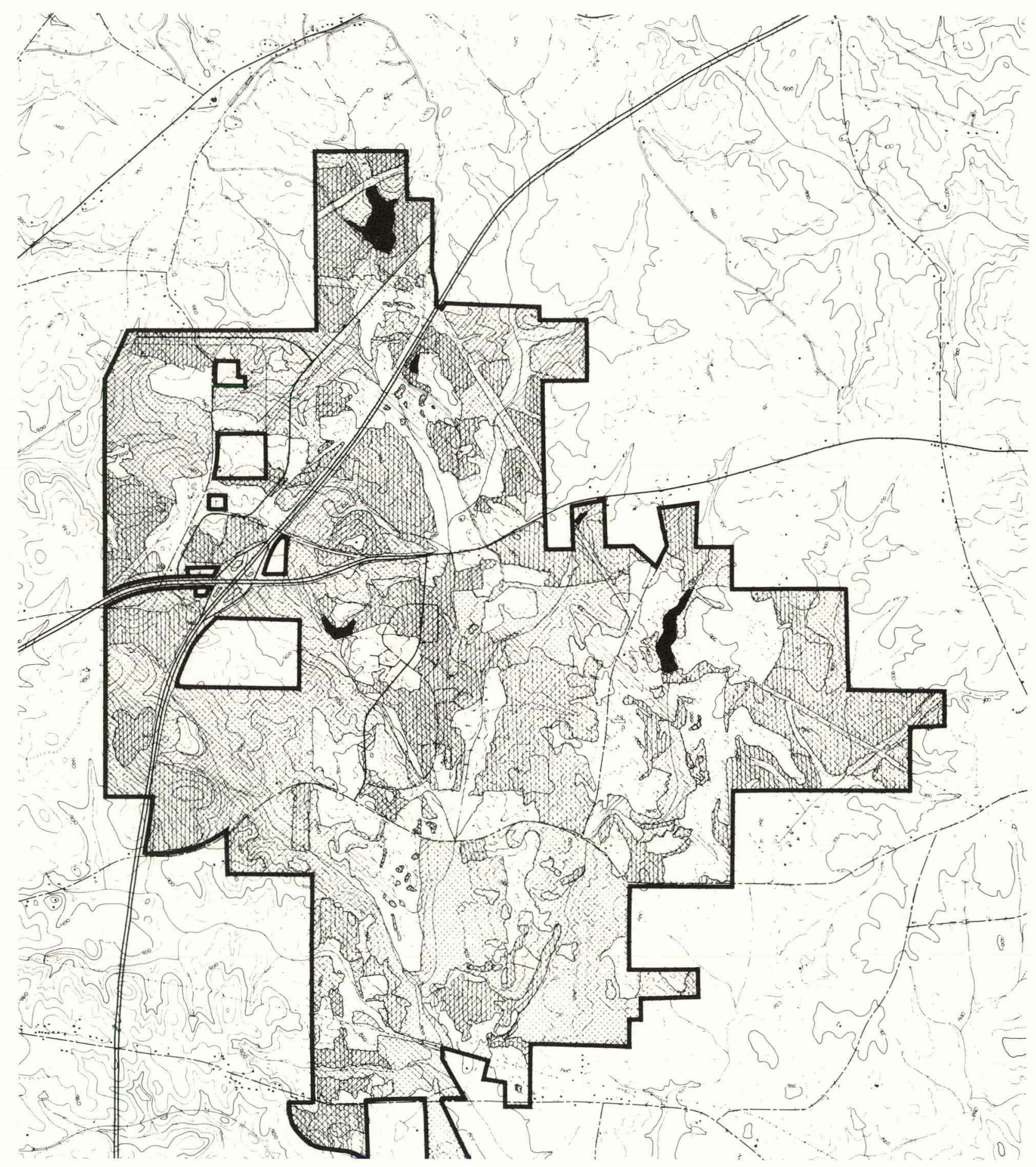

\section{Vegetation}

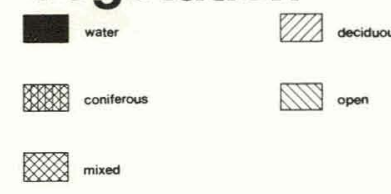

Atlanta, Ga.

HGSD Departments of Architecture

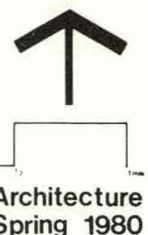

Fig. 4.0.15 


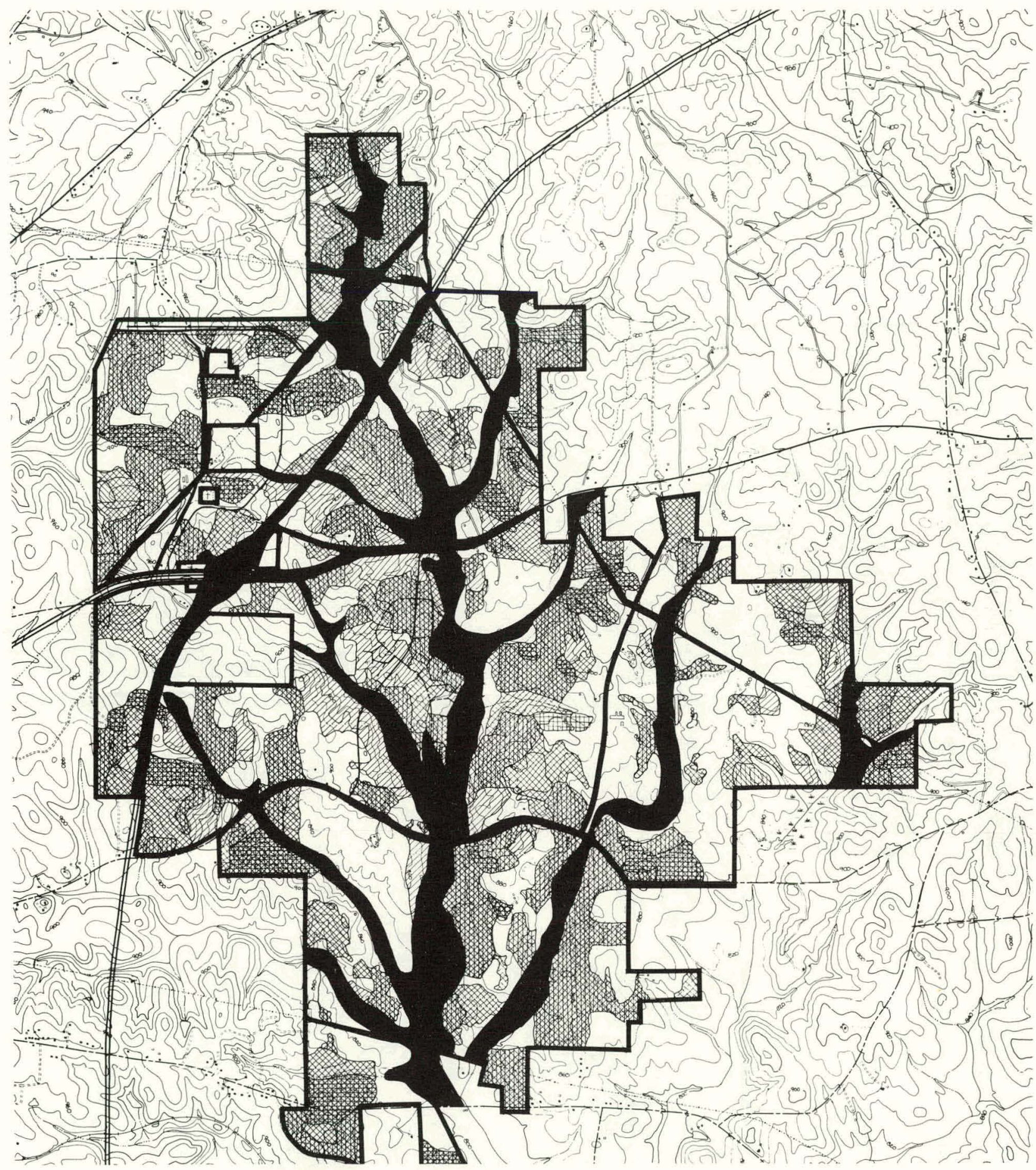

\section{Solar Opportunities}

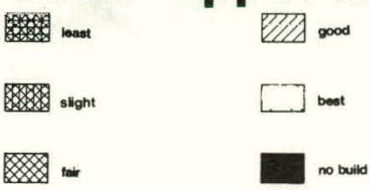

Fig. 4.0 .16

\section{Atlanta, Ga.}

HGSD Departments of Architecture and Landscape Architecture Solar Energy · Community Design Studin

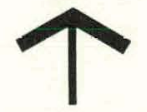

Spring 1980 


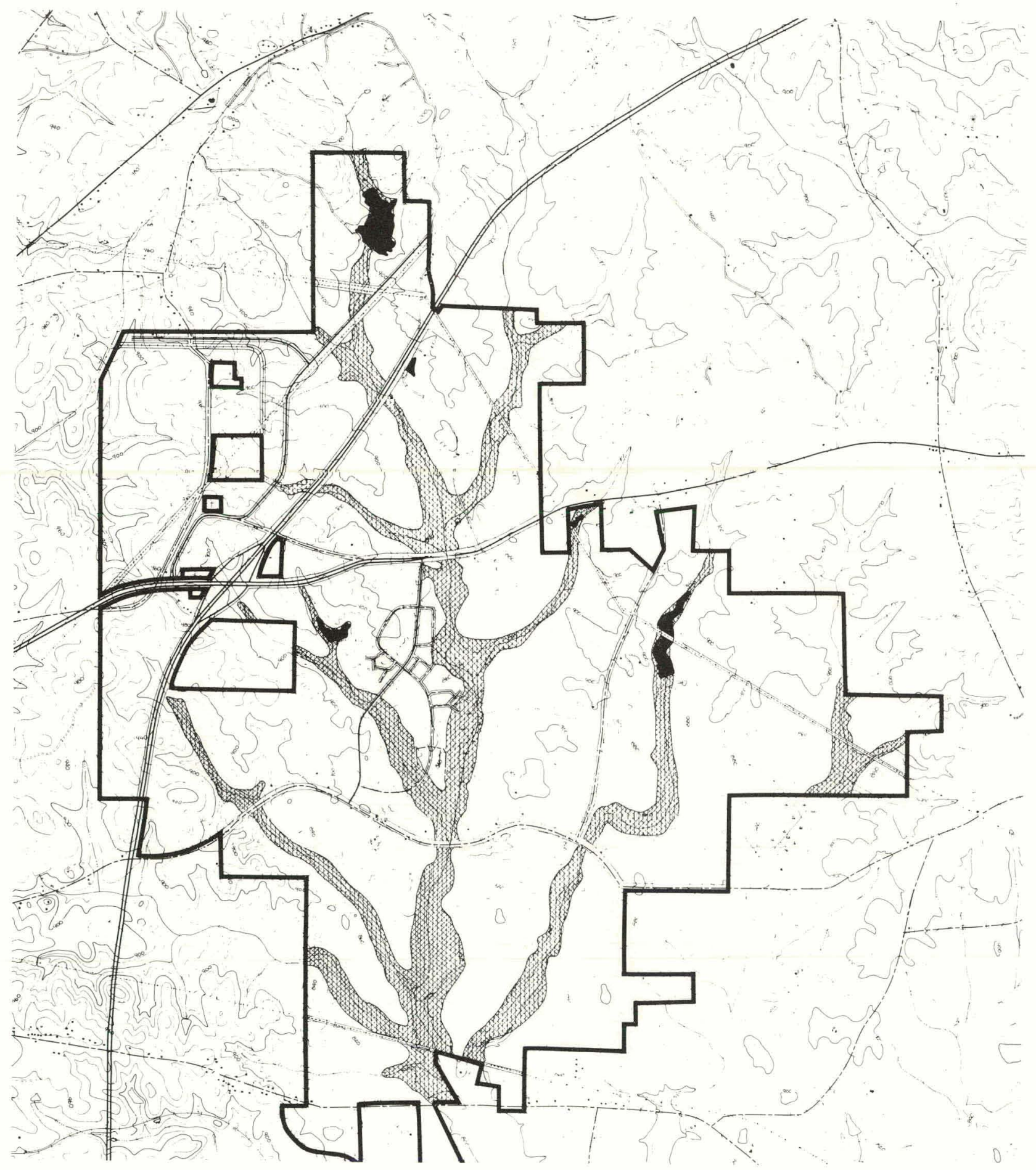

\section{Legal Constraints}
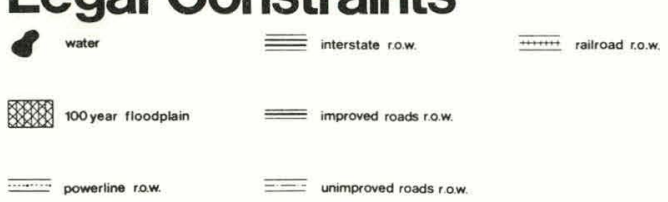

Fig. 4.0.17 


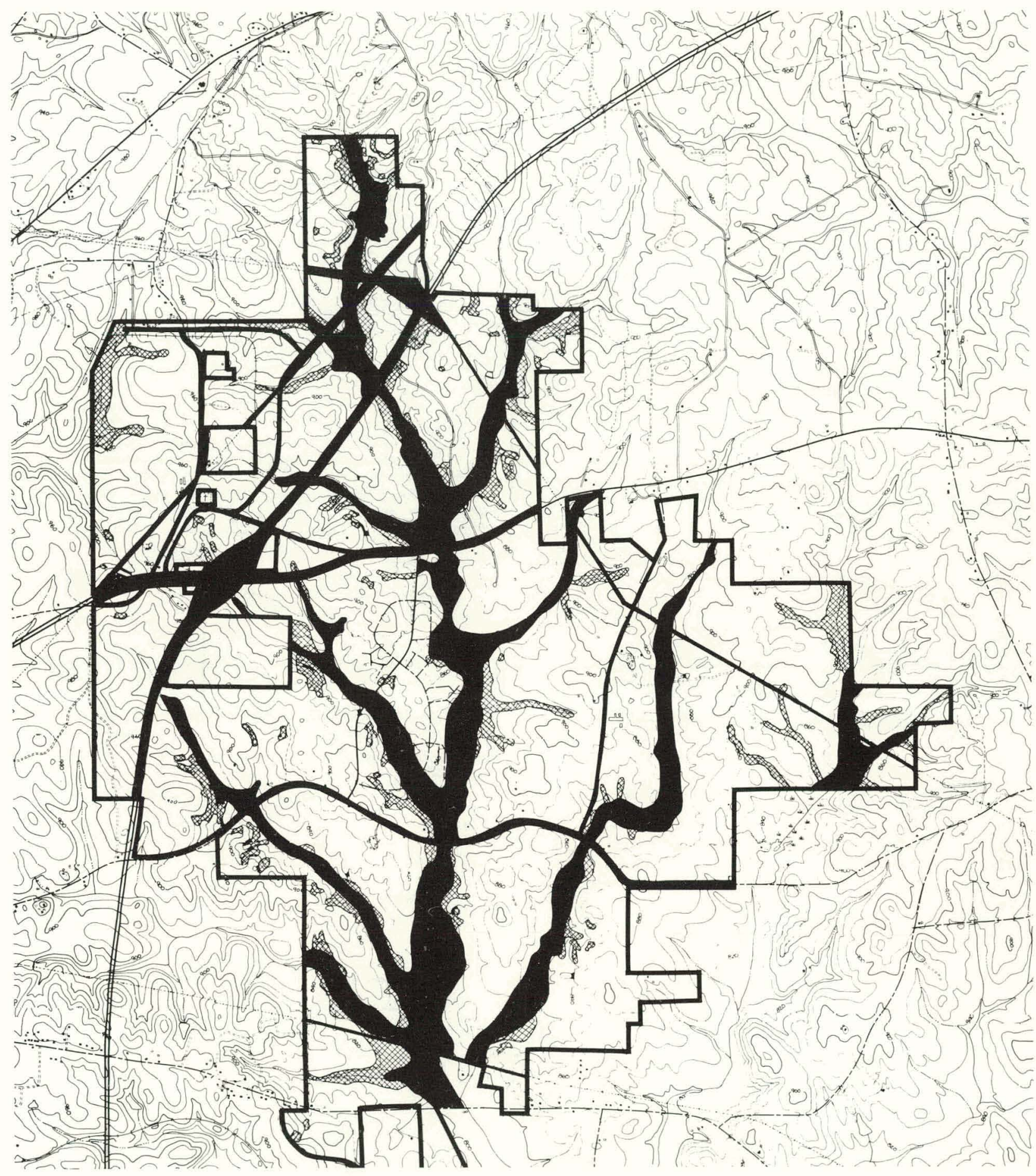

\section{Development Constraints}

- nat watsons

modorato
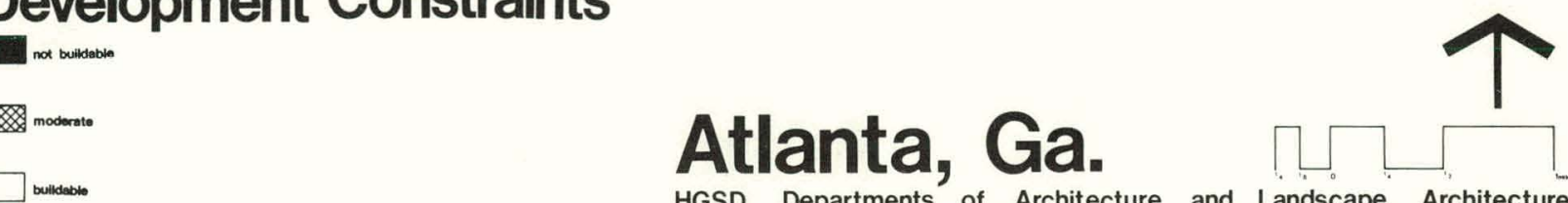

Fig. $4 \cdot 0.18$ 


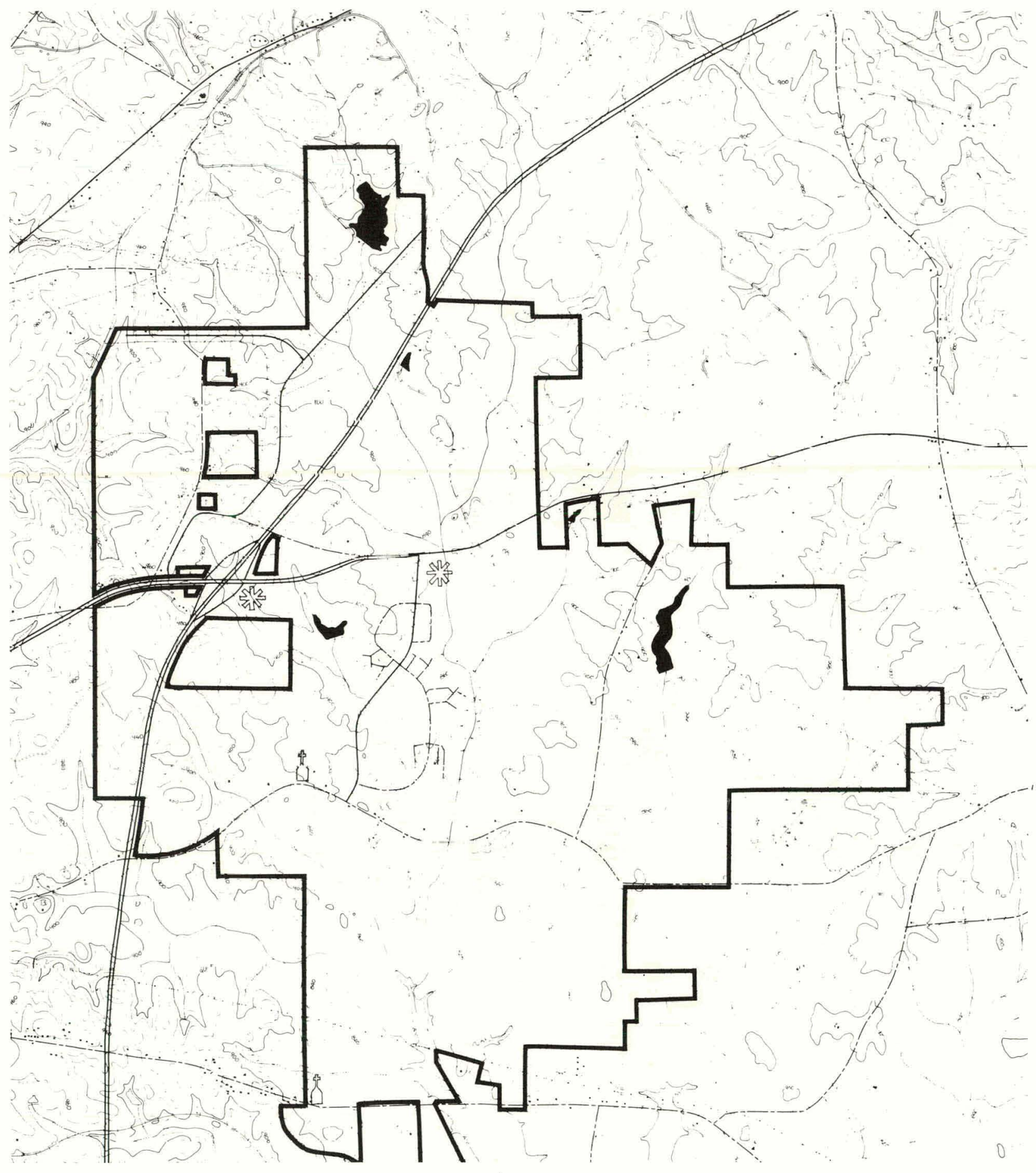

Site Amenities

sus site teature

$\triangle$ chuch

Fig. 4.0.19
Atlanta, Ga.

HGSD Departments of Architecture and Landscape Solar Energy C Community Design Studio

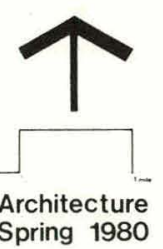

Architecture
Spring 1980 


\subsubsection{DESIGN STRATEGY}

Atlanta 1 chose to concentrate on the site topography, existing access roads and built community as primary design determinants. A decentralised community plan is located around a man-made lake on the eastern side of the site. Most of the community's electricity is supplied by parabolic dish collectors. About half of heating and cooling demands are met by passive thermal means on a buildingby-building basis. A further $20 \%$ is met from the thermal by-product of the electricity cycle and the remaining $30 \%$ is provided by electrically operated heat pumps.

Community Plan Description (Figs. 4.1.1.1, 4.1.1.2, 4.1.1.3)

The Atlanta I design increases the visual, recreational, and marketable potential of the flood plain area by damming White Creek to create a large lake. Serving as an organizing and identifying element for the new community, the lake offers a visual focus for housing and commercial development. It also provides a regional open space and recreation amenicy. The most dense residential development is situated along the lake edge, with clusters and single-family units progressing up the slope away from the lake as their densities decrease. Fields of parabolic dish collectors parallel the edge of the outermost, least-dense, single-family developments and maintain an identifiable boundary to the community.

Housing is grouped into neighborhoods, each with a range of housing densities, separated and delineated by open space. Serving as recreation space and pedestrian corridors, these open areas link the residential neighborhoods with the commercial center and various public places, connecting the outermost development with the lake edge. In addition, the open areas increase the cooling function of the water body by collecting and channeling the summer breezes into the built areas. A traditional rectilinear grid, modified by 
the site's topography, has been used in the design of the major collector roads and the minor residential streets. The existing Shenandoah Boulevard and its accompanying development is incorporated into the design. The extension and realignment of the boulevard should accomodate new development along the lake's western edge. A new major collector, paralleling Shenandoah Boulevard, provides access to the residential areas and commercial center along the eastern shore of the lake. The northernmost floodplain zone, bounded by Shenandoah Boulevard and Route 34, has been developed into a golf course. This will supplement the existing Shenandoah Recreation Center and provide a marketable focus for new development. Industry is sited along Interstate 85 , south of the Route 34 interchange.

Phasing (Fig. 4.1.1.3)

The first phase of the scheme includes the construction of the lake, the reconstruction of Lower Fayetteville Road which bridges the lake at its midsection, the realignment of the southernmost portion of Shenandoah Boulevard and its extension south of Lower Fayetteville Road and, finally, the construction of the parallel north-south artery, east of the lake. Following these projects is the construction of the north-east quadrant as described by the site plan. This includes the Marina, the Town Center, the parabolic dish collection fields, the various densities of residential buildings (highest density being given precedence), and a golf course situated in the floodplain area near the existing recreation center. This latter amenity would serve as a significant landscape feature for those entering the community from Route 34. Incorporated in this first phase are the residential roads and buildings which complement the exisiting Shenandoah Community and complete the north-west quadrant of the scheme. An elementary school, as already sited within the existing neighborhood, would serve the growing community. Two additional elementary schools, in the north-east and south-east quadrants, follow in later phases as warranted by the population. 
The second phase of the scheme consists essentially of the south-east quadrant, including a range of housing densities, the associated "energy fields" of parabolic dish collectors, and the junior/senior high school complex. The south-west quadrant is completed in a third phase. At this stage of development, it is speculated that the community or county could finance a second marina at the southernmost and deepest portion of the lake as well as a major park in the predominantly floodplain area bordering the lake in this region.

\subsubsection{ENERGY STRATEGY (Figs. 4.1.2.4, 4.1.2.5)}

Energy demand calculations for the community design were based on current (March, 1980) BEPS guidelines. It is believed that these guidelines represent a realistic baseline for energy consumption calculations.

\section{Assumptions}

The team's major assumption is that advances in technology and changes in lifestyle will result in a continuing decrease in energy demands.

Microclimatic impacts are recognized to provide for maximum thermal gain in the winter, with breezes captured in the summer for their cooling effect.

Total energy supplied from centralized facilities to dwelling units is roughly apportioned according to building density. The higher densities receive a larger component of their heating and cooling requirements in addition to a standardized amount of electircal energy.

\section{Electrical Generation Strategy}

Electrical energy for the community is provided by a series of parabolic dish collector fields. The collectors have a hot-0il, heat-transfer medium circulated through their foci. The medium passes through a heat exchanger, producing steam and driving a series of steam turbine generators. In order to produce most of the average annual daily load, it is calculated that about 120 acres of concentrating collectors are required. Storage capacity (hot $0 i 1$ ) is sized to provide six hours of an average daily load requirement. 
The central power plant is also equipped with wood-burning boilers to augment the highly variable solar power production which is expected in this area. This arrangement capitalizes on locally abundant wood resources. An average of 20-30 tons of wood mill refuse is burned on a daily basis.

It is assumed that the community can meet its entire base-load electrical needs, and that provision for emergency standby capacity and mutually advantageous power exchange can be negotiated with the local utility company.

\section{Thermal Generation Strategy}

A by-product available from the energy electrical production system is medium temperature hot water $\left(200^{\circ}-250^{\circ} \mathrm{F}\right.$.). It is calculated that this will provide enough thermal energy to meet $20 \%$ of the total community cooling requirement and (easily) 20\% of its total heating requirement. This component of the total energy supply is directed to commercial, institutional, and high-density development, which are least likely to meet their full thermal requirements by passive technologies. Hot water from the power plant is pumped to the high-density areas to provide direct heating and hot water supply. During the cooling season large hot-water absorption chillers are used to supplement passive cooling techniques.

Low-density areas have their hot-water requirement met by flat-plate collectors on a building-by-building basis. They are more self-reliant for heating and cooling needs. Residents of medium-density development might cooperatively own electric heat pumps or hot-water absorption chillers associated with site-specific evacuated tube thermal collectors. Single-family, detached houses are essentially self-sufficient for heating and cooling needs. 
THIS PAGE

\section{WAS INTENTIONALLY LEFT BLANK}




\section{ATLANTA 1}

ASSUMPTIONS AND EXPLANATIONS

1. $80 \%$ of heating and cooling demands to be met by site-specific active and passive solar systems ( $50 \%$ passive).

2. Electric compression systems might add $10 \mathrm{MWh}(\mathrm{e}) /$ Day.

TYPE OF BUILDING OR

DEMAND

\begin{tabular}{|l|c|l|}
\hline \multicolumn{2}{|l|}{ UNITS/AREA } & ELECTRICAL \\
\hline QUANTITY & $\begin{array}{c}\text { AREA/UNIT } \\
\text { TOTAR AREA }\end{array}$ & Mwh/Day \\
\hline
\end{tabular}

\begin{tabular}{|l|c|c|c|}
\hline Single family housing & 470 & $2,000 \mathrm{s.f./u}$ & \\
\hline Single family housing & 630 & $1,500 \mathrm{~s} . \mathrm{f} . / \mathrm{u}$. & \\
\hline Single family housing & 150 & $1,350 \mathrm{~s} . \mathrm{f} . / \mathrm{u}$. & \\
\hline Cluster housing & 1575 & $1,350 \mathrm{~s} . \mathrm{f} . / \mathrm{u}$. & \\
\hline Cluster housing & 275 & $1,100 \mathrm{~s} . \mathrm{f} . / \mathrm{u}$. & \\
\hline Cluster housing & 550 & $900 \mathrm{~s} . \mathrm{f} . / \mathrm{u}$. & \\
\hline Apartments & 220 & $950 \mathrm{~s} . \mathrm{f} . / \mathrm{u}$. & \\
\hline Apartments & 124 & $750 \mathrm{~s} . \mathrm{f} . / \mathrm{u}$. & \\
\hline Apartments & 45 & $600 \mathrm{~s} . \mathrm{f} . / \mathrm{u}$. & \\
\hline Apartments & 53 & $400 \mathrm{~s} . \mathrm{f} . / \mathrm{u}$. & (tot.res. $) 50$ \\
\hline Schools & & & \\
\hline Central retail & & & (tot.ctr.).15 \\
\hline & & & \\
\hline & & & \\
\hline
\end{tabular}

\section{total community energy demand}




\begin{tabular}{|l|l|l|l|l|l|}
\hline \multicolumn{2}{|l|}{ HEATING LOAD } & \multicolumn{2}{l|}{ COOLING LOAD } & \multicolumn{2}{l|}{ DOMESTIC HOT WATER } \\
\hline $10^{6}$ Btu/Day & Mwh(Th)/Day & $10^{6}$ Btu /Day & Mwh (Th)/Day & $10^{6}$ Btu /Day & Mwh (Th)/Day \\
\hline
\end{tabular}

\begin{tabular}{|c|c|c|c|c|c|}
\hline & & 220.90 & 64.70 & 25.26 & 7.40 \\
\hline & & 220.50 & 64.60 & 33.87 & 9.92 \\
\hline & & 48.00 & 14.06 & 8.06 & 2.36 \\
\hline \multirow[t]{7}{*}{ tot.res.)296 } & (tot.res) 87 & 393.75 & 115.32 & 59.27 & 17.36 \\
\hline & & 60.30 & 17.66 & 10.35 & 3.03 \\
\hline & & 99.00 & 29.00 & 20.60 & 6.03 \\
\hline & & 39.60 & 11.60 & 5.90 & 1.73 \\
\hline & & 16.12 & 4.72 & 3.33 & 0.98 \\
\hline & & 4.95 & 1.45 & $1.27 !$ & 0.35 \\
\hline & & 4.24 & 1.24 & 1.42 & 0.42 \\
\hline \multirow[t]{9}{*}{ tot.ctr.)23. } & (tot.ctr.) 7 & 5.29 & 1.55 & 3.99 & 1.02 \\
\hline & & 18.77 & 5.5 & 8.60 & 2.52 \\
\hline & & & & & \\
\hline & & & & & \\
\hline & & & & & \\
\hline & & & & & \\
\hline & & & & & \\
\hline & & & & & 53 \\
\hline & & & 330 & & 30 \\
\hline
\end{tabular}


ATLANTA 1

supply

ASSUMPTIONS AND EXPLANATIONS

1. Excess electricity is sold to local grid.

2. Based on a projection of $200^{\circ} \mathrm{F}$ "waste-water" thermal byproduct.

\begin{tabular}{|l|l|l|l}
\hline ENERGY SOURCE & APPLICATION & CONFIGURATION & $\begin{array}{l}\text { SUPPLY } \\
\text { Mwh/Day }\end{array}$ \\
\hline
\end{tabular}

\section{STORAGE SYSTEMS}

1. Hot-oil storage

\begin{tabular}{|l|l|l|}
\hline 6 hrs. of average & storage tanks & $\sim 8 \mathrm{MWh}$ (Th) \\
\hline daily load require- & & /Day \\
\hline ment (for non-sun & & \\
\hline hours) & & \\
\hline & & \\
\hline & & \\
\hline & & \\
\hline
\end{tabular}

SUPPLY SYSTEMS

\begin{tabular}{|l|l|l|l|}
\hline 1. Parabolic dish & 1. E lectrical demand & 1. 115 acre field & $65-80$ MWh(e) \\
\hline & 2. 20\% of heating and & 2. Therilal byproduct & \\
\hline & cool ing require- & of electrical & \\
\hline & ment & generation & up to 140 \\
\hline & & & MWh(Th) \\
\hline 2. Wood burning plant & 1.Back-up and peak & $20-30$ dry tons wood & $20-30$ MWh(e) \\
\hline (integrated with & demand loads & /day & \\
\hline central generating & 2.Back-up thermal & & \\
\hline facility) & energy & & \\
\hline
\end{tabular}

\section{total community energy supply $85 \min ($ e)}




\subsubsection{SITING ISSUES \& HOUSING (Figs. $4.1 .3 .6,4.1 .3 .7,4.1 .3 .8$ )}

The construction of a north-south lake has created a number of challenging site-planning and architectural problems. Sites characterised by less favorable solar orientation (gentle north-northwest slopes) have become prime building sites due to their relationship to the lake. Similarly, in areas close to the lake, major eastern or western views should be exploited, while at the same time accommodating maximum solar access. The proposed architectural prototypes address these often conflicting site features.

High Density Housing (Fig. 4.1.3.7)

The high-density prototype (15-20 D.U./acre) is designed for flexibility in siting, density and unit-type distribution. Individual units are staggered in plan and section to provide a southern exposure. Main living spaces open predominantly to the south for solar access and the east-west for views toward the lake. East-west exposure is used less frequently and northern fenestration is minimal. The units can be built in a variety of ways to respond to changes of slope, orientation, and program. Density can be varied with two and threestory cluster configurations.

Medium Density Housing (Fig. 4.1.3.8)

Solar access is the priority issue in the prototypical unit design for mediumdensity housing. Gentle slopes toward the northwest and southwest are chosen for specific investigation. The primary element of the urit is a two-story, glazed wall oriented due south $\left( \pm 15^{\circ}\right)$. During the day, solar radiation is absorbed within a two-story, thermal-mass wal1. At night, the giazed wall is insulated against heat loss and the thermal mass re-radiates stored heat to the interior. An induced air current, with an intake point at ground level on the northeast or northwest side of the unit and with an exhaust point on the western side of the highest portion of the roof, provides a cooling effect during the summer months. Rooftop solar collectors providing domestic hot water are integrated into the building design at roof level. 
While the medium-density housing utilizes individual-unit solar collection to achieve a greater degree of self-sufficiency, the high-density housing assumes a greater reliance on the community solar collection system. As timber is plentiful locally, it is thought to be the most suitable building material. In general, construction of low-profile timber structures for residential as well as commercial buildings seemed most appropriate with respect to the landscape and traditions of the area. 


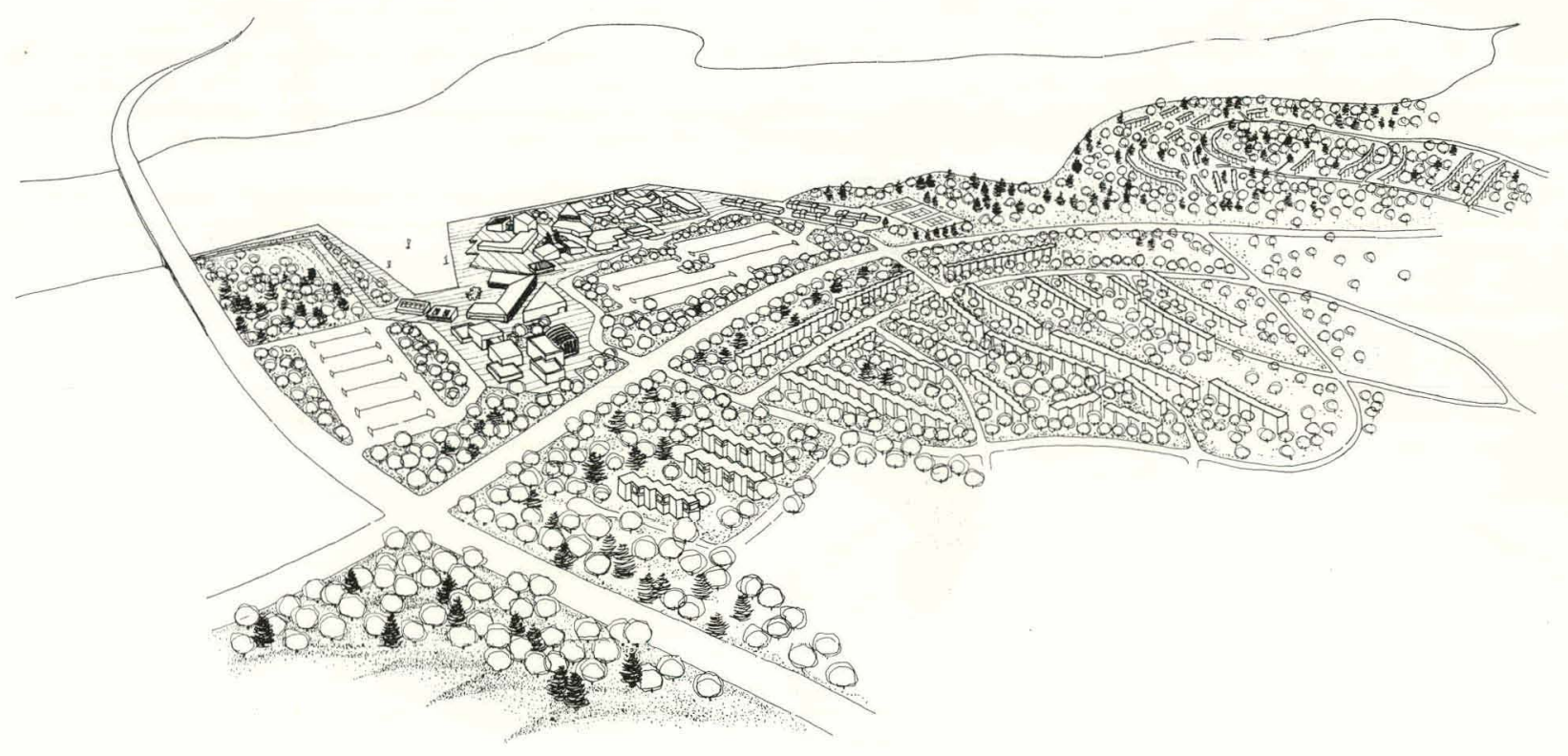

TEAM 1

Atlanta, Ga.

HGSD Departments of Architecture and Landscape Architecture Solar Energy - Community Design Studio $\quad$ Spring 1980

Fig. 4.1.1.1 


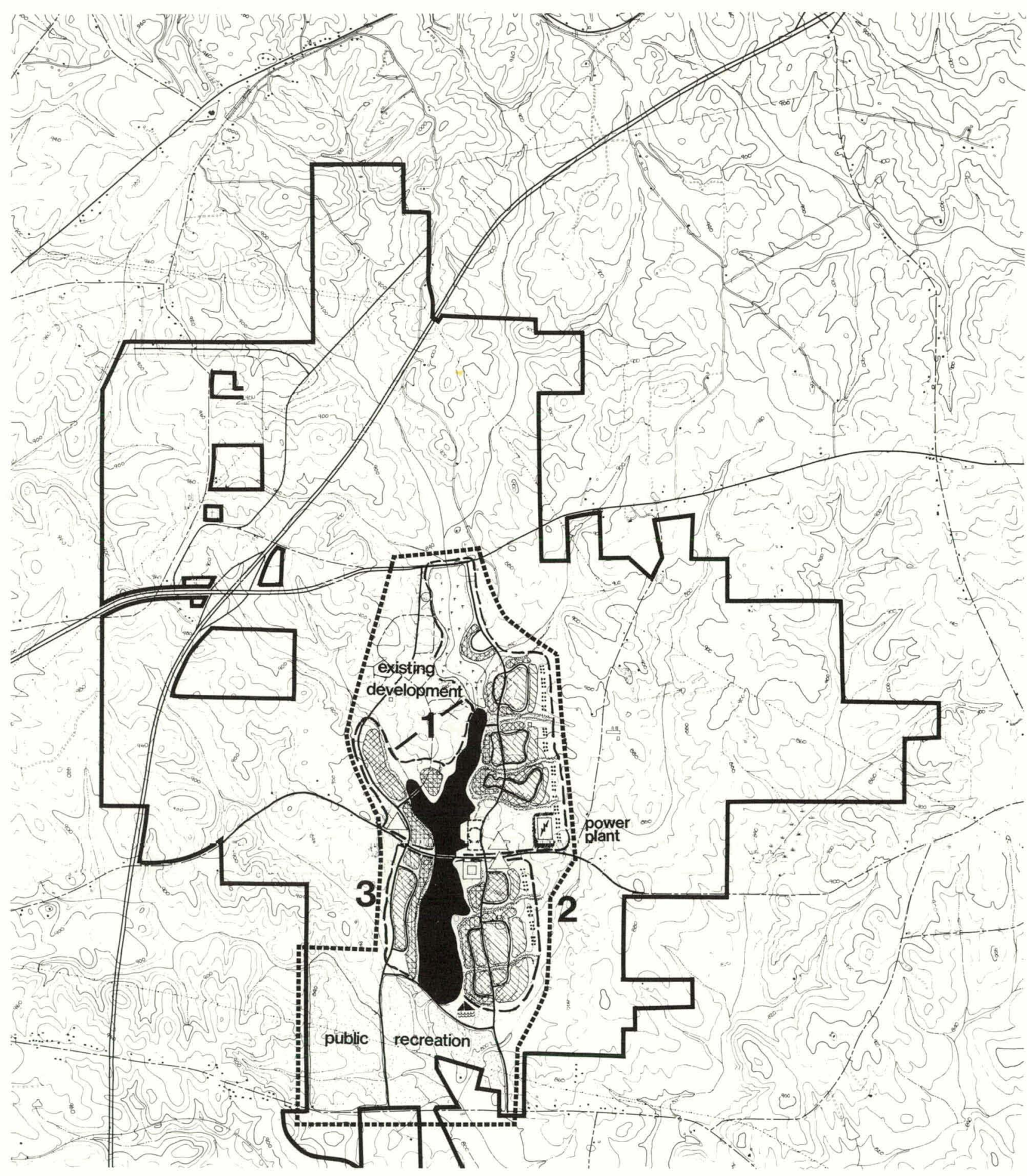

Concept / Phasing

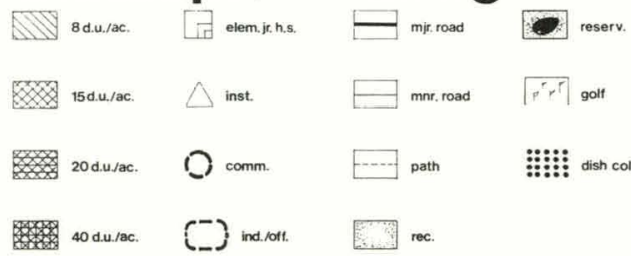

TEAM 1

Atlanta, Ga. HGSD Departments of Architecture and Landscape Architecture Solar Energy - Community Design Studio $\quad$ Spring 1980

Fig. 4.1.1.2 


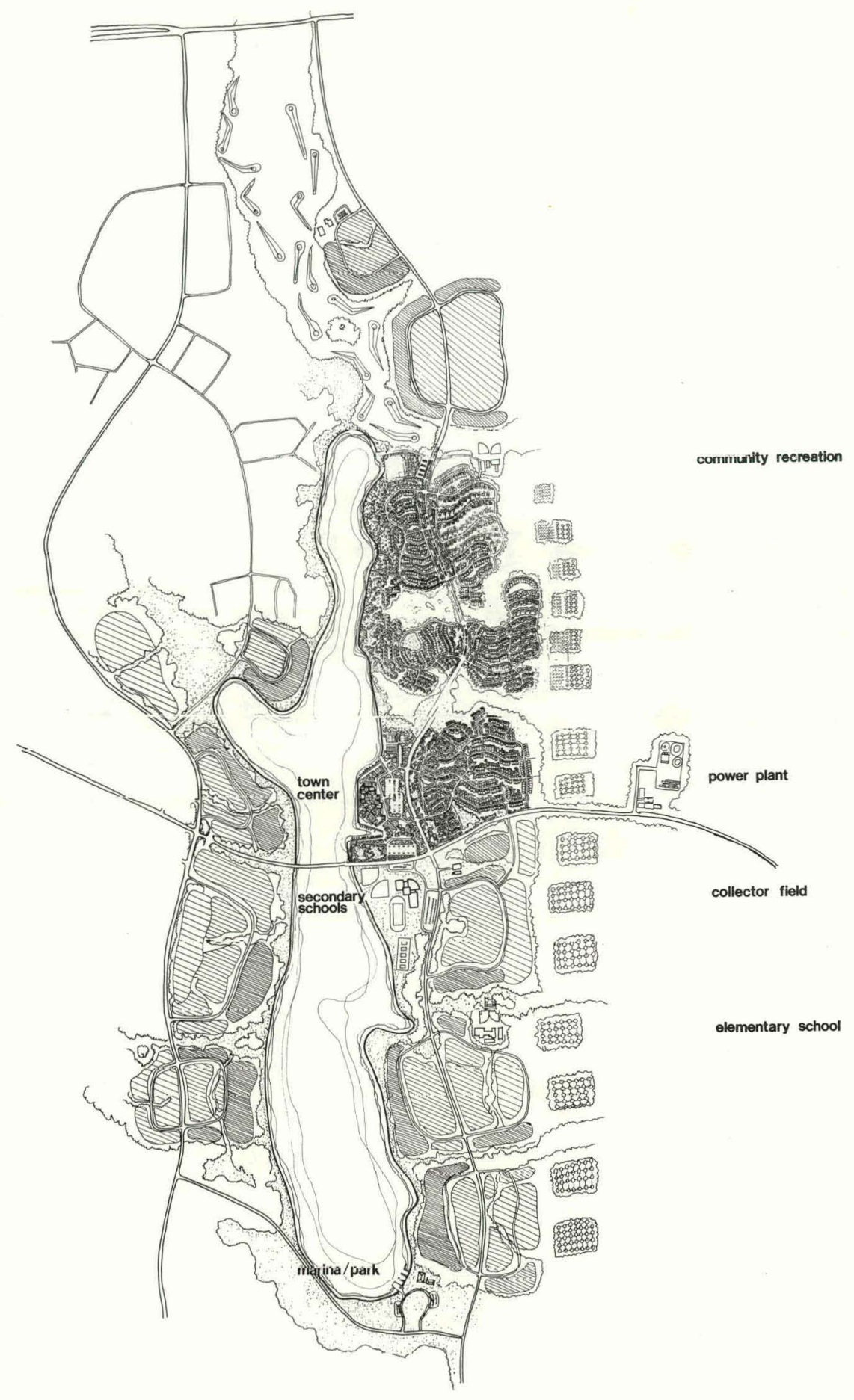

Site Plan

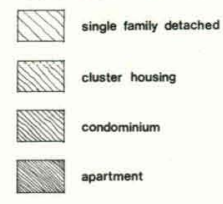

Fig. 4.1.1.3
TEAM 1

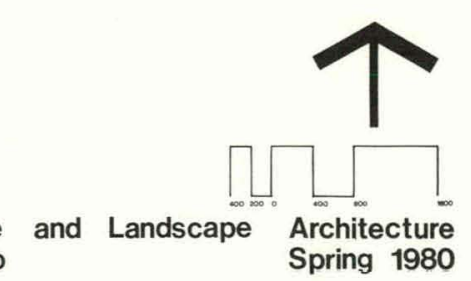




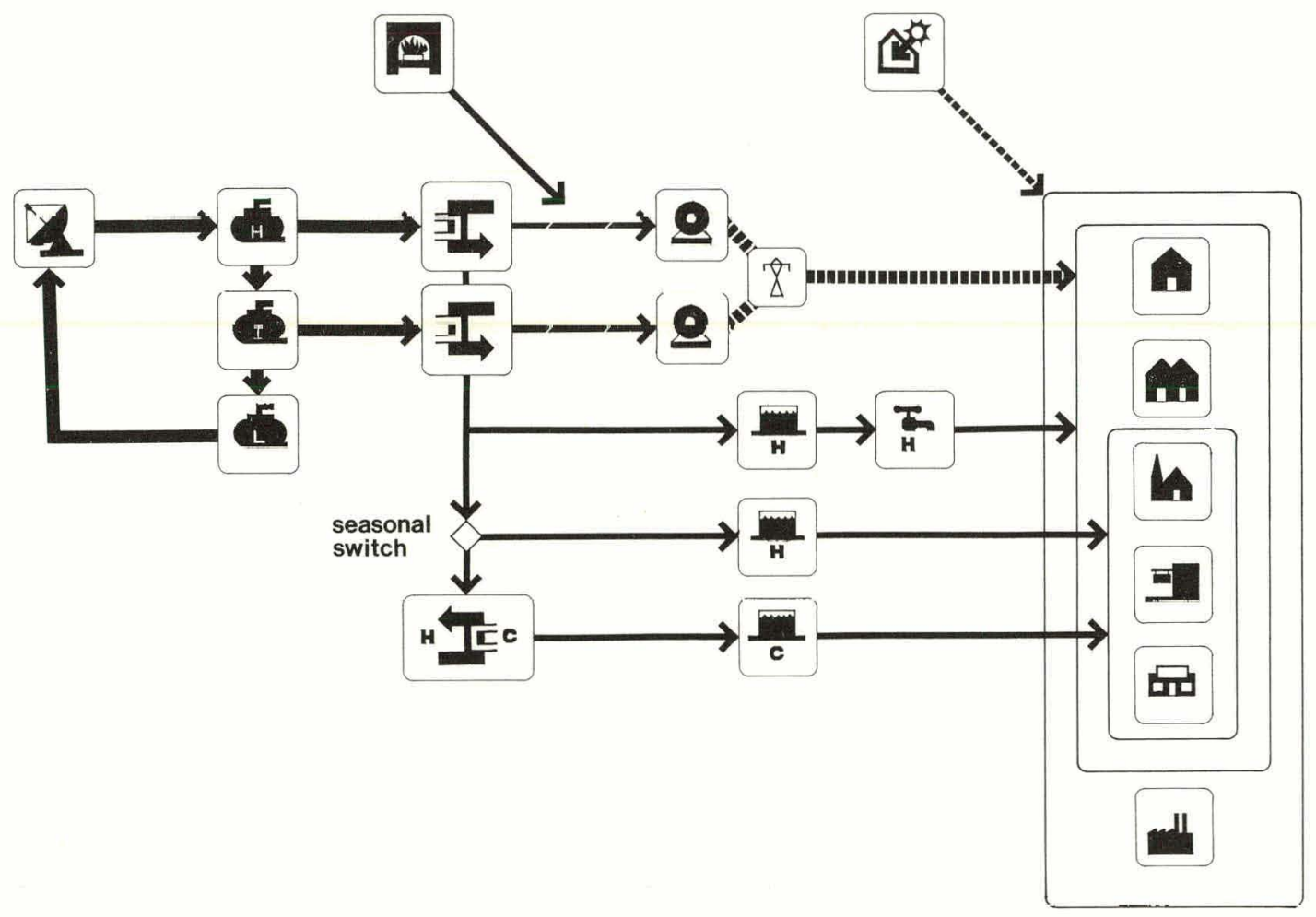

Energy Diagram

TEAM 1

Atlanta, Ga.

HGSD Departments of Architecture
Solar Energy Community Design Studio
Architecture Spring 1980

Fig. 4.1.2.4 


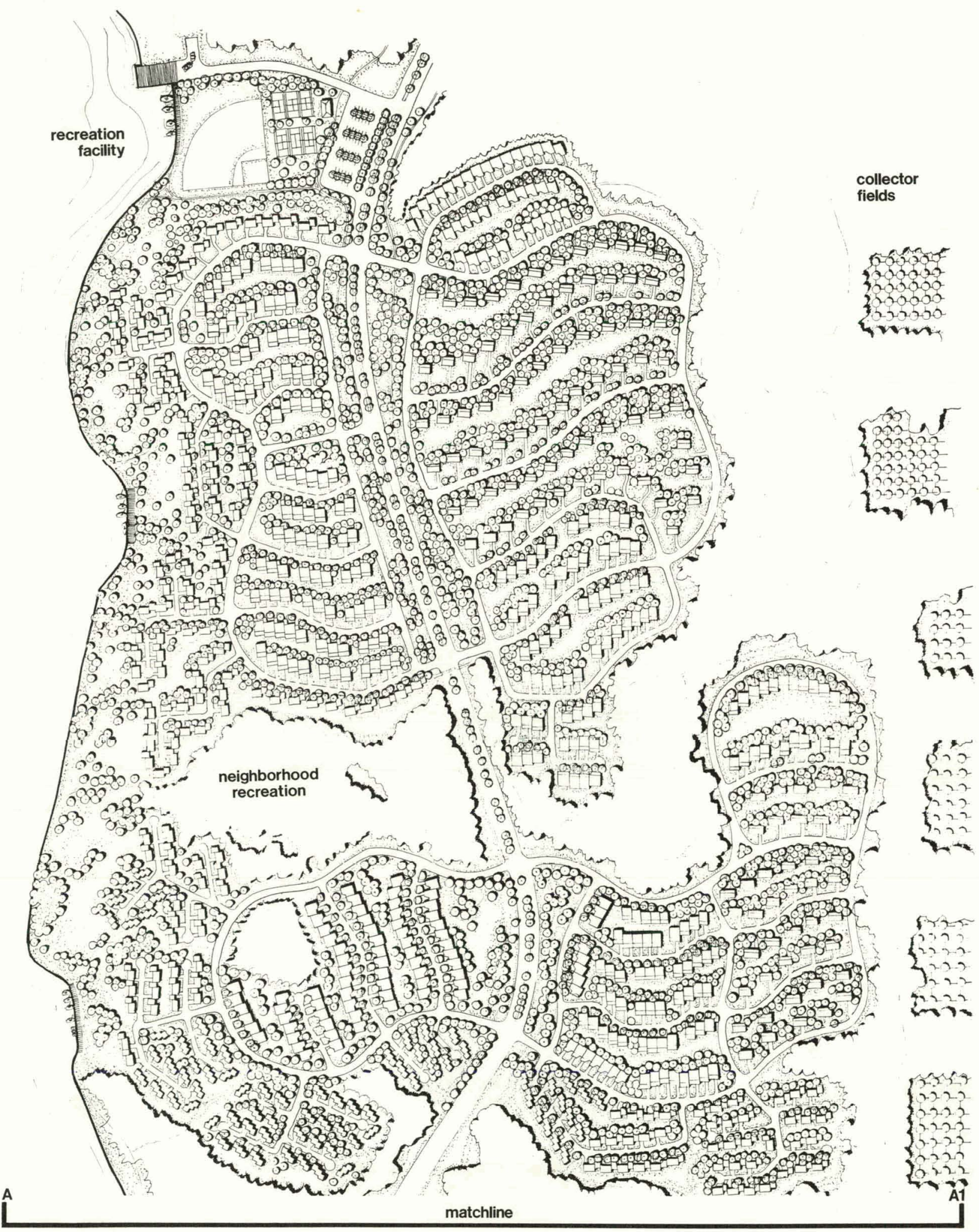




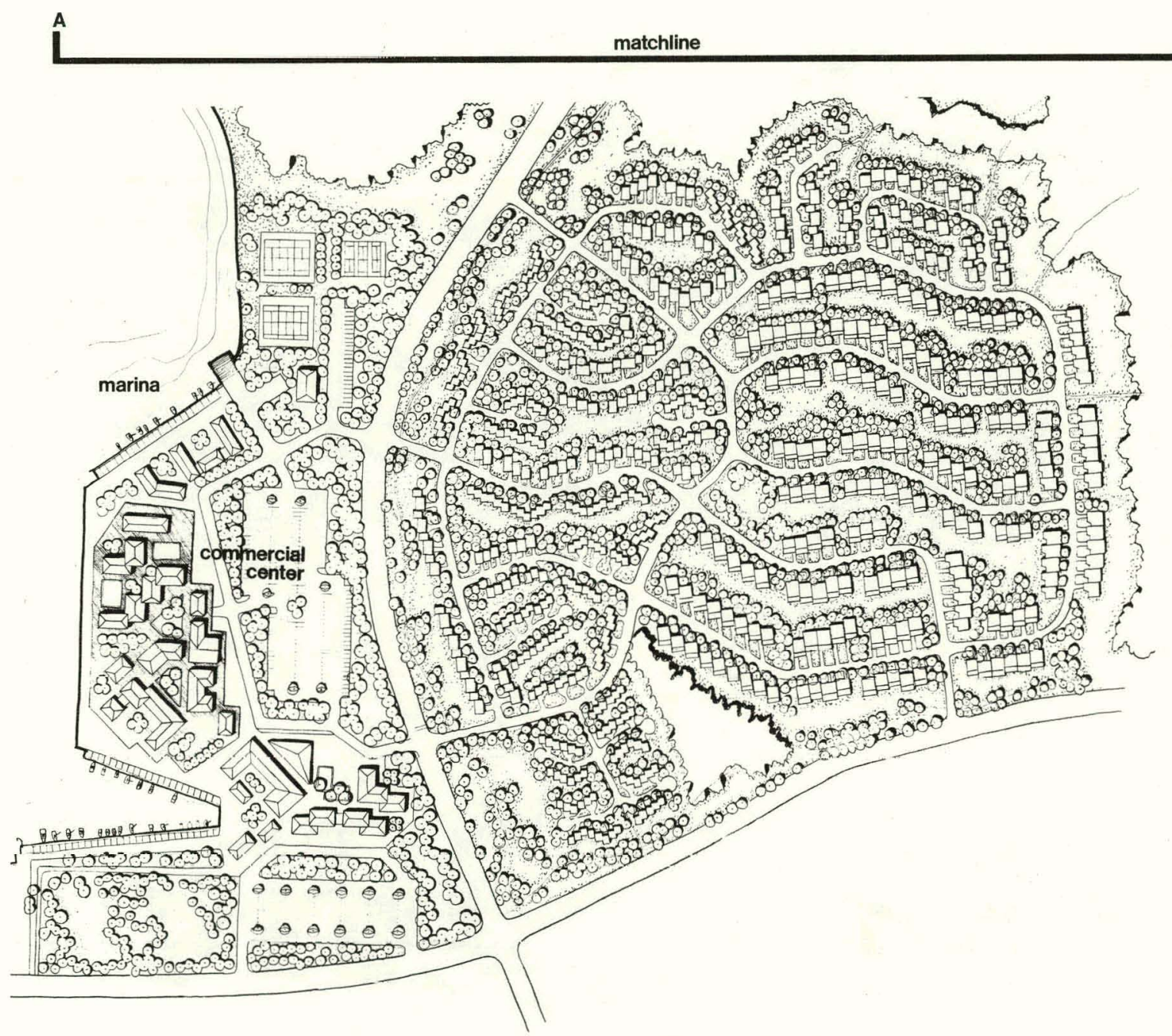

Site Plan

TEAM 1

Atlanta, Ga.

HGSD Departments of Architecture and Landscape Architecture Solar Energy · Community Design Studio Spring 1980

Fig. 4.1.3.6 

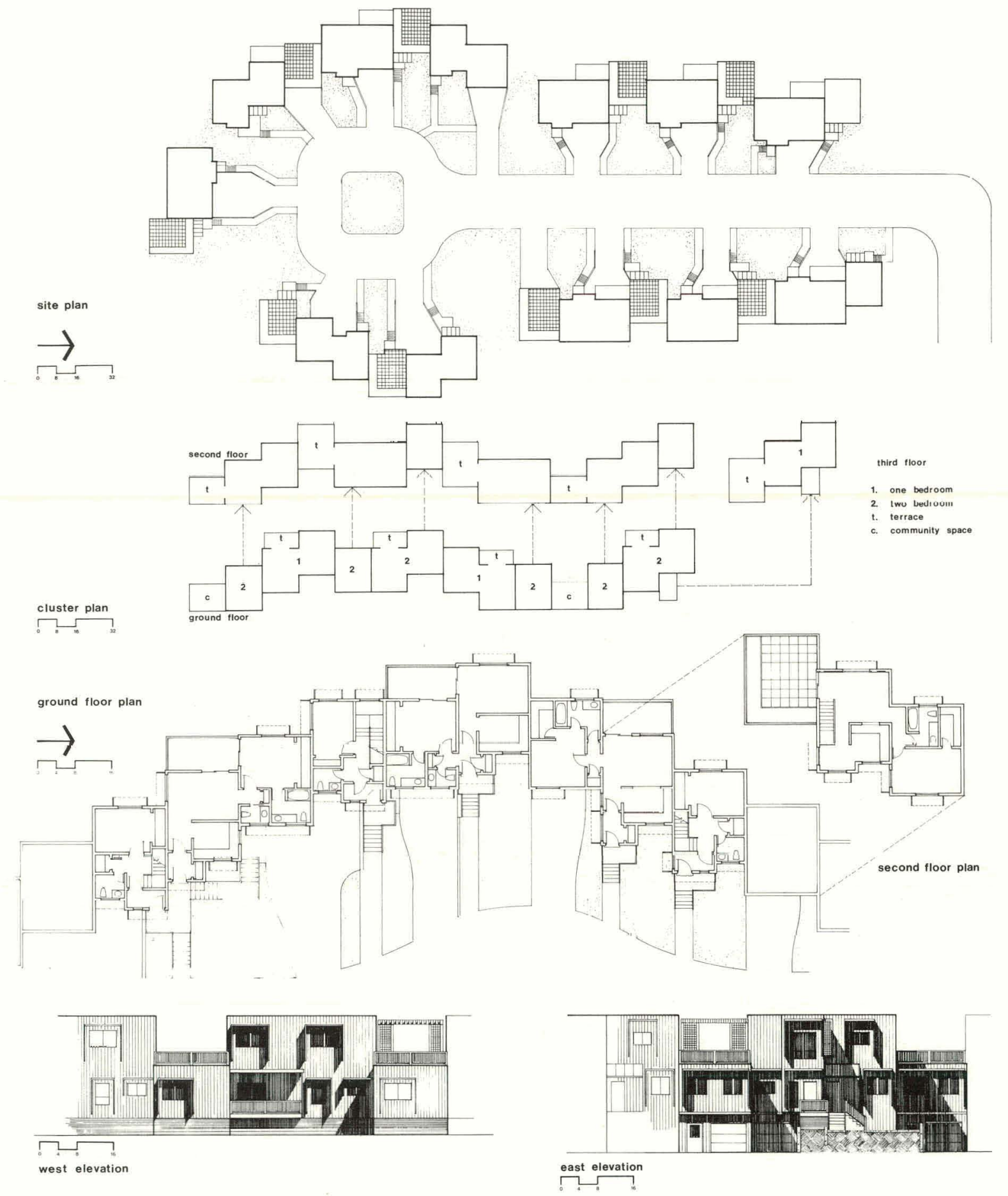

Housing

15 - 20 d. u. / acre

Fig. 4.1.3.7
TEAM 1

TEAM 1

Atlanta, Ga.

HGSD Departments of Architecture and Landscape Architecture Solar Energy · Community Design Studio

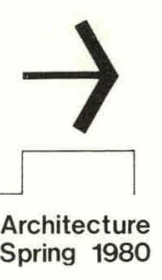



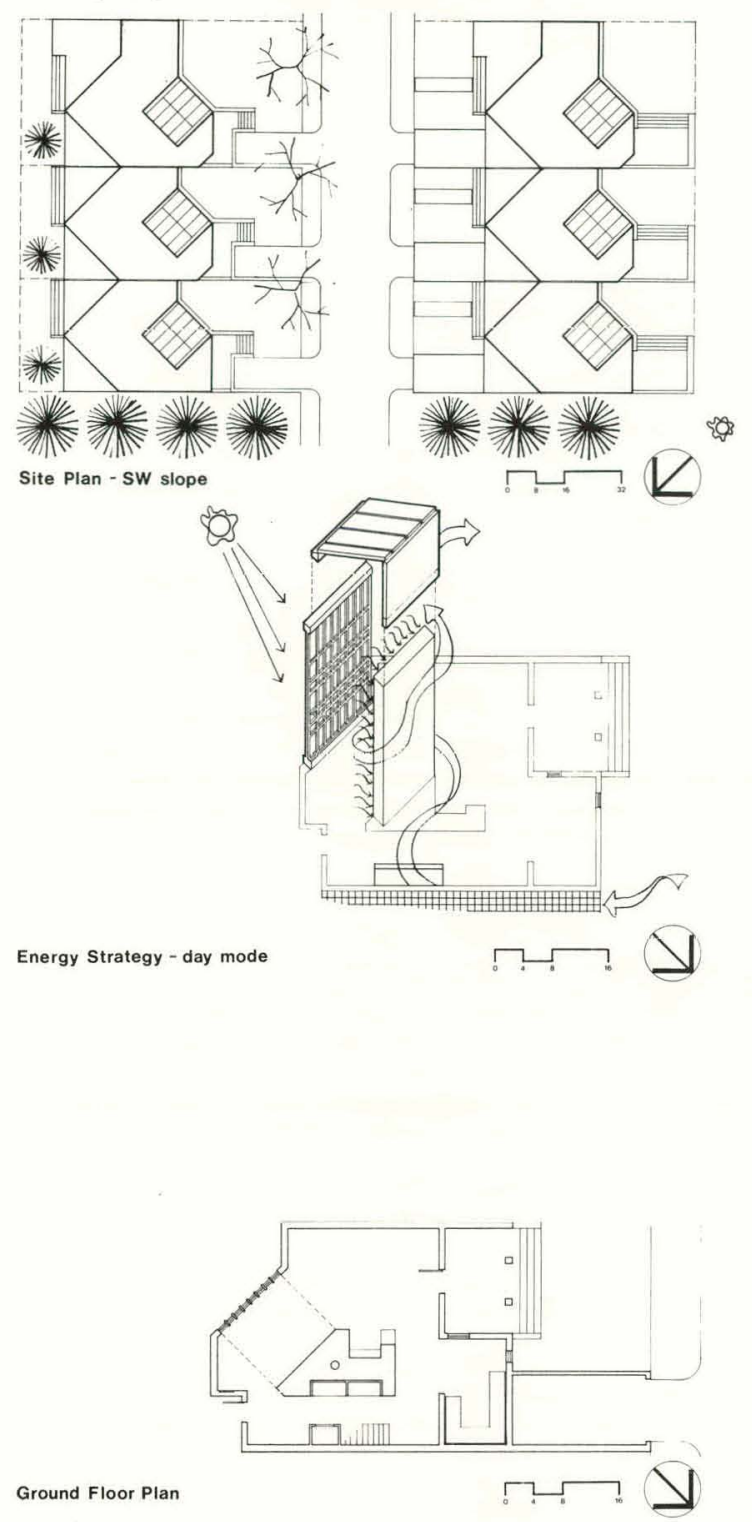

NW Elevations

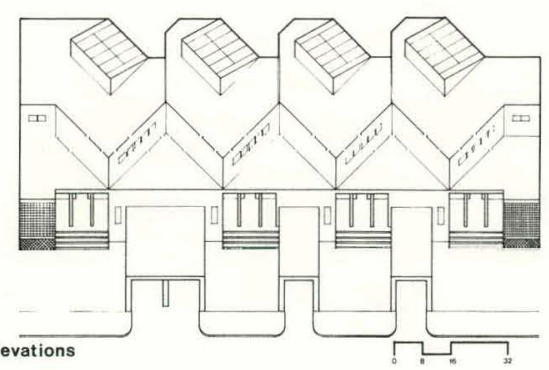

\section{Housing}

8 - 15 d.u. / acre

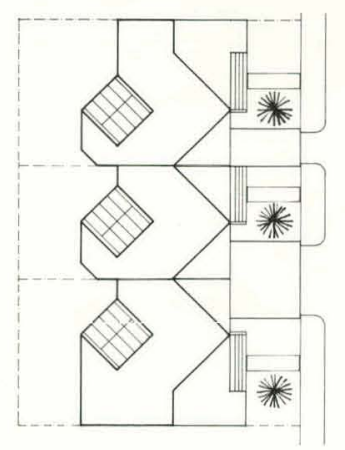

Site Plan - NW slope

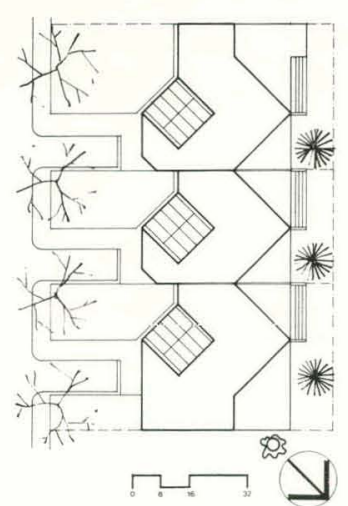

(5)
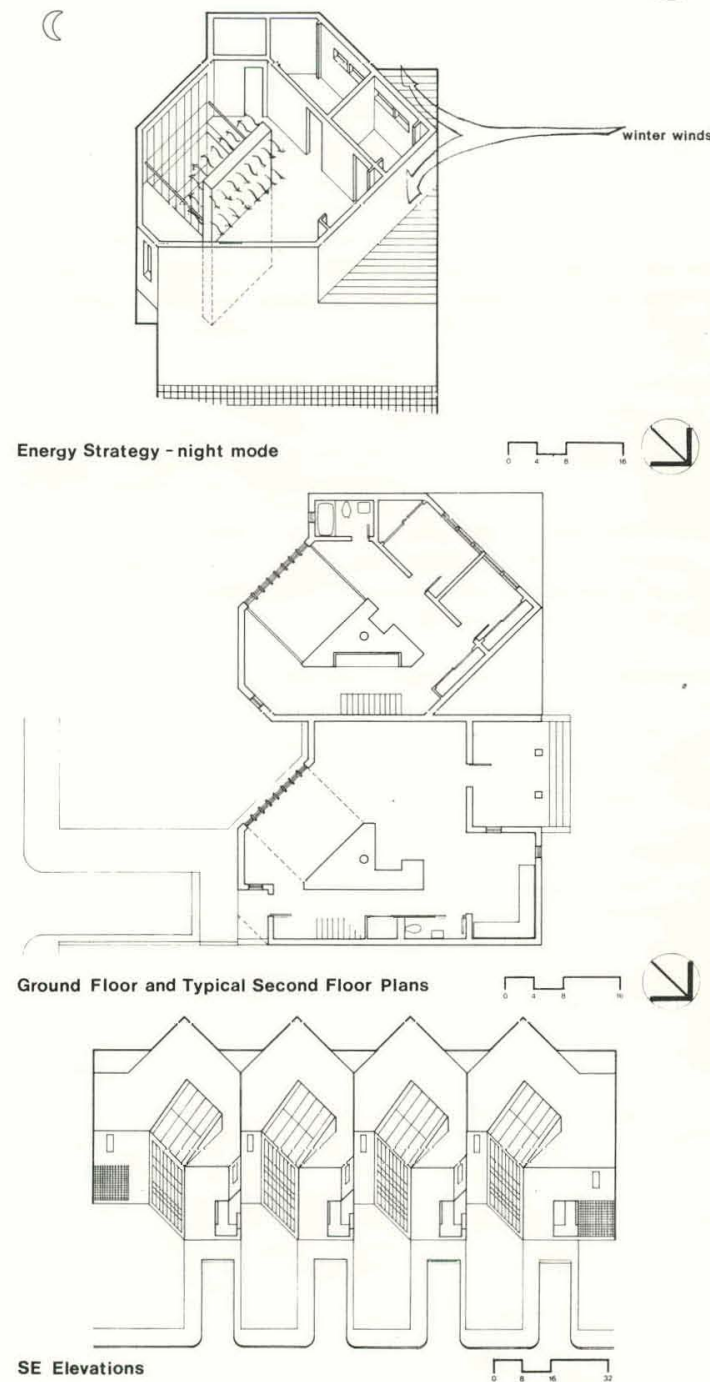

SE Elevations
TEAM 1

Towan
Atlanta, Ga.

HGSD Departments of Architecture and Landscape Architecture Solar Energy $\cdot$ Community Design Studio

Fig. 4.1.3.8 


\subsection{DESIGN STRATEGY}

Atlanta 2 proposes a concentrated pattern of housing, which is in close proximity and easily linked to all major community services through a pedestrian greenbelt system. Road infrastructure is kept to a minimum. The use of the automobile within the community is discouraged and pedestrian and bicycle use are favored. Given existing site conditions, maximum solar access is provided wherever possible.

Community Plan Description (Figs. 4.2.1.1., 4.2.1.2, 4.2.1.3)

Perched on a "peninsula" jutting into the flood plain, the centrally located town center is easily reached from all housing areas by pathways, beginning at the neighborhood scale and continuing to the center through the community park and open space system in the flood plain. By relocating Route 34 to just south of the existing recreation center, this recreation facility, in conjunction with the proposed tennis courts and swimming poor, becomes an integral part of the new community center. The existing community to the south of the town center is also integrated into the scheme through its direct access to the center via Shenandoah Boulevard. All major community facilities (except elementary schools) including post office, library, theaters, high school, office and retail space, are located either within or on the periphery of the proposed town center. A loop road is proposed at approximately a half-mile radius from the center. This road serves as the arterial collector for all proposed neighborhoods north of Route 34 . The highestdensity housing is generally located inside this loop and immediately adjacent to the floodplain. This provides the majority of the community's residents with easy access by foot or bicycle to all community facilities and open space.

A peripheral pedestrian path continues around the 100-year flood plain, in the event that flooding presents an access problem. Included in each neighborhood is a small convenience center. Facilities in these centers include a small retail establishment, elementary school, church, and neighborhood recreation facilities. 
All industry is located along Interstate 85 , close to the Route 34 interchange. It is from this interchange that most people will approach the community. At the entrance to the community, 50 acres of solar collectors frame the roadway to establish a "gateway" to the solar development.

Phasing (Fig. 4.2.1.2)

Phase 1 is located near the interchange because of the economic attractiveness of these industrial sites and a reliance on connections to the region. Phase 1 includes most of the high-density housing and industry, an elementary school, a church, and 32 acres of solar collectors. As shown on the concept diagram, Phase 2 includes the neighborhood south of Route 34 and east of the existing community, taking advantage of its excellent solar access and minimal infrastructure needs. The town center, whose construction starts near the end of Phase I, would near completion by the end of Phase 2. The junior high school with its adjacent residential neighborhood would be built, and the necessary pedestrian and bicycle circulation pathways connecting the residential areas to the community center would be completed. Phase 3 would complete the development, and future growth would continue northward, adjacent to the flood plain.

\subsubsection{ENERGY STRATEGY (Figs. 4.2.2.4, 4.2.2.5)}

Atlanta 2 has devised a strategy that responds to heating and cooling demands for individual structures and electricity supply. A major determinant of the plan is solar access planning to insure maximum passive and active solar utilization on individual structures.

\section{Assumptions}

The team has assumed that housing trends demandsmall dwelling units, in comparison to present size standards. This allows for greater residential densities per acre. Automobile trends indicate smaller cars, in comparison to present models. Narrow paved surfaces and smaller parking-storage facilities are designed. Highways, roads and street patterns provide for planning and design solutions which maximize solar orientation. Technological 
advances are assumed to decrease demands while increasing efficiency of energy supply methods.

Based on the energy assumptions, decisions were made that all residential areas of high density would have a greater dependency on large collector sources for thermal supply, and that areas of low residential density would have little or no dependency on large collector sources for thermal supply. All residential densities would require complete dependency on large collector sources for electricity supply.

\section{Electric Generation Strategy}

Electricity is supplied to the community by two central generating plants. Each generating plant is composed of a field of parabolic dishes, a "hot-oil" high-temperature thermal-storage facility, and a power plant. The power plant houses wood-fired boilers, turbine generators for conversion of high temperature thermal energy to electricity and a pumping station for distribution of $250^{\circ} \mathrm{F}$ hot water to the community for heating and cooling purposes. The parabolic dish fields associated with the generating stations are 42 and 36 acres respectively.

The parabolic dish collector fields are sized to provide $50 \%$ of the annual electrical needs of the community, the remainder being generated by the woodfired power system. Excess solar energy collected during the day is stored in hot oil for nighttime use. This permits a relatively even loading of the wood-fired boilers. Boiler loads may be further reduced, and emergency standby capacity assured, by means of a purchase arrangement (18.2 mwh/day) with the local utility grid.

A cascading power cycle is employed to provide hot water at $200^{\circ}$ to $250^{\circ} \mathrm{F}$. for distribution to the community. The specific thermal requirements of the community (supplied by the central generating stations) are fully met by cogeneration for seven months of the year. For the other five months the thermal deficit is supplied by site specific solar collectors and by increased utilization of the wood-fired boiler system. 
Wood consumption for electrical generation and supply of thermal energy is roughly estimated at 18,800 tons per year or 52 tons per day. A survey of three sawmill operations within 40 miles of the Shenandoah site indicates the availability of approximately 60,700 tons per year of currently unused waste wood. It is proposed that the full requirements of the wood fired power cycle be obtained from these off-site sources.

\section{Thermal Generation Strategy}

Single-family detached (SFD) housing units are independent of the central plant. These incorporate passive methods and active flat-plate collectors for both heating and hot water supply. Electrically powered heat pumps provide a supplemental and back-up energy source, and provide for cooling needs.

High-density housing units, including clusters, apartments, and condominiums, depend on the central plant. These units incorporate passive heating methods and thermal distribution from the central plant. They make maximum use of passive ventilation and are supplemented by individual hot water absorption chillers. Hot water $\left(250^{\circ} \mathrm{F}\right)$ is supplied by. the central plant and supplemented by site-specific flat-plate (e.g., evacuated tube) collectors. As housing density increases, unit solar collection capability decreases, and the increasing demand is met by the central plant.

Commercial facilities depend on the central plant. Location in the dense town center necessitates reliance on hot water $\left(250^{\circ} \vec{F}\right)$ sources not available from site specific sources. The town-center units, composed of commercial, community services and town houses, depend on maximum passive ventilation supplemented by the mechanical plants located at intervals along main supply corridors in the center. These supply chilled water to individual buildings. The mechanical plants contain large, hot water, absorption chillers, using hot water $\left(250^{\circ} \mathrm{F}\right)$ supplied by the central plant. 


\section{THIS PAGE \\ WAS INTENTIONALLY \\ LEFT BLANK}




\section{ATLANTA 2}

ASSUMPTIONS AND EXPLANATIONS

1. Industry is self-sufficient in demand and supply, and is not included.

2. $26-84 \%$ of maximum (summer) demand is met by site-specific active and passive means.

\begin{tabular}{|l|l|l|l|}
\hline $\begin{array}{l}\text { TYPE OF BUILDING OR } \\
\text { DEMAND }\end{array}$ & \multicolumn{2}{|l|}{ UNITS/AREA } & ELECTRICAL \\
\cline { 2 - 4 } & QUANTITY & $\begin{array}{r}\text { AREA/UNIT } \\
\text { TOTAL AREA }\end{array}$ & MWh/Day \\
\hline
\end{tabular}

\begin{tabular}{|l|c|c|c|}
\hline Single family housing & 1152 & 1,300 s.f./u. & \\
\hline Cluster housing & 2241 & 1,100 s.f./u. & \\
\hline Condominium housing & 7.20 & 1,100 s.f./u. & \\
\hline Apartments & 450 & 575 s.f./u. & (tot.res .) 51 \\
\hline Schools & & & \\
\hline Community facilities & & & \\
\hline Community services & & & \\
\hline Churches & & & \\
\hline Local retail & & & \\
\hline Regional retail & & & \\
\hline Dffices & & & \\
\hline & & & \\
\hline & & & \\
\hline & & & \\
\hline
\end{tabular}

\section{total community energy demand}


demand

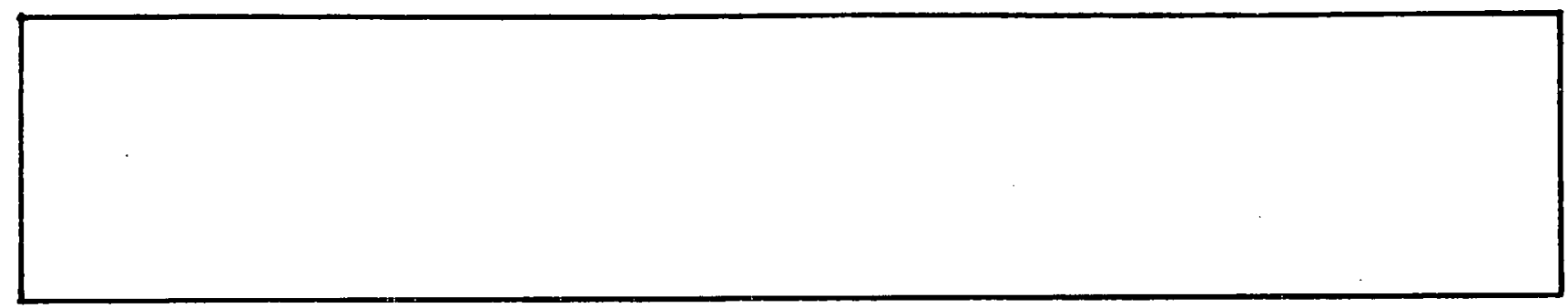

\begin{tabular}{|l|c|l|l|l|l|}
\hline \multicolumn{2}{|l|}{ HEATING LOAD } & \multicolumn{2}{l|}{ COOLING LOAD } & \multicolumn{2}{l|}{ DOMESTIC HOT HATER } \\
\hline $10^{6}$ Btu/Day & Mwh(Th)/Day & $10^{6}$ Btu /Day & Mwh (Th)/Day & $10^{6}$ Btu/Day & Mwh (Th)/Day \\
\hline
\end{tabular}

\begin{tabular}{|c|c|c|c|c|c|}
\hline 86.85 & 25.37 & 343.80 & 100.70 & 50.33 & 17.67 \\
\hline 145.60 & 42.64 & 469.70 & 137.56 & 77.66 & 22.74 \\
\hline 46.50 & 13.62 & 150.90 & 44.19 & 34.83 & 10.20 \\
\hline 17.4 & 5.1 & 58.10 & 17.02 & 12.08 & 3.54 \\
\hline 5.84 & 1.71 & 14.00 & 4.10 & 3.49 & 1.02 \\
\hline 3.67 & 1.08 & 7.10 & 2.08 & 0.26 & 0.08 \\
\hline 3.42 & 1.00 & 13.25 & 3.88 & 0.29 & 0.08 \\
\hline 0.90 & 0.26 & 0.51 & 0.15 & 0.01 & 0.002 \\
\hline 1.20 & 0.35 & 5.80 & 1.70 & 0.20 & 0.05 \\
\hline 7.60 & 2.23 & 18.20 & 5.33 & 8.60 & 2.52 \\
\hline 0.84 & 0.25 & 10.20 & 2.99 & 0.11 & 0.03 \\
\hline & & & & & \\
\hline & & & & & \\
\hline & & & & & \\
\hline & & & & & \\
\hline & & & & & \\
\hline 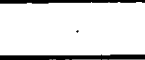 & & & & & \\
\hline & 94 & & 320 & & 58 \\
\hline
\end{tabular}


ATLANTA 2

ASSUMPTIONS AND EXPLANATIONS

1. Electrical qeneration surplus sold to local utility grid.

\begin{tabular}{|l|l|l|l}
\hline ENERGY SOURCE & APPLICATION & CONFIGURATION & $\begin{array}{l}\text { SUPPLY } \\
\text { Mwh/Day }\end{array}$ \\
\hline
\end{tabular}

\begin{tabular}{|l|l|l|l|}
\hline STORAGE SYSTEMS & night-time & $27.73 \mathrm{mwh} / \mathrm{d}$ & \\
\hline 1. hot oil storage & thermal and & demand & \\
\hline & electrical & (excess thermal & \\
\hline & demand & supply) & \\
\hline & & & \\
\hline & & & \\
\hline & & & \\
\hline & & & \\
\hline
\end{tabular}

\begin{tabular}{|l|l|l|l|}
\hline SUPPLY SYSTEMS & \multicolumn{2}{|l|}{ (8 acres } & \\
\hline 1. parabolic dish & domestic hot & electrical & 44 MWh(e) \\
\hline field & water, electri- & & \\
\hline & city, thermal & thermal & up to 96 \\
\hline & (heating and & MWh(Th) \\
\hline 2. wood-burning plant & cooling) demands & 2, 4-Mw(e) plants & 47 MWh(e) \\
\hline & & thermal & up to 100 \\
\hline & & & MWh(Th) \\
\hline & & & \\
\hline
\end{tabular}

\section{total community energy supply $91 \operatorname{MNh}(\mathrm{e})$}




\subsubsection{SITING ISSUES AND HOUSING}

General siting principles include siting the highest-densities on the edge of the flood plain to take advantage of the breezes that flow up and down through this area. Deciduous trees are planted on south facing walls and coniferous trees are left on northern and western boundaries to screen winter winds. Passive design methods have been incorporated into all housing unit designs, but the units are not $100 \%$ thermally self-sufficient.

High Density Housing (Figs. 4.2.3.6, 4.2.3.9)

High density housing west of the town center at a density of 16-24 D.U.S/acre is sited to obtain maximum solar exposure, while maintaining a high density. South-facing groups of two and three-story apartment units are sited on either side of an east-west pedestrian street. With respect to room orientation, living and dining rooms are located on the south-facing side of the unit. Bathrooms, corridors and storage space are located on the northern sides. Great emphasis has been placed on the use of outdoor decks, patios, terraces, and similar spaces which when covered with trellises or sun shading devices become living rooms in the summer months. Summer rooms would incorporate wood or fabric shading devices erected and dismantled by individual occupants. To induce further passive cooling, townhouses in the town center (Fig. 4.2.3.9) contain "black" chimneys which are heated by the sun and draw cocler exterior air across floor surfaces and through living spaces. Throughout the design process Atlanta 2 strove to utilize low energy intensive materials. Wood and several types of masonry are less energy intensive and are incorporated in all architectural prototypes.

Low and Medium Density Housing (Cul-De-Sac Development) (Fig. 4.2.3.9)

Low and medium density housing is organized around cul-de-sacs which are primarily oriented along the east-west axis. The roof ridge lines of the dewelling units parallel the cul-de-sac, permitting a large area of south facing wall and roof for both passive and active solar collection. Dwelling units located on the south side of the cul-de-sac are sited close to the street with primary outdoor private living spaces to the rear of the unit. 
Dwelling units on the north side of the street are set back, with the primary outdoor private space located in a fenced court between the street and the unit. Deciduous planting on the south sides of the dwelling units provide summer shade, and funnel the easterly breezes (predominant during humid weather) for ventilation. Coniferous planting on the north-west corners of the units protects them from the predominant winter winds. Existing coniferous vegetation on the south side of the units is selectively thinned to provide solar access.

Single family attached and townhouse units, sited at densities of 6 to 10 units per acre, are constructed primarily of wood. Wall framing is accomplished with members of $6^{\prime \prime}$ depth to accommodate a greater insulation thickness. Passive solar heating is facilitated with the use of greenhouses and direct gain wailis on the south facade of the units. The portion of south facing facade devoted to passive collection is at ground level. With the exception of this portion of the south facade, the first level of the dwelling units is raised approximately 4 feet off the ground. The resulting under-floor crawl space serves as a cold air sink from which ventilation air may be drawn during periods of low cooling load. Heat which is passively collected and stored is directly distributed to spaces adjoining the collection area and is drawn through to more remote living spaces.

Requirements for mechanical heating and cooling are reduced with a heavily insulated building shell, air lock entry design, passive heat collection and cool air intake from under-floor crawl areas. 


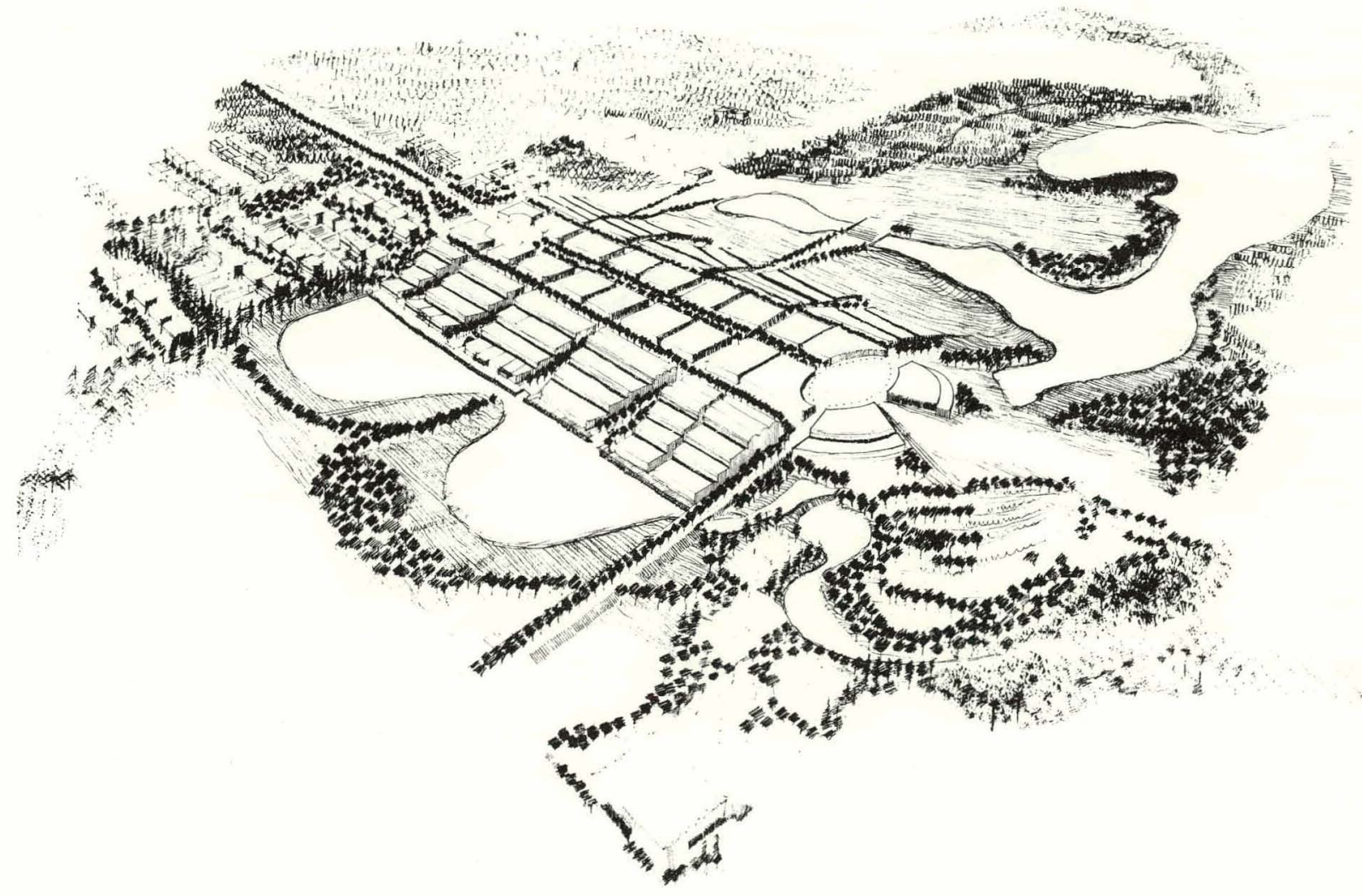

TEAM 2

\section{Atlanta, Ga.}

HGSD Departments of Architecture and Landscape Architecture Solar Energy · Community Design Studio Spring 1980

rig. 4.2.1.1 


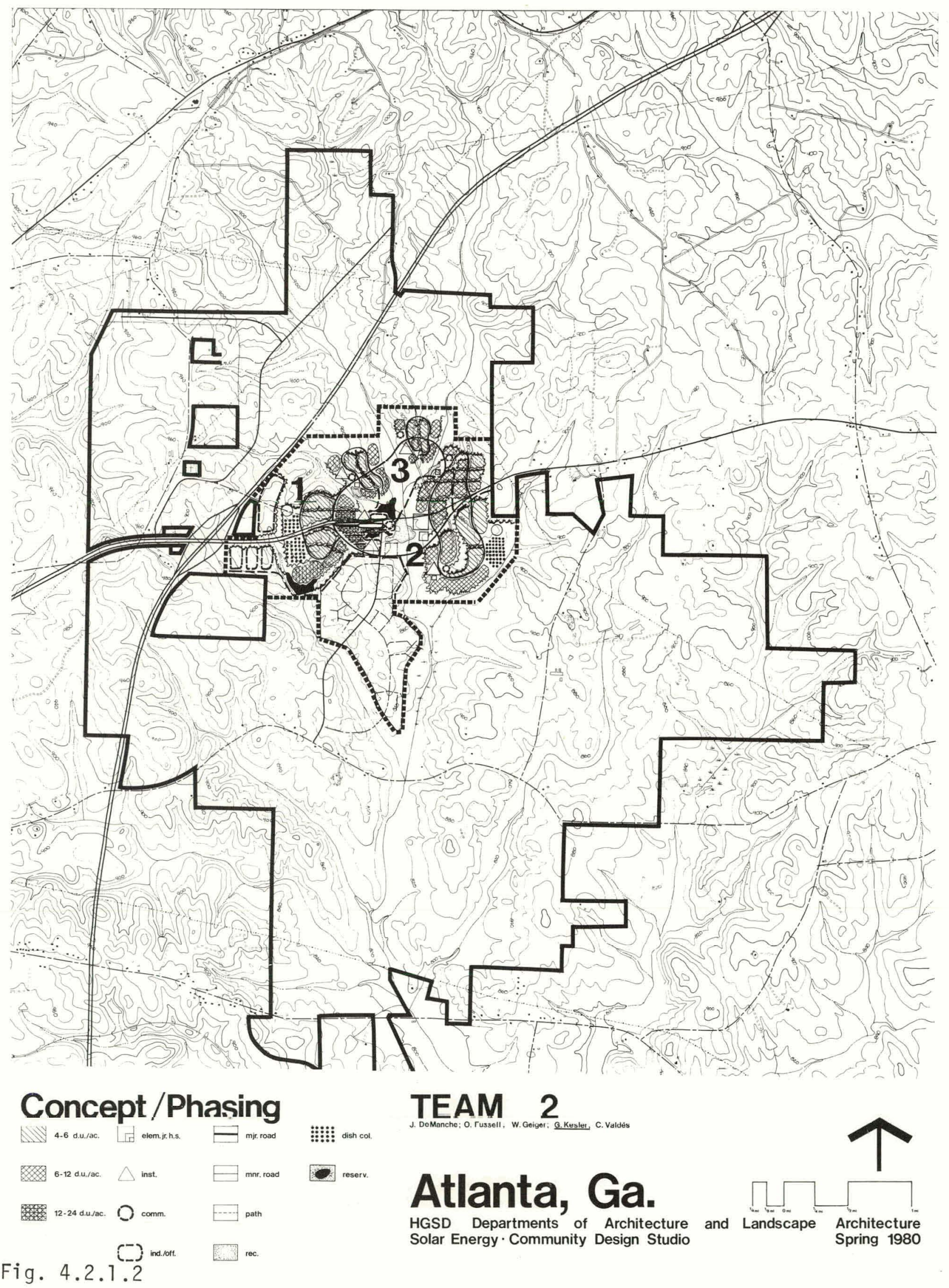




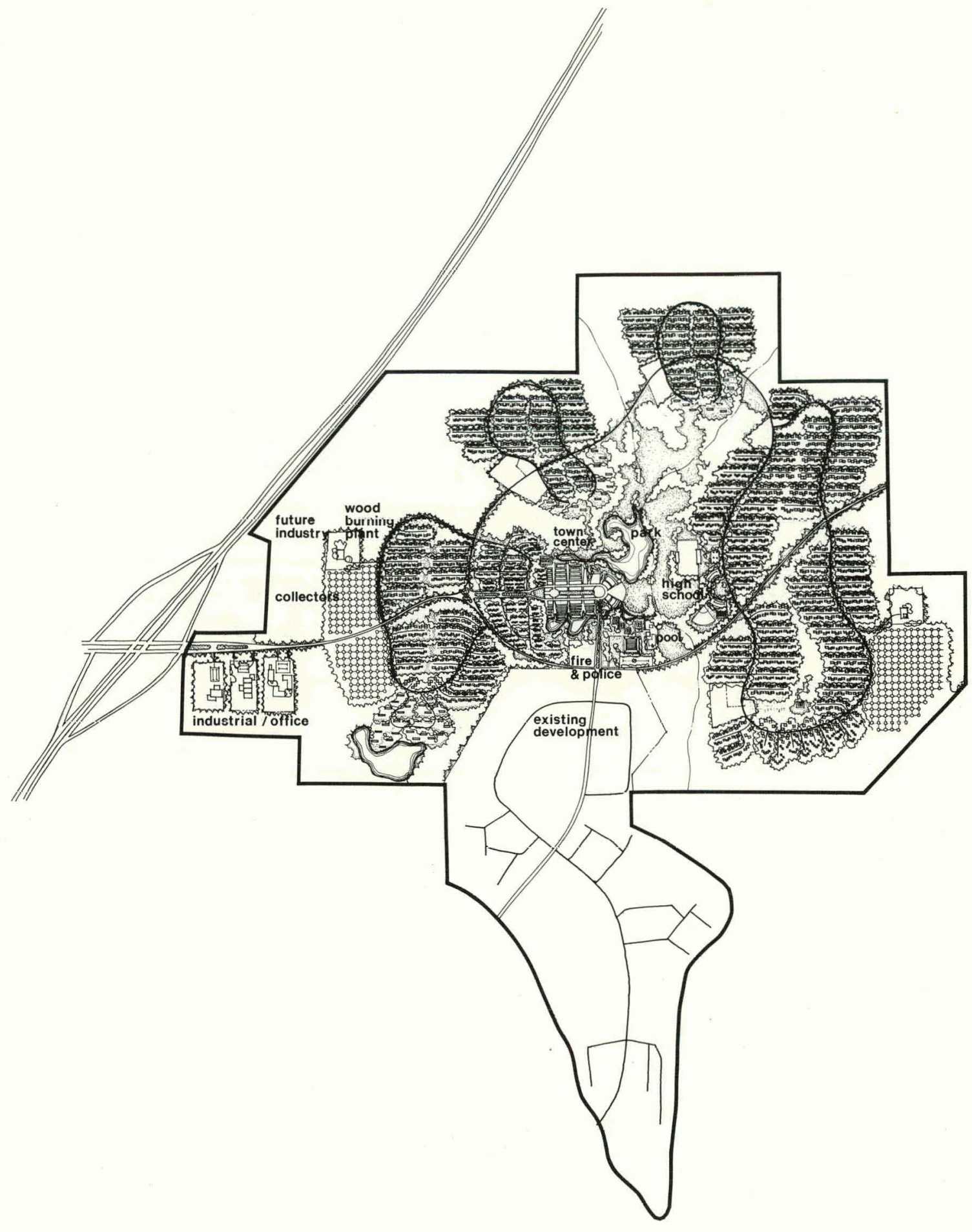

Site Plan

TEAM 2

Atlanta, Ga. HGSD Departments of Architecture Solar Energy · Community Design Studio

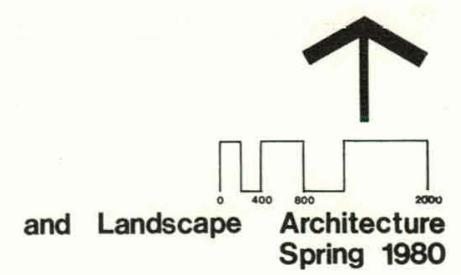

Fig. 4.2.1.3 


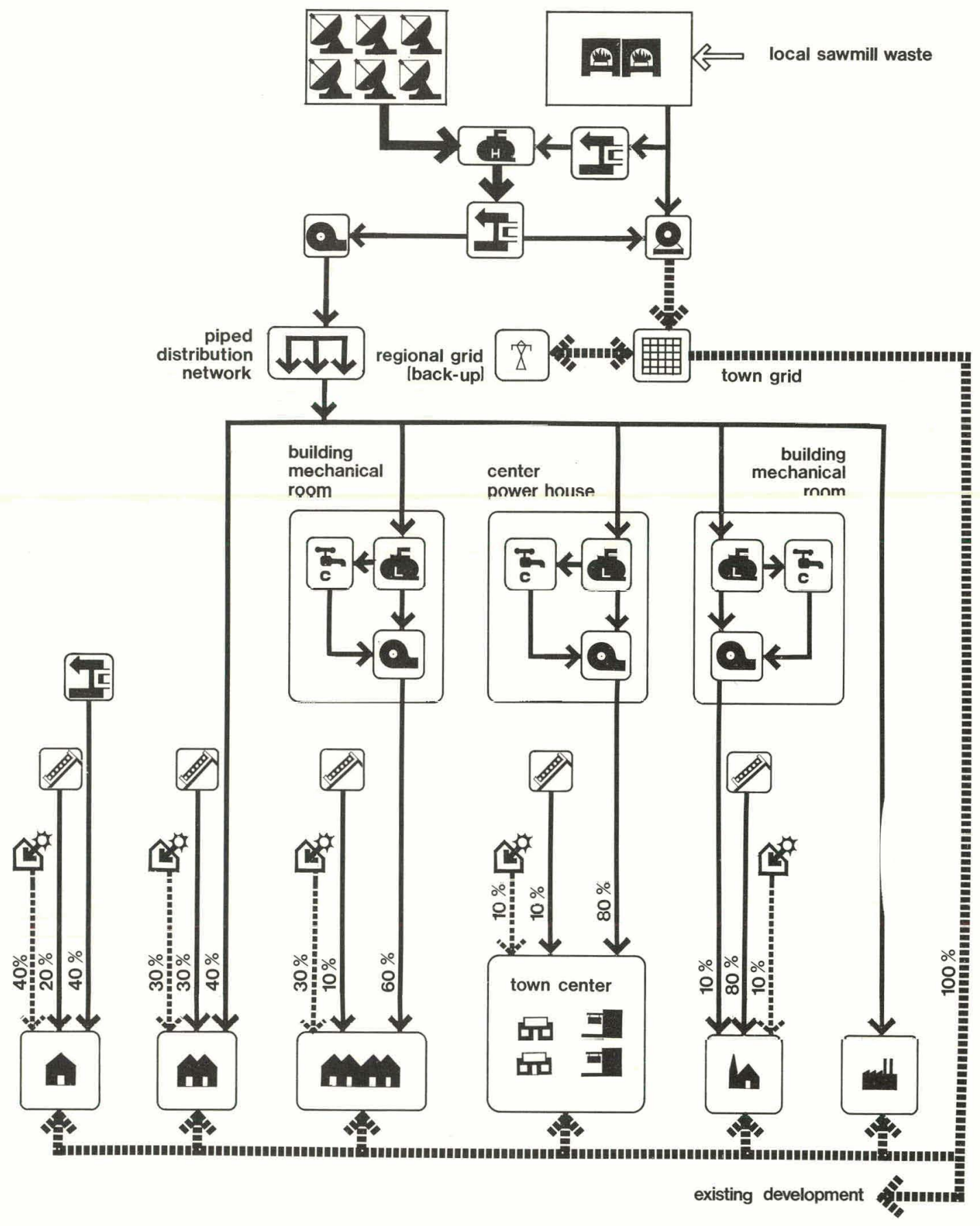

Energy Diagram

Fig. 4.2.2.4
TEAM 2

\section{Atlanta, Ga.}

HGSD Departments of Architecture and Landscape Solar Energy Community Design Studio
Architecture Spring 1980 


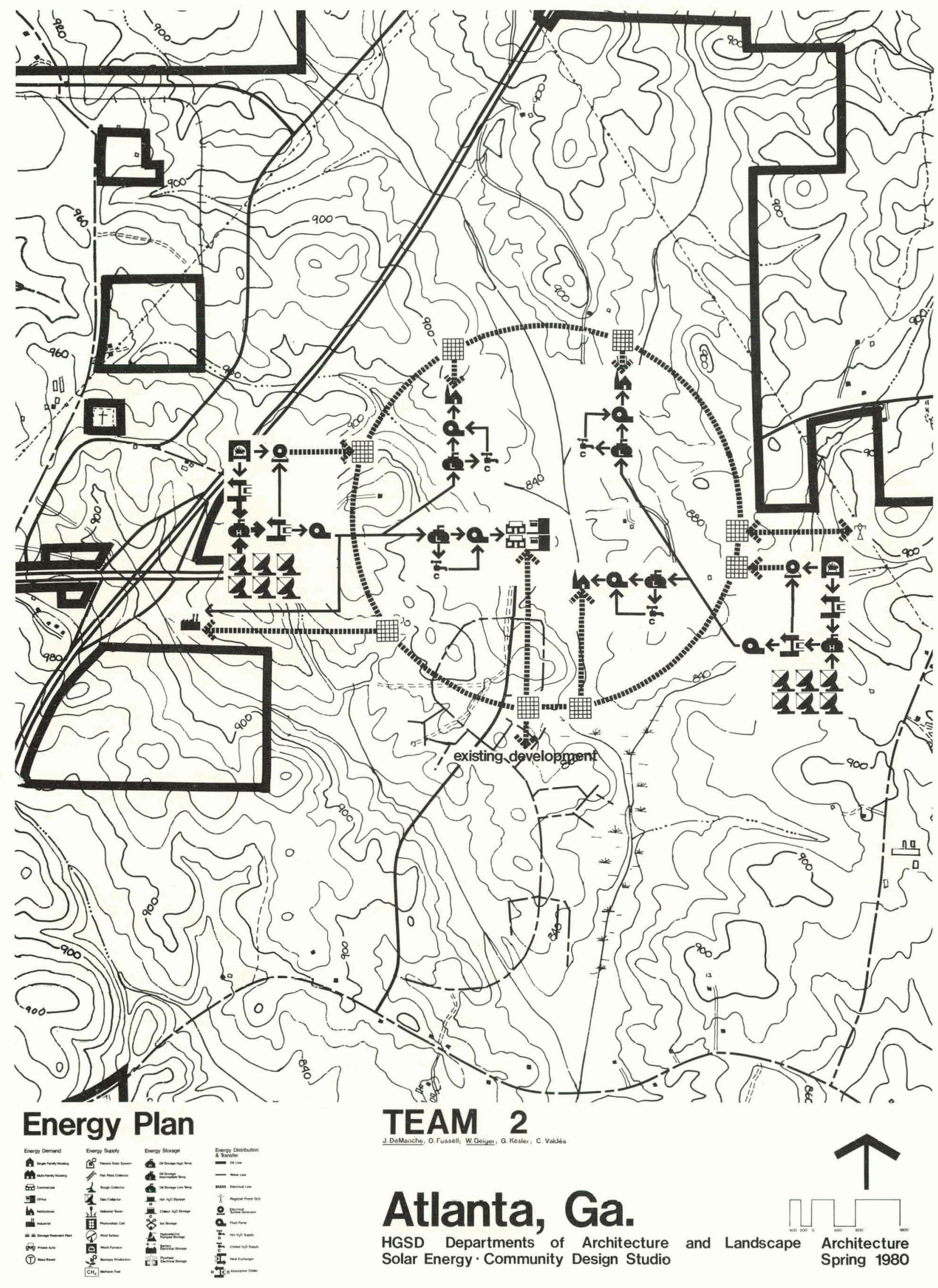

Fig. 4.2.2.5 


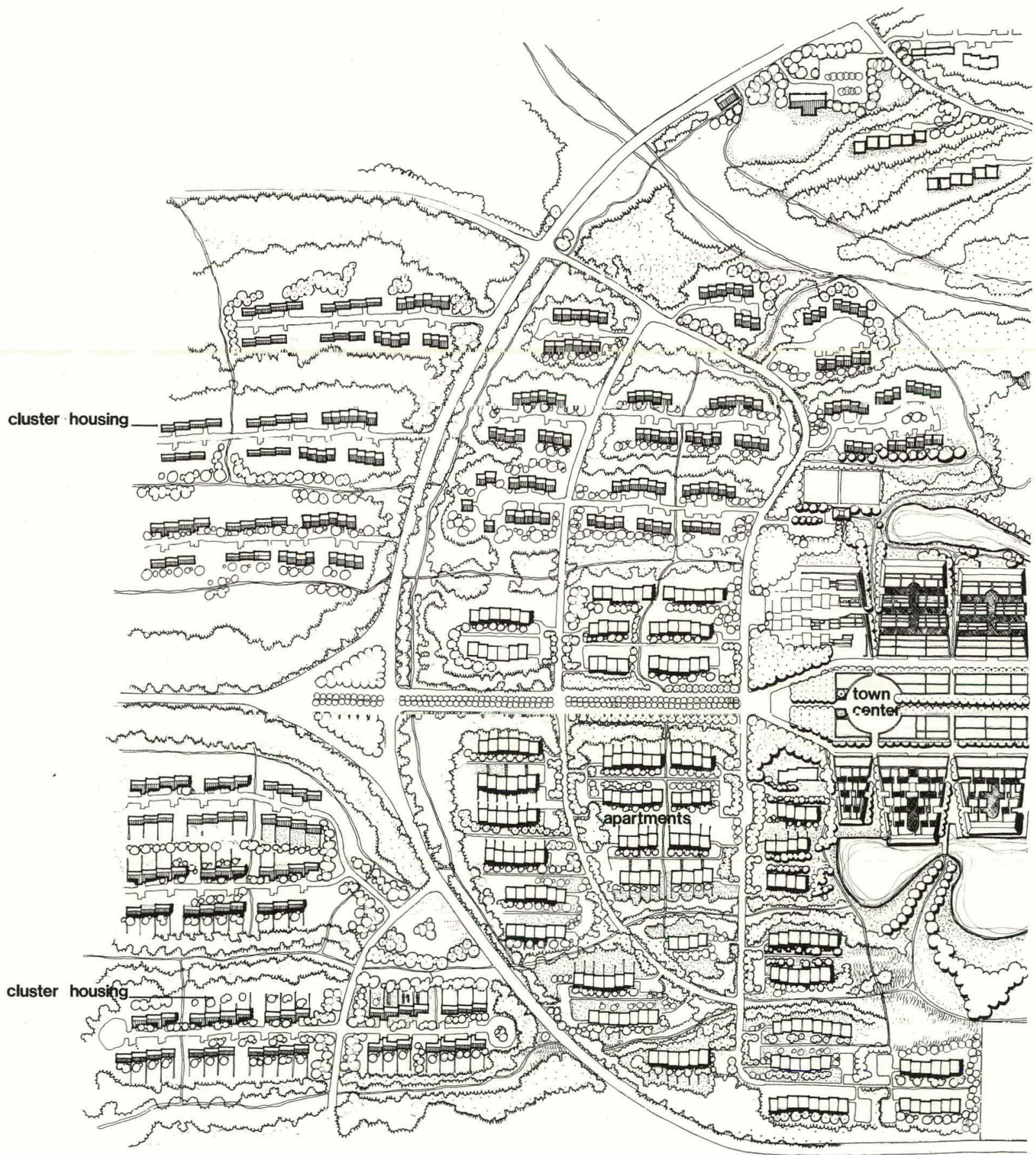




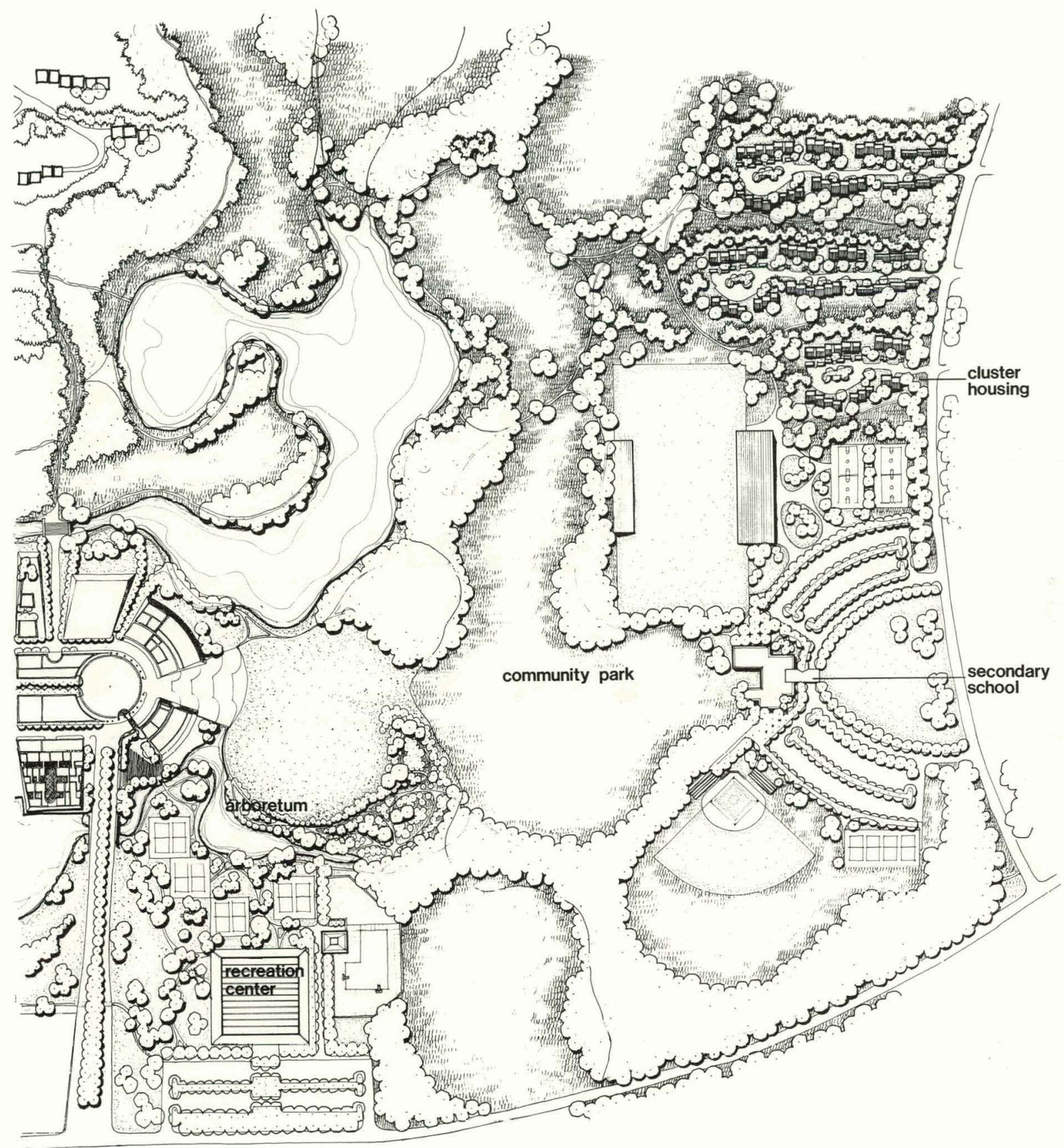

Town Center

TEAM 2

Atlanta, Ga.

HGSD Departments of Architecture and Landscape Architecture Solar Energy - Community Design Studio

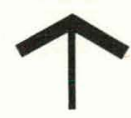

Spring 1980

Fig. 4.2.3.6 

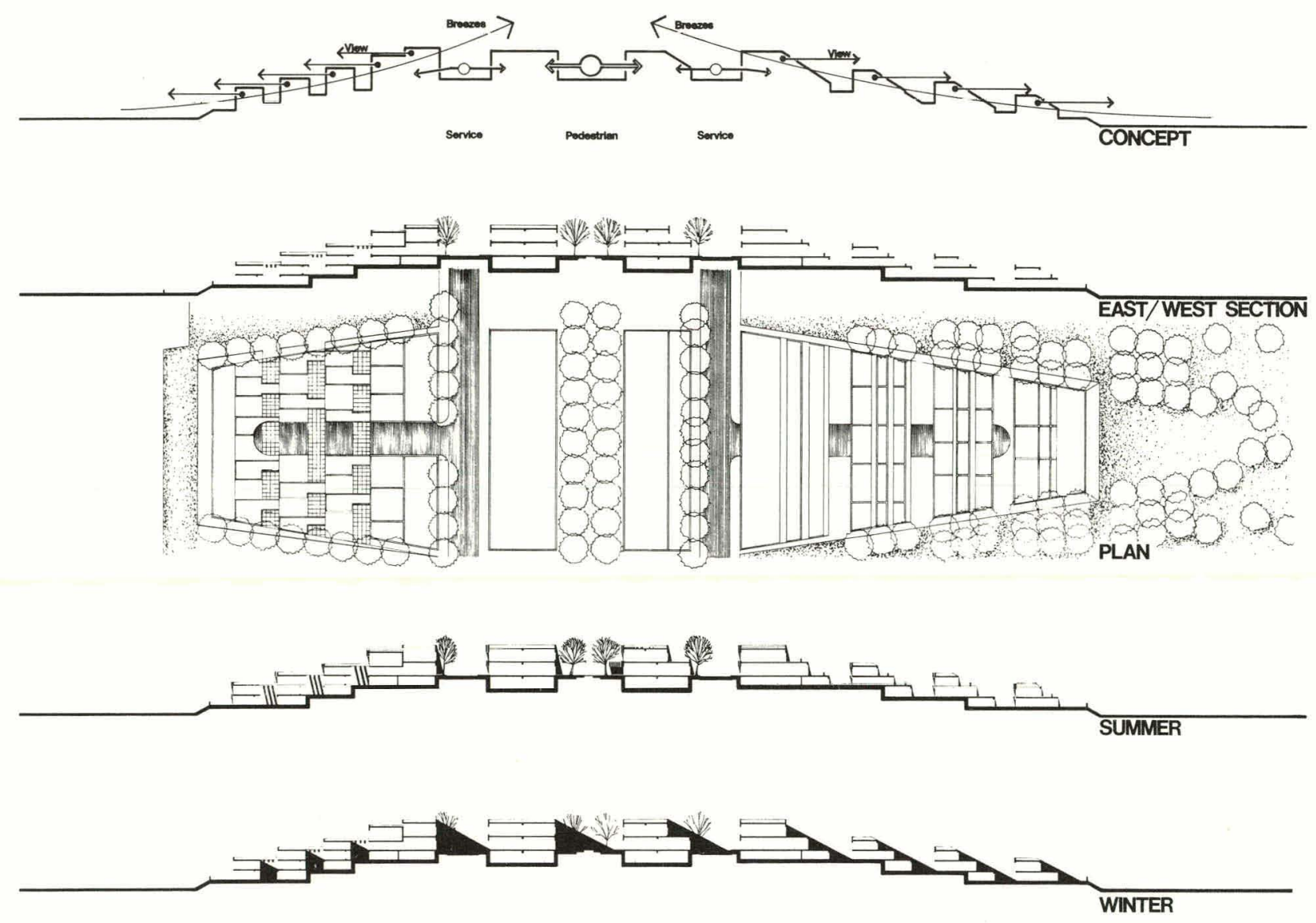

\section{Town Center}

Fig. 4.2.3.7
TEAM 2 2.

\section{Atlanta, Ga.}

HGSD Departments of Architecture Solar Energy - Community Design Studio

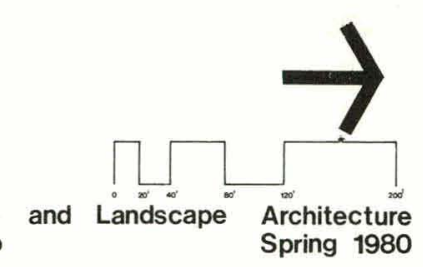




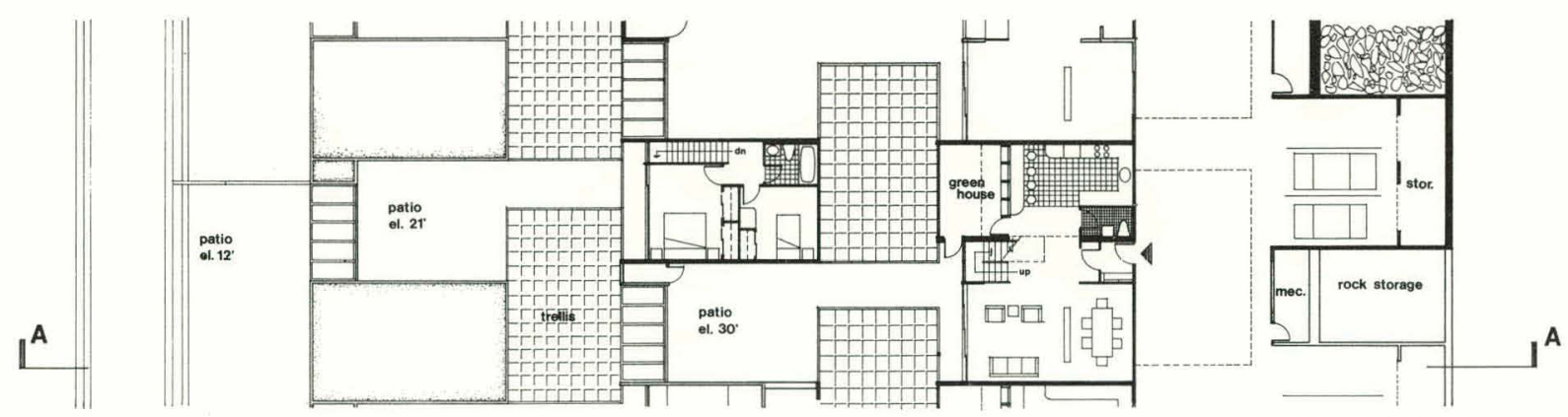

PLAN EI. 30'-0"

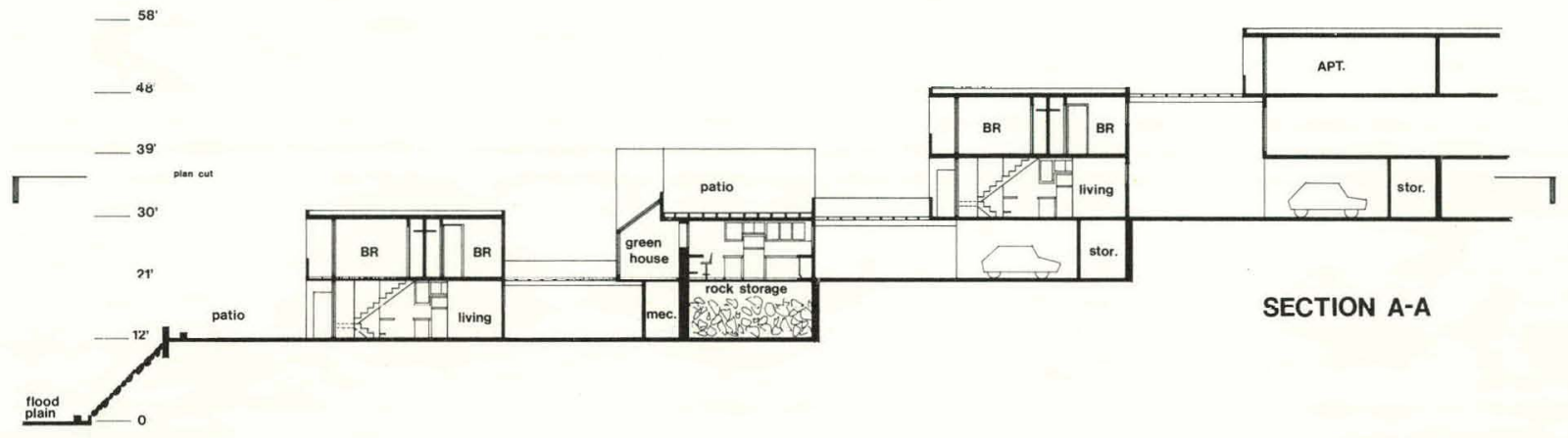

Town Center Residential

12-24 d.u./acre

Fig. 4.2.3.8

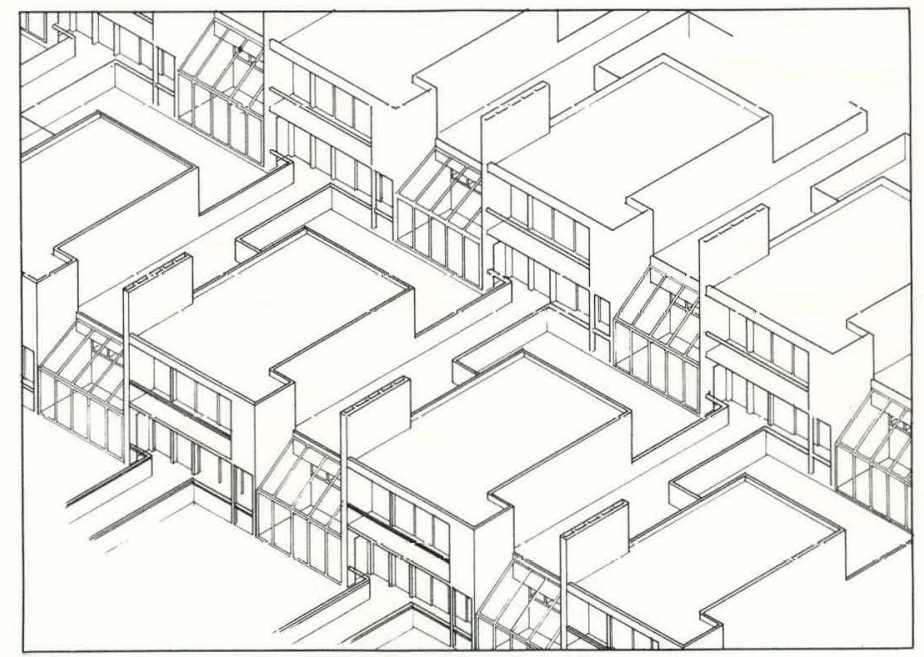

TEAM 2

\section{Atlanta, Ga.}

HGSD Departments of Architecture Solar Energy · Community Design Studio
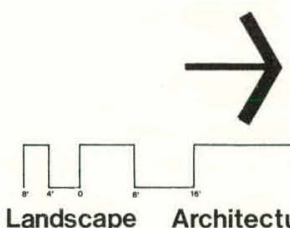

Architecture Spring 1980 


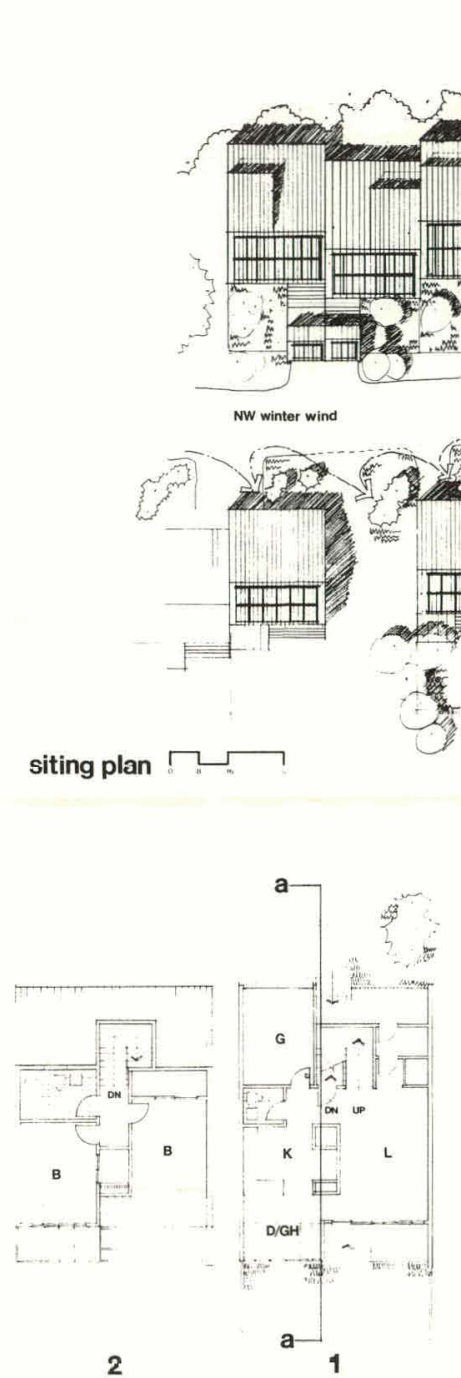

plan-south twnhse.

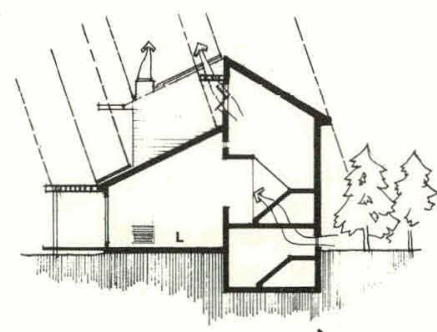

section C.C SUMMER N

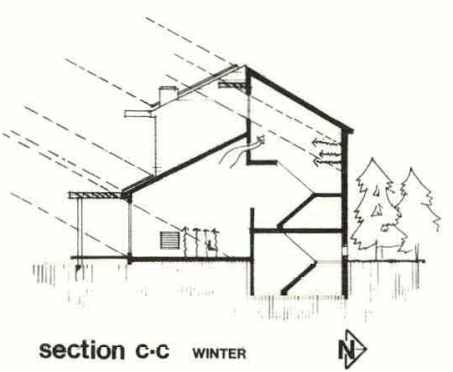

plan-north twnhse.

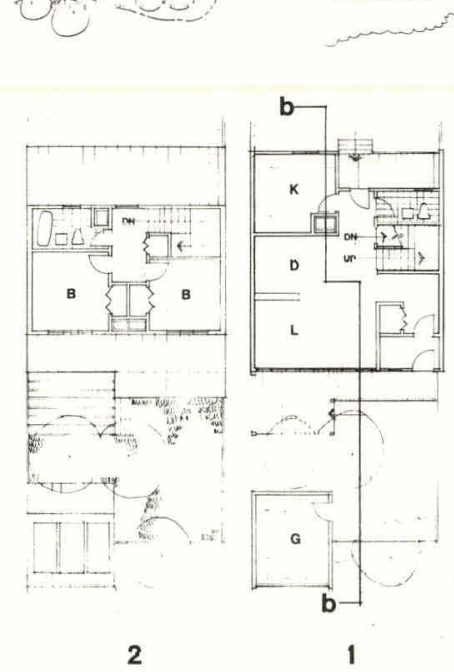

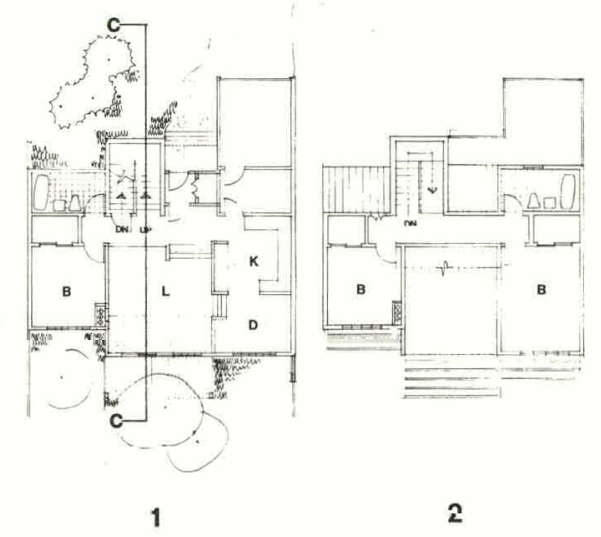

plan-s. fam. attached

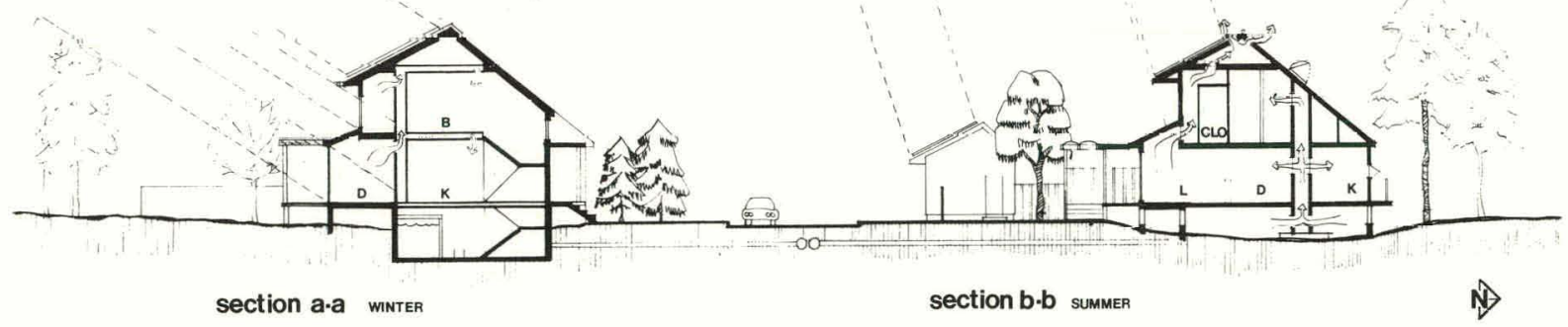

Cluster Housing

6-12 d.u. / acre
TEAM 2 2

Atlanta, Ga.

HGSD Departments of Architecture and Landscape Architecture Solar Energy - Community Design Studio

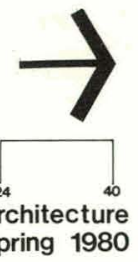

Fig. 4.2.3.9 
The Talcott property is 3,000 acres and is located one mile from Plymouth, Massachusetts, 30 miles south of Boston. Summers are warm, temperatures range from $65^{\circ}-80^{\circ} \mathrm{F}$, and winters can be very cold with temperatures ranging from $18-40^{\circ} \mathrm{F}$. The annual rainfall for Plymouth is 33.5 inches, and the prevailing winds are north/northwest. Climate tables are shown in Fig. 5.0.2.

The site is characterized by a kettle and kame topography. A number of ponds occur in the lower depressions of the kettle areas, and there is an adequate supply of ground water. A large proportion of the site is covered with large mature stands of pitch pine and scrub oak. There are two small areas of meadow and pasture located in the central portion of the site. The area is subject to severe fire hazard in early spring. Its major physical feature is the Pine Hills, a terminal moraine with consistently high wind exposure. 


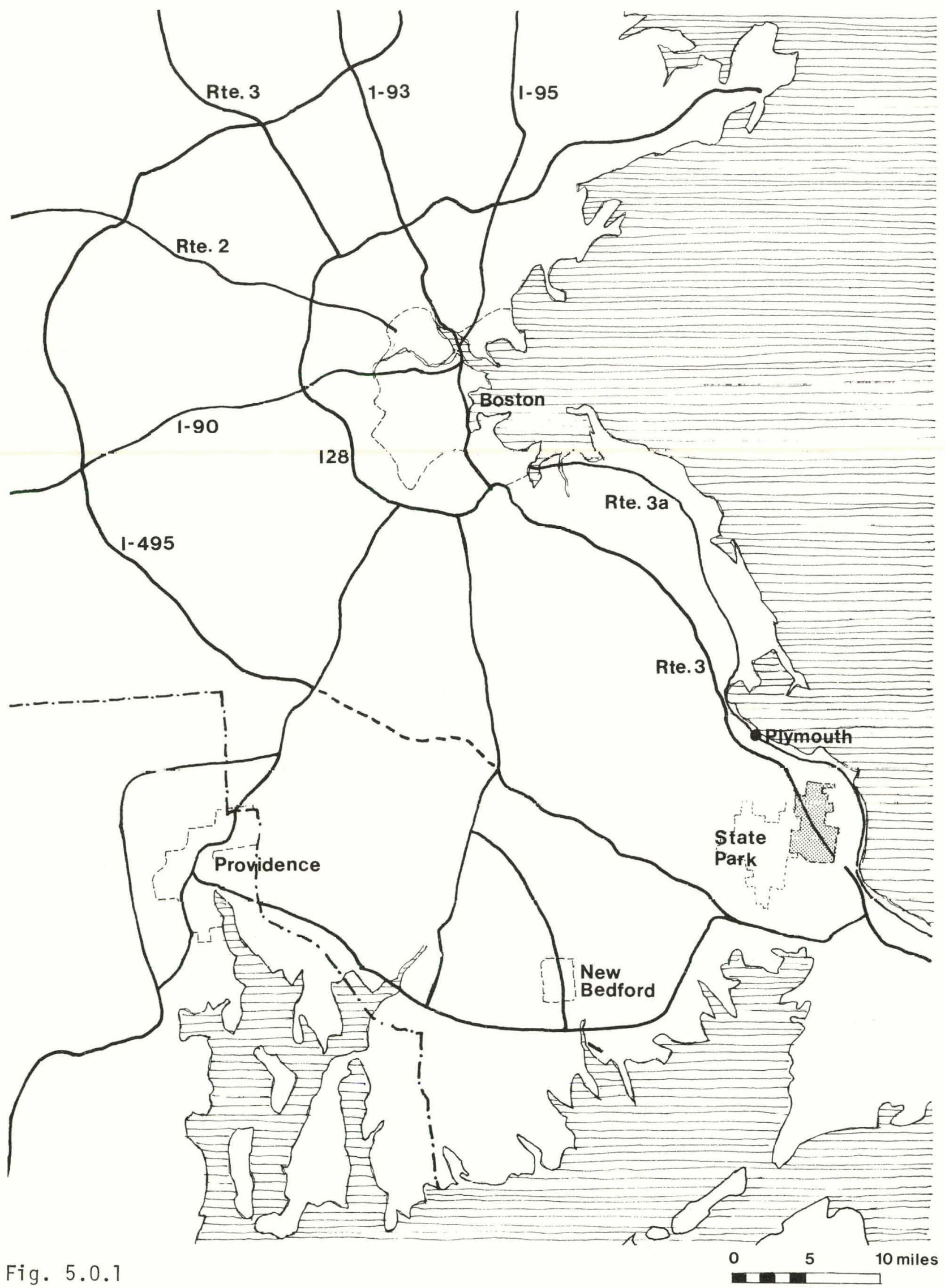




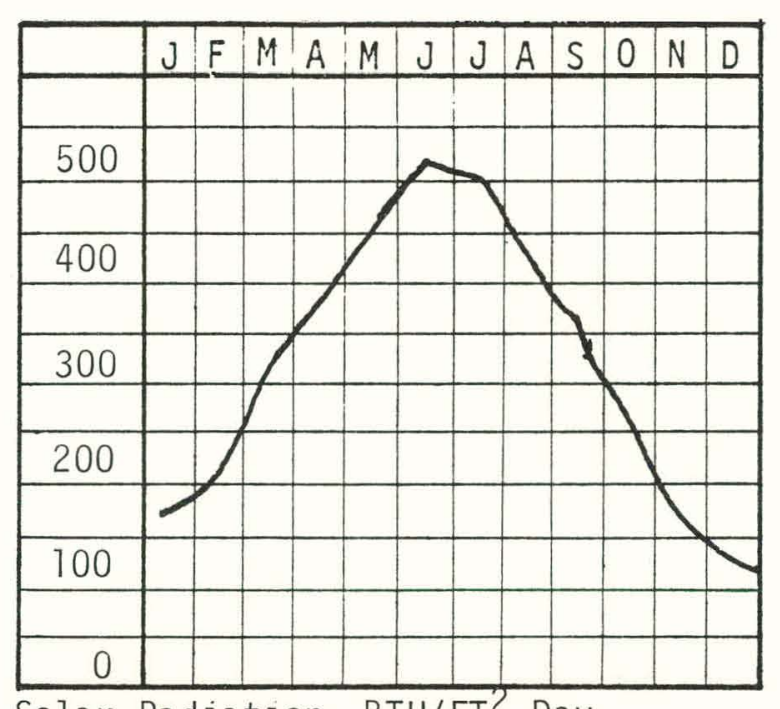

Solar Radiation BTU/FT' Day

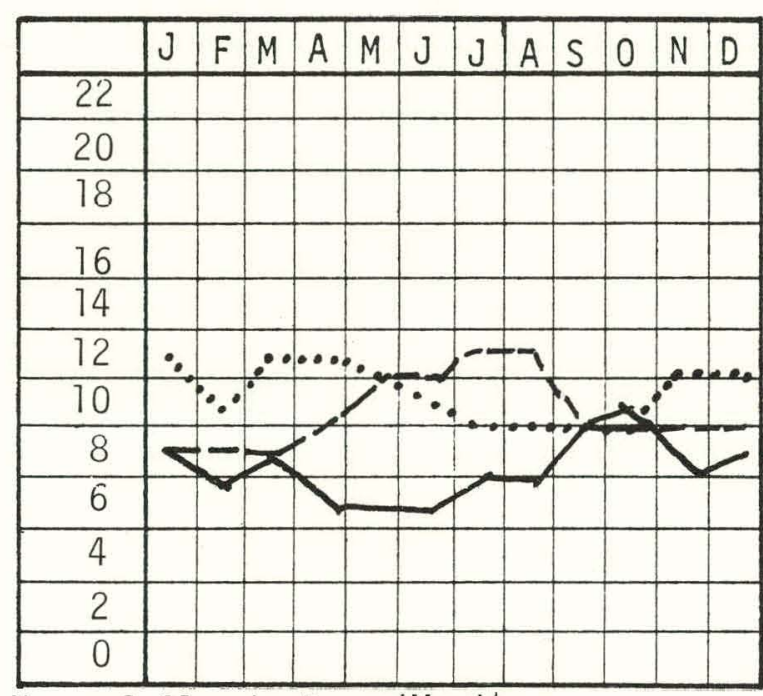

No. of Cloudy Days/Month

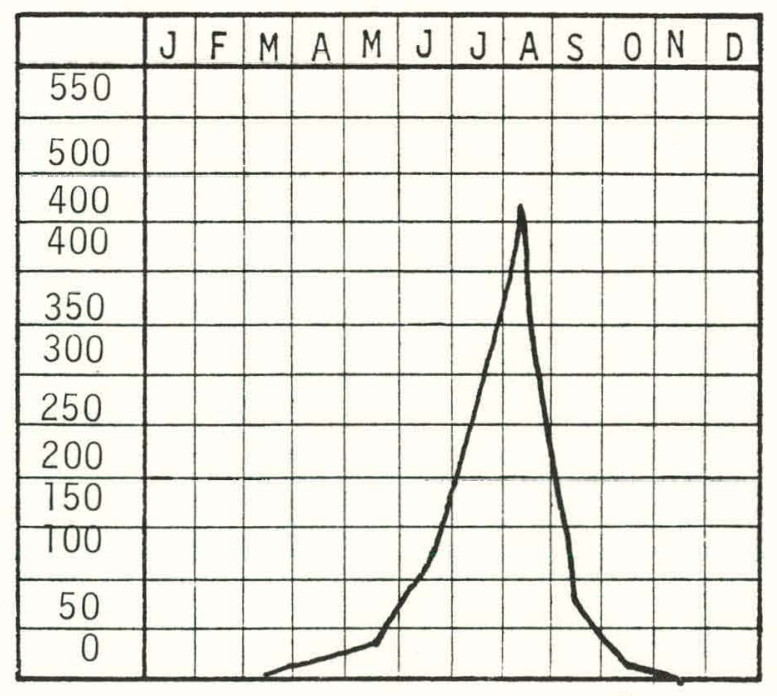

Cooling Degree Days/Month, $65^{\circ} \mathrm{F}$. Base

Table 3.0.2

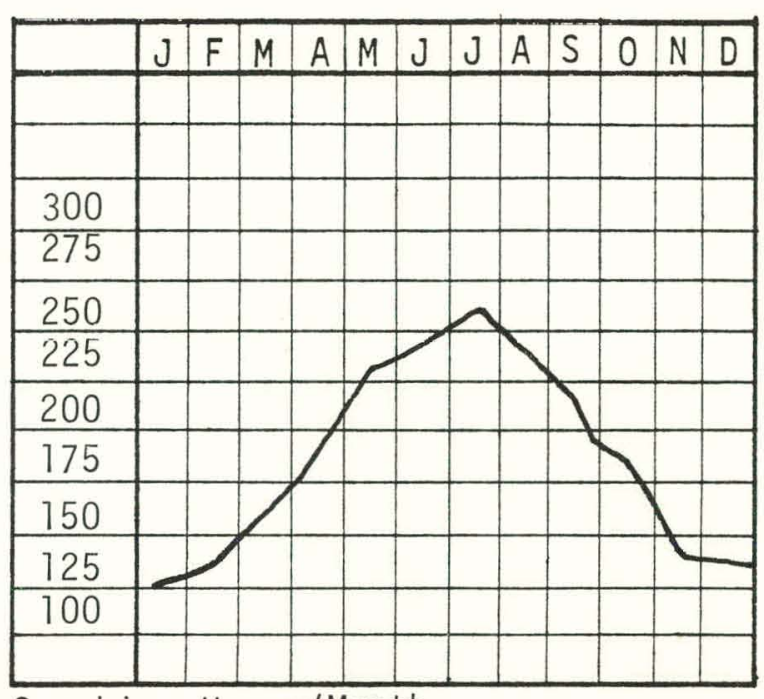

Sunshine Hours/Month
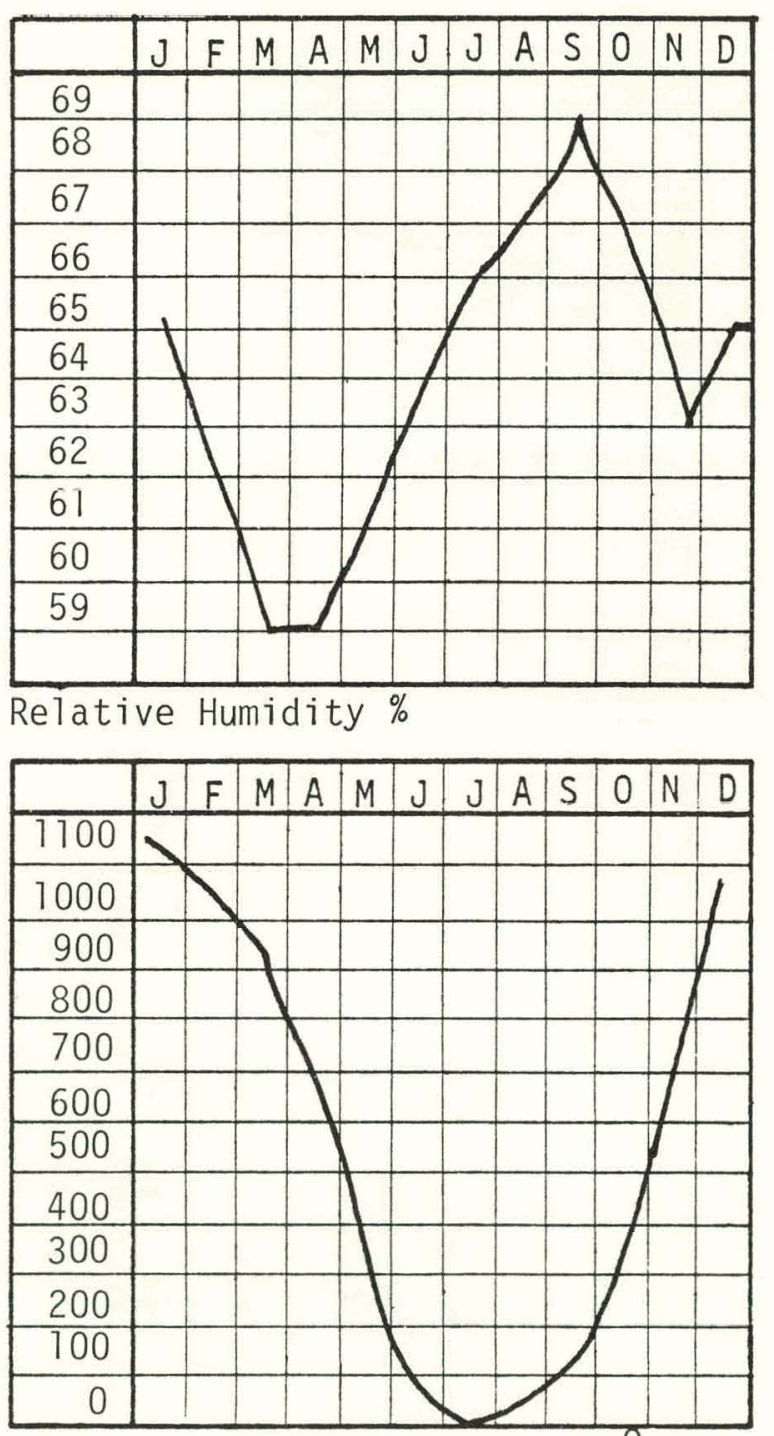

Heating Degree Days/Month, $65^{\circ} \mathrm{F}$. Base 

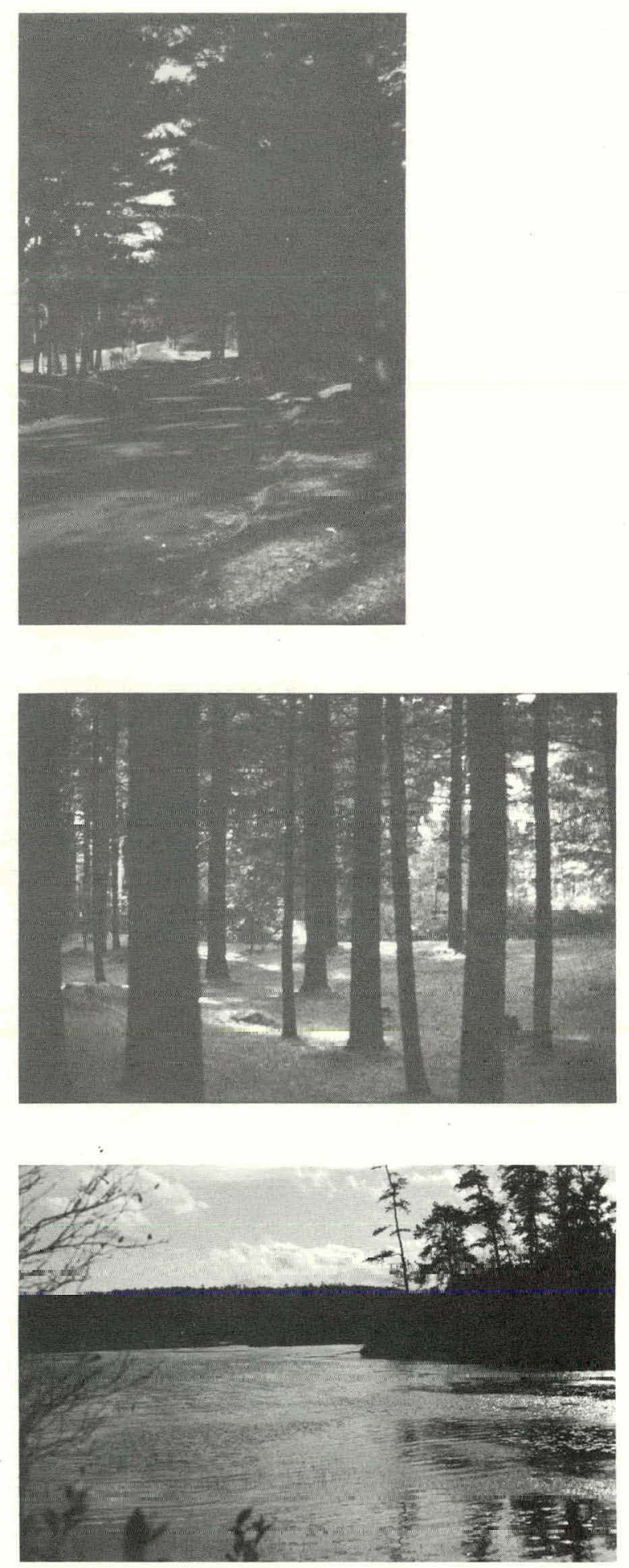

Fig. ๖.0.3

Entrance to Talcott property

Fig. 5.0.4

Mature sland of pine

Fig. 5.0 .5

View across northern lake from the Talcull Eslale 

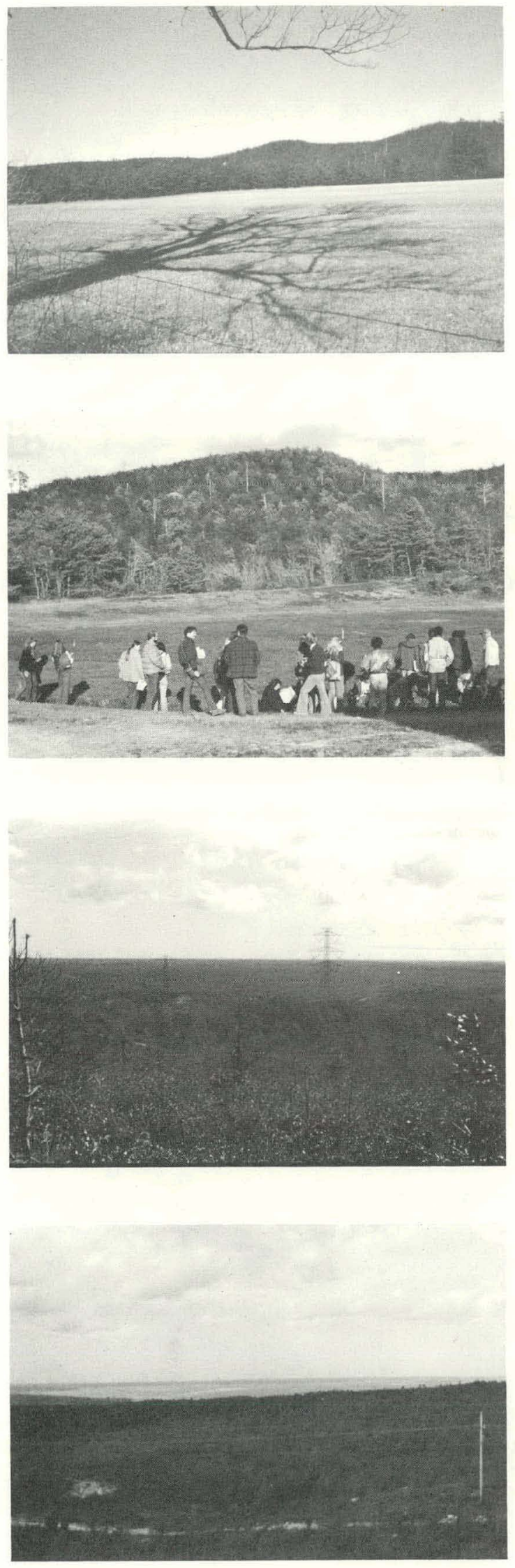

East view to ocean from the Pine Hills

Pine Hills

\section{Cranberry bog}

Fig. 5.0.8

West view across property from the

\section{Fig. 5.0.9}

Fig. 5.0 .6

Open meadow

Fig. 5.0 .7 


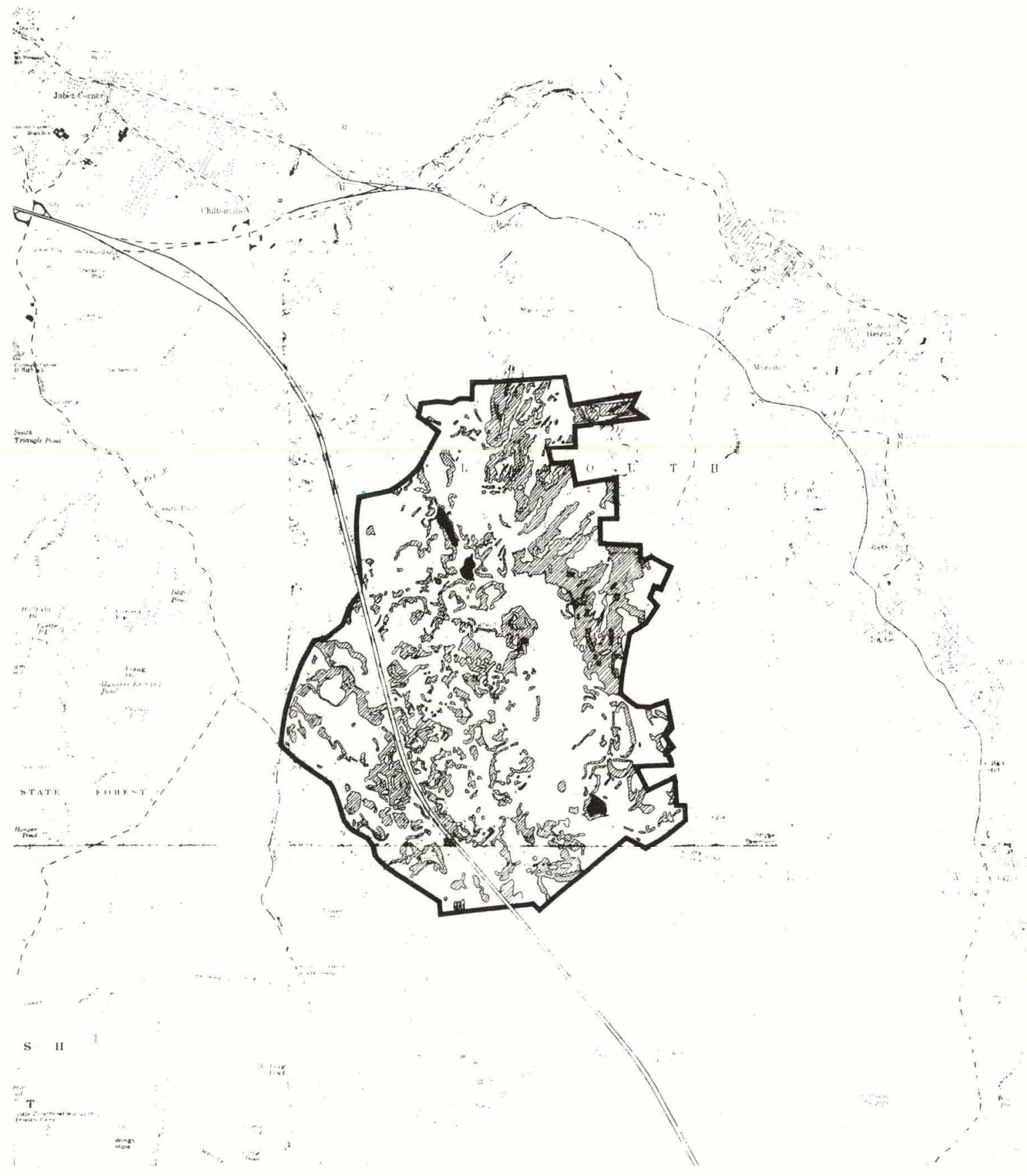

\section{Slope}

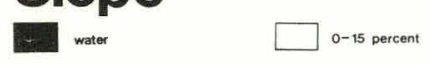

greater than 35 percent

U2A 15-35 percent

Fig. 5.0 .10 


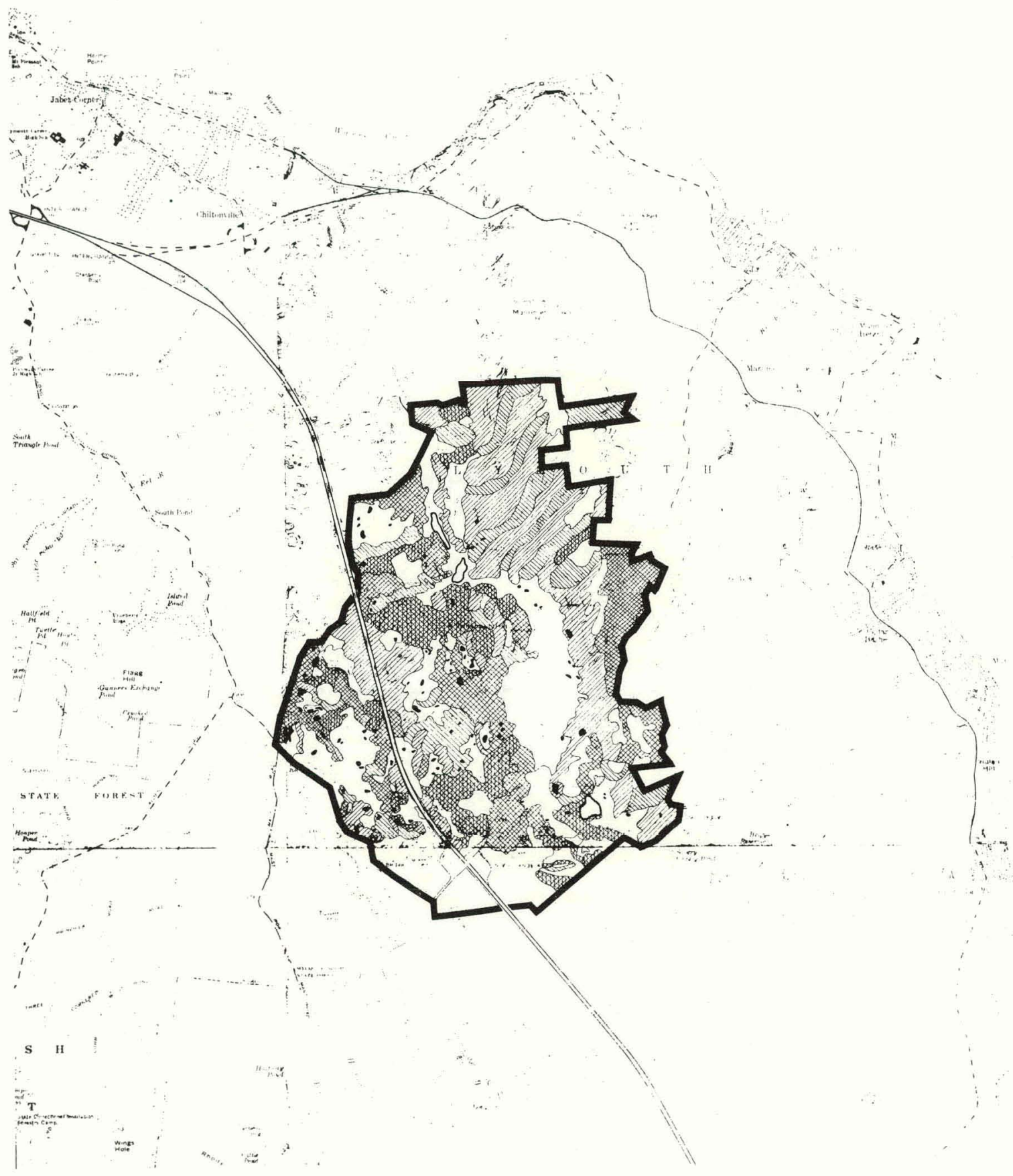

\section{Orientation}

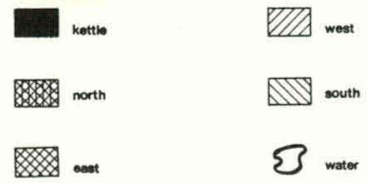

Fig. 5.0.11

Plymouth, Ma.
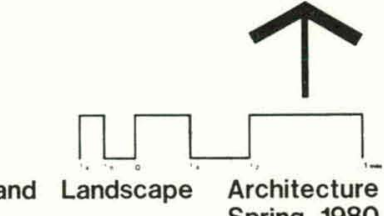
Spring 1980 


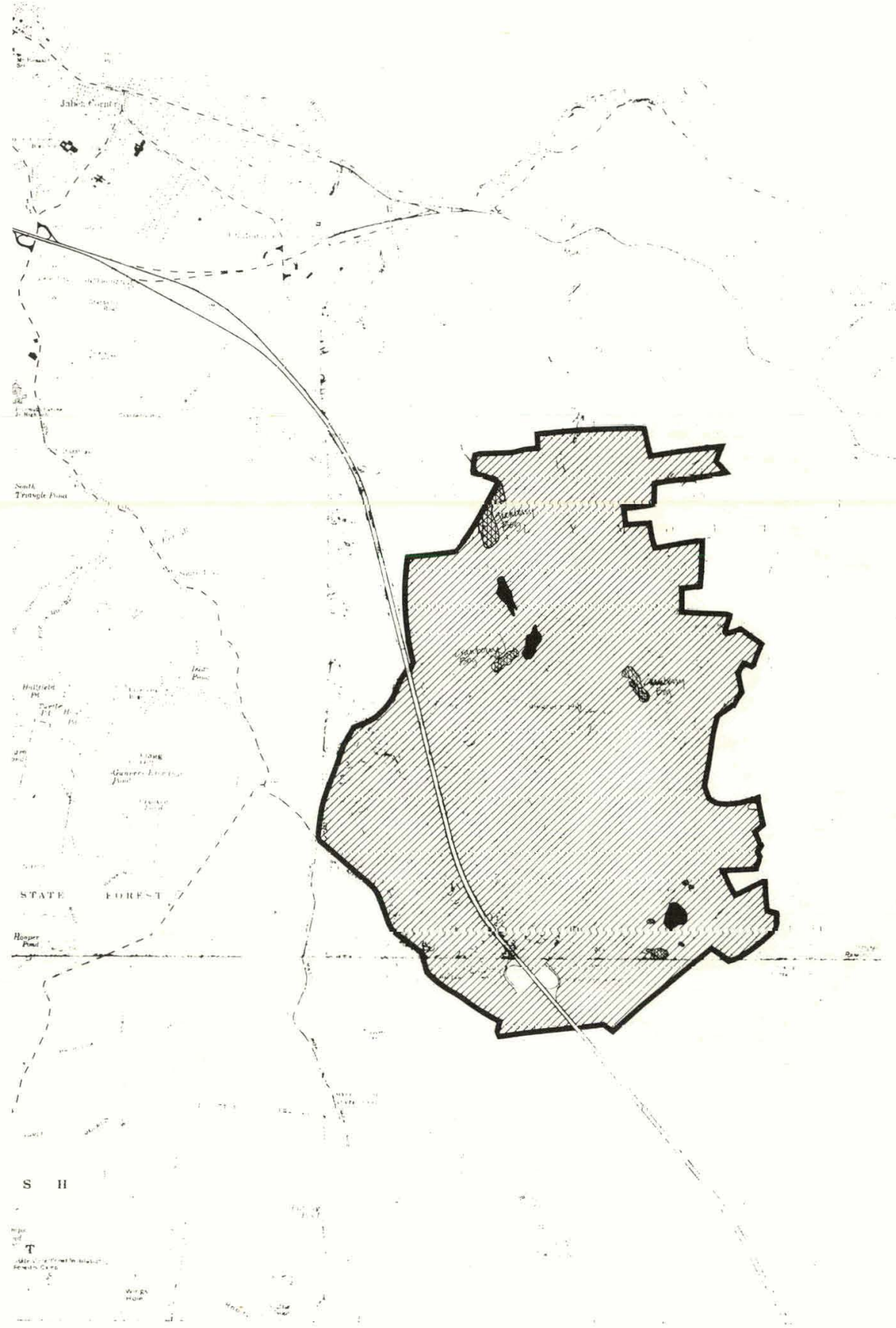

\section{Soils}
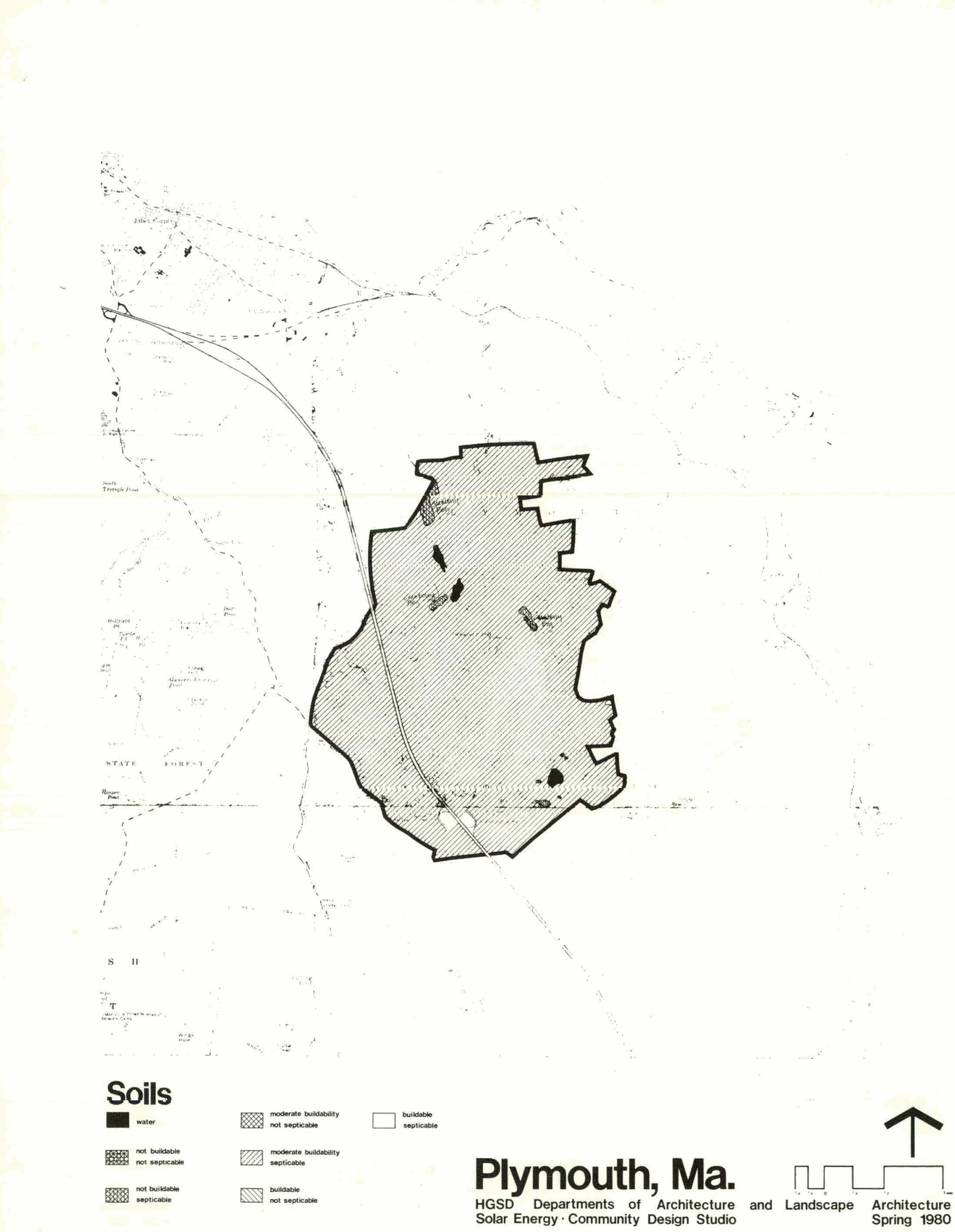

Fig. 5.0 .12 


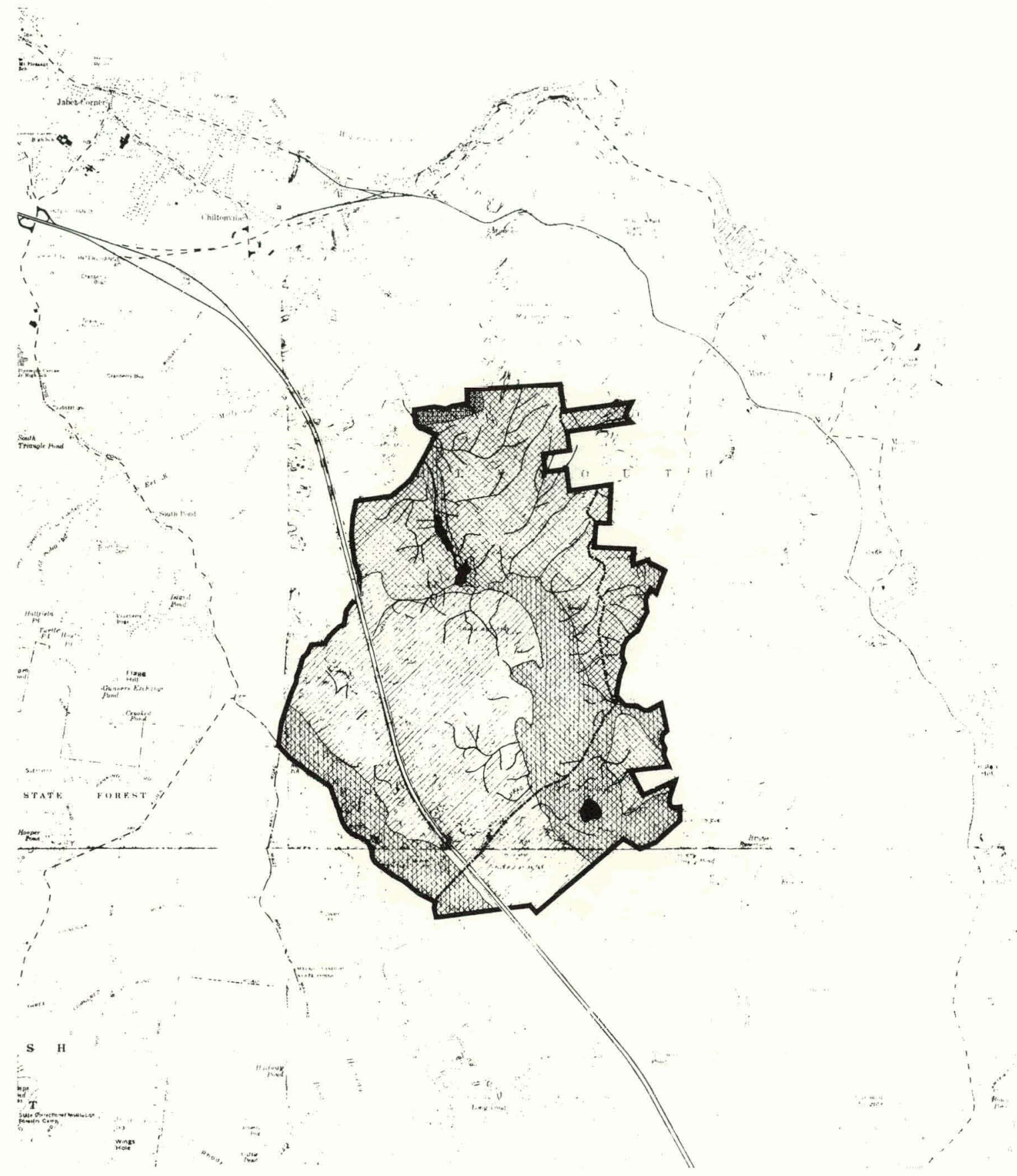

\section{Hydrology}

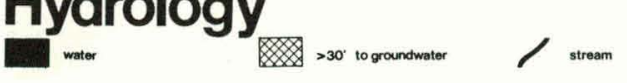

<10 to groundwater

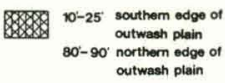

Fig. 5.0.13 


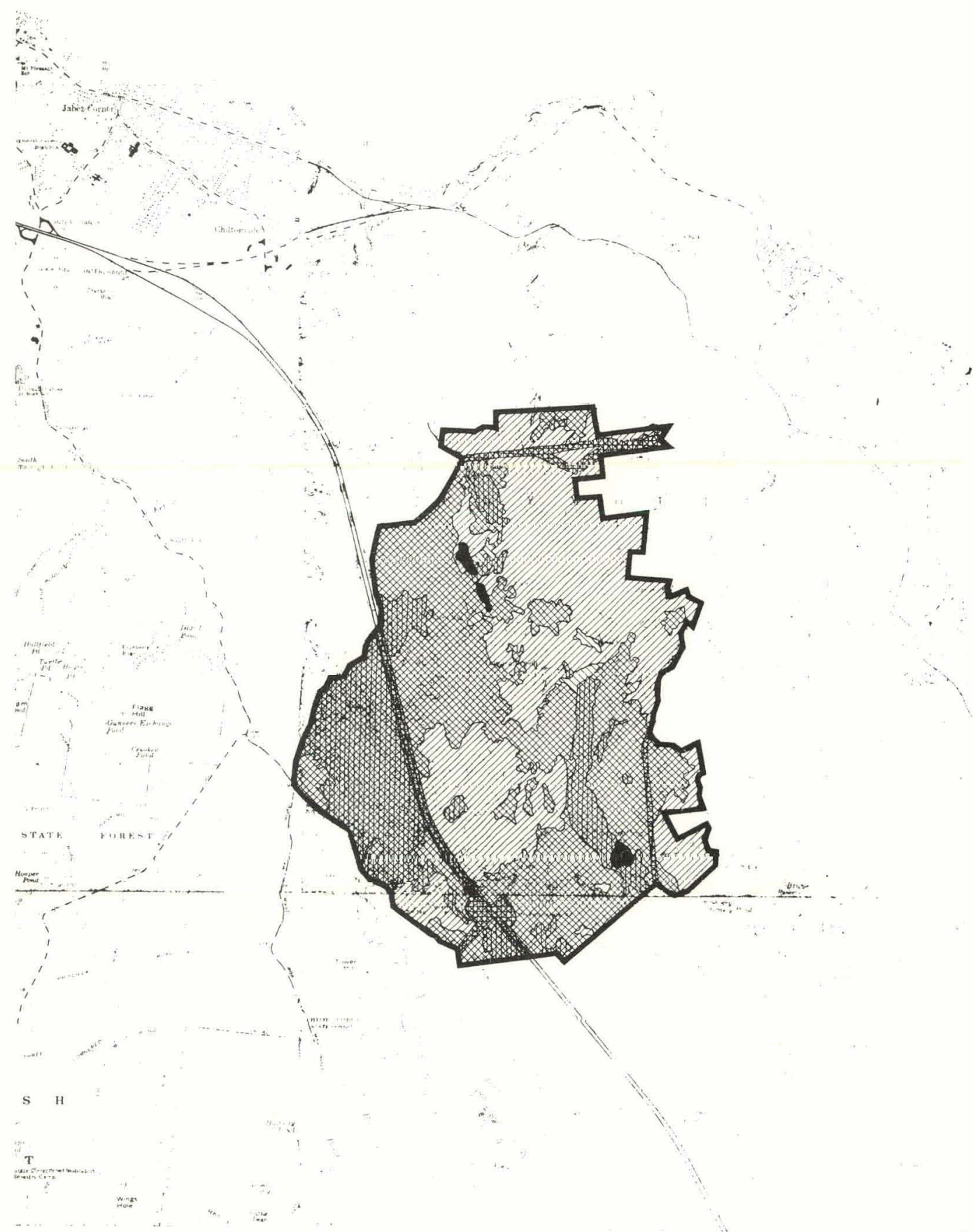

\section{Vegetation}

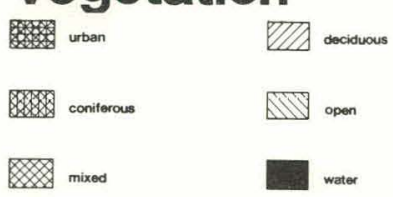

Fig. 5.0.14
Plymouth, Ma. HGSD Departments of Architecture
Solar Energy · Community Design Studio

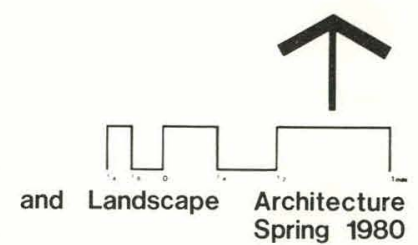




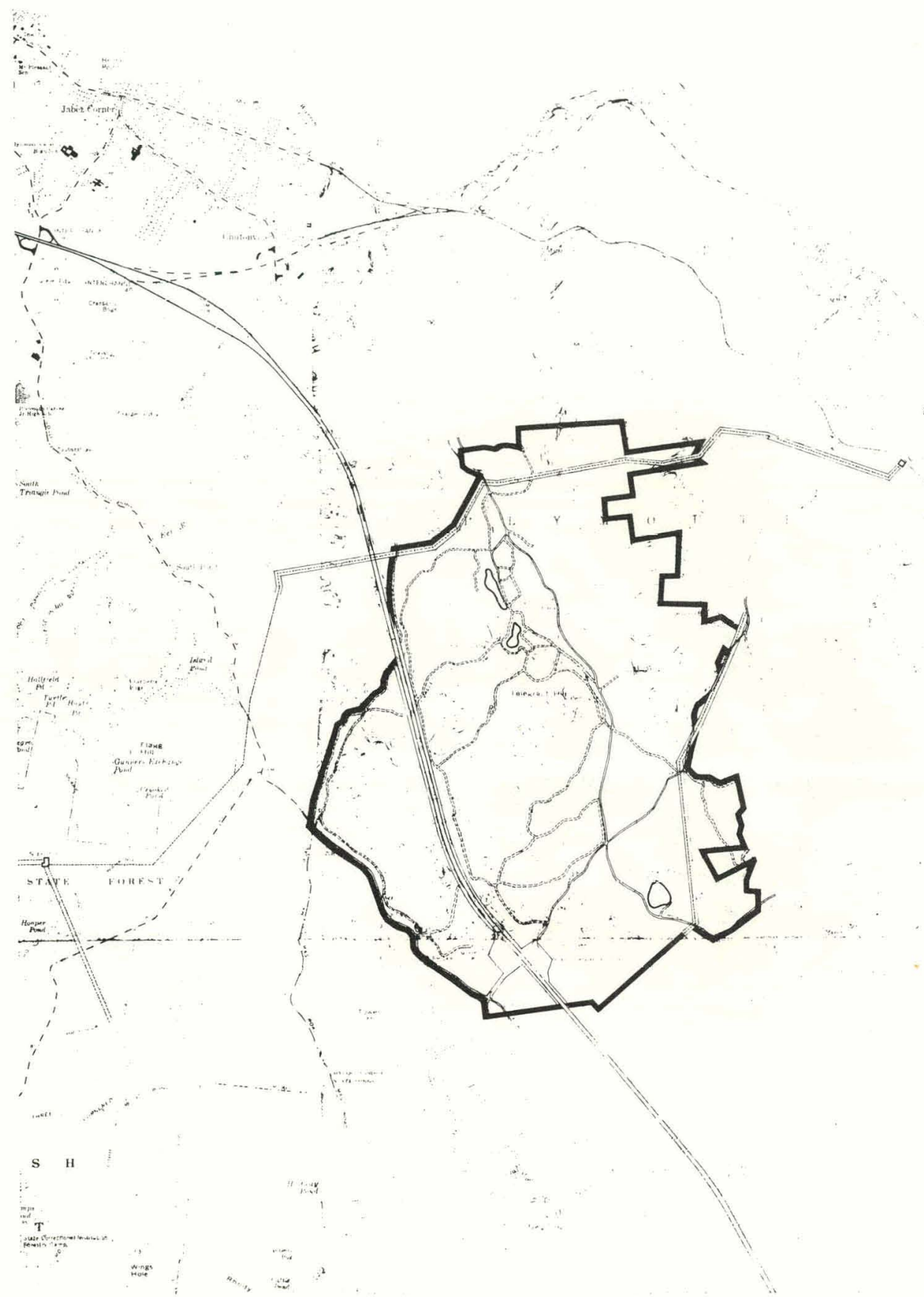

\section{Utilities}

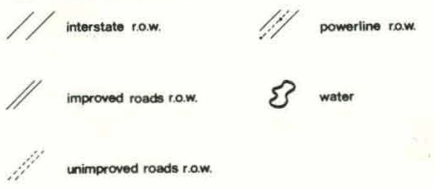

Fig. 5.0 .15

Plymouth, Ma. HGSD Departments of Architecture
Solar Energy - Community Design Studio

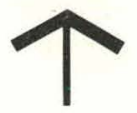

and Landscape

Architecture Spring 1980 


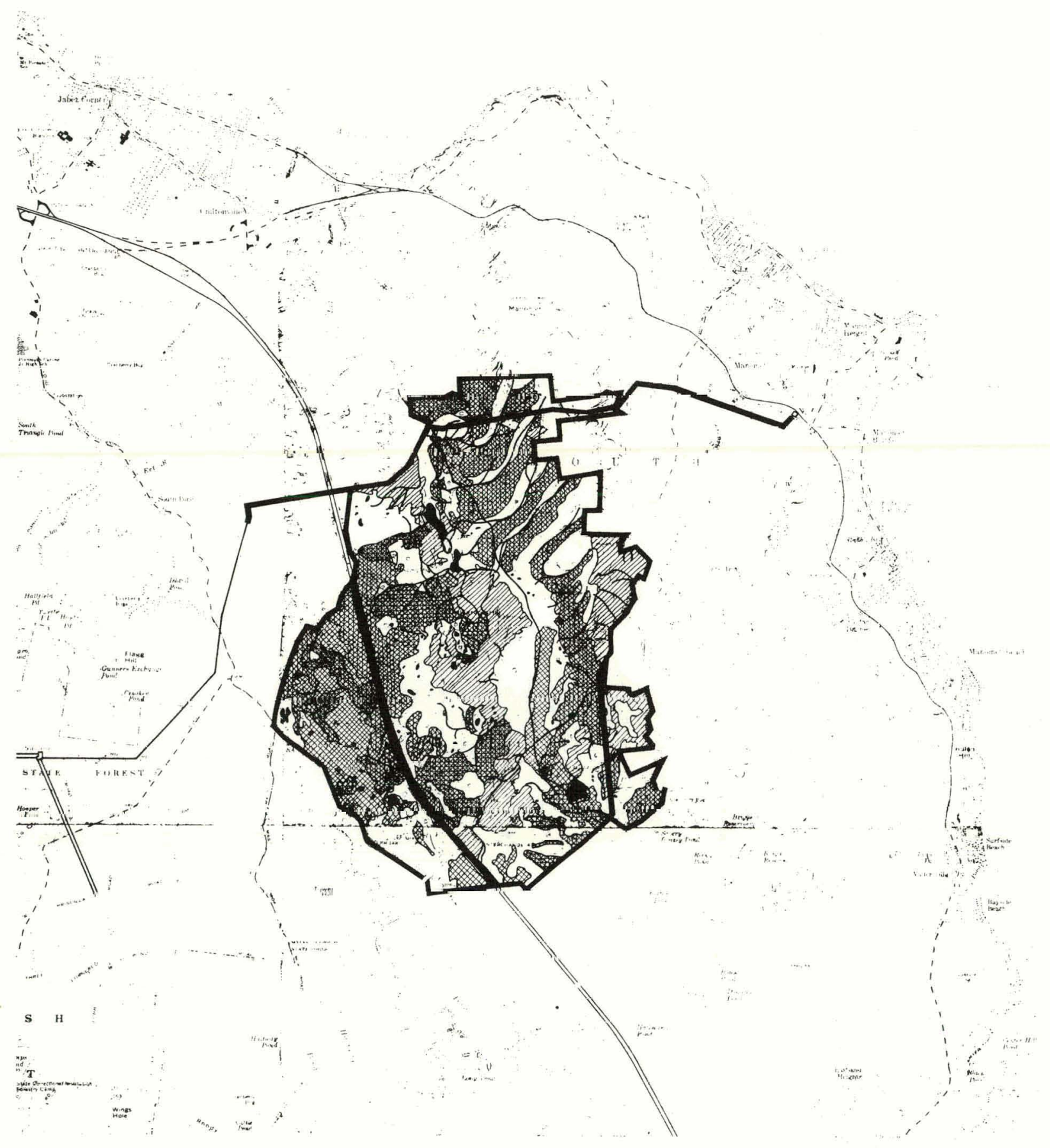

Solar Opportunities

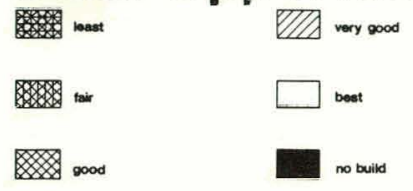

Plymouth, Ma.

HGSD Departments of Architecture and Landscape Architecture Solar Energy - Community Design Studio $\quad$ Spring 1980

Fig. 5.0.16 


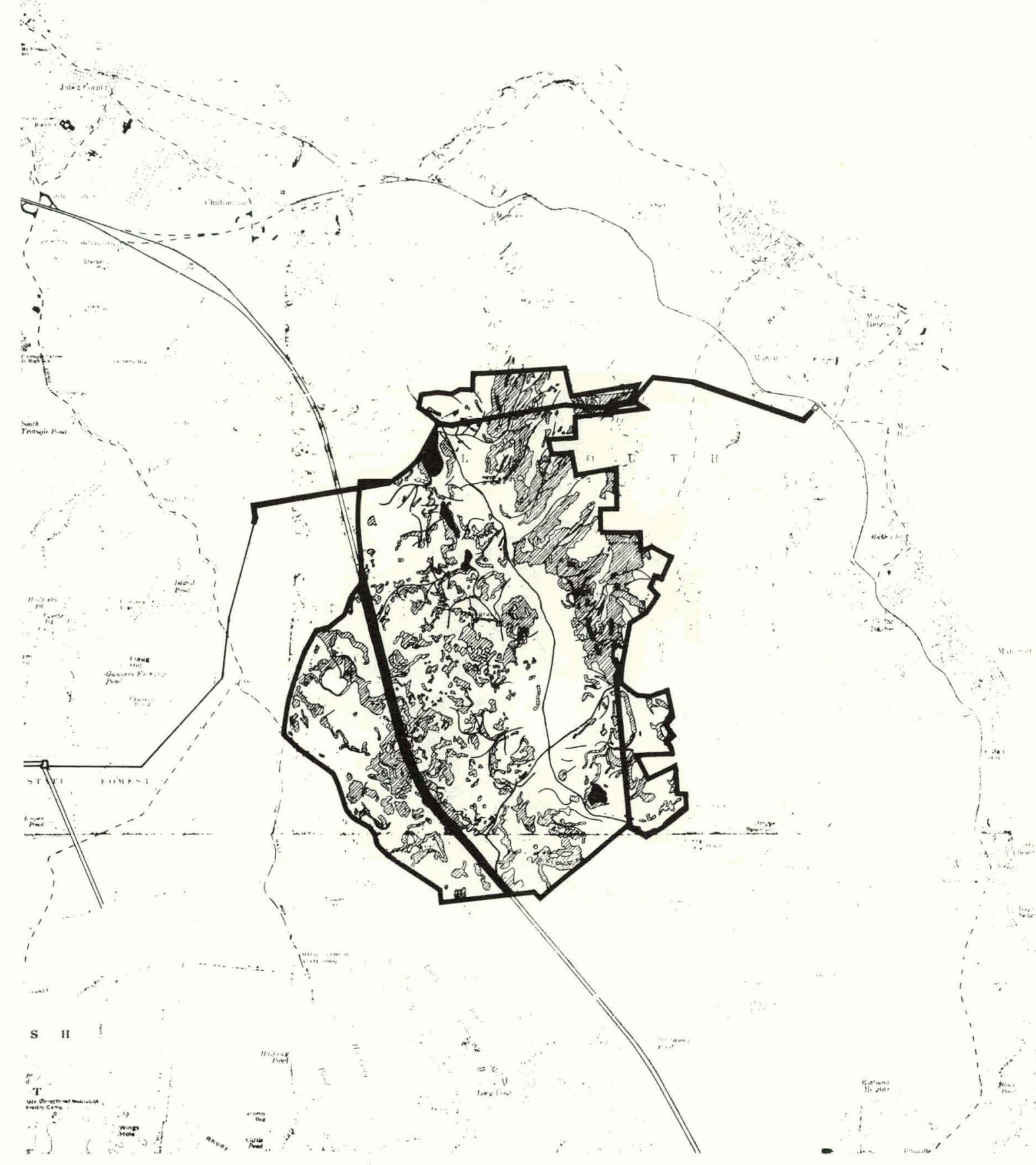

\section{Development Constraints}

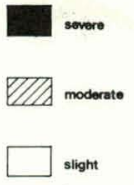

Fig. $5 \cdot 0.17$
Plymouth, Ma.

HGSD Departments of Architecture Solar Energy - Community Design Studio

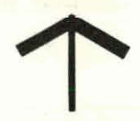

and Landscape
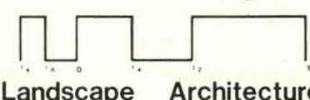

Architecture Spring 1980 


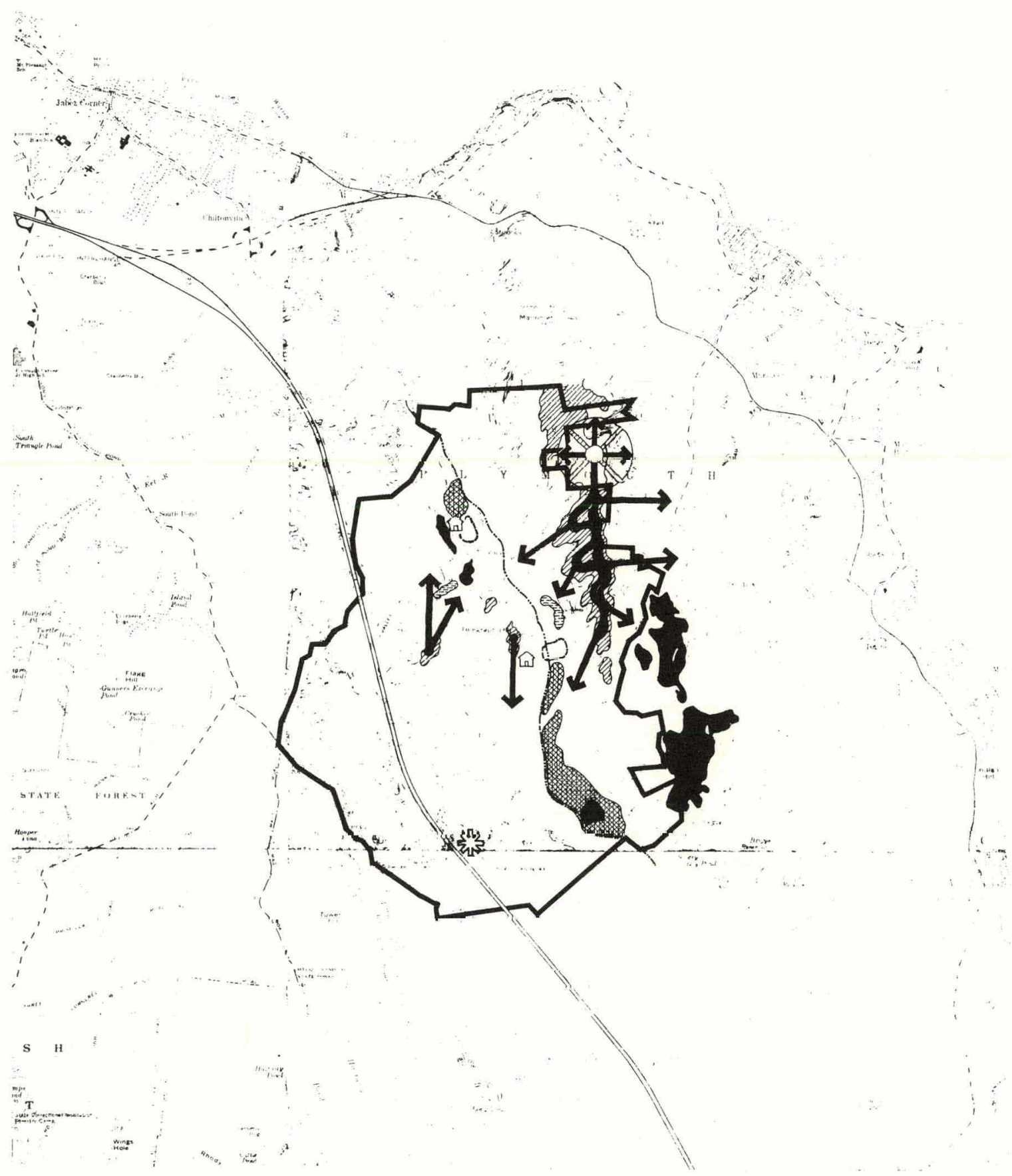

\section{Site Amenities}

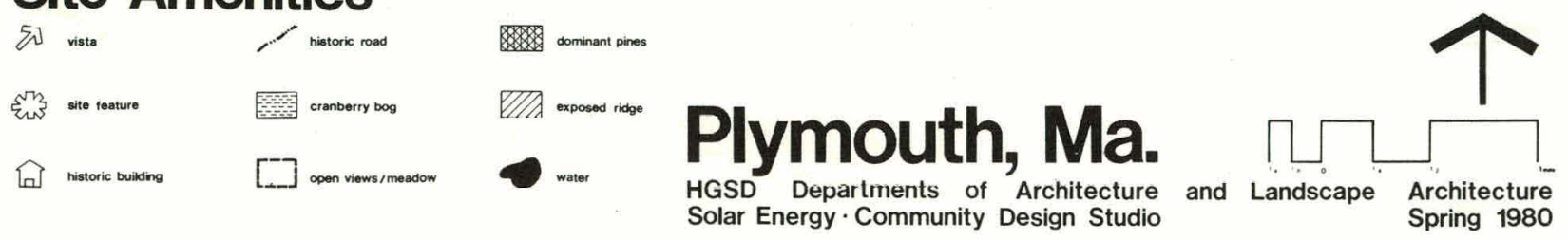

Fig. 5.0 .18 
5.1.1. PLYMOUTH 1

Design Strategy

Plymouth 1 's goal is to provide $100 \%$ of the community's energy needs by a strategy that integrates compact, dense community design with centralized energy generation and distribution, utilizing the natural sources of the sun and the wind. Thermal energy demands can be reduced by approximately 50\% through the high-density aggregation of dwelling units, the improvement of building construction standards, and strict attention to the principles of passive solar design. Remaining thermal and electrical needs are supplied by high technology systems using dish collectors and wind turbines, linked to a central storage and distribution network.

Community Plan Description (Figs. $5.1 .1 .1,5.1 .1 .2,5.1 .1 .3$ )

The site design is based on the concept of a community becoming more energy efficient as it becomes more compact. This strategy also has the advantage of leaving as much of the natural woodland of the Talcott Estate as possible available for recreational activities. The centralized, compact design provides maximum accessibility to services and major recreational features.

The primary entrance to the site is from Route $3 /$ Clarke Road Interchange. 01d Sandwich Road winds through a tall stand of pines, and into the central valley of the Talcott Estate. The valley is defined on its east and northeast by the Pine Hills, and on the west by the kettle and kame area. Telegraph Hill is a natural focus at the center of the site, linking the valley floor with the kettle and kame area and the lake to the north. Development is concentrated on the southern slopes of the Pine Hills bordering the valley, and in the areas protected by the hills from the prevailing northern winds. Housing density is highest on the southern slopes with their maximum exposure for solar access. Housing is sited to take advantage of views down the valley, and west toward the lake.

The town center has been sited into the base of the Pine Hills opposite Telegraph Hi11, protected from northerly winds and receiving maximum solar 
access. Its location is determined by its accessibility to the largest part of the community's population, and its visual prominence which provides a sense of arrival and identity. The focus of the town center is the semi-circular "winter garden" surrounding a public plaza and reflecting pool on its southern side. Retail, library, community services, theatre, and office space all have access to the winter garden. The town center has pedestrian links to the community recreational center, to the lake's edge, and to the high school and junior high school complex at the base of Telegraph Hill. All housing is less than a mile from the town center. Smaller neighborhood centers, including churches, elementary schools and convenience stores are located within half a mile of the community center. Pedestrian and bicycle circulation are emphasized over automobile transportation within the community.

Phasing (Fig. 5.1.1.2)

There are 4 phases to this "centralized" site plan. Phase 1 is divided into two sections. The first section consists of the high density residential area on the Pine Hills and the infrastructure connecting it. The development of the commercial/community service complex is part of this section. The second part of Phase I includes an additional loop road to the south, the neighborhood center, the church, and the industrial complex at the intersection of Route 3 and Clarke Road.

Phase 2 includes two additional residential roads between Sandwich Road and the pond area to the north, a second elementary school, neighborhood center, chuch, and additional housing. Phase 3 includes enlarging the pond, building the community recreation facilities, additional housing and associated infrastructure on the edge of the lake and the junior and senior high school complex. 


\subsubsection{ENERGY STRATEGY (Figs. 5.1.3.4, 5.1.4.5.)}

Plymouth's energy strategy is based on the concept that if a community is dense and centralized it can be more energy efficient. Centralization decreases transportation costs and energy distribution distances. The community does not have detached single-family housing. The community is supplying $100 \%$ of its energy demand from two primary sources, the wind and the sun. The energy plan involves a central collection and storage system with a distribution network for both thermal and electrical energy.

\section{Assumptions}

The team's approach assumes that, through aggregation of units, improved building standards and passive solar collection, thermal energy demand can be reduced by $50 \%$. The remaining $50 \%$ of thermal demand is supplied by a dish collector/thermal storage and distribution system. Thermal losses in this distribution system are assumed to be approximately $15 \%$. $60 \%$ of the electrical demand is met from steam electric generation with the dish collector system. The remaining $40 \%$ of electrical demand is met by seven wind turbines located on the Pine Hills.

Thermal Generation Strategy

Assuming the thermal energy demand can be reduced by $50 \%$ by the above means, the remaining thermal demand is supplied by the dish collector system. Rejected heat from electrical power generation, buffered by large underground thermal storage tanks is distributed and used for both heating and domestic hot water. If passive cooling is not entirely adequate, hot water distributed in the summer could be used in multi-dwelling unit absorption chillers for active cooling.

\section{Electrical Generation Strategy}

In meeting the electrical demand for this community three sources are utilized: the dish collector system, the wind turbines and the regional grid. The dish collectors, which contribute 51 mwhe/day in winter, collect energy from the sun and convert it to steam through a heat exchanger. The steam is used to power 
turbine generators. The wind turbines, which contribute 49 mwhe/day collect and distribute the energy directly to the community grid. The community is also connected to the regional power grid in order to sell excess energy, and for emergency back-up.

\subsubsection{SITING ISSUES \& HOUSING}

The team chose to explore high-density housing prototypes in detail.

High-density Housing (Figs. 5.1.3.12, 5.1.3.13)

The high-density housing is sited facing south, immediately north of the town center. The units step down the slope, and give residents excellent views down the valley. The complex contains 1,000 units at 40 D.U.s/per acre. Parking is underground, and the complex is provided with private green spaces and pedestrian access to the town center.

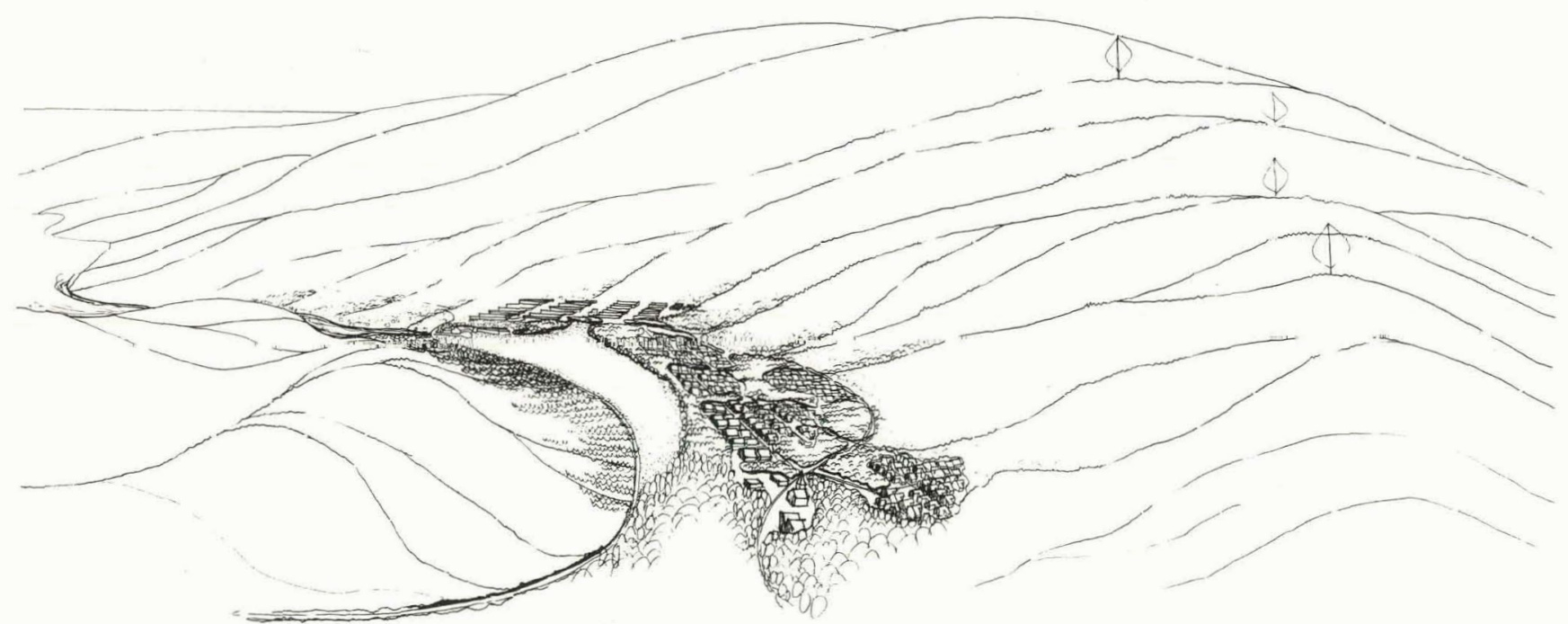

TEAM 1

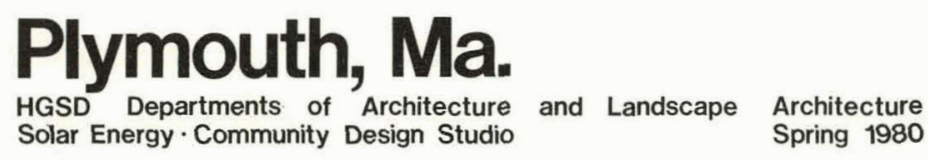


THIS PAGE

\section{WAS INTENTIONALLY LEFT BLANK}


PLYMOUTH 1

ASSUMPTIONS AND EXPLANATIONS

$1.50 \%$ of heating and $100 \%$ of cooling needs will be met by passive systems on a building by building basis.

2. Additional domestic hot water could be provided from roof-mounted systems if necessary.

\begin{tabular}{|l|l|l|l|}
\hline $\begin{array}{l}\text { TYPE OF BUILDING OR } \\
\text { DEMAND }\end{array}$ & \multicolumn{2}{|l|}{ UNITS/AREA } & ELECTRICAL \\
\cline { 2 - 4 } & UUANTITY & $\begin{array}{c}\text { AREA/UNIT } \\
\text { TOR. AREA }\end{array}$ & Mwh/Day \\
\hline
\end{tabular}

\begin{tabular}{|l|c|c|c|}
\hline Hillside housing & 250 & 1,350 s.f./u. & \\
\hline Hillside housing & 500 & 950 s.f./u. & \\
\hline Hillside housing & 250 & 700 s.f./u. & \\
\hline Lake housing & 200 & 1,500 s.f./u. & \\
\hline Lake housing & 100 & 800 s.f./u. & \\
\hline Other housing & 335 & 2,000 s.f./u. & \\
\hline Other housing & 850 & 1,500 s.f./u. & \\
\hline Other housing & 1600 & 1,350 s.f./u. & \\
\hline Ollier liousing & 335 & 900 s.f./u. & (tot.res.) 53 \\
\hline Schools & & & \\
\hline Community services & & & \\
\hline Churches & & & \\
\hline Local retail & & & \\
\hline Central retail & & & \\
\hline 0ffices & & & \\
\hline
\end{tabular}

\section{total community energy demand}


demand

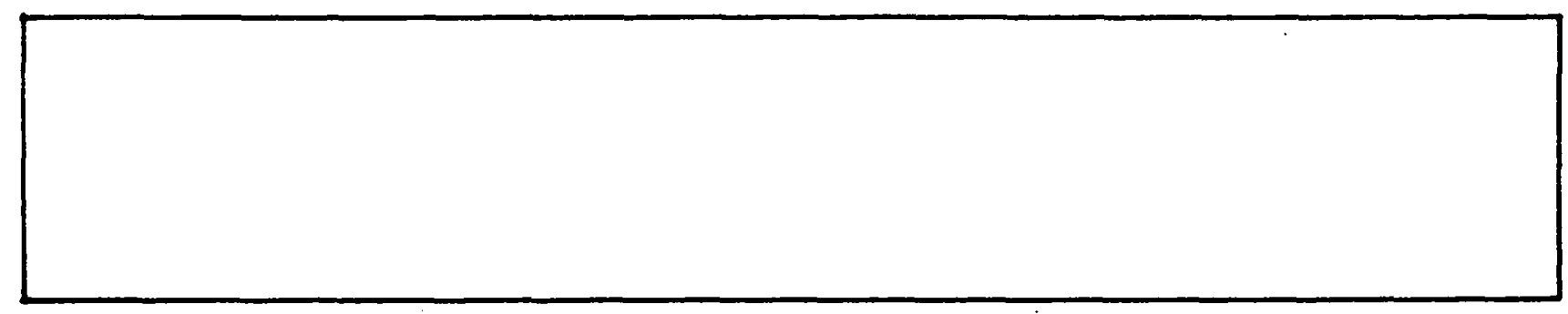

\begin{tabular}{|l|l|l|l|l|l|}
\hline \multicolumn{2}{|l|}{ HEATING LOAD } & \multicolumn{2}{l|}{ COOLING LOAD } & \multicolumn{2}{l|}{ DOMESTIC HOT WATER } \\
\hline $10^{6}$ Btu/Day & Mwh (Th)/Day & $10^{6}$ Btu/Day & Mwh(Th)/Day & $10^{6}$ Btu/Day & Mwh(Th)/Day \\
\hline
\end{tabular}

\begin{tabular}{|c|c|c|c|c|c|}
\hline 27.00 & 7.91 & - & & 11.50 & 3.37 \\
\hline 38.00 & 11.13 & & & 19.00 & 5.56 \\
\hline 12.50 & 3.66 & & & 6.75 & 1.98 \\
\hline 28.00 & 8.20 & & & 10.80 & 3.16 \\
\hline 7.60 & 2.23 & & & 3.80 & 1.11 \\
\hline 62.40 & 18.27 & & & 24.50 & 7.18 \\
\hline 119.00 & 34.85 & & & 45.90 & 13.44 \\
\hline 201.60 & 59.04 & & & 73.60 & 21.56 \\
\hline 28.80 & 8.44 & & & 12.70 & 3.72 \\
\hline 13.20 & 3.87 & & & 6.30 & 1.85 \\
\hline 2.00 & 0.59 & & & 0.10 & 0.03 \\
\hline 12.60 & 3.69 & & & 0.80 & 0.23 \\
\hline 2.00 & 0.59 & & & 0.10 & 0.03 \\
\hline 0.60 & 0.18 & & & 0.106 & 0.01 \\
\hline 1.60 & 0.47 & & & 1.70 & 0.50 \\
\hline & & & & & \\
\hline & & & & & \\
\hline & & & & & \\
\hline
\end{tabular}




\section{PLYMOUTH 1}

\section{supply}

\begin{tabular}{|c|c|c|c|}
\hline ENERGY SOURCE & APPLICATION & CONFIGURATION & $\begin{array}{l}\text { SUPPLY } \\
\text { Mwh / Day }\end{array}$ \\
\hline \multicolumn{4}{|l|}{ STORAGE SYSTEMS } \\
\hline \multirow{2}{*}{$\begin{array}{l}\text { 1. Low temperature } \\
\text { thermal storage }\end{array}$} & space and hot water & buried tank & \\
\hline & heating, supply/ & & \\
\hline & demand buffer & & \\
\hline 2. High temperature & electrical genera- & hot oil storage & \\
\hline thermal storage & tion for about 6 & system & \\
\hline & hours & & \\
\hline & & & \\
\hline & & & \\
\hline
\end{tabular}

\begin{tabular}{|l|l|l|l|}
\hline SUPPLY SYSTEMS & \multicolumn{3}{|l|}{} \\
\hline 1. Dish collector & 1. Electrical demand & 1.92 acre field & 51 Mh(e) \\
\hline fields & 2. Thermal demand & 2. by product & 113 MWh (Th) \\
\hline 2. Wind turbines & 1. Electrical demand & 1.7 turbines 0 & \\
\hline & & 7 MWh(e)/Day & 49 MWh(e) \\
\hline & & & \\
\hline & & & \\
\hline & & & \\
\hline & & & \\
\hline
\end{tabular}

\section{total community energy supply too mance}




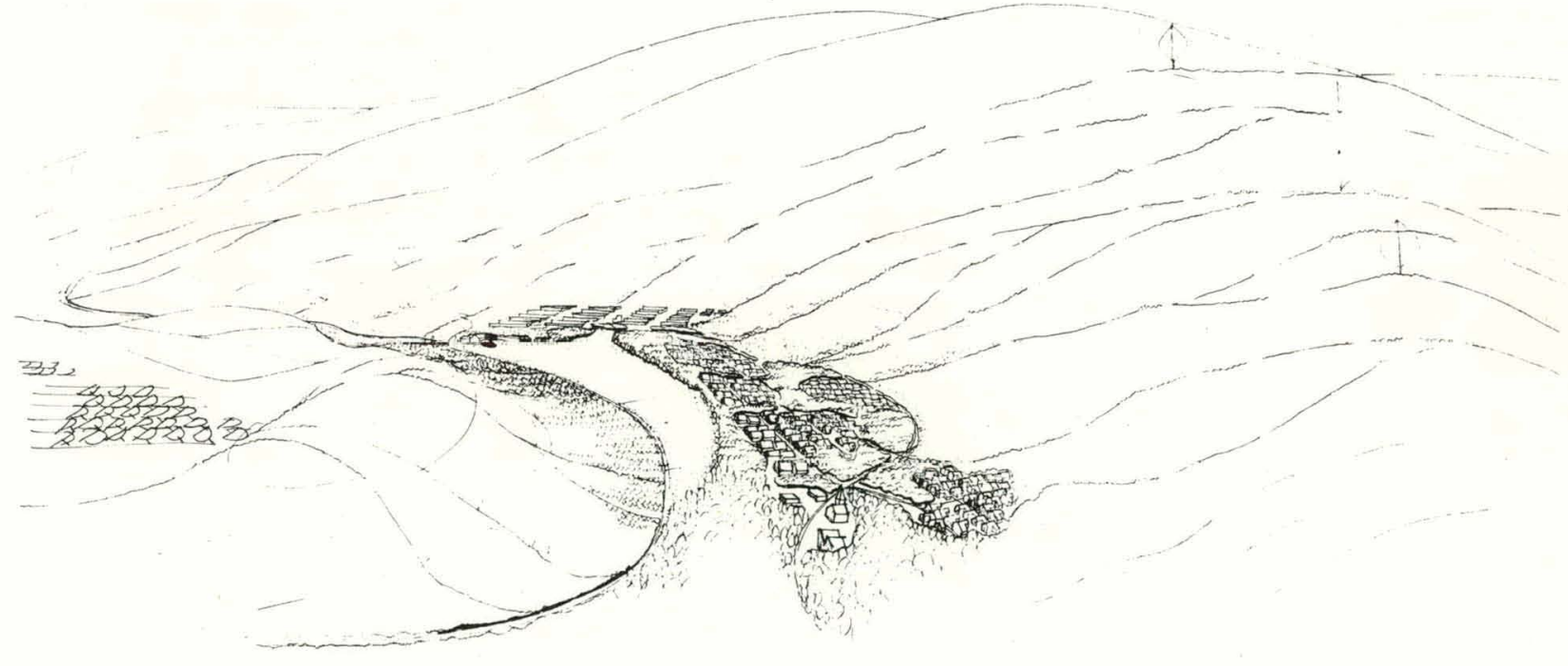

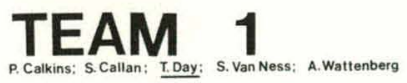

Fig. 5.1.1.1 


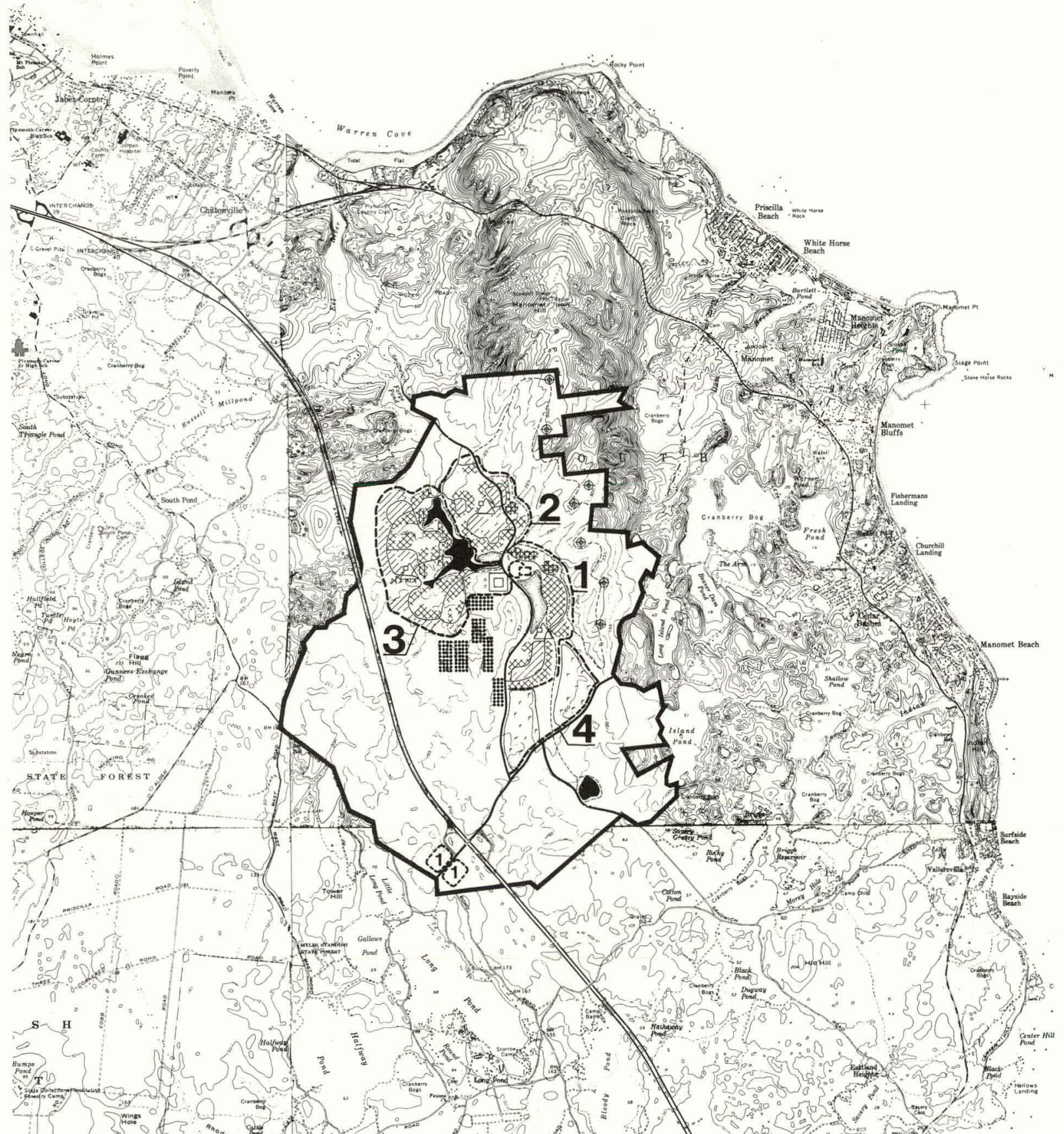

\section{Concept/Phasing}

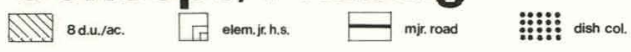

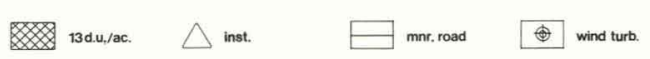

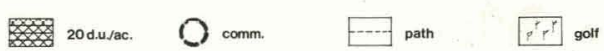

40.u./ac. (5) indort.

Fig. 5.1.1.2

\section{TEAM 1}

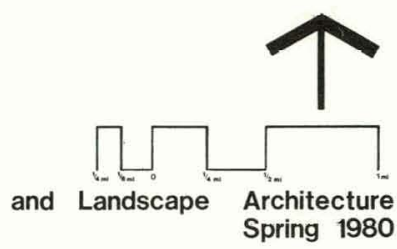




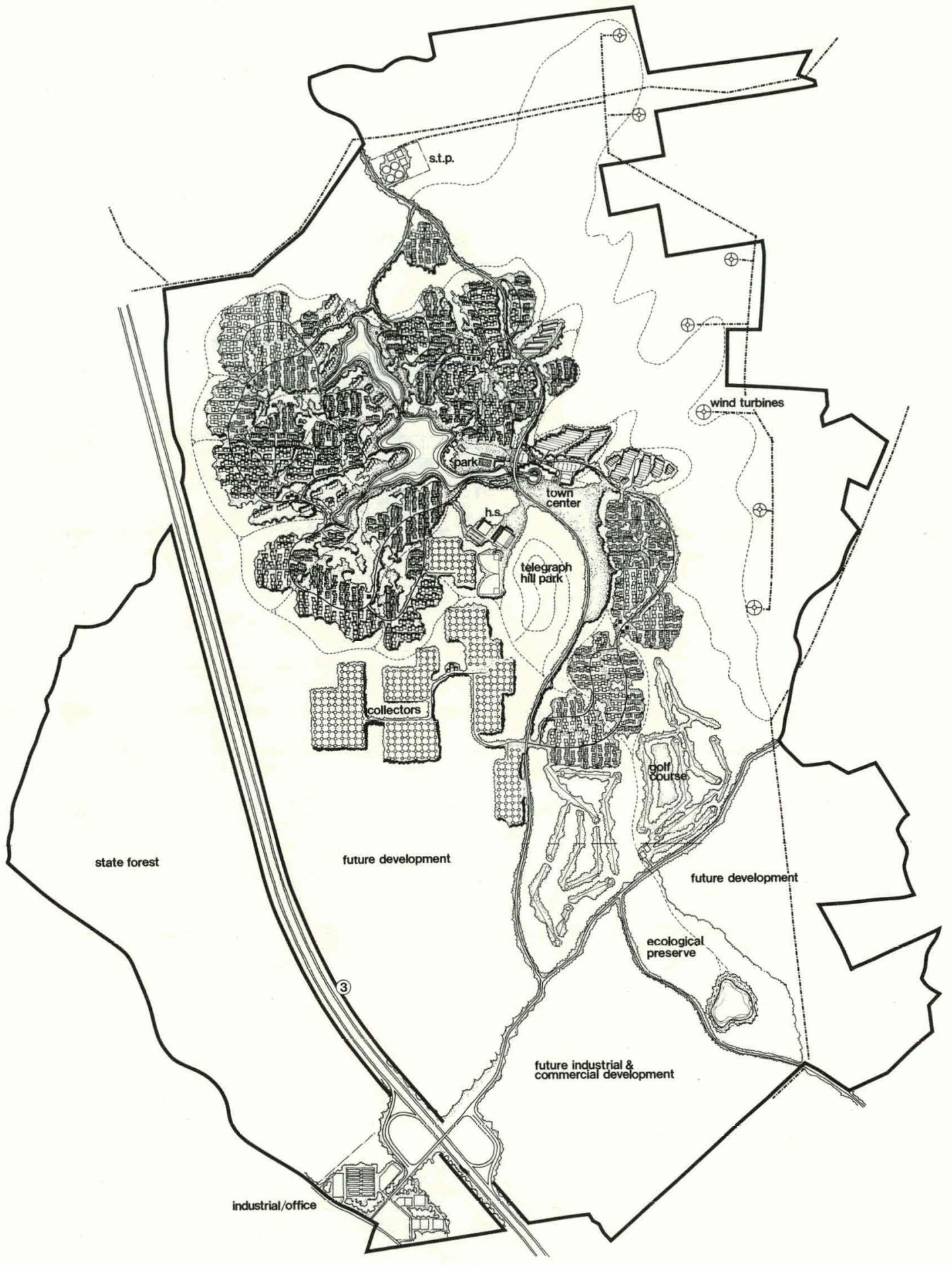

Site Plan

TEAM 1

Plymouth, Ma.

HGSD Departments of Architecture Solar Energy - Community Design Studio
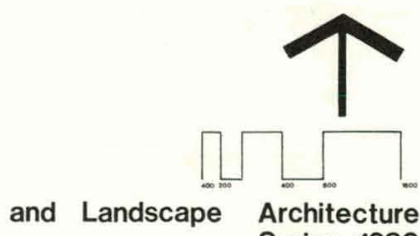

Fig. 5.1.1.3 


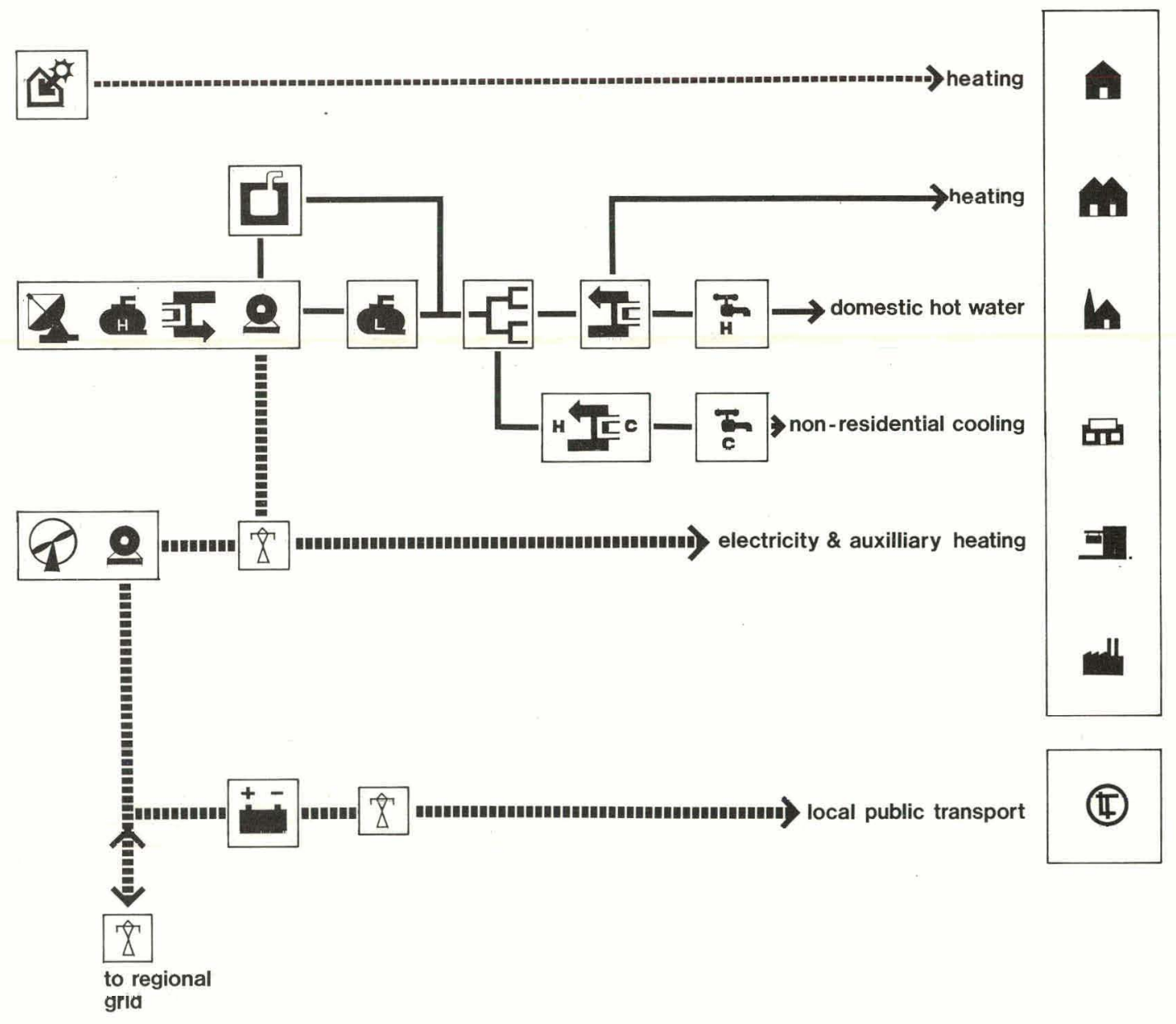

\section{Energy Diagram}

TEAM 1

Fig. 5.1.2.4 


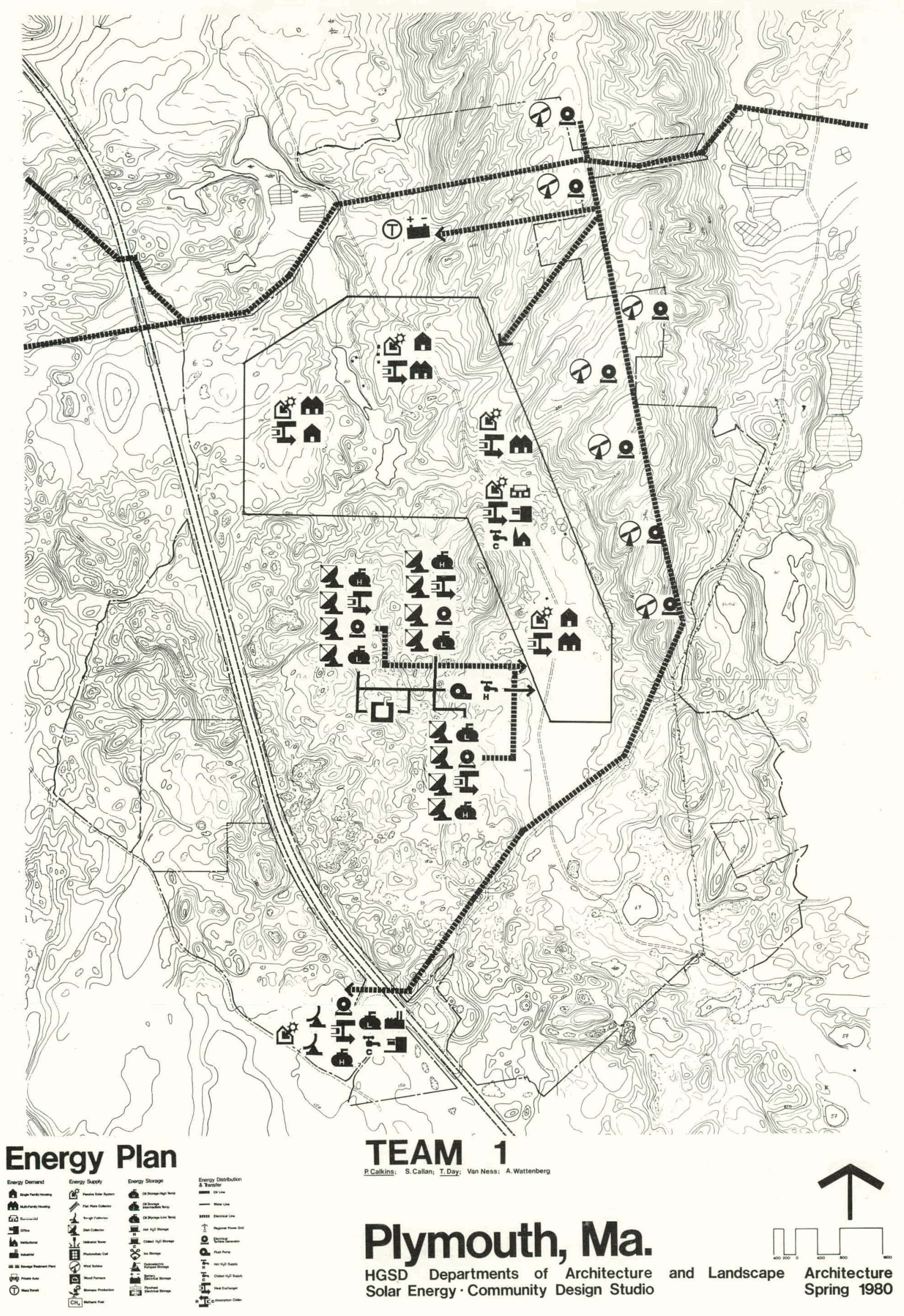

Fig. 5.1.2.5 


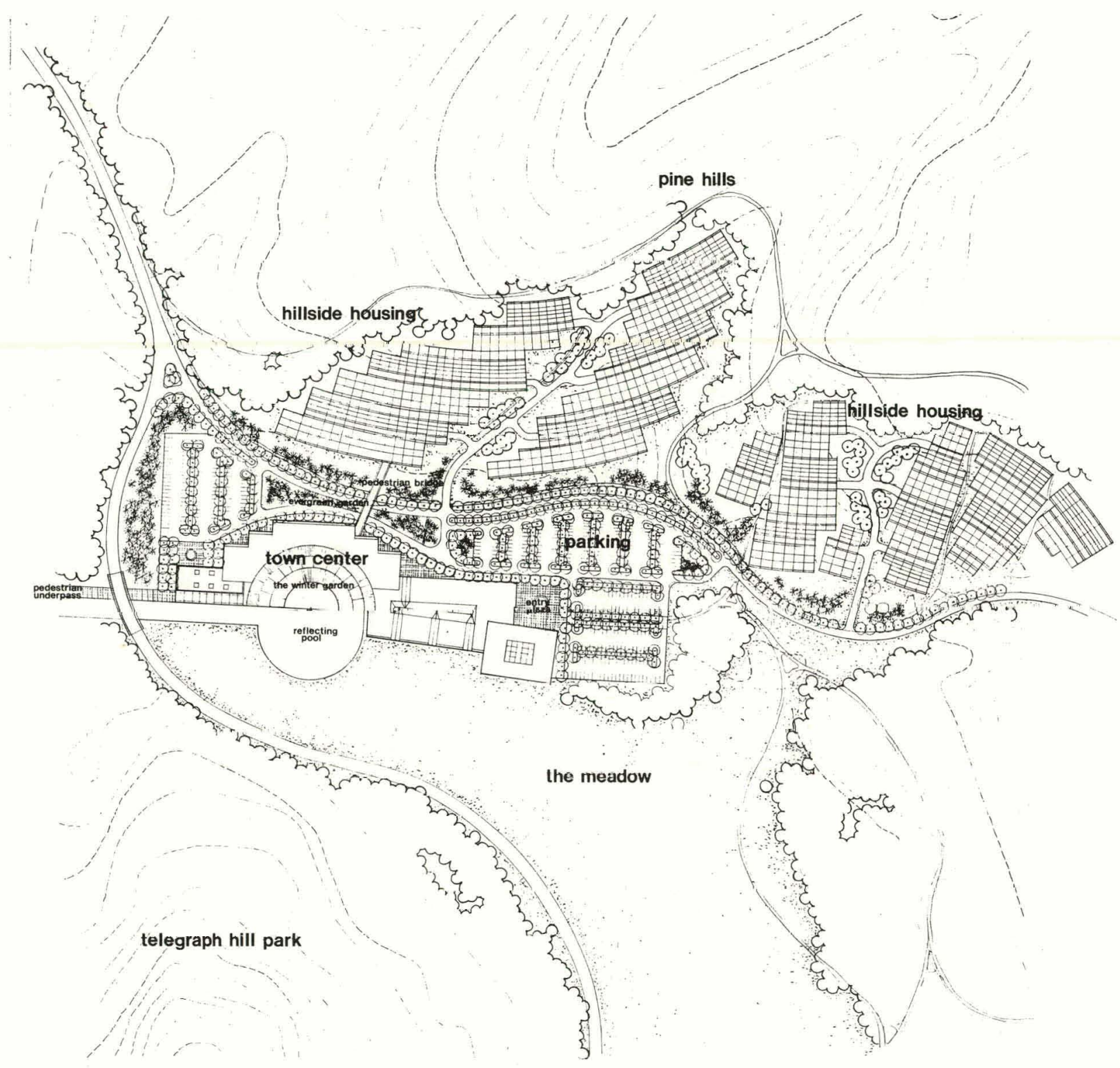

Town Center Site Plan
TEAM 1

Plymouth, Ma. HGSD Departments of Architecture
Solar Energy - Community Design Studio
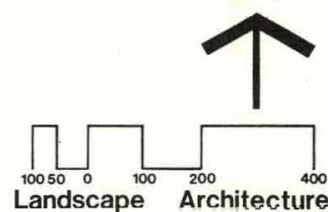
Spring 1980

Fig. 5.1.3.6 

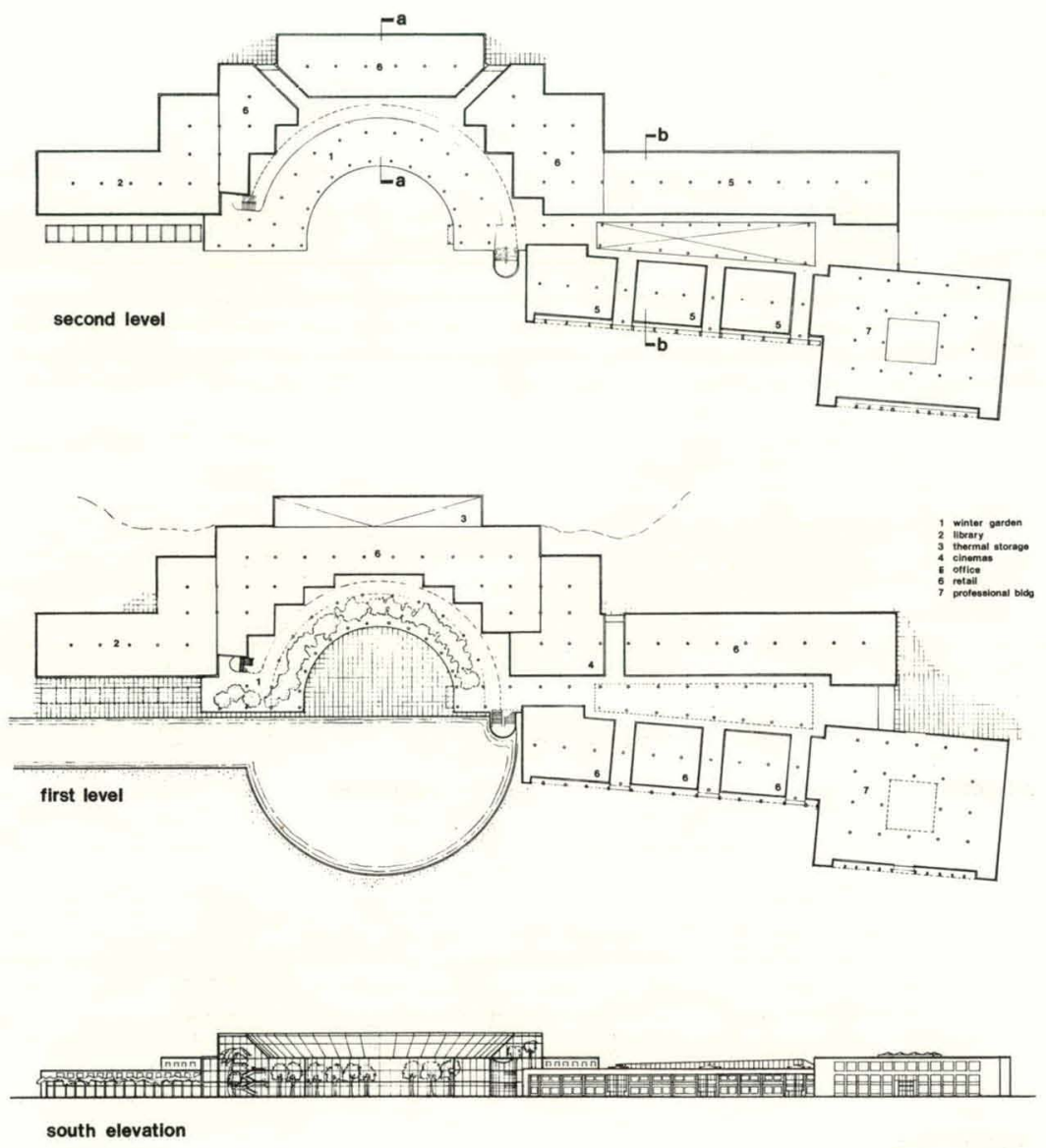

\section{Town Center}

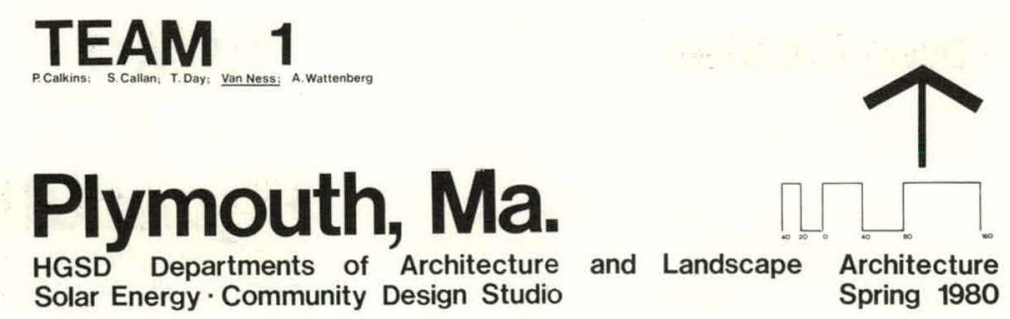

Fig. 5.1.3.7 

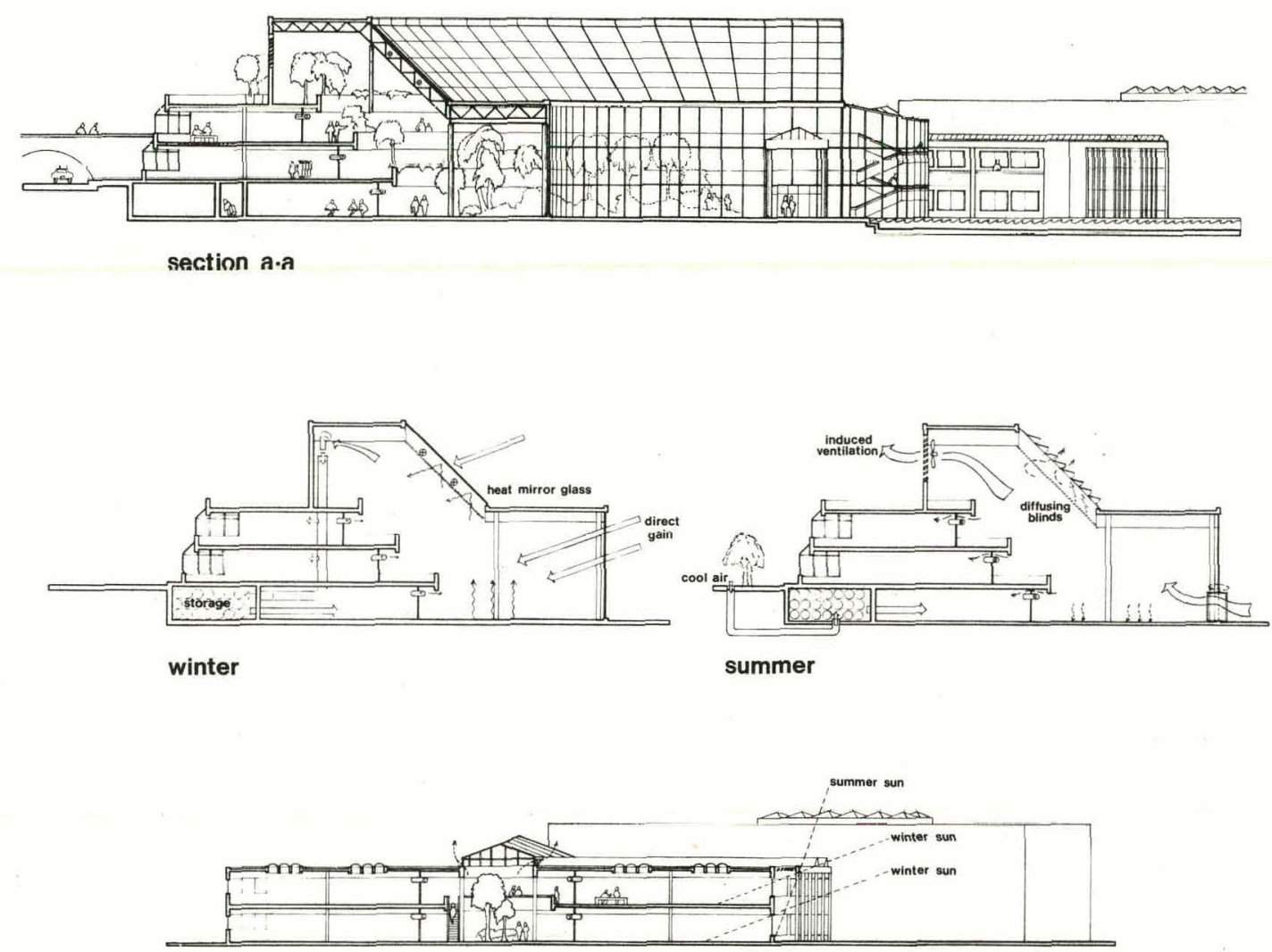

section $\mathbf{b} \cdot \mathbf{b}$

Town Center

Fig. 5.1.3.8
TEAM 1

P. Calkins: S. Callan: Y. Day: S. Van Ness: A Wattenherg

Plymouth, Ma. HGSD Departments of Architecture
Solar Energy - Community Design Studio

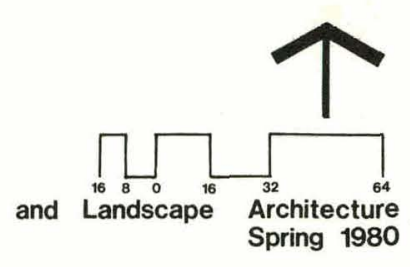



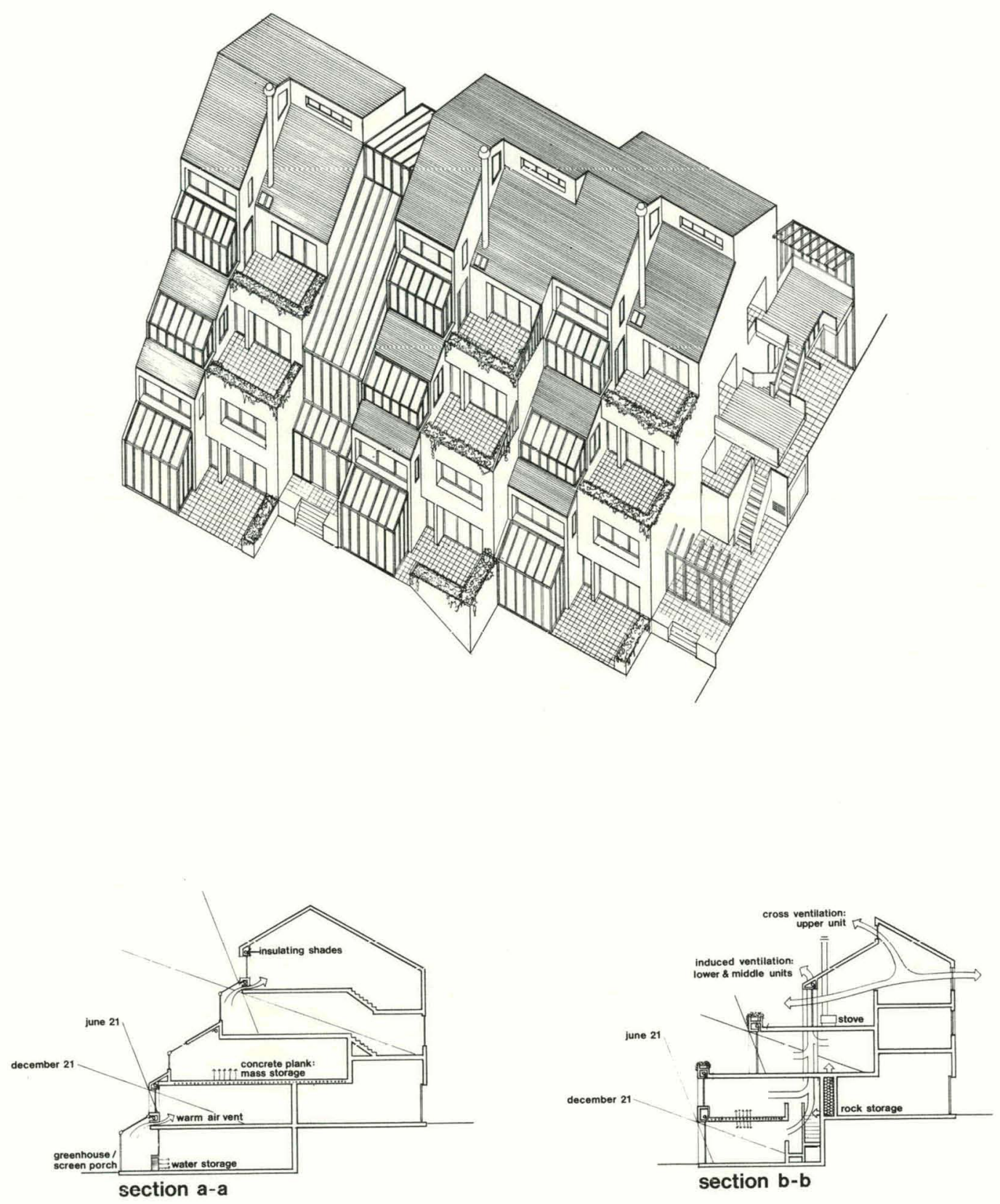

\section{Lake Housing}

\section{TEAM 1}

Plymouth, Ma.

HGSD Departments of Architecture
Solar Energy - Community Design Studio
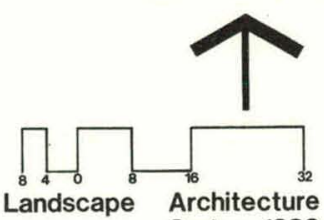
Architecture
Spring 1980

Fig. 5.1.3.9 

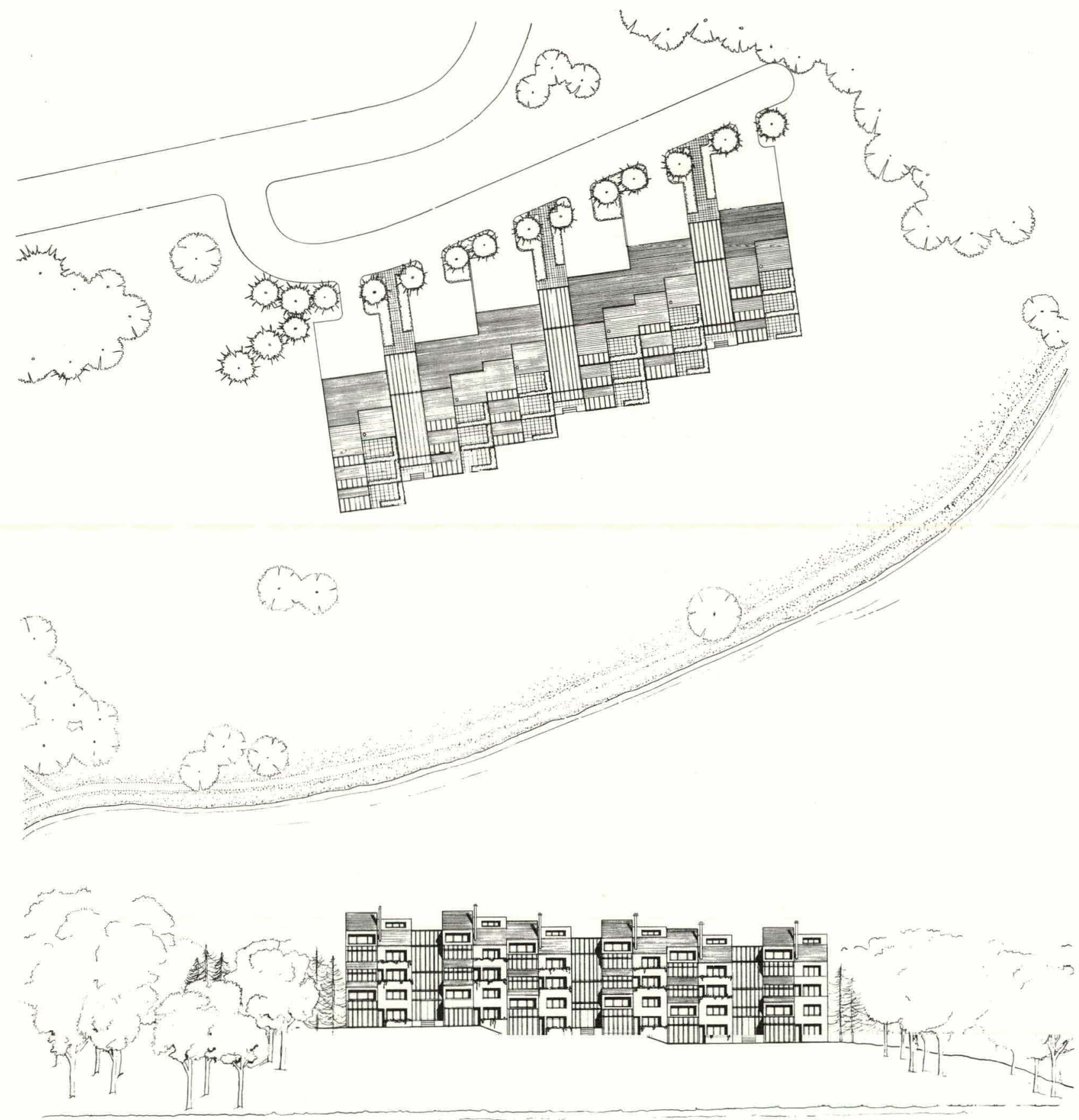

\section{$\underset{8-13 \text { d.u. / acre }}{\text { Lake Housing }}$}

TEAM 1

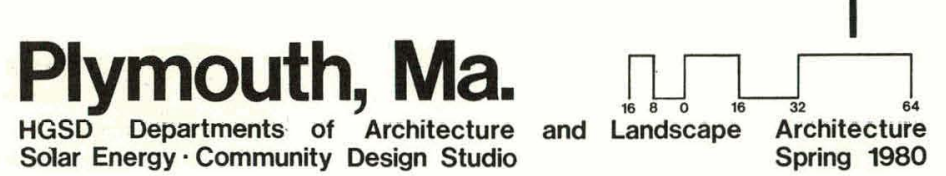

Fig. 5.1.3.10 

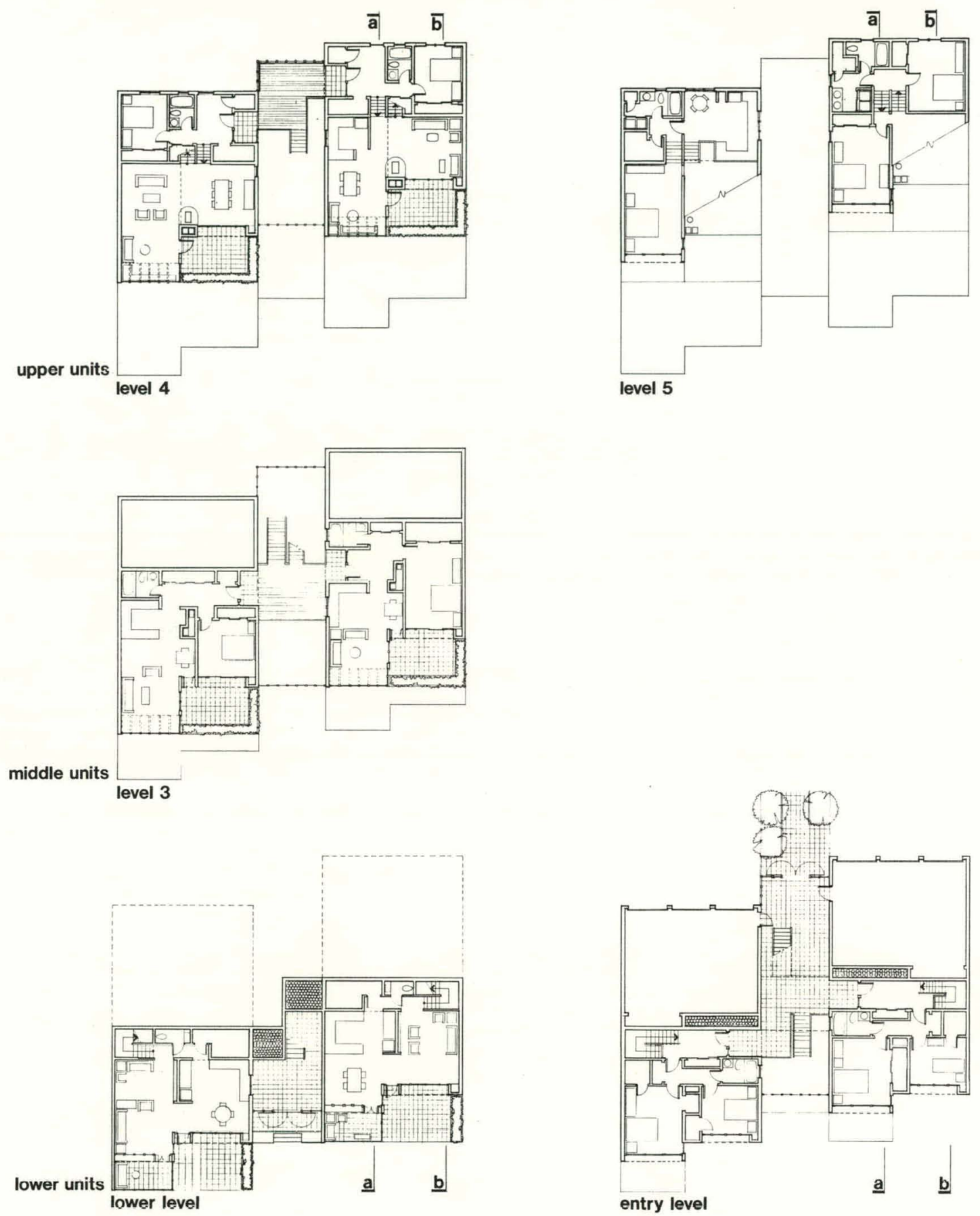

\section{Lake Housing}

8-13 d.u. / acre

\section{TEAM 1}

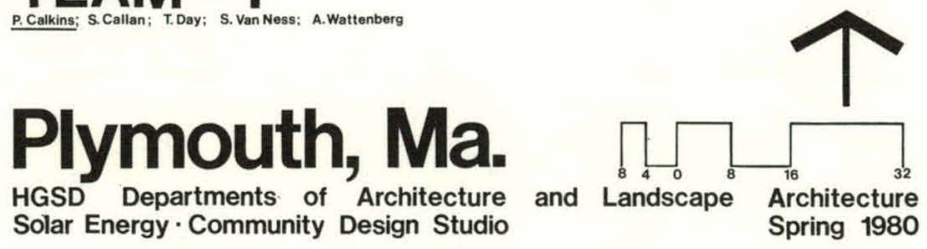

Fig. 5.1.3.11 

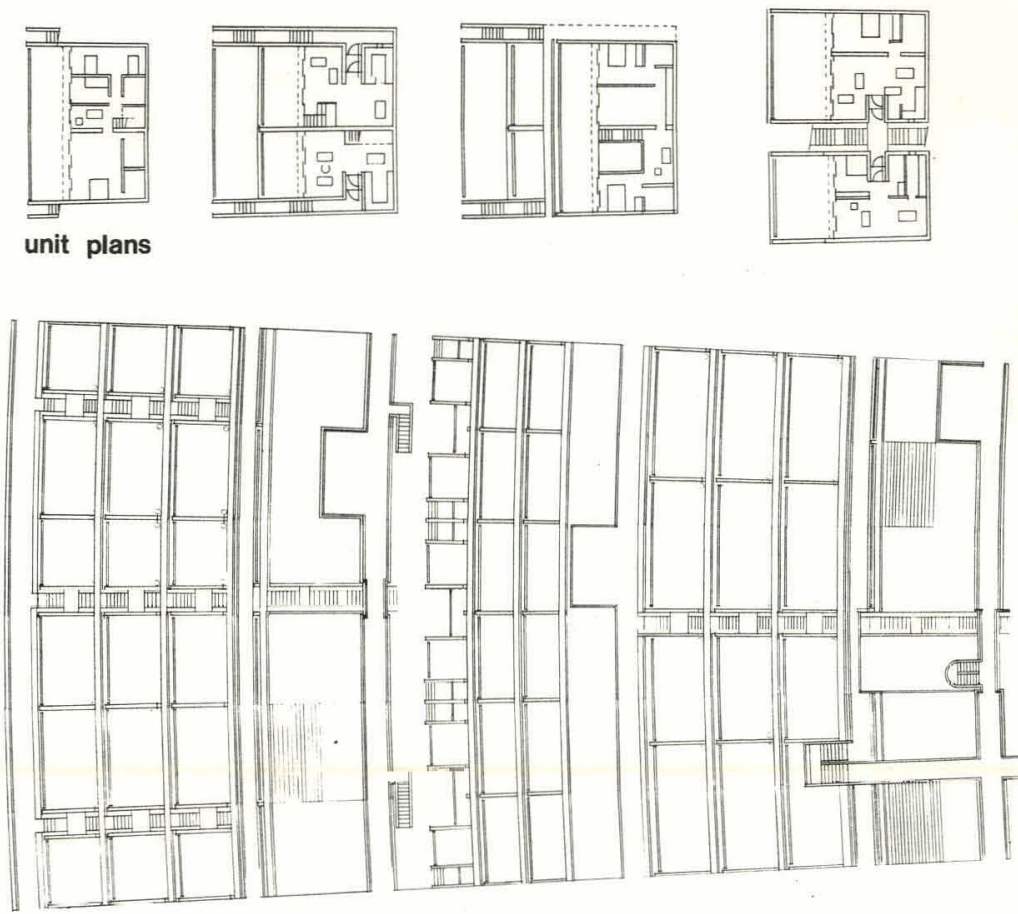

typical roof plan

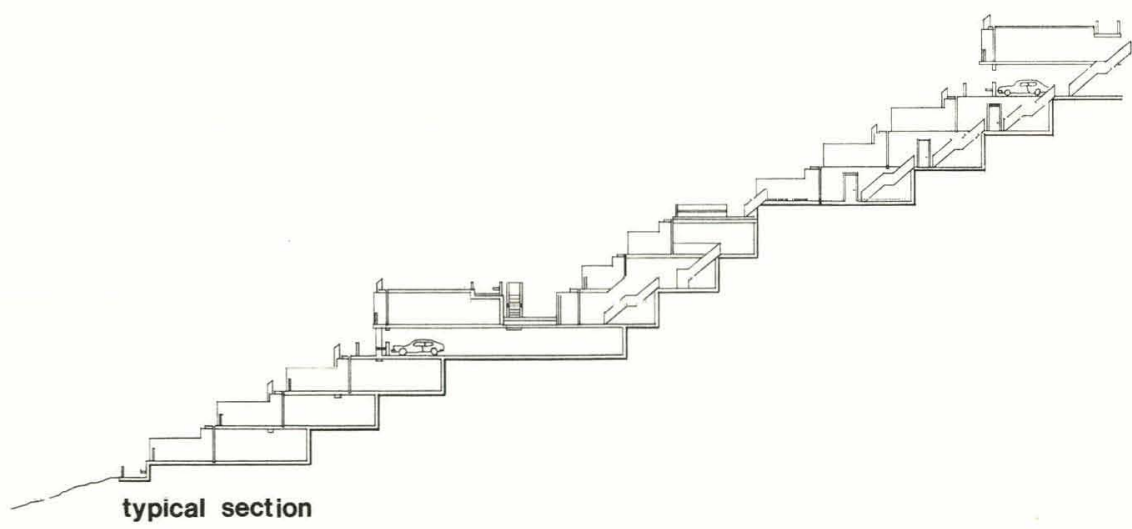



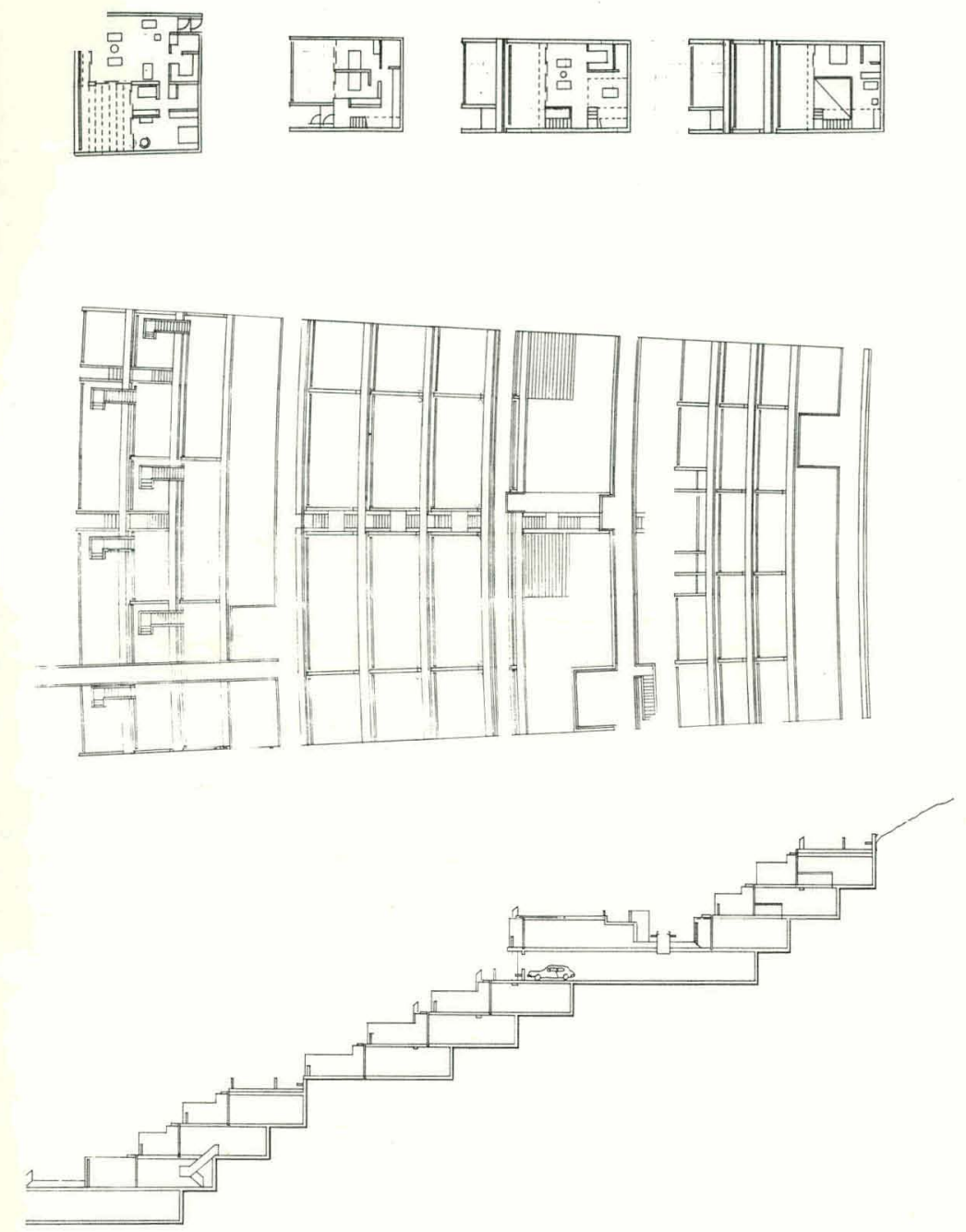

Hillside Housing

40 d.u. / acre

public walk

semi.private walk
TEAM 1

P. Calkins; S. Callan: T. Day; S. van Ness: A. Wattenberg

Plymouth, Ma.

HGSD Departments of Architecture Solar Energy · Community Design Studio

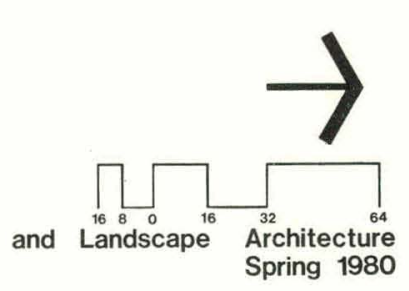

Fig. 5.1.3.12 


\section{THIS PAGE WAS INTENTIONALLY LEFT BLANK}




\subsection{PLYMOUTH 2}

\subsubsection{DESIGN STRATEGY}

Plymouth 2's main goal is to integrate the community and energy production facilities and preserve the essential character of the site. The major concerns are three: site, community, and energy. A decentralized community plan sited in the kettle and kame area of the site preserves the valley and adjacent hills as regional scenic and recreational resources. Decentralization also favours the use of lower technology solar energy systems; $70 \%$ of the heating and hot water demands and $100 \%$ of cooling demands are met on a buildingby-building basis. The technologies proposed to support this system include wind turbines and hydroelectric generation; they are both appropriate to the site and the community plan.

Community Plan Description (Figs. 5.2.1.1, 5.2.1.2, 5.2.1.3)

The diverse nature of the Talcott property incorporates three major topographic features and is the main determinant of the community's form and plan. The design is a narrow, linear community running in a north-south direction through the kettle and kame area on the eastern portion of the site. The linear plan is accentuated by the creation of open-space between the community and the valley. The village centers, high-density housing and community facilities are sited along the edge of the valley. These locations avoid the negative microclimatic impacts of the sea winds which flow up the valley.

The kettle and kame topography provides an opportunity to develop small housing and open-space groupings at a sensitive; site-specific scale. Housing takes advantage of slope, and the kettle valleys provide the basis for a linear network of recreation and pedestrian links to the village centers. Residential street layout follows topographical determinants where necessary, remaining near the top of ridges to ensure easy pedestrian movement in the community. The primary determinant of the layout pattern in low-density, single-family and cluster housing areas has been optimum solar access. This has resulted in a nearly rectilinear grid, arranged in a north-south, east-west pattern. 
The dispersed nature of the community plan dictated small neighborhoods of mixed densities. A major collector boulevard connects the neighborhoods to three small village centers. Distances and amenities in the village centers are designed for pedestrian use and localized neighborhood needs. No one need walk more than half a mile to a village center. The preserved and historic sections of the site, which occur in the valley, become the focus for community recreation and outdoor activities.

The three village centers reflect the character and image of their particular site characteristics. A "lake and recreation-oriented" center is located on the main northern reservoir. An "administrative" center is situated in the center of the community. It provides community management and professional scrviccs. The third ccnter is a valley-related "marketplace"! overlooking the agricultural section of the valley and located close to the regional retail shopping mall and the highway interchange. In addition, industrial office development and the regional retail center are located in the southern part of the site, south of Clarke Road at the main entrance to the community.

Phasing (Fig. 5.2.1.2)

The community will be developed in four phases, over fifteen years. Each phase is complete in itself and integral to the whole plan.

Phase 1 includes development of the regional retail center and office/industrial park associated with the interstate interchange. This is to provide the project with start-up capital and revenue.

Phase 2 will develop hydroelectric facilities in the valley, at Forge Pond and Talcott Pond, providing an amenity base and energy for development of the first village center. At the northern end of the site, the phased construction of a sewage treatment plant will begin and local roads will be upgraded. The first (northern) village center and recreational facilities associated with the reservoir ponds will be constructed.

Phase 3 will extend public utilities, sewage, and water from north of the site. 01d Sandwich Road will be re-routed. The agricultural area and valley rec- 
reational facilities associated with the southern village center will be developed and this yillage center south of Clarke Road will be developed. Development of the Darrieus rotor field on Pine Hills and construction of the hilltop hydroelectric reservoir and distribution network will begin. The recreational and interpretative facilities will be developed in association with the wind turbine powerline construction.

Phase 4 will complete the development of the infrastructure and road systems to tie the north and south villages together. The middle village center will be built as administrative and social focus of the community. The major community recreational facilities on the Talcott estate site will be developed and will tie into the regional trails system. The recreational development of the Pine Hills and western sections of the property will be completed.

\subsubsection{ENERGY STRATEGY (Figs. 5.2.2.4, 5.2.2.5)}

A major determinant of the plan is solar access planning to insure maximum passive and active solar insolation utilization on a building-by-building (in some cases unit-by-unit) basis. This is a major determinant of the decentralized organization of the community plan. Infrastructure planning will optimize solar access site planning considerations and traveling distances by pedestrian means. Housing and other buildings are designed to be sitespecific and optimum for solar access. Microclimatic benefits are maximized by site planning in the kettle and kame areas. A self-sufficient sewage treatment plant and wood-burning fireplaces may provide additional sources of electricity and heat. The means for providing electricity and auxilliary heating, in the form of wind turbines and hydroelectric dams, has been spatially integrated into the community design. The community has been designed to be $100 \%$ self-sufficient in energy needs.

\section{Assumptions}

In the energy strategy, $70 \%$ of all space heating and domestic-hot-water-heating needs, and $100 \%$ of all cooling needs, are met by active and passive solar systems on a unit-by-unit basis or building-by-building basis. The other $30 \%$ of space heating and domestic hot water heating needs are met by electricity; by means of heat pumps. 
Similarly, it is assumed that $100 \%$ of the cooling needs of the community are taken care of by passive solar design.

A further option is the wood stove. Calculations for this component of the system do not appear in the table, as building design, firewood supply and pollution control legislation may make it of limited value on a communitywide basis. It does remain a viable opportunity in the heavily wooded New England region. A typical system comprises an enclosed 'heatilator' type stove with low velocity forced hot air heating, or a properly designed and insulated fireplace relying on convection vents to circulate hot air.

\section{Electrical Generation Strategy}

On the Plymouth site, the consistent high wind velocity makes wind the best available and most dependable source of energy. Eleven 250' Darrieus rotors (wind turbines) sited on the Pine Hills immediately to the east, within the property line and on nearby easements, will generate enough electricity to meet the needs of the community.

$30 \%$ of all heating and hot water needs are met hy electric heat pumps on a building-by-building basis. Heat pumps used for heating can also be used in the summer for cooling if necessary. Heat pumps are most suited to this dual purpose. Based on the various demands outlined in the community total demand table, a total electrical demand has been computed for the community. These demands are premised on the use of enerqy-conservative measures in building and lighting. An important element of the community plan is an electric-powered bus system, running as either a 'jitney' service or on the main community spine as an established route. Electricity for this system (and potentially, other demands) is stored in batteries or delivered dirert.ly to the bus (if on a route) through an underground cable. For the longer periods of calm, hydroelectric capacity is utilized. During "off" hours, the wind turbines power pumps to fill three storage reservoirs from the ground water system, and, when needed, the hydroelectric generators are turned on. Approximately half a day's (winter) electrical demand is stored in the reservoirs. more than enough for those windy winter months. In a similar way, excess 
electricity generated by the system is sold to the regional electricity grid. The connection also provides reliability benefits.

\section{Thermal Generation Strategy}

Most of the energy needs in Massachusetts' cool temperate climate are for heating during the winter months. Active and passive solar systems using existing technology are planned on a building-by-building or unit-by-unit basis. Research has led to the assumption that fully $70 \%$ of the winter heating demands, including $70 \%$ of domestic hot-water demands, can be met using a preheat cycle. By using today's available technology, as proposed in the architectural designs; family life styles will not be significantly. altered. Techniques employed include high rates of insulation, hot-water storage, forced-air heating and cooling, direct gain through windows and clerestories, and flat plate (roof) hot-water heating.

In the more concentrated village centers, not all buildings have been sited for optional solar access. In these relatively small areas a thermal hot-water distribution system is proposed and this can adequately meet energy distribution demand. 
PLYMOUTH 2

ASSUMPTIONS AND EXPLANATIONS

1. $70 \%$ of heating and domestic hot water provided passively and actively on a building-by-building basis.

2. $100 \%$ of cooling needs provided passively and actively on a building by building basis.

\begin{tabular}{|c|c|c|c|}
\hline \multirow{2}{*}{$\begin{array}{l}\text { TYPE OF BUILDING OR } \\
\text { MFMANח }\end{array}$} & \multicolumn{2}{|c|}{ UNITS/AREA } & ELECTRICAL \\
\hline & OUANTITYY & $\begin{array}{l}\text { AREA/IINTT } \\
\text { OR } \\
\text { TOTAI_ AREA }\end{array}$ & Mwh/Day \\
\hline
\end{tabular}

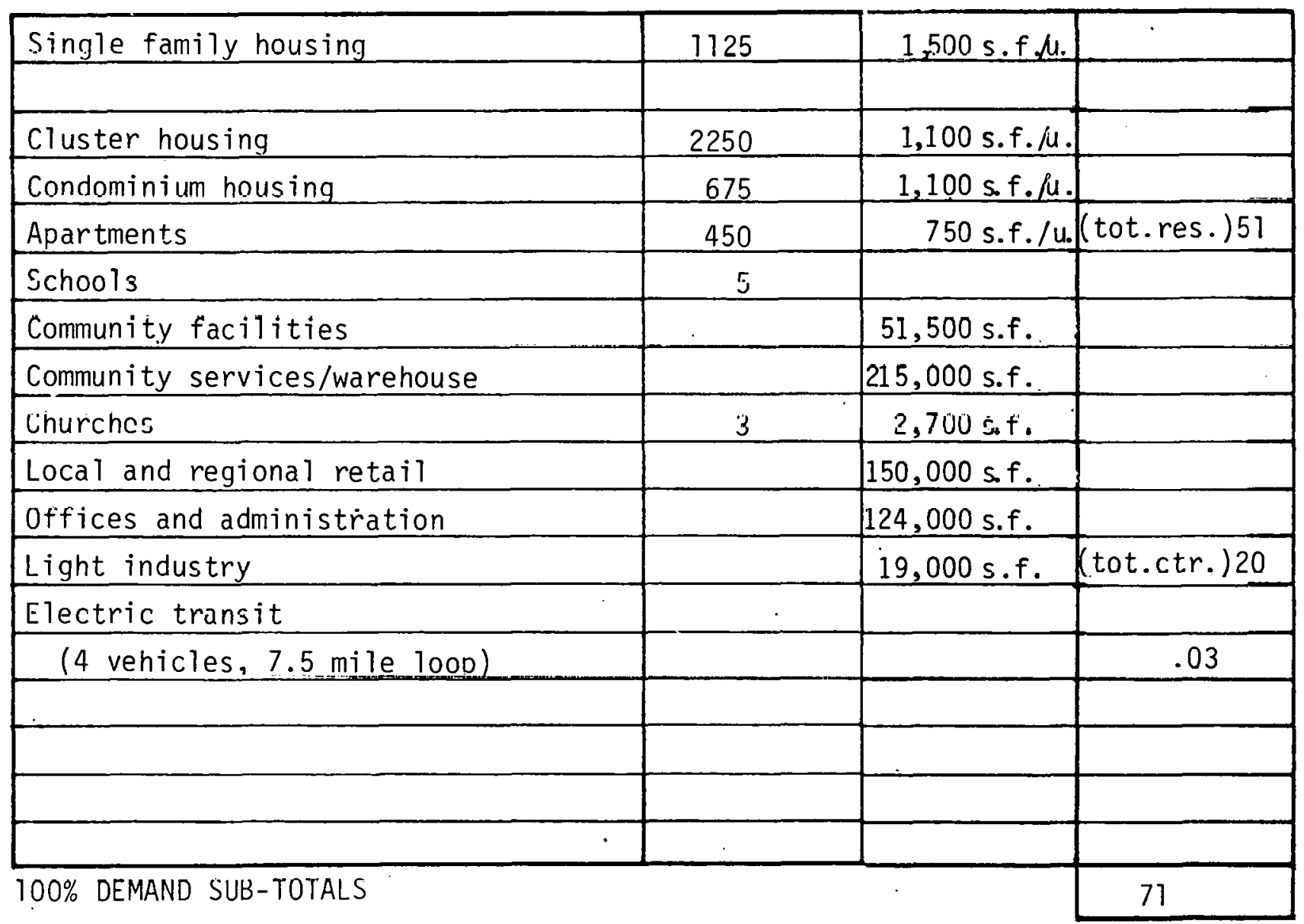

\section{total community energy demand}




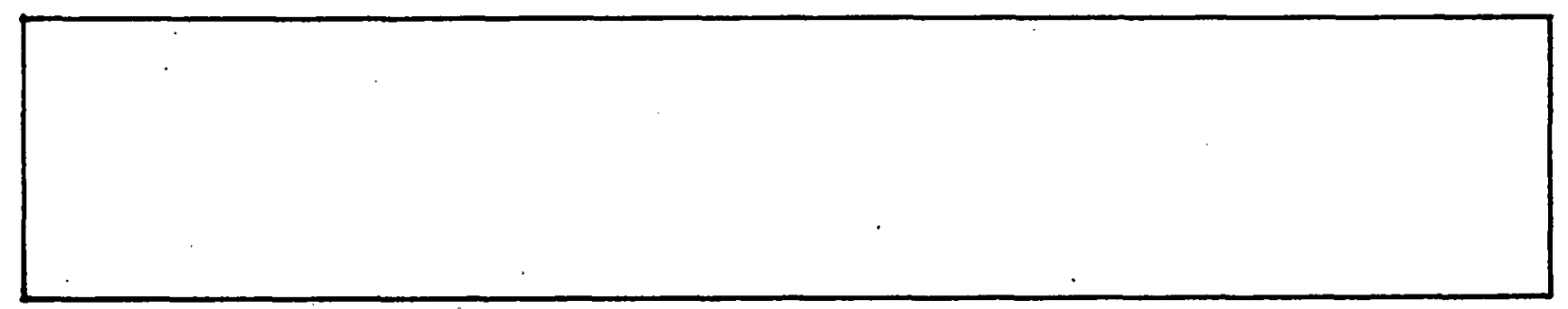

\begin{tabular}{|l|l|l|l|l|l|}
\hline \multicolumn{2}{|l|}{ HEATING LOAD } & \multicolumn{2}{l|}{ COOLING LOAD } & \multicolumn{2}{l|}{ DOMESTIC HOT WATER } \\
\hline $10^{6}$ Btu/Day & Mwh(Th)/Day & $10^{6}$ Btw/Day & Mwh(Th)/Day & $10^{6}$ Btu/Day & Mwh(Th)/Day \\
\hline
\end{tabular}

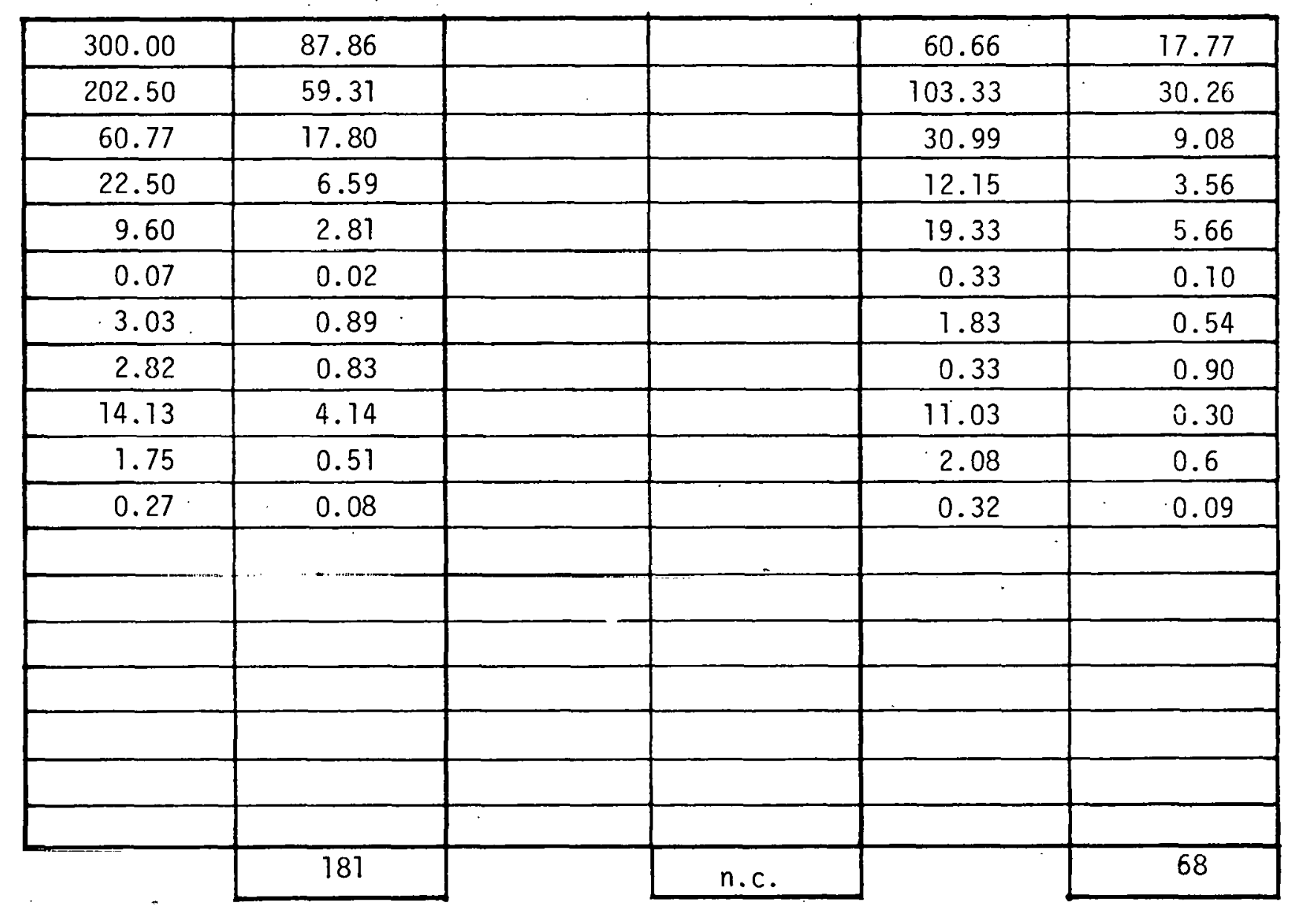


PLYMOUTH 2

supply

ASSUMPTIONS AND EXPLANATIONS

1. Wind calculations based on wind frequency of $60 \%$ at a useable velocity.

2. 10 days to $f i 11$ reservoirs at $65 \%$ efficiency.

3. Excess energy distributed to local grid, for possible future development, and backup for peak demand.

\begin{tabular}{|l|l|l|l|}
\hline ENERGY SOURCE & APPLICATION & CONFIGURATION & $\begin{array}{l}\text { SUPPLY } \\
\text { Mwh/ Day }\end{array}$ \\
\hline
\end{tabular}

STORAGE SYSTEMS

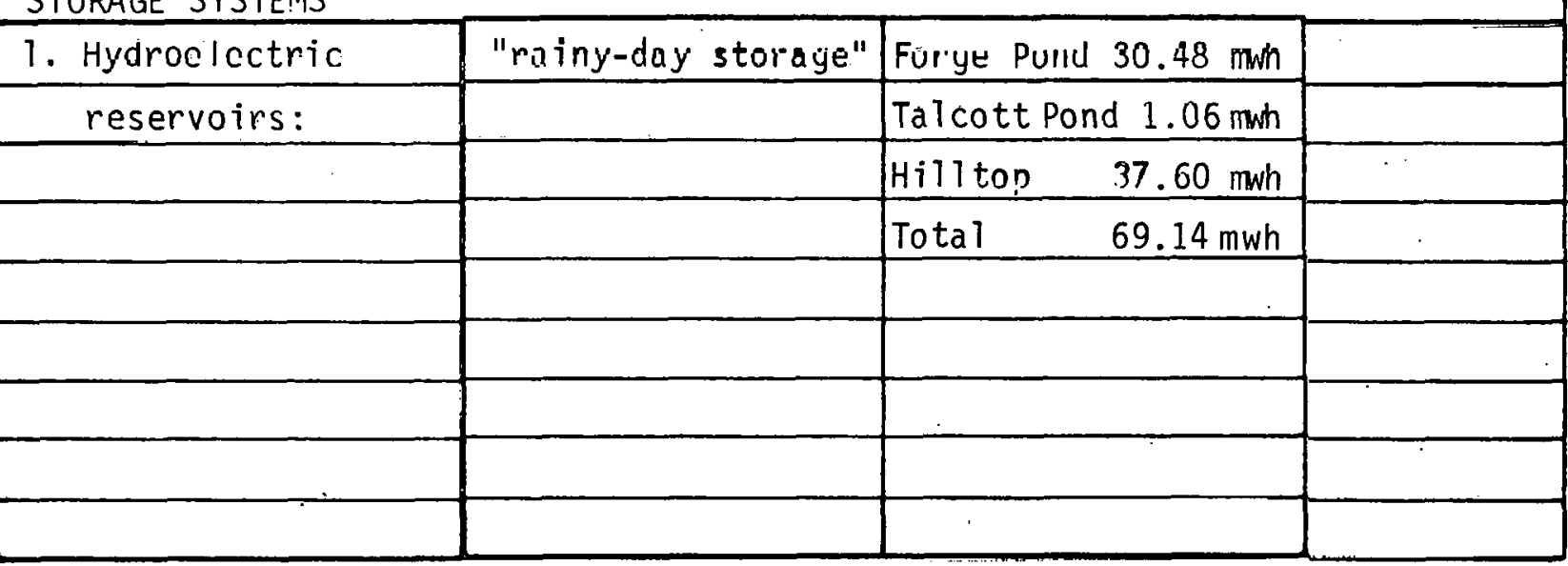

\begin{tabular}{|l|l|l|l|}
\hline SUPPLY SYSTEMS & eleclrical demand, & 11 turbines rated & 150 MWh(e) \\
\hline Darrieus wind & $30 \%$ heating and & at about 1 MWh(e) & \\
\hline turbines & domestic hot & each & \\
\hline & water demand & & \\
\hline & & & \\
\hline & & & \\
\hline & & & \\
\hline
\end{tabular}

\section{total community energy supply 150. Mhh $(e)$}




\subsubsection{SITING ISSUES \& HOUSING}

Kame \& Kettle Design (Fig. 5.2.3.6)

Landscape and site development principles in the kame and kettle area include: -Maximize the warming effects of the sun in fall and spring, and especially in the winter by thinning trees on site to allow penetration of the sun and to create sun pockets.

-Maximize cooling effects in summer by siting structures on upper slopes for maximum breezes. Plant deciduous shade trees on the south, east, and west sides of structures. Channel summer winds with vegetation or berms, over shaded lawns and vegetation.

-Reduce the impact of cold winter winds by berming and using coniferous windbreaks on the north side of structures.

- Decrease summer humidity by planting high-canopy shade trees which shade and allow breezes to ventilate structures. Avoid shrubs planted close to buildings on the south side.

-Reduce glare and reflection by planting shade trees along roadsides and parking areas. Reduce paved surfaces on south, southeast, and southwest sides of buildings: substitute with grass and ground covers.

Low, Medium and High Density Housing (Figs, 5.2.3.7, 5.2.3.8, 5.2.3.9)

In general, the areas adjoining the neighborhood centers are high density; density decreasing with distance from the Town Center. A concerted effort, however, is made to mix housing types while still maintaining the required. density. The varied topography of the site is the basis for the design of different prototypes appropriate to the microclimate, solar access, slope, and view. The following prototypical housing is presented: clusters on north, south, east and west facing slopes (Types 1 and 3) (Fig.5.2.3.7), clusters on south facing slopes in the kettle area, (Types 9 and 10) (Fig. 5.2.3.8) and apartments on south facing slopes (Types 8 and 10) (Fig.5.2.3.9).

Regardless of the topographic orientation of the building, living space and the flat plate collectors receive direct solar exposure. The efficiency of the building envelope is considered: building shape and the area/volume 
ratio are important in reducing exposure to the north while providing as much southern exposure as possible. Service spaces are on the northern face. Natural ventilation is provided to meet summer cooling demand. Facade treatment responds to orientation: in particular, aperture sizes, glazing, shading devices, and night shutters are considered. For multi-family housing, a public, air-lock area serves as an entrance and buffer. Greenhouses stabilize space heating and humidity levels. Reinforced-concrete, load-bearing walls are designed to meet structural requirements and, as a thermal mass, the heat storage demand.

For these housing types, the solar enerqy strategy for meeting energy demands is as follows:

Space heating: $50 \%$ Passive solar system (greenhouse, heat trap, etc.) $20 \%$ Active solar system (flat plate collector) $30 \%$ Back-up system (electricity) (heat pump)

Space cooling: 70\% Passive solar system (chimney effect, orientation, building design, etc.)

$30 \%$ Back-up system (electric heat pump)

Domestic hot $70 \%$ Active solar system (flat plate collector) (preheat system) water: $30 \%$ Back-up system (electric heat pump)

Site Planning Single-Family Residential Areas for Solar Access (Fig. 5.2.10)

This exercise suggests how site planning for solar access in the fine-grained, but rugged topography of New England can take place. It deals with singlefamily residential development, still one of the most common types of housing in New England. The community, situated in the most rugged portion of the Talcott property, presents a wide variety of siting opportunities and constraints. Much of the development is proposed on slopes and, in step with the concept of decentralization, is widely dispersed.

Rather than develop a whole matrix of contexts and solutions for single-family, solar-access planning, the design criteria have been simplified. East-west and then north-south roads provide the best orientations for solar planning; north and south-facing slopes are the two most typical situations for singlefamily residences in the community. Several assumptions were made: December 
2lst, the day of lowest sun altitude was used to describe a "worst condition" for shadows; east-west and north-south road orientations were assumed; north-facing and south-facing slopes of $5-10 \%$ were used as typical topographical situations.

Using two typical solar house designs (one by Donald Watson and one by Massdesign/Gordon Tully), the project drawings illustrate the restraints imposed by shadow casting from buildings and trees and show how lots should be minimally configured, how houses can be optionally sited, and what typical minimum site planning would be like. 


\section{THIS PAGE}

\section{WAS INTENTIONALLY LEFT BLANK}




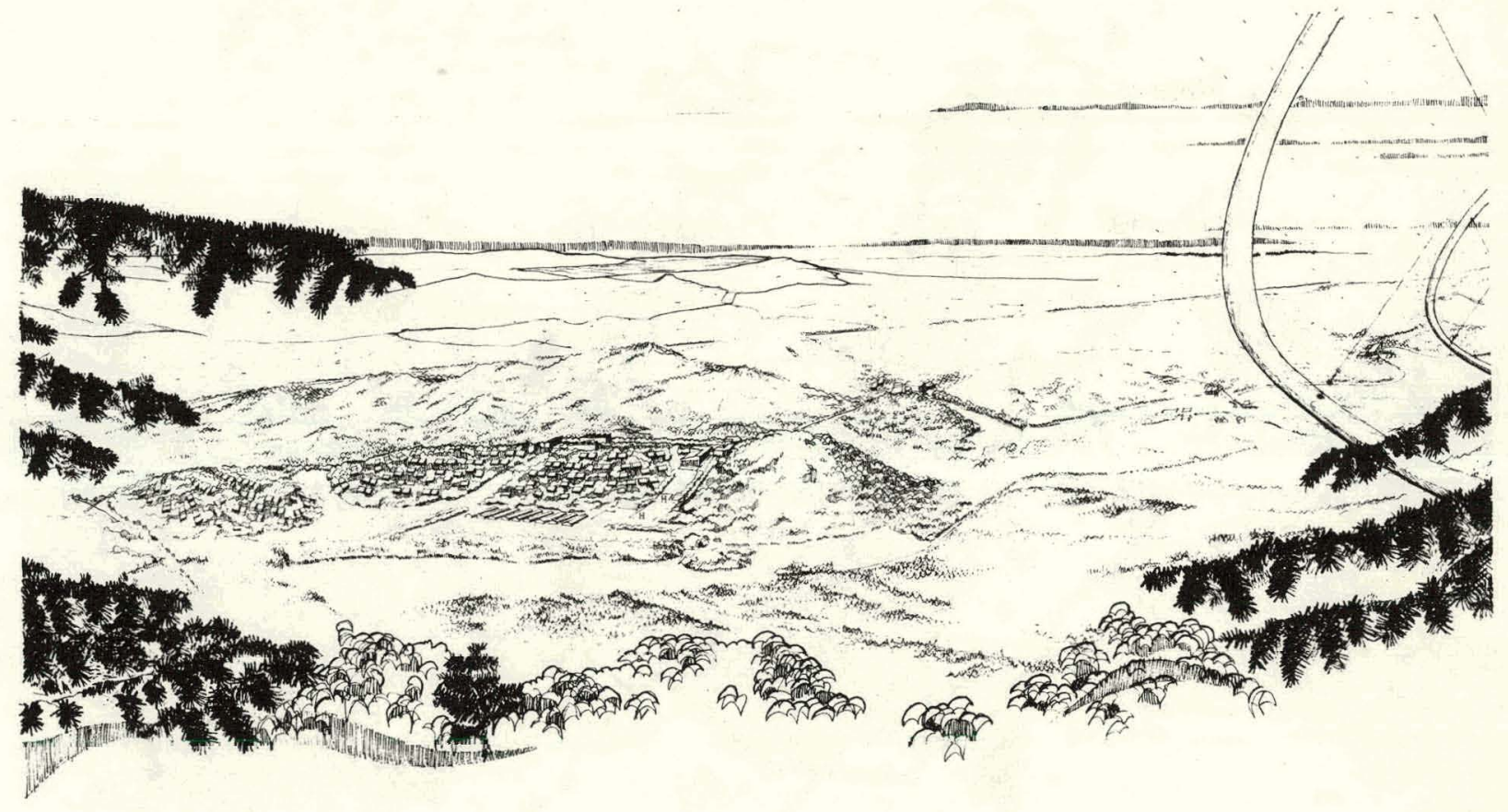

TEAM 2

Plymouth, Ma.

HGSD Departments of Architecture and Landscape

Architecture Spring 1980

Fig. 5.2.1.1 


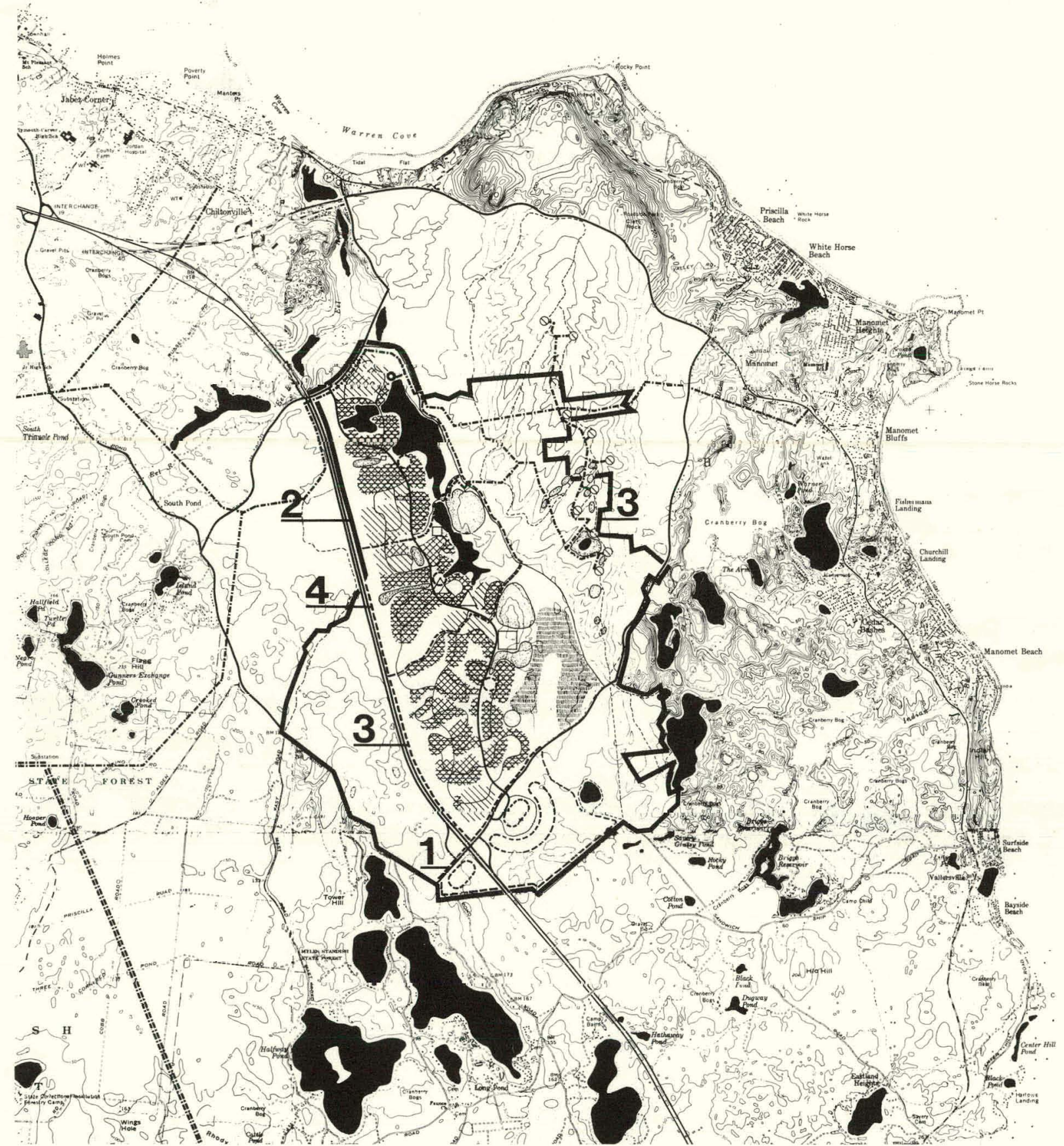

Concept / Phasing

TEAM 2

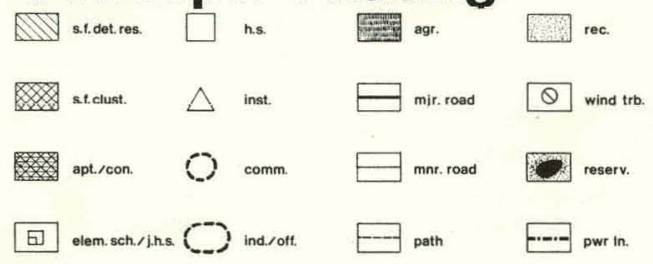

Fig. 5.2.1.2 


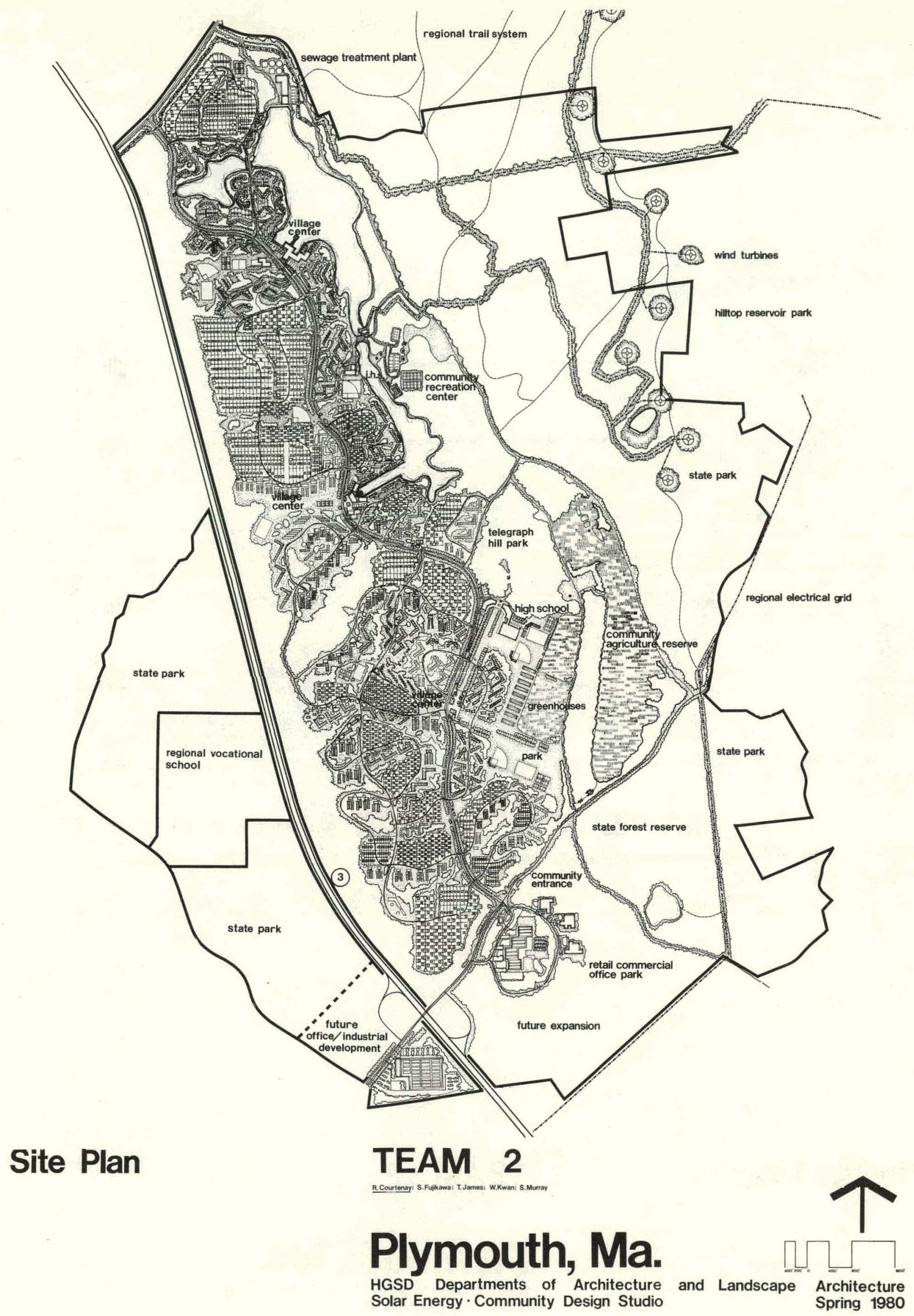

Fig. 5.2.1.3 


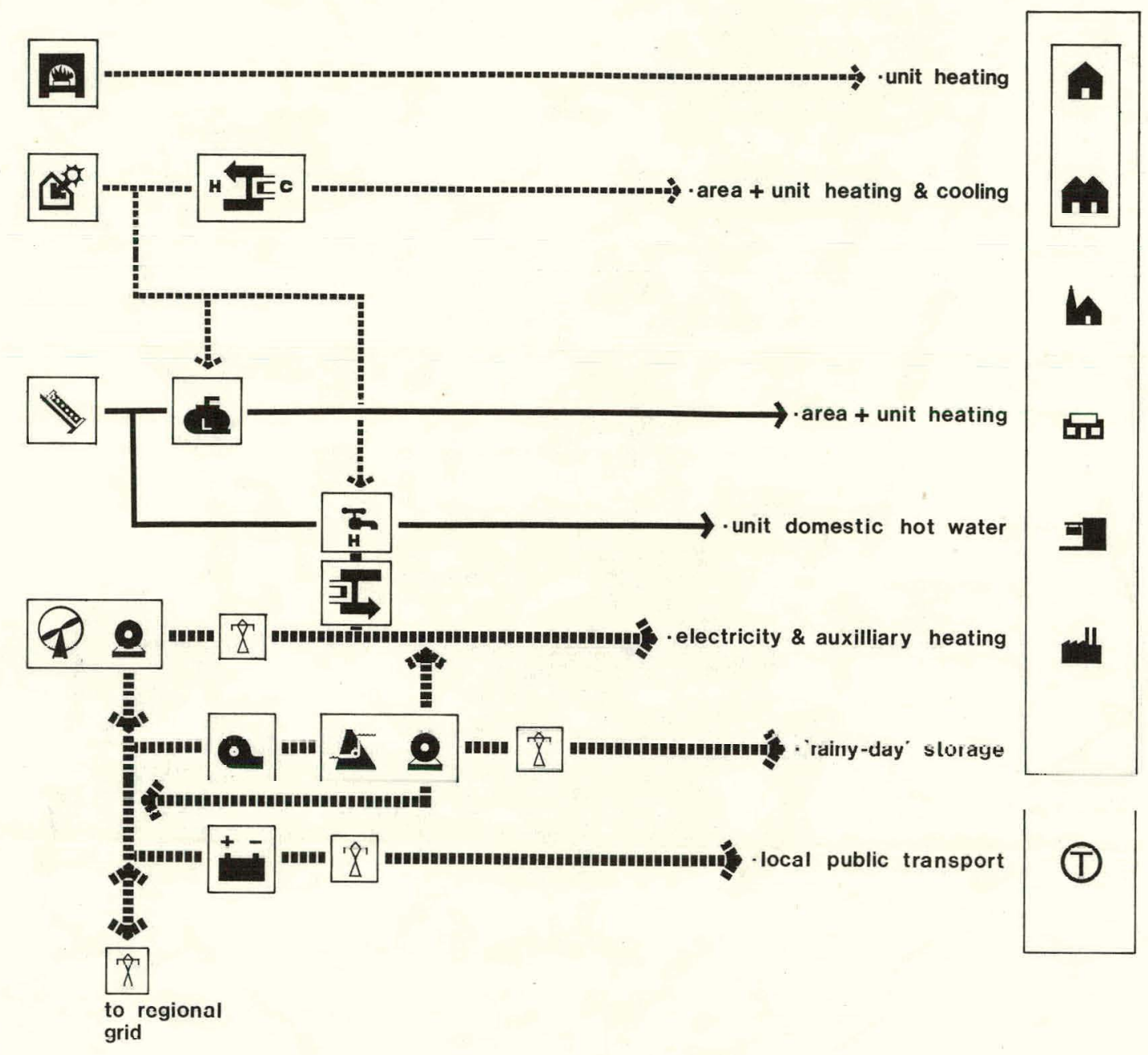

\section{Energy Diagram}

TEAM 2

R. Courtenay; S.Fujikawa; W. Kwan; T. James; S. Murray

Fig. 5.2.2.4 


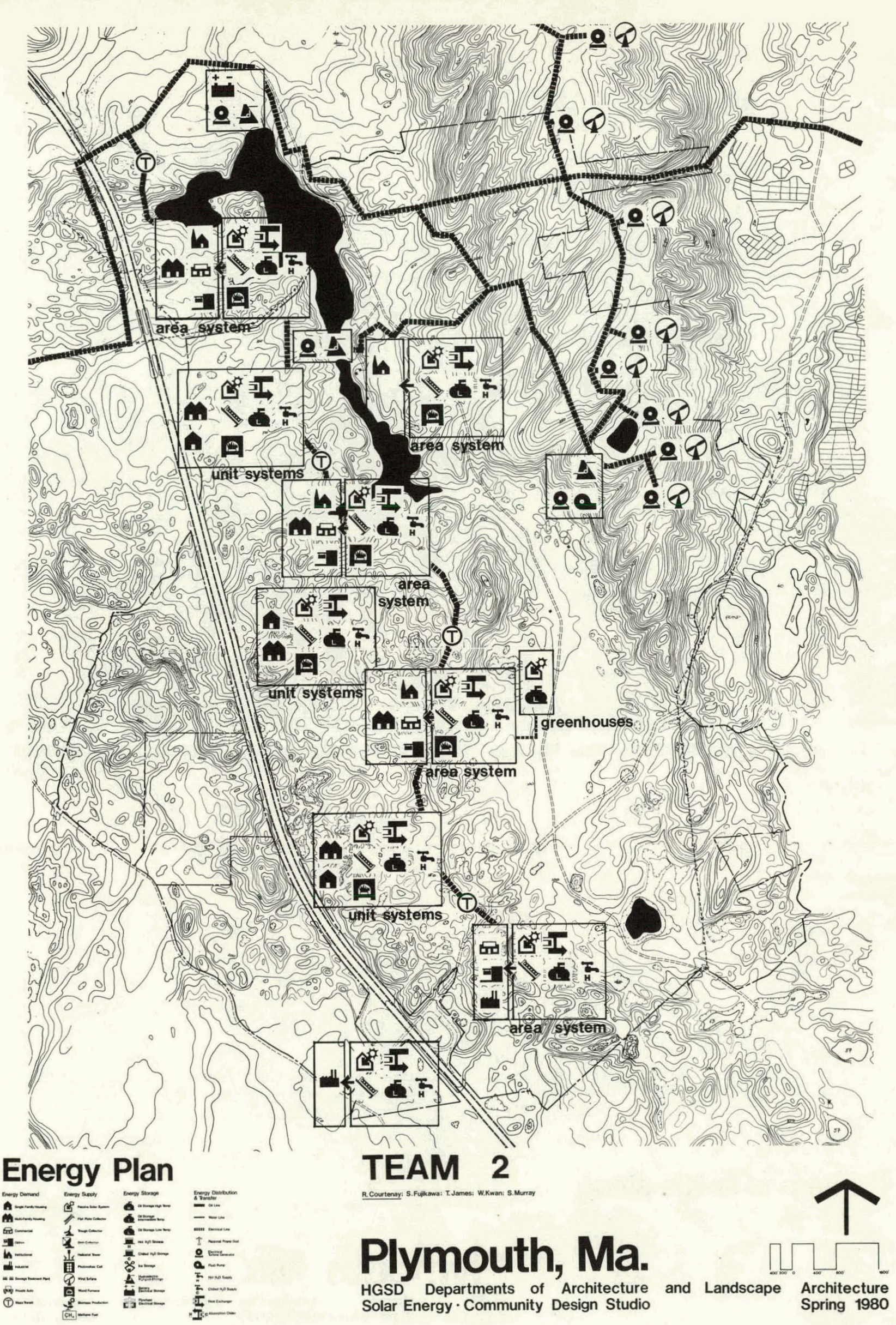

Fig. 5.2.2.5 


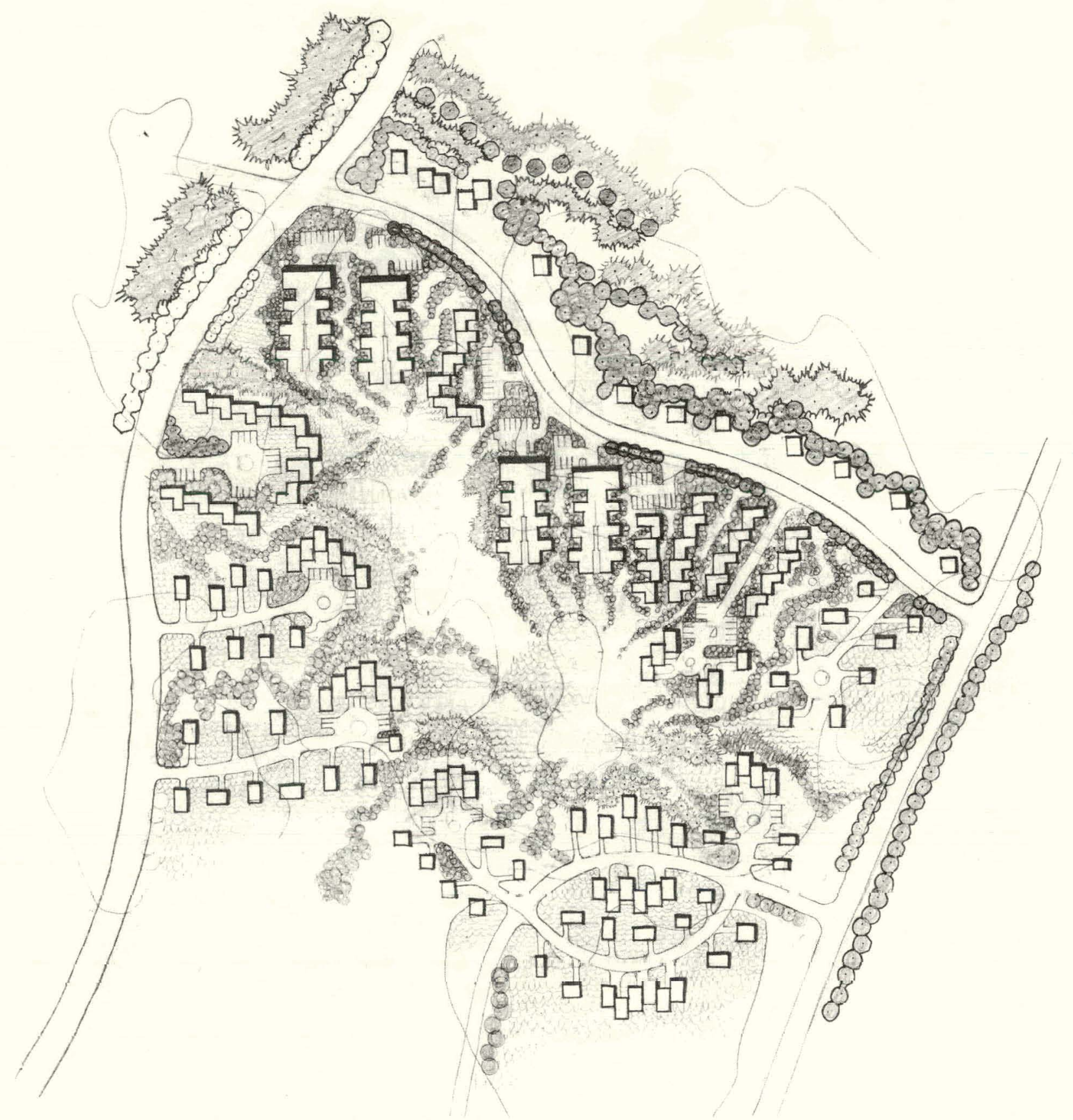

Kame and kettle siting

TEAM 2

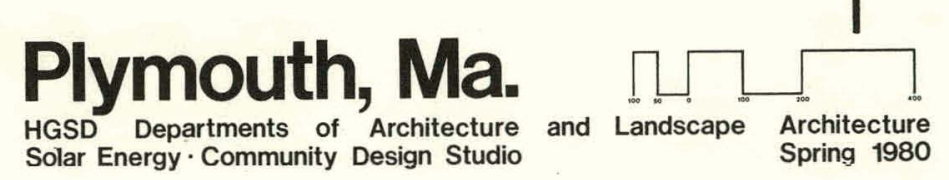

Fig. 5.2.3.6 
type 3
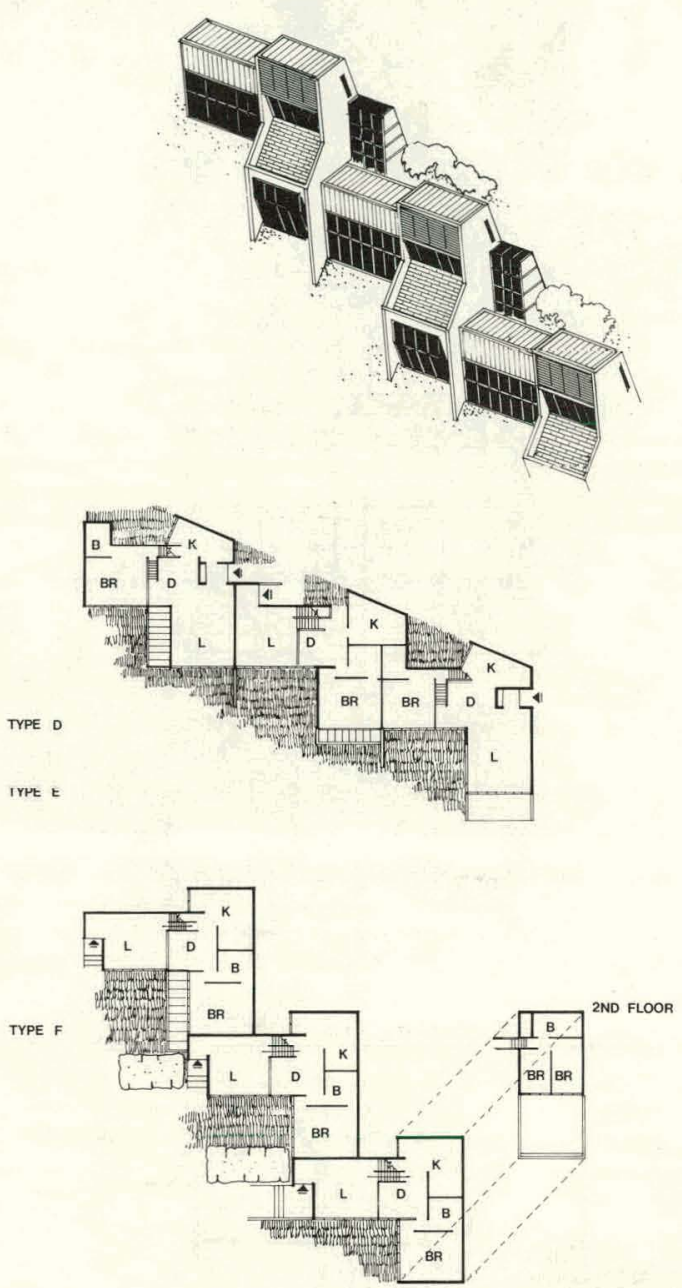

ground floor plan type 1
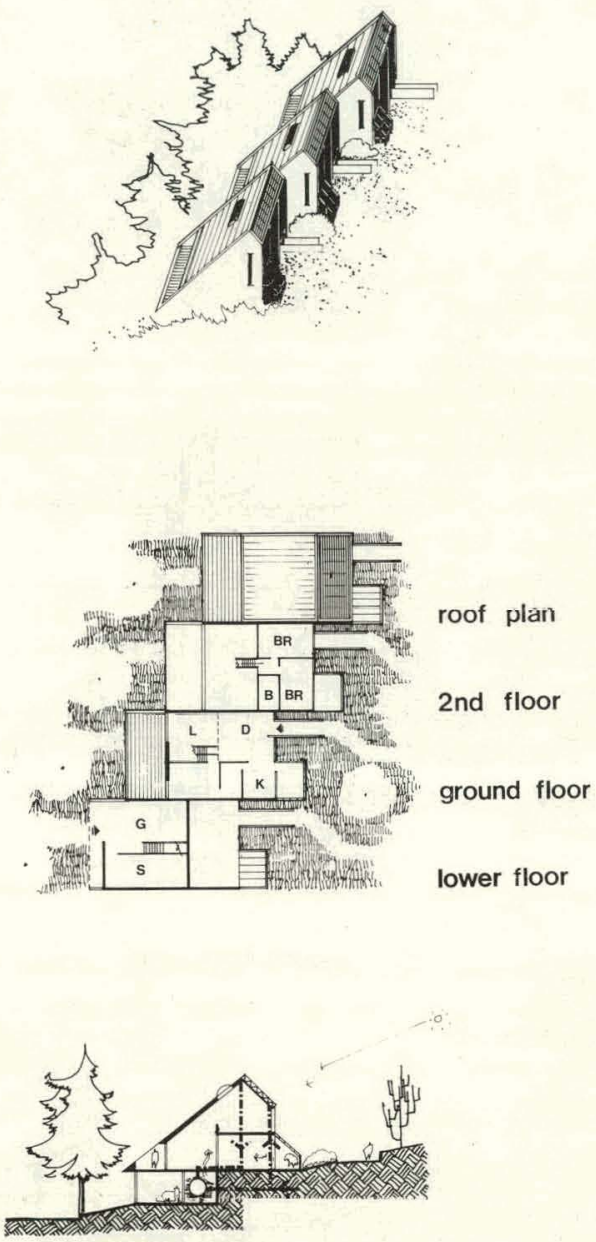

section

\section{Housing}

4-6 d.u. / acre
TEAM 2

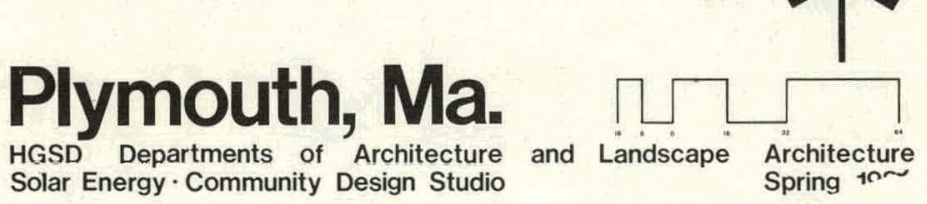

Fig. 5.2.3.7 


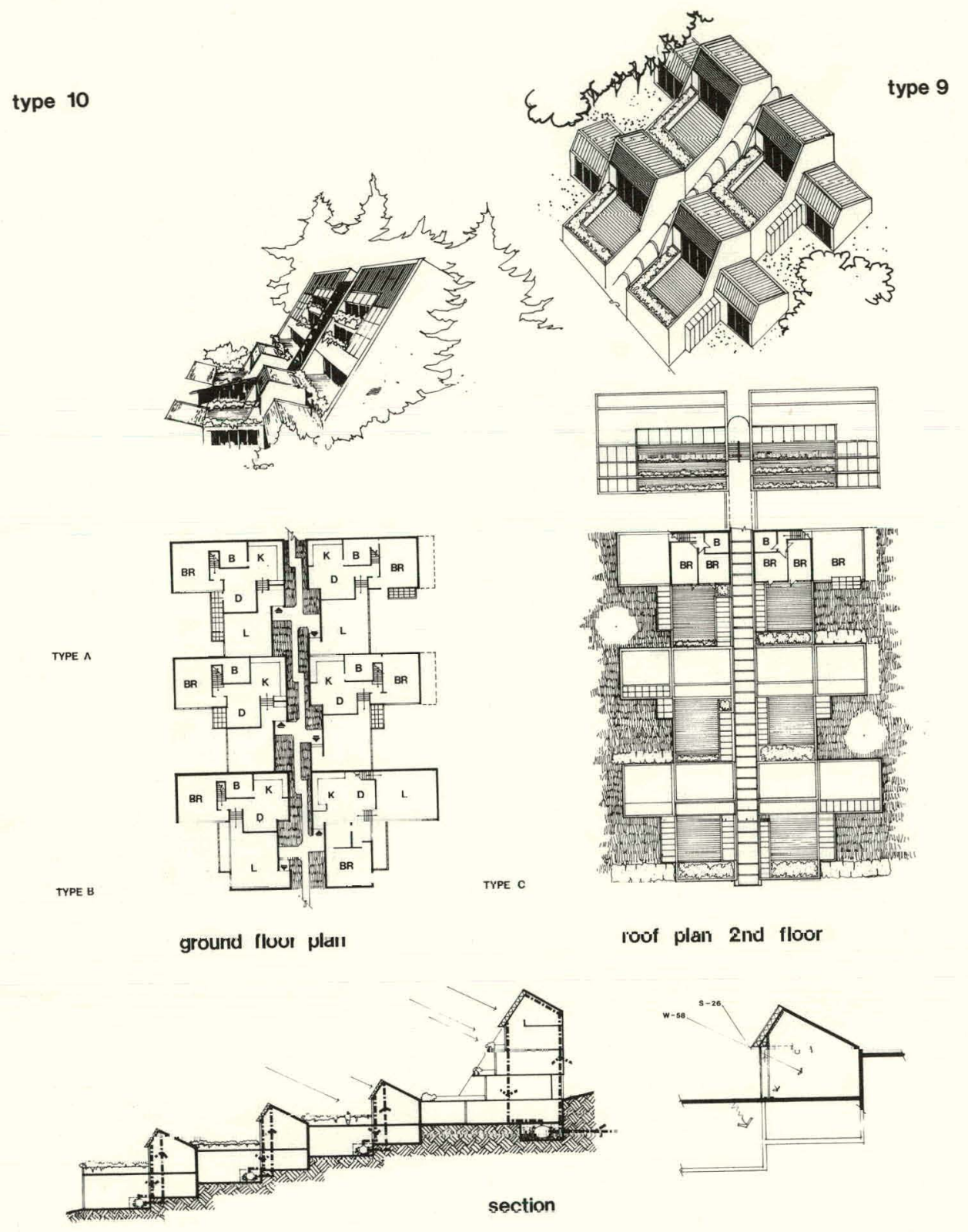

Housing

8-10 d.u. / acre

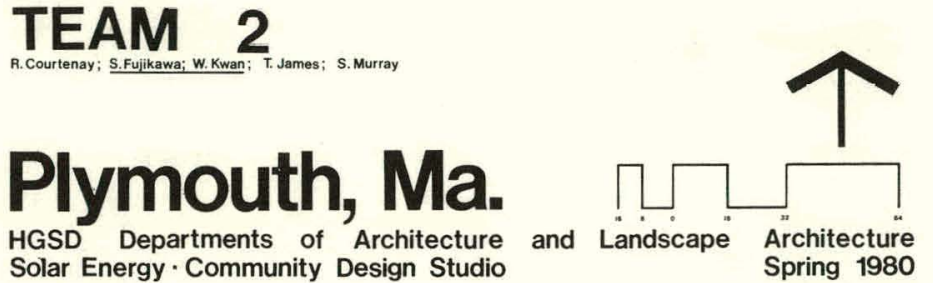

Fig. 5.2.3.8 


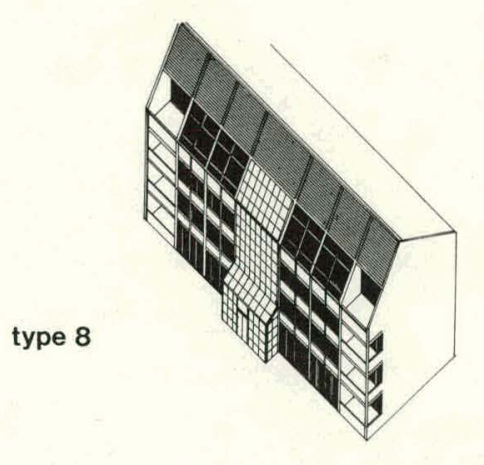

type 10
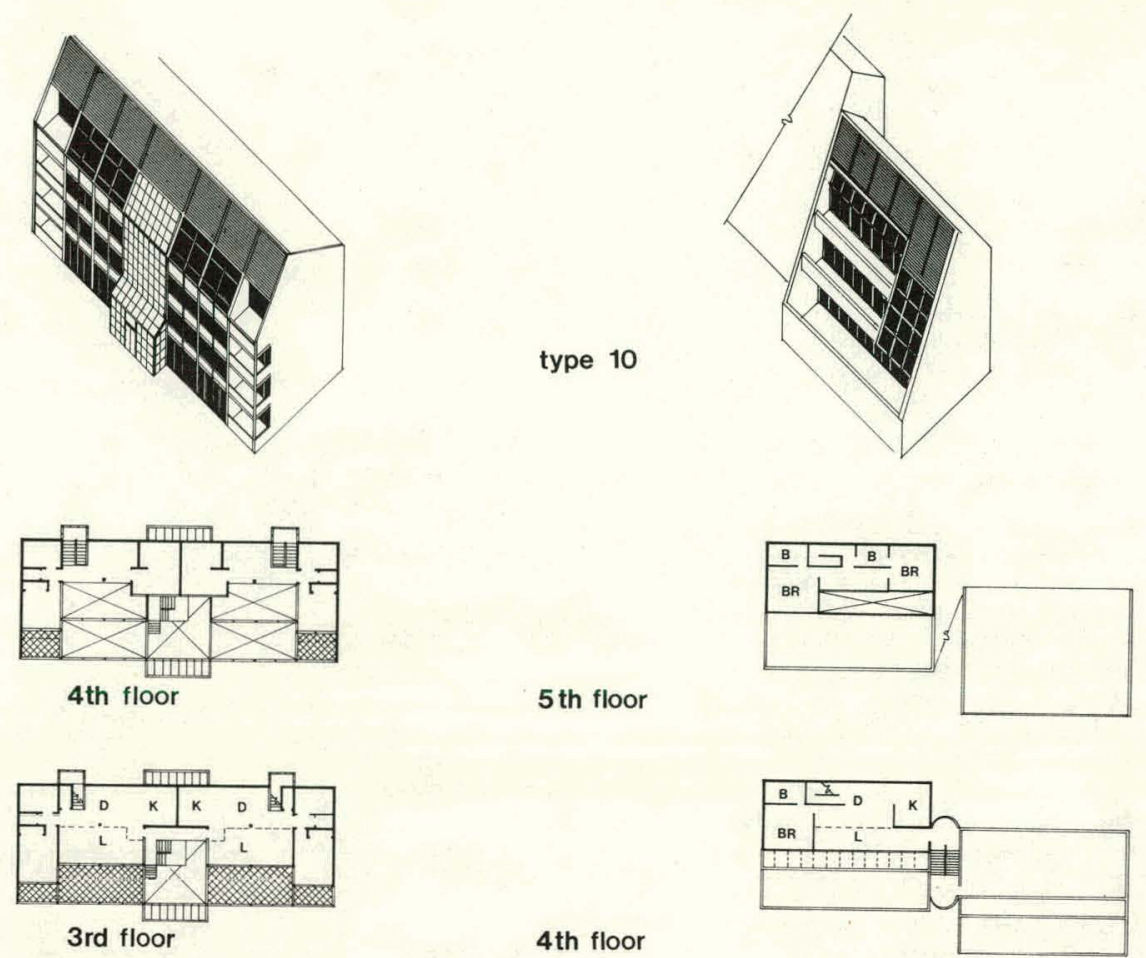

5 th floor
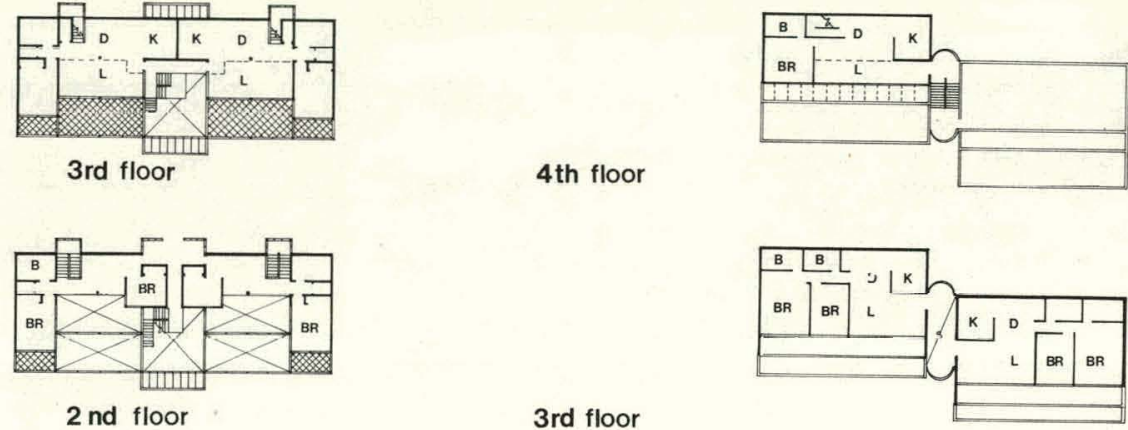

4th floor
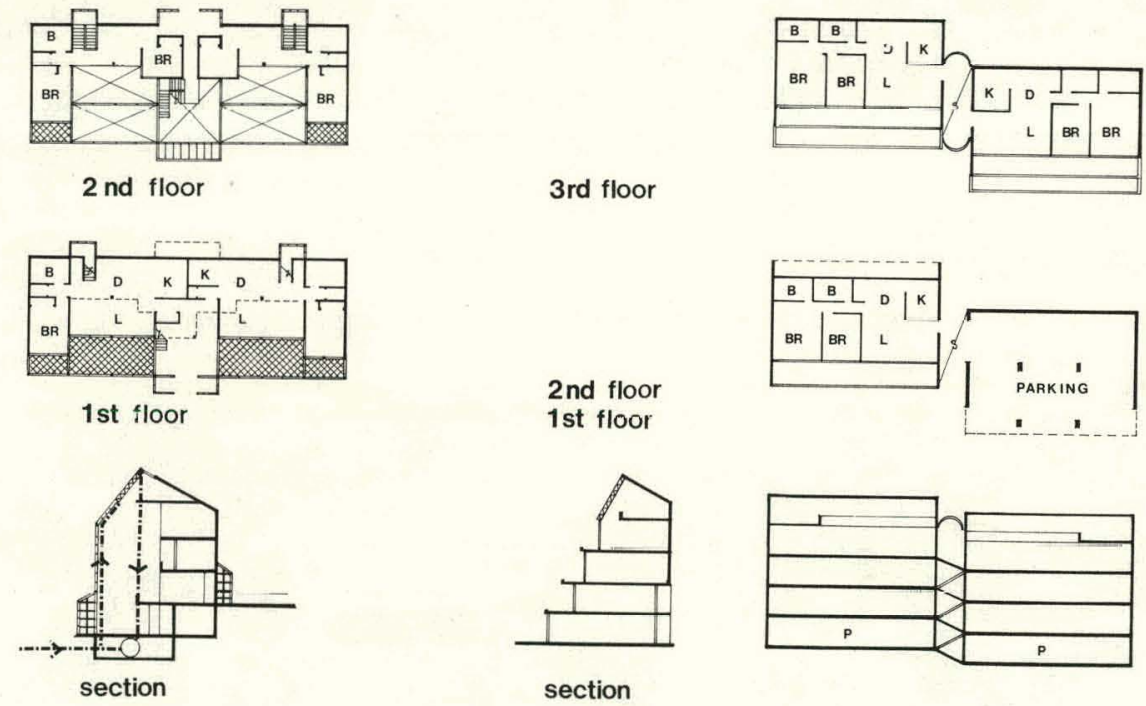

3rd floor

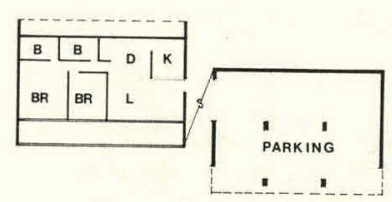

\section{Housing \\ 12-15 d.u. / acre}

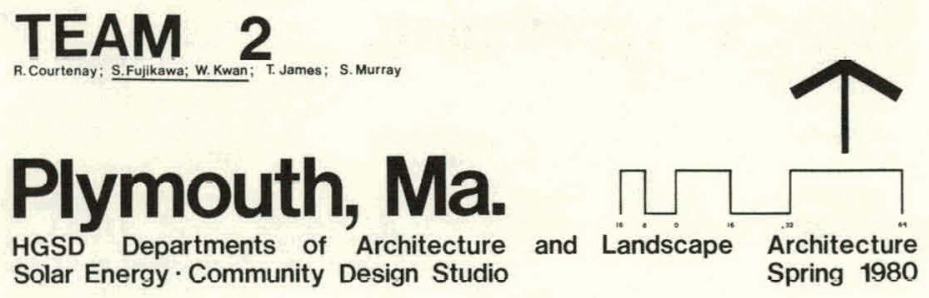

Fig. 5.2.3.9 
solar site planning

for low density housing

site conditions studied

1. north and south facing slopes of 5-10\%

2. 4 \& 8 d.u./acre housing densities.

3 east-west \& north-south roads.

4. solar conditions assumed:

1. least sun day-december 21 st.

2. $30^{\circ}$ azimuth, $20^{\circ}$ altitude at $10 \mathrm{am} / 4 \mathrm{pm}$

3. plymouth, ma. $42^{*}$ latitude.

site planning considerations

1. $80^{\prime} \mathrm{min}$. coniferous tree setback.

2. 30' min deciduous tree setback.

3. plans show minimum typical site develop ment for privacy, solar acoess.

4 minimum int size and rnnfiguratinn th achieve solar access.

prototypical housing units:

1200 sq. ft., 2-storey unit, with greenhouse, flat plate solar heating system, by Donald Watson.

1900 sq. ft., 2 storey solar saltbox; with flat plate solar heating system, by Massdesign.
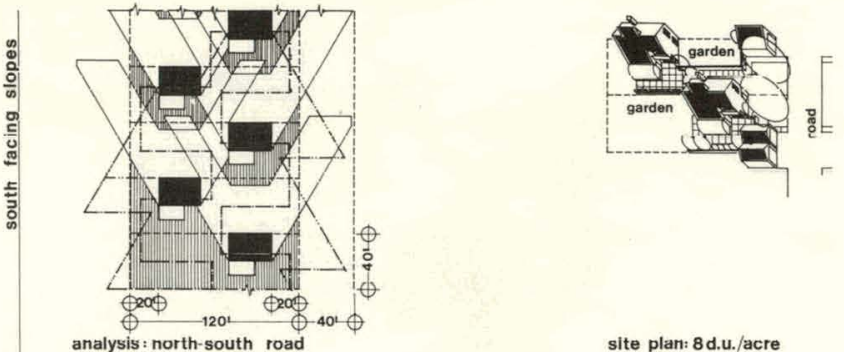

site plan: 8 d.u./acre

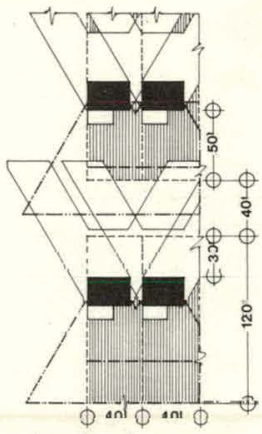

analysis : east-west roa
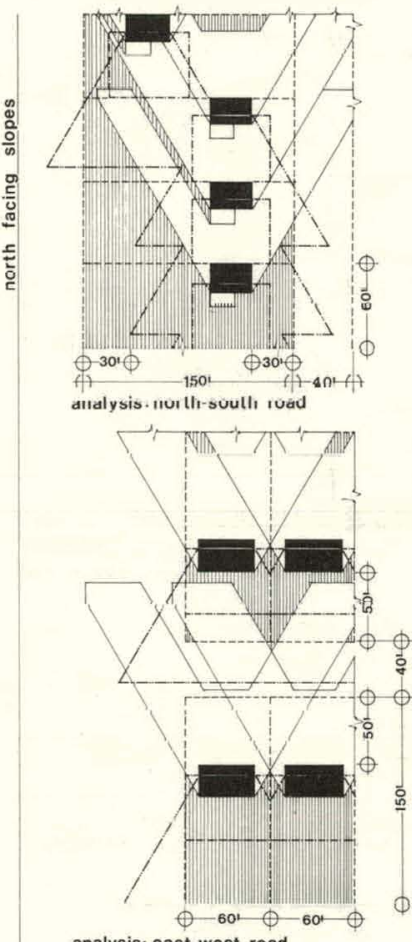

site plan: 4 d.u. /acre sile plant : 4 U.u. $/$ acre

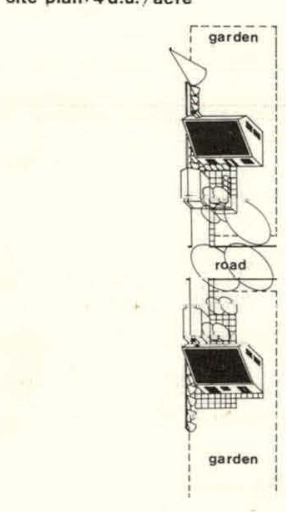

site plan: 8 du. $/$ acre

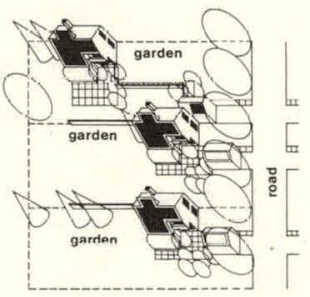

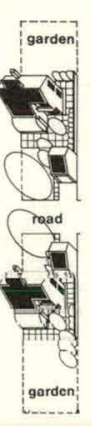

\section{Solar site planning}

for low density housing

\section{TEAM 2}

Plymouth, Ma.

HGSD Departments of Architecture Solar Energy - Community Design Studio

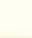


This study was conducted by graduate students in landscape architecture, architecture, urban design and city planning who were using a design case study method as a way of exploring the implications of solar energy selfsufficiency upon community design. The process which was followed was iterative: issues were raised and resolved as part of the increasingly detailed levels of design solutions, and were often revised. The problem statement which was posed (Section 2.0)did not diminish the responsibility of considering the range of site and architectural design aspects of the program. However, a very high proportion of the design students' attention focused on the energy-related issues which were discovered during the course of the study and which are described in this summary section. These issues and their implications can be grouped into five major categories: the community development plans, the energy strategy, the residential neighborhood, building design, and life-style changes.

\section{-6. THE COMMUNITY DEVELOPMENT PLAN}

Each of the sites had conflicts between solar objectives and those which would govern good urban design and site planning. The best solar sites were often those deemed best to be kept for open space and view (Tucson 1, Plymouth 1); or the most desirable solar sites were the least accessible to roads or town centers (Tucson 1, Atlanta 1). Two teams chose to accept less than desirable road access conditions (Tucson 2, Fig. 3.1.1.2; Atlanta 2, Fig. 4.1.1.2) in order to use land considered good for a solar community and one team (Plymouth 2, Fig. 5.2.3.6) built in difficult kettle and kame terrain in order to preserve the amenity values of an unique hillside. In almost all cases these large scale decisions had ramifications at the micro-scale, where several conflicts were often evident between building pressures, site conditions, and the need for good solar access.

The concept behind the site development plans in each context was governed by a combination of key decisions concerning the locations of the center, the kind of major amenity to be provided, the degree to which accessibility from the major highway was critical, the internal movement systems assumed, the 
visual image of the settlement and the degree of compactness of the community itself. Ranked in different orders by each team and matched against the site analysis, each site had two distinctive initial approaches; one leaning toward a relatively compact centrally focussing scheme and the other towards dispersal. As work progressed, (and micro-scaled decisions were made) these distinctions became obscured. Finally the density ranges were not that dissimilar. No scheme had major amounts of large lot housing and none had highrise elevator buildings.

The phasing of the schemes on each site had a major impact on energy decisions and on the organization of residential areas on the site. The two Atlanta teams and both Plymouth teams were forced by the land form to divide the community into separated residential areas which allowed for easy phasing, but which ultimately decreased the ability to unify and centrally focus the community. This approach inevitably led to the provision of a series of localized energy components.

The Tucson teams were able to find single contiguous development zones and * were thus able to provide more centralized energy production systems, although these too were designed to expand with the various stages of community growth.

\subsection{THE ENERGY STRATEGY}

In choosing an energy strategy for their communities, the designers were influenced by the potential of site resources such as wind in Plymouth. and wood in Atlanta. However, the teams had difficulty choosing among the seemingly infinite number of options which were available to solve, the energy supply needs in each climatic context. While they were given a great deal of technical assistance at both the community and building scale, they had to resolve many philosophical, ethical, aesthetic and environmental design issues.

"Passive design first" was used as the conceptual baseline in the studies, it being a sensible cost effective approach. However, the electric power produced via cogeneration resulted in byproduct thermal energy, and this competed with the idea of passive design as a priority. At a more abstract leyel, the design students were concerned about the relative degree of "control" 
which the more centralized systems would have on the every day inhabitants, versus the degree of independence represented by more decentralized technical solutions such as photovoltaics. Linked to that issue was the question of how the community would pay for the energy: would community members be billed as utility users or would the energy cost be included in that of the dwelling units?

The cost of community solar energy systems at the front end and the degree to which the design proposals would therefore be marketable was an underlying concern, particularly when linked to the large land area required. There was concern about the rate of technical change in all the various energy systems and their potential obsolescence. As a result, there was a tendency to select more than one kind of energy package and to reject the idea of one central energy plant. Most teams wished to retain technical and spatial options for the future. Another concern was the visual impact of the various energy systems and the extent to which they were considered acceptable components of a residential environment. This concern was linked to the consideration of whether or not to create a "solar image" for the community. By and large, the teams had difficulty reconciling the appearance of $0 i 1$ storage tanks for trough collectors, fields of heliostats and central receiver towers with the more traditional physical character associated with residential design. Safety was also a key factor. The possibility of a fire caused by oill leaks, even though this hazard can and will be resolved technically in the future, was a deterrent to a close integration within the built areas. The probable need to fence or wall the collector fields for safety, creating large zones which become barriers in the community, influenced the design students to place these fields on the periphery of the community. The bright light spot of a central receiver was perceived to be a potential risk to eyesight and was finally excluded from many designs which integrated this technology in early design phases. Most teams did attempt to integrate the community scaled energy systems into their designs at an early stage to save land and to provide a "solar image," but for these aesthetic and safety reasons the larger energy supply systems were generally moved to the edges of the residential areas, though they were often located in visible "entry" positions (Tucson 2, 
Fig. 3.2.1.3, Atlanta 2, Fig. 4.2.1.3, and Plymouth 1, Fig. 5.1.1.3.)

The large number of unknowns regarding projected costs of energy supply and distribution systems tended to influence the design teams to favor multiple systems. An appropriate extreme is the proposal of Plymouth 2 (Fig. 5.2.2.5) which combines wind, hydro and several solar sources into its energy strategy. Among the decentralized options, "passive first" was favored; the use of photovoltaics was generally discarded as an option because of variable and often contradictory projected cost figures. At the architectural scale, only the components of "passive-design" considered marketable were consistently integrated. An interesting exception is the housing designed for Tucsion 2 (Fig. 3.2.3.12/13), which is the only proposal to integrate photovoltaic cell technology into the buillding design. All teams aimed for $100 \%$ self-sutficiency and calculated this to the best of their ability, knowing that there were too many assumptions present to be sure of any estimation.

\subsection{THE RESIDENTIAL NEIGHBORHOOD}

In designing at the neighborhood scale, requirements for solar access posed a series of problems. The more true to solar south and the more vigorous the application of solar orientation principles (e.g. Tucson 2, Fig. 3.2.3.6, Atlanta ", 「ig. 4.2. 1.3), the more likely it was that a problem would arisc of residential homogeneity. The question became one of finding the right amount of diversity within limitations posed by solar orientation or solving of the orientation needs by architectural means (Atlanta 1, Figs, 4.1.3.6, 4.1.3.8.). With the exception of the Tucson site, the topography ruled out the use of a true solar grid. Most design teams had to adapt to a less than perfect set of conditions, often contradictory, to solve the dual goals of providing a good environment and a solar one. On the Atlanta and Plymouth sites topography and vegetation were the primary obstacles to providing optimal solar access. In Atlanta, the pine forest was the only significant pre-existing amenity, and in Plymouth, it was a major component of the attractiveness of the site. In the two Plymouth proposals and in Atlanta, solar access and direction of major views to the west and north were also in conflict. Attempts to resolve the conflict and preserve a significant.amount of tree cover led to lower density designs (Atianta 1, Fig. 4.1.1.3, 
Plymouth 2, Fig. 5.2.1.3) or designs of higher densities on steeper slopes (Plymouth 1, Figs. 5.1.3.9, 5.1.3. 2, Plymouth 2, Fig. 5.2.3.8). In general, at least half of the vegetation cover would be lost in residential areas for both building and roads and to ensure solar access (Fig. 5.2.3. 0).

Inevitably these decisions had economic ramifications. The conflict between maximizing solar access and minimizing cost surfaced again when the designers decided wider lots were needed to provide minimum east-west walls, maximize the southern exposure and allow for through ventilation (Atlanta 2, Fig. 4.2.3.9). This ran counter to earlier goals of minimizing street and utility lengths. Many sites were also judged "unbuildable" from a solar point of view and were thus skipped over, causing more dispersed and potentially expensive construction (Plymouth 2, Fig. 5.2.3.6). The design of streets in a "solar grid" proved to have significant problems; "fronts" and "backs" of houses faced onto the street contradicting the normal street front pattern found in residential areas. Several teams decided to deemphasize their energy goal of minimizing window opening to the north in favor of providing a more neighborly attitude towards the street (Atlanta 1, Fig. 4.1.3.8, Atlanta 2, Fig. 4.2.3.9), and to shield private, south-facing rooms from street view. These issues were found to be resolvable in some measure by architectural design but would nevertheless alter the traditional pattern of the public street in front with private back yards. Street landscaping, particularly with tall indigenous conifer trees, caused shadow problems and traditional urban design devices such as boulevards had to be used cautiously.

\subsection{BUILDING DESIGN.}

Because of a decision to eliminate elevators in order to conserve energy, most higher density housing forms were "walk-up" apartments and condiminiums three or four floors high. Sometimes these made use of sloped sites (Tucson 1, Plymouth 2). Because of the conflict involved in maximizing solar access, tree cover, the economies in the street layout and other amenities in the environment these low rise buildings could not be clustered as densely as originally estimated in the program. (Single-family houses on larger lots had been minimized in all of the schemes.) As a result, the density range. 
of different segments of each scheme was relatively narrow, and the differences between the compact and dispersed schemes was not seen in terms of housing densities. The decision as to whether or not it was possible or desirable to solve the solar access at the urban design scale had ramifications on the design of the individual dwelling units. Plymouth 2 used complex topography which required fine-tuned integration of housing prototypes, landscape design and urban design. Plymouth 1 had similar conditions. Atlanta 1 had the most conflicts between major western views and solar objectives. These had to be resolved through the housing design. Often, traditional housing forms were rediscovered (Tucson 1, Fig. 3.1.3.13, Atlanta 1, Fig. 4.1.3.7). and old passive design methods used (Tucson 1, Fig. 3.1.3.13, Atlanta 1 , Fig. 4.1.3.8, Atlanta 2, Fig. 4.2.3.8, Plymouth 1, Fig. 5.1.3.9, Plymouth 2, Fig. 5.2.3.9). The integration of plant material for passive solar gain was attempted (Plymouth 1 ). Small scale active systems for hot-water heating were preferred over larger systems by most designers. Thermal chimneys and convection systems were tried most successfully in the Tucson proposals (Figs. 3.1.3.13,3.2.3.12).

In schemes with the "free" thermal energy provided via co-generation, earlier concepts about passive design and earlier ideas about the residential aesthetic were changed. Passive elements such as greenhouses were deemed unnecessary although correct orientation remained a design goal. The advent of by-product energy raised several philosophical questions since it permitted less environmentally responsive design. Since much of the residential architecture design generated in these schemes did not exhibit a solar image, attempts were made by two teams to give the commercial center at the focus of the community the solar imaqe (Atlanta 2, Fig. 4.2.1.1, Plymouth 1, Fig. 5. 1.3.8). Other teams used the strategic placement of collector fields at entry points to the community for this purpose.

\subsection{LIFE STYLE CHANGES}

The decision to emphasize walking and to design in consideration of walking distances (Tucson 1, Fig. 3.1.1.3, Atlanta 2, Fig. 4.2.1.3, Plymouth 1:, Fig. 5.1.1.3) assumed certain life-style changes as well as an attitude towards automobile ownership (1 per unit). In all the "compact" schemes the housing 
forms chosen were in conflict with the prevailing market, and assumed fundamental changes in life style priorities. By and large it was assumed that individuals choosing to live in such a context would buy the concept of a "solar community" and an energy-saving lifestyle. From the perspective of the future inhabitant of the solar communities proposed, a series of tradeoffs or choices would be required. Greater emphasis would be placed on modes of travel other than auto with the expectation that many facilities would be. accessible by foot or bicycle, regardless of climate. Higher density living with its attendant changes would be necessary, private outdoor space would be decreased, and housing standards would be lowered by size but not by quality. A more locally oriented life style might be expected. The use of the residential street and front yard might change and with it patterns of neighbor relationships. Shared open space and amenities would compensate for smaller amounts of private space. The likely housing costs, even with subsidies, would be higher. Many of the technical components of solar energy would finally become commonplace and be accepted as part of the everyday visual and functional environment.

\subsection{CONCLUSION}

The design teams felt that new communities which incorporate energy selfsufficiency as a central design goal are, or will soon be, feasible and acceptable in each of the three regions which were investigated. From a solar energy supply viewpoint, the Tucson region has an obvious advantage over Atlanta and Plymouth because of its higher insolation. However, the change in lifestyle required hy the more compact and cooler Tucson proposals may demand too radical a departure for the current marketplace to accommodate. Because of a temperate summer climate and sufficient wind and sun energy for winter heating, the Plymouth situation may be the easiest to solve from both energy and lifestyle criteria. Designs for the more humid Atlanta conditions can seemingly be made with the least influence from both solar energy and community life-style criteria. but they do demand close attention to architectural detail, especially with regard to breeze capture.

In each of the three study regions, the design teams believe that a strong case can be mader to support full-scale experiments, which can be a truer test of of the feasibility of solar independence at the scale of community design. 


\section{THIS PAGE \\ WAS INTENTIONALLY \\ LEFT BLANK}


The Aerospace Corporation.

1978. Solar Total Energy Systems, Final Technical Summary Report. Vol. I of the Solar Total Energy Systems Market Penetration. U.S. Dept. of Energy.

American Institute of Architects.

1975. Energy, AIA Enerqy Notebook, An Information Service on Energy of

the Built Environment. Vol. I \& II.

American Institute of Architects.

1975. Energy: AIA Energy Notebook. (Appendix).

American Institute of Architects.

- 1951. Regional Climate Analysis and Design Data, Charleston, South

Carolina Area. September 1951.

American Institute of Architects.

1950. Regional Climate Analyses and Desian Data, The Arid Southwest Area. House Beautiful. March 1950.

AIA Research Corporation.

No date. Regional Guidelines for Building Passive Energy Consuming Homes.

U.S. Dept. of Housing and Urban Development and U.S. Dept. of Energy.

AIA Research Corporation.

1976. Solar Dwelling Design Concepts. U.S. Dept. of Housing and Urban Development.

AIA Research Corporation.

1979. A Survey of Passive Solar Buildings.

Anderson, Bruce and J. Douglas Balcomb.

1979. Passive Solar Design Handbook. U.S. Dept: of Energy (Draft).

Anderson, Bruce N.

1977. Solar Energy: Fundamentals in Building Design. MCGraw-Hill.

Anderson, Bruce.

1976. The Solar Home Book: Heating, Cooling and Designing with the Sun.

Cheshire Books.

Aronin, Jeffrey. E.

1953. Climate and Architecture. Reinhold Publishing Corp.

Bahadori, M. N.

1979. Conceptual Development of a Solar Energy Town in Iran. Solar Energy. 23 (1).

Bahadori, M. N.

1978. Passive Cooling Systems in Iranian Architecture. Scientific

American. February, 1978. 
Bainbridge, David, Judy Corbett, and John Hofacre.

1979. Village Homes Solar House Designs. Rodale Press.

Balcomb, J. Douglas.

1979. A Semi-Empirical Method for Estimating the Performance of Direct Gain Passive Solar Heated Buildings. Third Annual Passive Solar Conference, San Jose, Calif., January 11-13, 1979. Los Alamos Scientific Laboratory of the Univ. of California.

Bligh, Thomas P.

1978. Energy Comparison and Where to Insulate Earth Sheltered Buildings and Basements. Presented at Earth Covered Settlements, U.S. Dept. of Energy Conference, Forth Worth, Texas, May 1978.

Bligh, Thomas $P$.

1976. Energy Conservation by Building Underground. Underground Space, Vol. I, p. 19-33, Pergamon Press.

Blue, J. L.; K. H. Lowe; B. J. Hurlbut; G. E. Liepins; A. B. Rose; M. A. Smith, and M. G. Strohlein.

1979. Buildings Energy Use Data Book. Edition II. Dak Ridge National Laboratory and U.S. Dept. of Energy.

Boegley, William J., Jr.

1978. Solid Waste Utilization-Incineration with Heat Recovery. Oak Ridge National Laboratory and U.S. Dept. of Energy.

Brookhaven National Laboratory.

1975. Land Use and Energy Utilization, Interim Report.

Caborn, J. M.

1965. Shelterbelts and Windbreaks. Faber and Faber, London.

Carrol1, Owen T., and Robert Nathans.

1979. Solar in Suburbia: A Case Study on Long Island. National Endowment of the Arts:

Center for Landscape Architecture Education and Research.

1978. Options for Passive Energy Conservation in Site Design.

Chirico, Suzanne.

1978. Rincon Area Plan Development Capability Report. Pima County Planning and Zoning Department.

Christian, J. E.

1977. Central Cooling-Absorptive Chillers. Oak Ridge National Laboratories, and U.S. Dept. of Energy.

Christian, J. E.

1980. Resource Recovery for Institutions: A Technical Environmental and Economic Feasibility Analysis for the Oak Ridqe National Laboratory. Master Thesis for University of Tennessee. 
City of Tucson Planning Department.

1976. Industrial Site Study One, Industrial Patterns and Trends: A Community Analysis for the Tucson Urban Area.

Cohn, Steve.

1978. Fuel Choice and Aggregate Energy Demand in the Commercial Sector.

Oak Ridge National Laboratory, and U.S. Dept. of Energy.

Coldwell Banker and Company.

1978. Rocking K Ranch. Tucson, Arizona.

D'Alessanaro, Bill.

1979. Villagers Light the Way. Solar Age, May, 1979.

Davis and Schubert.

1974. Alternative Energy Sources in Building Designs. Van Nostrand Reinhold Company.

de Winter, Francis.

1974. Solar Cooling for Buildings: Workshop Proceedings, Los Angeles, California, February 6-8, 7974 .

Dixon, John Morris; ed.

1979. Energy-Conscious Design. Progressive Architecture, Apri1 1979, p. $69-177$.

Dixon, John Morris; ed.

1980. Energy-Conscious Design. Progressive Architecture. Apri1, 1980, p. $92-170$.

Doernberg, A.

1977. Impact of Selected Energy Conservation Techniques on Baseline Demands. Brookhaven National Laboratory.

Duffey-Armstrong, Marilyn and Joe E. Armstrong.

1979. Community Impediments to Implementation of Solar Energy. U.S. Dept. of Energy.

Educational Facilities Lab., Inc.

1977. Energy and Educational Facilities: Costs of Conservation. Nationai Center for Education Statistics and Energy Research and Development Administration.

Eldridge, Frank R.

1975. Wind Machines. National Science Foundation.

Erley, Duncan and Martin Jaffe.

1979. Site Planning for Solar Access/A Guidebook for Residential Developers and Site Planners. American Planning Association.

Fraize, W. E., P. Dyson and S. W. Gouse, Jr.

1974. Energy and Environmental Aspects of U.S. Transportation. Energy Primer: Selected Transportation Topics. U.S. Dept. of Transportation. 
Geiger, Rudolf.

1965. Climate Near the Ground. Harvard University Press.

GE' Electric.

1978. Solar Total Energy-Large Scale Experiment at Shenandoah, Georgia; System Description. U.S. Dept. of Energy.

Graban, William; and Charles G. Moscarillo.

1978. A11 Electric Homes, Annual Bi11s-January 1, 1978, Cities of 50,000 and More. U.S. Dept. of Energy.

Harrigan, R. W.

1975. Application of Solar Total Energy to a Mixed Load Community.

Sandia Laboratory, Solar Energy Division.

Hickok, Floyd.

1975. Handbook of Solar and Wind Energy. Cahners Books International.

High, Colin.

1978. Evaluation of Locations for a 50-MW Wood-Fired Power Plant in Northern Vermont. Vermont State Energy Office and U.S. Dept. of Commerce, Economic Development Administration.

Holl, R. J.

1978. Definition of Two Small Central Receiver Systems. Sandia Laboratories, and U.S. Dept. Of Energy.

Hutchins, Paul F., and Eric Hirst.

1978. Engineering-Economic Analysis of Single-Family Dwelling Thermal

Performance. Oak Ridge National Laboratory and U.S. Dept. of Energy.

Jackson, Jerry R., and William S. Johnson.

1978. Commercial Energy Use: A Disaggregation by Fuel, Building Type, and End Use. Oak Ridge National Laboratory and U.S. Dept. of Energy.

Jackson, Jerry R., Steve Cohn, Jane Cope and William Johnson.

1978. The Commercial Demand for Energy: A Disaggregated Approach.

Oak Ridge National Laboratory and U.S. Dept: of Energy.

Jaffe, Martin and Duncan Erley.

1979. Protecting Solar Access for Residential Development/ A Guidebook for Planning Officials. American Planning Association.

Kalhammer, F. R.

1979. Energy Storage Systems. Scientific American. December, 1979.

Karaki, Susumu and Paul J. Wilbur.

1977. Solar Cooling. The Franklin Institute Press.

Kreith, Frank.

1977. The First Day of Solar Power. Solar Age. May, 1977. p. 26-29. 
Laity, W. W.; D. T. Aase, W. J. Apley; S. P. Bird; J. W. Currie; M. K. Drost;

M. Jannol; S. C. Schulte; A. M. Sutey; T. A. Williams.

1979. Assessment of Solar Options for Smal1 Power Systems Applications, Vol. I, Executive Summary. Pacific Northwest Laboratory and U.S. Dept. of Energy.

Land Design Research, Inc.

1976. Cost Effective Site Plannina: Single Family Development. National Association of Home Builders.

Landsberg, Helmut.

1958. Physical Climatolgy. Gary Printing Co.

Lawler, Barry.

1979. Davis: An Energy Conservina City. Energy and Alternatives 2(4): 25-26, and 49-54. (Winter 1979).

Leckie, Jim; Gil Masters; Harry Whitehouse and Lily Young.

1975. Other Homes and Garbage, Designs for Self-Sufficient Living. p. 188213. Sierra Club Books.

Lee, Kaiman.

1977. Encyclopedia of Energy-Efficient Building Design. Environmental Design and Research Center.

Lentz, Craig.

1976. ASHRAE 90-75, Impact on Building Energy Usage and Economics. ASHRAE Journa1, Apri1, 1976, p. 25.

Little, Arthur D., Inc.

1978. Distributed Energy Systems, Vol. I \& II, (draft final report). U.S. Dept. of .Energy.

Lowe, Charles.

1977. Arizona's Natural Environment, Landscapes and Habitats. University of Arizona Press.

Lynch, James D., and Suzanne McLean.

1979. Rincon Area Plan, Proposed Plan and Policies, July 1979. Pima County, Planning and Zoning Department.

Margen, Peter.

1978. Central Plants for Annual Heat Storage. Solar Age 3(10). October, 1978.

Margen, Peter; Kjell Larsson; Lars-Alce Cronholm and Jan-Erik Marklund.

1979. District Heating/Cogeneration Application Studies for the Minneapolis-St. Paul Area. Oak Ridge National Laboratory and U.S. Dept. of Energy.

Massachusetts Institute of Technology, Energy Laboratory and Lincoln Laboratory.

1979. Residential Application Implementation Plan. U.S. Dept. of Energy, Photovoltaic Program. 
Mazria, Edward.

1979. The Passive Solar Energy Book. Rodale Press.

McDonnel Douglas Astronautics Co.

1977. Industrial Applications of Solar Energy: Final Report, Vol.I.

McLean, Suzanne Chirico.

1979. Rincon Area Plan, Public Participation, April 1979. Pima County Planning and Zoning Department.

Meader, John T.

1978. Thermal Conveyance Systems. Oak. Ridge National Laboratory and

U.S. Dept. of Energy.

Michaely, Al1an I., David Eissenbera, and Marianne McCarthy.

1979. Proceedings of Solar Energy Storage Options, San Antonio, Texas, March 19-20 1979. Vol. II.

Millner, A. R.

1979. Flywheels for Energy Storage. Technology Review. November, 1979.

Milne, Murray, Marvin Adelson, and Ruthann Corwin.

1979. Three Solar Urban Futures: Characterization of a Future Community Under Three Energy Supply Scenarios. U.S. Dept. of Energy.

Mixon, W. R.

1976. Technology Assessment of Modular Integrated Uti] ity Systems, Vol. I, Summary Report. Oak Ridge National Laboratory and U.S. Dept. of Energy.

Mixon, W. R.

1977. Technology Assessment of Modular Integrated Utility Systems, Vol. II. Oak Ridge National Laboratory and U.S. Dept. of Energy:

Morris, David.

1979. Planning for Energy Self-Reliance; A Case Study of the District of Columbia. Institute for Local Self-Reliance.

Morris, Reiniger and Associates.

1979. New Mexico Solar Freenhouse Study. Office of Technology Assessment, Congress of the United States.

Myers, Barry Lee.

1978. Solar Access Rights in Residential Developments. The Practical

Lawyer. Vol. 24, March, 1978, p. 13-20.

Dak Ridge National Laboratory.

1979. Buildings Energy Use Data Book.

Dak Ridge National Laboratory.

1979. District Heating/Cogeneration Symposium. U.S. Dept. of Energy.

Oak Ridge National Laboratory.

1979. Transportation Energy Conservation Databook, Third Edition. ORNL

Pulbication 5493. 
Office of Technology Assessment.

1978. Application of Solar Technology to Today's Energy Needs, Vol. II.

01 gay, Victor.

1963. Design with Climate. Princeton University Press.

0liker, I.

1979. Assessment of Existing and Prospective Piping Technology for District Heating Applications. Oak Ridge National Laboratory and U.S. Dept. of Energy.

01 iver, John E.

1973. Climate and Man's Environment. John Wiley and Sons.

0'Neal, Dennis, Janet Carney and Eric Hirst.

1978. Regional Analysis of Residential Water Heating 0ptions: Energy Use and Economics. Oak Ridge National Laboratory and U.S. Dept. of Energy.

Phoenix City Council.

1976. Area Plan for Phoenix, Arizona, South of the Rio Salado.

Pima County, City of Tucson, City of South Tucson and Town of Oro Valley. 1977. Comprehensive Plan, Policies; A Physical Development Guide for Eastern Pima County.

Pima County, Arizona.

1975. Floodplain Management Ordinance, Pima County Ordinance No. 19741986.

Pima County Planning Department.

1980. County Zoning Plan, Pima County, Arizona.

Pima County Plannina Department.

1970. Rincon Valley Area.Plan.

Plymouth Planning Board.

1979. Village Centers Plan. Plymouth, Massachusetts.

Plymouth Planning Board.

1978. Zoning Bylaw, Town of Plymouth, Massachusetts.

Reay, D. A.

1977. Industrial Energy Conservation: A Handbook for Engineers and Managers. Pergamon Press.

Richardson, M. L.., and M. L. Miller.

1974. Report and Interpretations for the General Soil Map, Pima County, Arizona. USDA, Soil Conservation Service and Pima County Natural Conservation District.

Ritschard, Ronald L.

1979. Assessment of Solar Energy Within a Community: Summary of Three Community-Level Studies. U.S. Dept. of Energy. 
Robinette, Gary 0.

1977. Landscape Planning for Enerqy Conservation. U.S. Dept. of Housing and Urban Development. Environmental Design Press.

Robinette, Gary 0.

1972. Plants; People and Environmental Quality. U.S. Dept. of Interior, National Park Service and the American Society of Landscape Architects.

Roose, R. W.

1978. Handbook of Eneray Conservation for Mechanical Systems in Buildings. Van Nostrand Reinhold.

Schiflett, Mary and John V. Zuckerman.

No date. Solar Heating and Cooling: State and Municipal Legal Impediments and Incentives. Natural Resources Journal. Vol. 18, p. 313-316.

Schoen, R.

1975. New Energy Technologies for Buildings. Ballinger Publishing Co.

Schmidt, Donald J., And Beverly A. Boyle.

1978. The Zoning Act, Chapter 40A, General Laws. Massachusetts Department of Community Affairs, Office of Local Assistance.

Segaser, Charles S., and Jeffrey E. Christian.

1979. Low Temperature Thermal-Energy Storage. Oak Ridge National Laboratory and U.S. Dept. of Enerqy.

Segaser, C. L., and W. R. Mixon.

1976. MIUS Systems Analysis-The Effects of Thermal Energy Storage and Solid Waste Incineration 0ptions on MIUS Cost and Fuel Consumption. Oak Ridge National Laboratory and U.S. Dept. of Energy.

Shellard, H. C.

1965. Microclimate and Housing: Effects of Orientation. The Architect's Journal Information Library, January 13, 1965, p. 81-84.

Shellard, H. C.

1965. Microclimate and Housing: Topographical Effects. The Architect's Journal Information Library. January 6, 1965, p. 21-26.

Shenandoah Development Inc.; Georgia Institute of Technology; LaubmannReed and Assoc.; Newcomb and Boyd Inc.; Williams-Russell and Assoc.,;

Finch, Alexander, Barnes, Rothschild and Paschal, Inc.

1980. A Case Study of Project Planning and Design for Energy Conservation. Shenandoah, Georgia. U.S. Dept. of Enerqy.

Shonka, D. B.

1979. Transportation Energy Conservation Data Book: Edition III. Dak Ridge National Laboratory and U.S. Dept. of Energy.

Shurcliff, William A.

1977. New Inventions in Low Cost Solar Heating. Brick House Publishing Company. 
Shurcliff, William A.

1977. Solar Heated Buildings, A Brief Survey. Cambridqe, Mass.

Shurcliff, William A.

1978. Solar Heated Buildings of North America. Brick House Publishing Company.

Skinrood, A. C.

1978. Barstow-Prototypical Power Tower. Solar Age 3(5). June, 1978.

Solar Energy Research Institute.

1979. Solar Design Workbook, Draft I. U.S. Dept. of Energy and SERI.

Stanford Research Institute.

1972. Patterns of Energy Consumption in the United States: Office of Science and Technology, Executive Office of the President.

Steadman, Philip.

1979. Energy and Patterns of Land Use. Energy Conservation Through

Building Design. p. 246-260.

Stobaugh, Robert and Daniel Yergin.

1979. Energy Futures. Random House.

Stromberg, R. P.

1975. A Status Report on the Sandia Laboratories Solar Total Energy

Program. Solar Energy. Vol. 17, p. 359-366.

Sullivan, James, Ron Cornman, and David Morris.

1979. Baltimore: Solar and Conservation Potential by the Year 2000.

Institute of Local Self-Reliance.

Thayer, Robert L.

1977. Designing an Experimental Solar Community. Landscape Architecture May 1977: 223-228.

Thornton, Ted.

No date. An Assessment of Anaerobic Digestion in U.S. Agriculture.

Economics, Statistics and Cooperative Science, U.S. Dept: of Agriculture.

Tucson Gas and Electric.

1975. Annual Report.

U.S. Congress, Office of Technology Assessment.

1977. Application of Solar Technology to Today's Energy Needs. Vol. I \& II. June, 1978.

USDA Forest Service.

1975. National Forest Landscape Management, Volume 2, Chapter 2, Utilities. U.S. Dept. of Agriculture, Agricultural Handbook 478. 
U.S. Dept. of Agriculture, Soil Conservation Service, and Plymouth Conservation District.

1966. Soils and Their Interpretations for Various Land Uses. Town of Plymouth. Plymouth County, Massachusetts.

U.S. Dept. of Commerce.

1979. Climatic Atlas of the United States. Reprinted by National Oceanic and Atmospheric Administration.

U.S. Dept. of Commerce.

1974. Energy Conservation Handbook for Light Industries and Commerical Buildings.

U.S. Dept. of Energy.

1979. Appendix A. Base Case Energy Model Conventional Plan, Greenbrier, Chesapeake, Virginia. Draft.

U.S. Dept. of Energy.

1979. Appendix B. Base Case Energy Model Conservation Options, Greenbrier, Chesapeake, Virginia Draft.

U.S. Dept: of Energy.

No date. Assessment of Solar Options for Small Power Systems

Applications, Vol. I. Pacific Northwest Laboratory.

U.S. Dept. of Energy, Office of Conservation and Solar Energy.

1979. Energy Performance Standards for New Buildings; Proposed Rulemaking and Public Hearings. Federal Register. Vol. 44, No. 230.

U.S. Dept. of Energy.

1979. Executive Summary, "A Case Study of Project Planning and Design for Energy Conservation" Greenbrier, Chesapeak, Virginia. Draft, April 27, 1979.

U.S. Dept. of Energy.

No date. Solar Thermal Power Systems Program-Program Summary.

U.S. Dept. of Health, Education, Welfare, Health Resources Administration.

1976. Energy Strategies for Health Care Institutions.

U.S. Dept. of Housing and Urban Development.

1976. Atlanta Residential Energy Consumption.

U.S. Dept. of Housing and Urban Development.

1979. Protecting Solar Access for Residential Development. U.S. Dept. of Energy.

Underground Space Center.

1978. Earth Sheltered Housing Design Guidelines, Examples and

References. University of Minnesota.

Watson, $P$.

1977. Designing and Building a Solar House: Your. Place in the Sun. Garden Way Publishing. 
Watson, D.

1979. Energy Conservation Through Building Design. McGraw-Hill.

Yeoman, John C. Jr.

1978. Wind Turbines. Oak Ridge National Laboratory.

Zanetto, J.

1979. Planning Solar Neighborhoods. Proceedings of 3rd National Passive Solar Conference. 